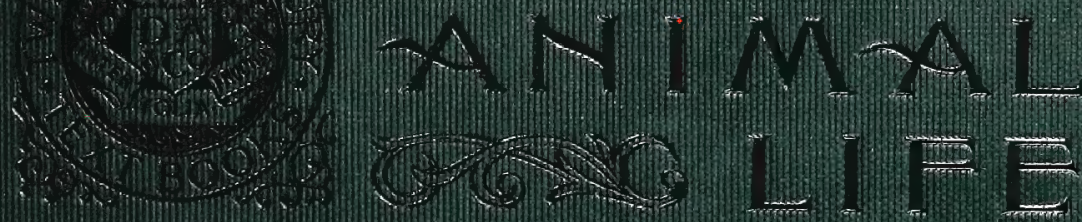

(-m

(2)

(1) 


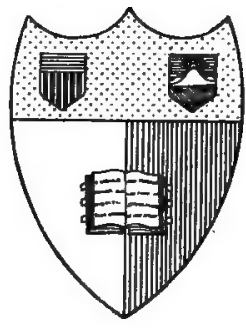

\section{2ิem 10ark \\ State Crallege af Agriculture}

At Gornell Alninersity

3tḩara, N.

\section{Millurary}




\section{Cornell University Llbrary \\ OL 48.J83}

Animal life; a first book of zoology; by

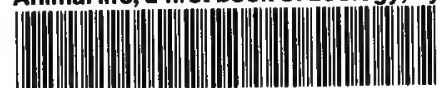

31924003160631 


\section{Cornell University Library}

The original of this book is in the Cornell University Library.

There are no known copyright restrictions in the United States on the use of the text.

http://www.archive.org/details/cu31924003160631 


\section{TWENTIETH CENTURY TEXT-BOOKS \\ EDITED BY}

A. F. Nightingale, Ph. D., LL. D.

SUPERINTENDENT OF SCHOOLS, COOK COUNTY, IELINOIS 


\section{TWENTIETH CENTURY TEXT-BOOKS.}

\section{ZOOLOGY.}

ANIMAL STUDIES. A one-book course in Zoology for secondary schools. By DAvid STARR JORDAN, President of Leland Stanford Jr. University; VernoN L. KelLoGG, M.S., Professur of Entomology, Leland Stanford Jr. University; and Harold Heath, Professor of Zoology, Leland Stanford Jr. University. Cloth, \$I.25 net.

ANIMAL LIFE. A First Book of Zoology. By David STARr Jordan and Vernon $l$. KeLlogG. Cloth, $\$ \mathrm{I} .20$ net.

ANIMAL FORMS. An Elementary Text-Book of Zoology. By DAvid STARR JORDAN and HAROLD HEATH. Cloth, \$1.ro net.

ANIMALS. A Text-Book of Zoology. By JORDAN, KELLOGG, and HEATH. (The two foregoing in one volume.) Cloth, $\$ 1.80$ net.

TEACHER'S MaNUals.

ANIMAL STRUCTURES. A Laboratory Manual of Zoology. By D. S. JORDAN and George C. Price, Associate Professor of Zoology, Leland Stanford Jr. University. Limp cloth, 50 cents net.

D. APPLETON AND COMPANY, NEW YORK. 



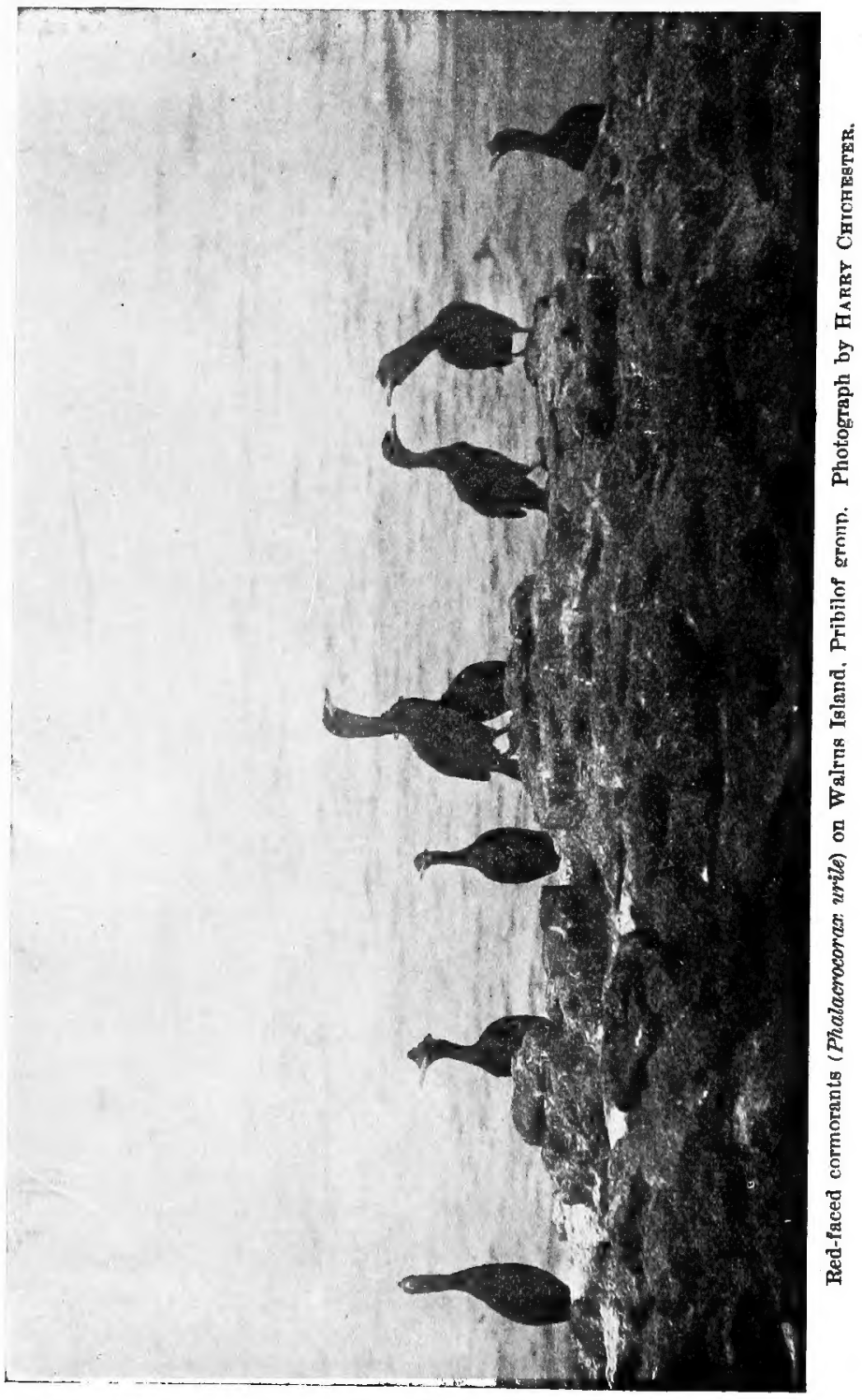




\title{
A NIMAL LIFE
}

A FIRST BOOK OF ZOÖLOGY

\author{
BY \\ DAVID STARR JORDAN, PH. D., LL. D. \\ PRESIDENT OF LEIAND STANIORD JUNIOR UNIVERSITY \\ AND \\ VERNON L. KELLOGG, M. S. \\ PROFESSOR IN LELAND STANFORD JUNIOR UNIVERSITY
}

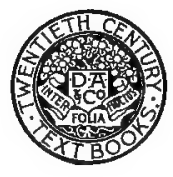

NEW YORK

D. APPLETON AND COMPANY 
Copyright, 1900

Bx D. APPLETON AND COMPANY 


\section{P R E F A C E}

THE authors present this book as an elementary account of animal ecology - that is, of the relations of animals to their surroundings and their responsive adaptation to these surroundings. The book takes the observer's point of view, who is especially concerned with the reasons for the varied structure and habits of animals. To understand how naturally and inevitably all animal form, habit, and life are adapted to the varied circumstances and conditions of animal existence should be the motive of the beginner in this fascinating study. The greatest facts of life, except that of life itself, are seen in the marvelously perfect methods which Nature has adopted in the structure and habits of animals. The keen observation of a fact should lead the student to inquire into the significance of that fact. The veriest beginner can be, and ought to be, an independent observer and thinker. In the study of zoölogy that phase which treats of the why and how of animal form and : habit not only absorbs the attention of the most advanced modern scholars of biology, but should also appeal most strongly to the beginner. The beginner and the most enlightened thinker in zoölogy should each have the same point of view. With this belief in mind the authors have tried to put into simple form the principal facts and approved hypotheses upon which the modern conceptions of animal life are based.

It is unnecessary to say that this book depends for its 
best use on a basis of personal observational work by the student in laboratory and field. Without independent personal work of the student little can be learned about animals and their life that will remain fixed. But presentday teachers of biology are too well informed to make a discussion of the methods of their work necessary here. As a matter of fact, the methods of the teacher depend so absolutely on his training and individual initiative tinat it is not worth while for the authors to point out the place of this book in elementary zoölogical teaching. That the phase of study it attempts to represent should have a place in such teaching is, of course, their firm belief.

The obligations of the authors for the use of certain illustrations are acknowledged in proper place. Where no credit is otherwise given, the drawings have been made by Miss Mary H. Wellman or by Mr. James Carter Beard, and the photographs have been made by the authors or under their direction.

$$
\begin{aligned}
& \text { Dafid Starr Jordan, } \\
& \text { Vernon Lyman Kellog. }
\end{aligned}
$$

Note-After the pages of the book were cast, it was thought that a transposition of Chapters III and IV would present a more logical arrangement, and leachers are advised to omit in their study scheme Chapter III until Chapter IV is completed.

D. S. J. V. L. K. 


\section{CONTENTS}

OHAPTER

I.-THE LIFE OF THE SIMPLEST ANIMALS .

The simplest animals, or Protozoa, 1.-The animal cell, 2.What the primitive cell can do, 5.-Amcba, 5.-Paramceium, 9. -Vorticella, 12.-Marine Protozoa, 15.-Globigerinæ and Radiolaria, 16.-Antiquity of the Protozoa, 20.-The primitive form, 20.-'The primitive but successful life, 21.

II.-The LIFE of THE SLIGHTLY complex ANimals . " *

Colonial Protozon, 24.-Gonium, 25.-Pandorina, 26.-Eudorina, 27.-Volvox, 28.-Steps toward complexity, 30.-Individual or colony, 31.-Sponges, 32.-Polyps, corals, and jelly-fishes, 37. -Hydra, 37.-Differentiation of the body cells, 41.-Meduse or jelly-tishes, 41.-Corals, 43.-Colonial jelly-fishes, 45.-Increase in the degree of complexity, 48.

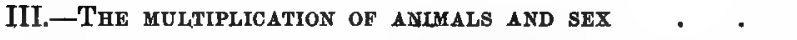

All life from life, 50.-Spontaneous generation, 51.-The simplest method of multiplication, 53.--Slightly complex methods of multiplication, 54.-Differentiation of the reproductive cells, 55 . - Sex, or male and female, 57.-The object of sex, 57.- Sex dimorphism, 58.-The number of young, 61.

IV.-Function AND STRUCTURE . . . • . . .

Organs and functions, 63.-Differentiation of structure, 64.Anatomy and physiology, 64.-The animal body a machine, 65 . -The specialization of organs, 66.-The alimentary canal, 66.Stable and variable characteristics of an organ, 73.-Stable and variable characteristics of the alimentary canal, 73.-The mutual relation of function and structure, 7 .

V.-The LIFE CYCle . . . . . . . . .

Birth, grow th and development, and death, 78,-Life cycle of simplest animals, 78.-The egg, 79.-Embryonic and post-embryonic development, 80.-Continuity of development, 83.-Development after the gastrula stage, 84.-Divergence of develop- 
ment, 84.-The laws or general facts of development, 86.-The significance of the facts of development, 89.-Metamorphosis, 90.-Metamorphosis among insects, 90.-Metamorphosis of the toad, 94.-Metamorphosis among other animals, 96.-Duration of life, 101.-Death, 103.

\section{VI,-ThE PRIMARY CONDITIONS OF ANIMAL LIFE .}

Primary conditions and special conditions, 106.-Food, 106.Oxygen, 107.- Temperature, pressure, and other conditions, 108. -Difference between animals and plants, 111.-Living organic matter and inorganic matter, 113.

VII.-THE CROWD OF ANIMALS AND THE STRUgGLE FOR EXISTENCE

The crowd of animals, 114.-The struggle for existence, 116. -Selection by Nature, 117.-Adjustment to surroundings a result of natural selection, 120.-Artificial selection, 120.-Dependence of species on species, 121.

VIII.-ADAPTATIONS.

Origin of adaptations, 123.-Classification of adaptations, 123. -Adaptations for securing food, 125.-Adaptations for self-defense, 128.-Adaptations for rivalry, 135.-Adaptations for the defense of the young, 137.-Adaptations concerned with surroundings in life, 143.-Degree of structural change in adaptations, 146.-Vestigial organs, 147.

IX.-ANimaL Communities aND Social LIFE • • • •

Man not the only social animal, 149.-The honey-bee, 149.The ants, 155.-Other communal insects, 158.-Gregariousness and mutual aid, 163.-Division of labor and basis of communal life, 168.-Advantages of communal life, 170.

X.-Commensalism aND SYMbiosis . . . . . .

Association between animals of different species, 172.-Commensalism, 173.-Symbiosis, 175.

XI.-Parasitism and degentration .

Relation of parasite and host, 179.-Kinds of parasitism, 180. -The simple structure of parasites, 181.-Gregarina, 182.-The tape-worm and other flat-worms, 183. -Trichina and other roundworms, 184.-Sacculina, 187.-Parasitic insects, 188.-Parasitio vertebrates, 193.-Degencration through quiescence, 193.-Degeneration through other causen, 197.-Immediate causes of degeneration, 198.--Advantages and disadvantages of parasitism and degeneration, 198.-Human degeneration, 200. 
Protective resemblance defined, 201.-General protective or aggressive resemblance, 202.- Special protective resemblance, 207.-Warning colors and terrifying appearances, 212--Alluring coloration, 216.-Mimicry, 218.-Protective resemblances and mimicry most common among insects, 221.-No volition in mimicry, 222.-Color : its utility and beauty, 222.

\section{XIII.-The SPEcIaL SENSES}

Importance of the special senses, 224.-Difficulty of the study of the special senses, 224.-Special senses of the simplest animale, 225.-The sense of touch, 226.-The sense of taste, 228. The sense of smell, 229.-The sense of hearing, 232.-Sound-making, 285 - The sense of sight, 237.

XIV.-INSTINCT AND REASON . . . . . . . .

Irritability, 240.-Nerve cells and fibers, 240.-The brain or sensorium, 241.-Reflex action, 241.-Instinct, 242,-Classification of instincts, 243.-Feeding, 244.-Self-defense, 245.-Play, 247.-Climate, 248.-Environment, 248.-Courtship, 248.-Reproduction, 249.-Care of the young, 250.-Variability of instincts, 251.-Reason, 251.-Mind, 255.

XV.—HOMES AND DOMESTIC HABITS

Importance of care of the young, 257.-Care of the young and communal life, 257.-The invertebrates (except spiders and insects), 258.-Spiders, 259.-Insects, 262.-The vertebrates, 264.

XVI.-Grographical distribution of antmals . . . .

Geographical distribution, 272.-Laws of distribution, 274.Species debarred by barriers, 274,-Species debarred by inability to maintain their ground, 275.-Species altered by adaptation to new conditions, 276.-Effect of barriers, 283.-Relation of species to habitat, 283 ,-Character of barriers to distribution, 288.-Barriers affecting fresh-water animals, 294.-Modes of distribution, 296. - Fauna and faunal areas, 296.-Realms of animal life, 297.Subordinate realms or provinces, 303,-Faunal areas of the sea, 304.

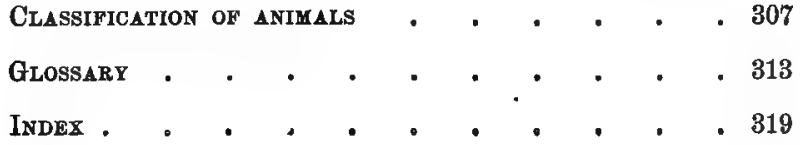





\section{ANIMAL LIFE}

\section{CHAPTER I}

\section{THE LIFE OF THE SIMPLEST ANIMALS}

1. The simplest animals, or Protozoa.-The simplest animals are those whose bodies are simplest in structure and which do the things done by all living animals, such as eating, breathing, moving, feeling, and reproducing in the most primitive way. The body of a horse, made up of various organs and tissues, is complexly formed, and the various organs of the body perform the various kinds of work for which they are fitted in a complex way. The simplest animals are all very small, and almost all live in the water; some kinds in fresh water and many kinds in the ocean. Some live in damp sand or moss, and still others are parasites in the bodies of other animals. They are not familiarly known to us; we can not see them with the unaided eye, and yet there are thousands of different kinds of them, and they may be found wherever there is water.

In a glass of water taken from a stagnant pool there is a host of animals. There may be a few water beetles or water bugs swimming violently about, animals half an inch long, with head and eyes and oar-like legs; or there may be a little fish, or some tadpoles and wrigglers. These are evidently not the simplest animals. There will be many very small active animals barely visible to the unaided eyes. These, too, are animals of considerable complexity. But if a single drop of the water be placed 
on a glass slip or in a watch glass and examined with a compouna microscope, there will be seen a number of extremely small creatures which swim about in the water-drop by means of fine hairs, or crawl slowly on the surface of the glass. These are among our simplest animals. There are, as already said, many kinds of these "simplest animals," although, perhaps strictly speaking, only one kind can be called simplest. Some of these kinds are spherical in shape, some elliptical or football-shaped, some conical, some flattened. Some have many fine, minute hairs projecting from the surface; some have a few longer, stronger hairs that lash back and forth in the water, and some have no hairs at all. There are many kinds and they differ in size, shape, body covering, manner of movement, and habit of food-getting. And some are truly simpler than others. But all agree in one thing-which is a very important thing-and that is in being composed in the simplest way possible among animals.

2. The animal cell.-The whole body of any one of the simplest animals or Protozoa is composed for the animal's whole lifetime of but a single cell. The bodies of all other animals are composed of many cells. The cell may be called the unit of animal (or plant) structure. The body of a horse is complexly composed of organs and tissues. Each of these organs and tissues is in turn composed of a large number of these structural units called cells. These cells are of great variety in shape and size and genera] character. The cells which compose muscular tissue are very different from the cells which compose the brain. And both of these kinds of cells are very different from the simple primitive, undifferentiated kind of cell seen in the body of a protozoan, or in the earliest embryonic stages of a many-celled animal.

The animal cell is rarely typically cellular in character -that is, it is rarely in the condition of a tiny sac or box of symmetrical shape. Plant cells are often of this char- 
acter. The primitive animal cell (Fig. 1) consists of a small mass of a viscid, nearly colorless, substance called protoplasm. This protoplasm is differentiated to form two parts or regions of the cell, an inner denser mass called the nucleus, and an outer, clearer, inclosing mass called the cytoplasm. There may be more than one nucleus in a cell. Sometimes the cell is inclosed by a cell wall which may be simply a tougher outer layer of the cytoplasm, or may be a thin membrane secreted by the protoplasm. In addition to the protoplasm, which is the fundamental and essential cell substance, the cell may contain certain so-called cell products, substances produced by the life processes of the protoplasm. The cell may thus contain water, oils, resin, starch grains, pigment gran-

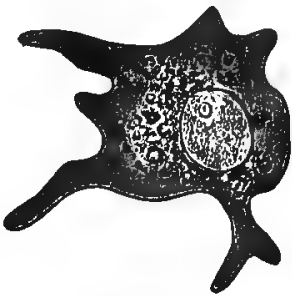

Fig. 1.-Blood cell of a crab (after HAECKEL), Showing cytoplasm and nucleus (the large, inner, nearly circular spot) and granules of various substances lying in the cytoplasm. ules, or other substances. These substances are held in the protoplasm as liquid drops or solid particles.

The protoplasm itself of the cell shows an obvious division into parts, so that certain parts of it, especially parts in the nucleus, have received names. The nucleus usually has a thin protoplasmic membrane surrounding it, which is called the nuclear membrane. There appear to be fine threads or rods in the nucleus which are evidently different from the rest of the nuclear protoplasm. These rods are called chromosomes. The cell is, indeed, not so simple as the words "structural unit" might imply, but science has not yet so well analyzed its parts as to warrant the transfer of the name structural unit to any single part of the cell-that is, to any lesser or simpler part of the animal body than the cell as a whole.

The protoplasm, which is the essential substance of the cell and hence of the whole animal body, is a substance 
of a very complex chemical and physical constitution. Its chemical structure is so complex that no chemist has yet been able to analyze it, and as the further the attempts at analysis reach the more complex and baffling the substance is found to be, it is not improbable that it may never be analyzed. It is a compound of numerous substances, some of these composing substances being themselves extremely complex. The most important thing we know about the chemical constitution of protoplasm is that there are always present in it certain complex albuminous substances which are never found in inorganic bodies. It is on the presence of these albuminous substances that the power of performing the processes of life depends. Protoplasm is the primitive basic life substance, but it is the presence of these complex albuminous compounds that makes protoplasm the life substance. A student of protoplasm and the fundamental life processes, Dr. Davenport, has said, "Just as the geologist is forced by the facts to assume a vast but not infinite time for earth building, so the biologist has to recognize an almost unlimited complexity in the constitution of the protoplasm." *

* The physical structure of protoplasm has been much studied, but even with the improved microscopes and other instruments necessary for the study of minute structure, naturalists are still very far from understanding the physical constitution of this substance. While the appearance of protoplasm under the microscope is pretty generally agreed on among naturalists, the interpretation of the kind of struoture which is indicated by this appearance is not at all well agreed on. Protoplasm appears as a mesh work composed of fine granules suspended in a clearer substance, the spaces of the mesh work being composed of a third still clearer substance. Some naturalists believe, from this appearance, that protoplasm is composed of a clear viscous subtance, in which are imbedded many fine granules of denser substance, and numerous large globules of a clearer, more liquid substance. Other naturalists believe that the fine spots which appear to be granules are simply cross sections of fine threads of dense protoplasm which lie coiled and tangled in the thinner, clearer protoplasm. And, finally, 
3. What the primitive cell can do.-The body of one of the minute animals in the water-drop is a single cell. The body is not composed of organs of different parts, as in the body of the horse. There is no heart, no stomach; there are no muscles, no nerves. And yet the protozoan is a living animal as truly as is the horse, and it breathes and eats and moves and feels and produces young as truly as docs the horse. It performs all the processes necessary for thic life of an animal. The single cell, the single minute speck of protoplasm, has the power of doing, in a very simple and primitive way, all those things which are necessary for life, and which are done in the case of other animals by the various organs of the body.

4. Amoba, - The simple and primitive life of these Protozoa can be best understood by the observation of living individuals. In the slime and sediment at the bottom of stagnant pools lives a certain specially interesting kind of protozoan, the Amoba (Fig. 2). Of all the simplest animals this is as simple or primitive as any. The minute viscous particle of protoplasm which forms its body is irregular in outline, and its outline or shape slowly but constantly changes. It may contract into a tiny ball; it may become almost star-shaped; it may become elongate or flattened; short, blunt, finger-like projections called pseudopods extend from the central body mass, and these projections are constantly changing, slowly pushing out or

others believe that protoplasm exists as a foam work; that it is a viscous liquid containing many fine globules (the granule-appearing spots) of a liquid of different density and numerous larger globules of a liquid of still other density. It is a foam in which the bubbles are not filled with air, but with liquids of different.density. This last theory of the structure of protoplasm is the one accepted by a majority of modern naturalists, although the other theories have numerous believers. But just as with what little we know of the chemical constitution of protoplasm, the little we know of its physical structure throws almost no light on the remarkable properties of this fundamental life substance. 
drawing in. The single protoplasmic cell which makes up the body of the Amoeba has no fixed outline; it is a cell without a wall. The substance of the cell or body is protoplasm, semiliquid and colorless. The changes in form of the body are the moving of the Amaba. By close watching it may be seen that the Amoba changes its position on the glass slip. Although provided with no legs or wings or
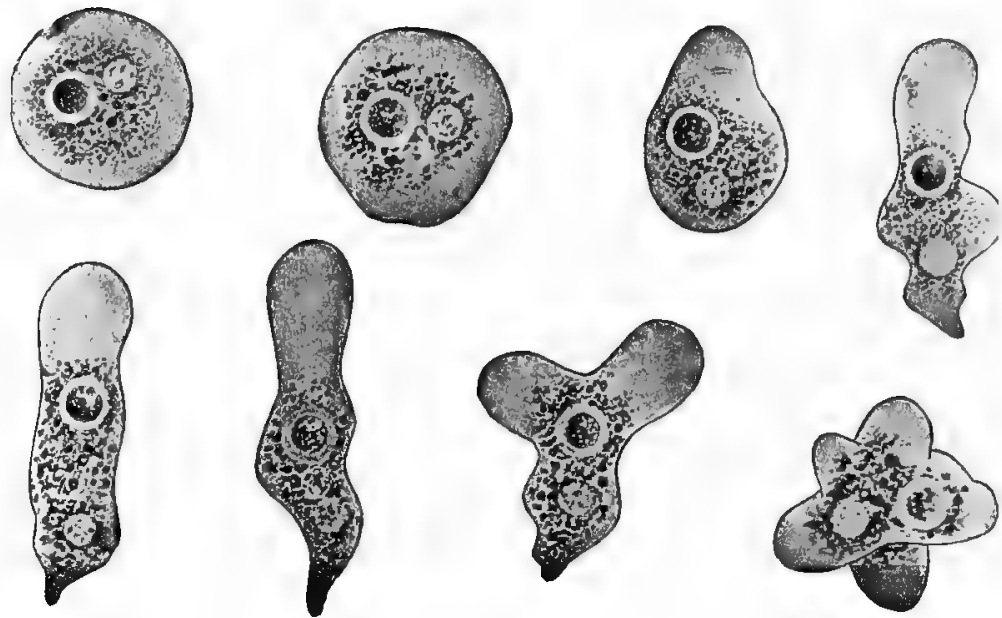

Fig. 2.-An Amoba, showing different shapes assumed by it when crawling. -After VerworN.

scales or hooks-that is, with no special organs of locomotion-the Amaba moves. There are no muscles in this tiny body; muscles are composed of many contractile cells massed together, and the Amoba is but one cell. But it is a contractile cell; it can do what the muscles of the complex animals do.

If one of the finger-like projections of the $A m \infty b a$, or, indeed, if any part of its body comes in contact with some other microscopic animal or plant or some small fragment of a larger form, the soft body of the Amoba will be seen 
to pross against it, and soon the plant or animal or organic particle becomes sunken in the protoplasm of the formless body and entirely inclosed in it (Fig. 3). The absorbed particle soon wholly or partly disappears. This is the manner in which the Amoba eats. It has no mouth or
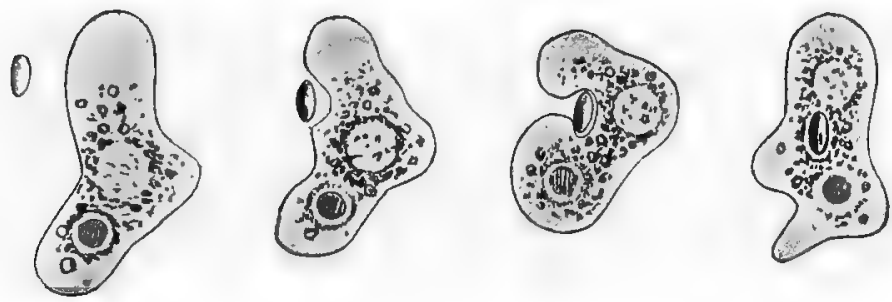

Fig. 3.-Amaba eating a microscopic one-celled plant.-After Verwokr.

stomach. Any part of its body mass can take in and digest food. The viscous, membraneless body simply flows about the food and absorbs it. Such of the food particles as can not be digested are thrust out of the body.

The Amoba breathes. Though we can not readily observe this act of respiration, it is true that the $A$ moba takes into its body through any part of its surface oxygen from the air which is mixed with water, and it gives off from any part of its body carbonic-acid gas. Although the Amoba has no lungs or gills or other special organs of respiration, it breathes in oxygen and gives out carbonic-acid gas, which is just what the horse does with its elaborately developed organs of respiration.

If the Amoba, in moving slowly about, comes into contact with a sand grain or other foreign particle not suitable for food, the soft body slowly recoils and flows-for the movement is really a flowing of the thickly fluid protoplasm - so as to leave the sand grain at one side. The Amoba. feels. It shows the effects of stimulation. Its movements can be changed, stopped, or induced by mechanical or chemical stimuli or by changes in temperature. The 
Ameba is irritable; it possesses irritability, which is sensation in its simplest degree.

If food is abundant the Amoba soon increases in size. The bulk of its body is bound to increase if new substance
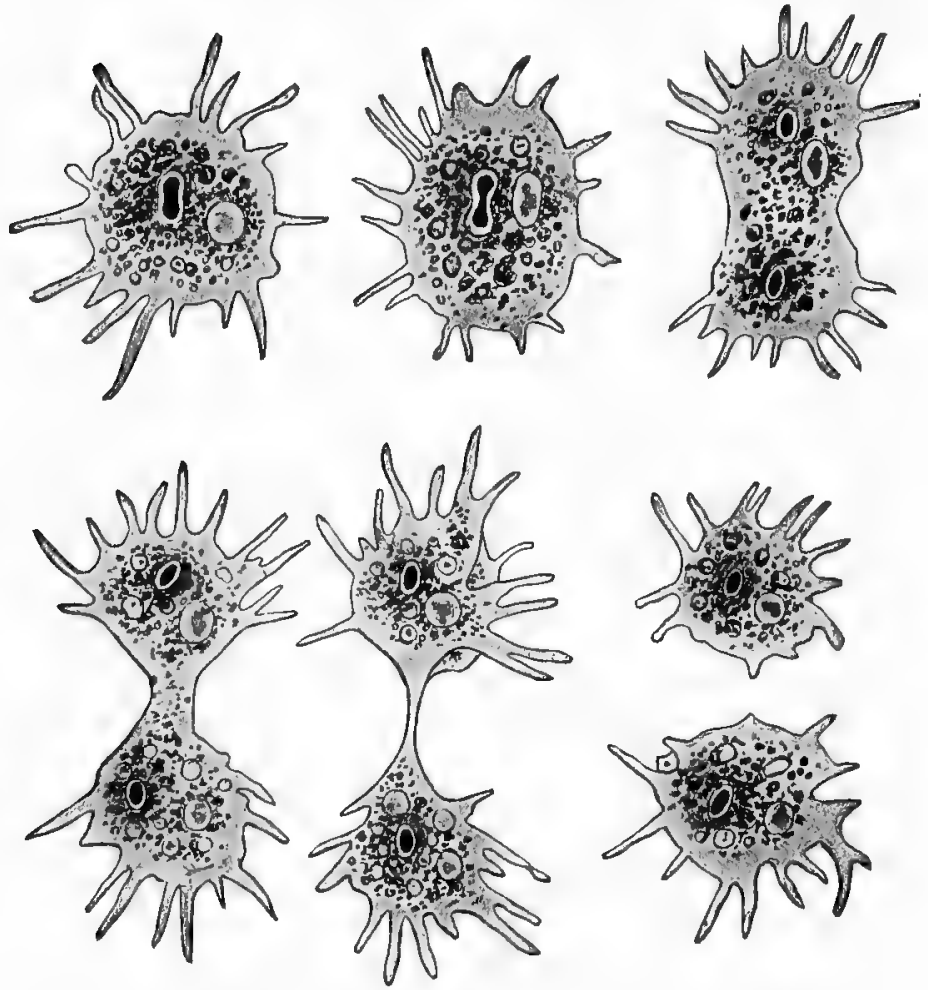

F1G. 4.-Amoba polyjudia in six successive stuges of division. The dark, whitemargined spot in the interior is the nucleas.-After F. E. Scholze.

is constantly assimilated and added to it. The Amoba grows. But there seem to be some fixed limits to the extent of this increase in size. No f maba becomes large. A remarkable phenomenon always occurs to prevent this. 
An $A m a e b a$ which has grown for some time contracts all its finger-like processes, and its body becomes constricted. This constriction or fissure increases inward, so that the body is soon divided fairly in two (Fig. 4). The body, being an animal cell, possesses a nucleus imbedded in the body protoplasm or cytoplasm. When the body begins to divide, the nucleus begins to divide also, and becomes entirely divided before the fission of the cytoplasm is complete. There are now two Amobce, each half the size of the original one; each, indeed, being actually one half of the original one. This splitting of the body of the $A m a b a$, which is called fission, is the process of reproduction. The original Amosa is the parent; the two halves of the parent are the young. Each of the young possesses all of the characteristics and powers of the parent; each can move, eat, feel, grow, and reproduce by fission. It is very evident that this is so, for any part of the body or the whole body was used in performing these functions, and the young are simply two parts of the parent's body. But if there be any doubt about the matter, observation of the behavior of the young or new Amrebe will soon remove it. Each puts out pseudopods, moves, ingests food particles, avoids sand grains, contracts if the water is heated, grows, and finally divides in two.

5. Paramocium.-Another protozoan which is common in stagnant pools and can be readily obtained and observed is Paramoecium (Fig. 5). The body of the Paramoecium is much larger than that of the $A m \infty b a$, being nearly one fourth of a millimeter in length, and is of fixed shape. It is elongate, elliptical, and flattened, and when examined under the microscope seems to be a very complexly formed little mass. The body of the Paramecium is indeed less primitive than that of the Amoba, and yet it is still but a single cell. The protoplasm of the body is very soft within and dense on the outside, and it is covered externally by a thin membrane. The body is covered with short fine hairs or cilia, 
which are fine processes of the dense protoplasm of the surface. There is on one side an oblique shallow groove that leads to a small, funnel-shaped depression in the body

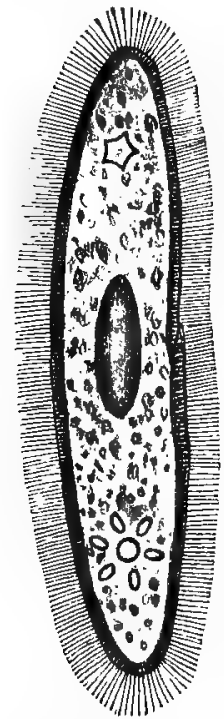

FrG. 5. - Paramacium aurelic (after VERWORN). At each end there is a contractile vacuole, and in the center is one of the nuclei. which serves as a primitive sort of mouth or opening for the ingress of food. The Paramocium swims about in the water by vibrating the cilia which cover the body, and brings food to the mouth opening by producing tiny currents in the water by means of the cilia in the oblique groove. The food, which consists of other living Protozoa, is taken into the body mass only through the funnel-shaped opening, and that part of it which is undigested is thrust out always through a particular part of the body surface. (The taking in and ejecting of foreign particles can be seen by putting a little powdered carmine in the water.) Within the body there are two nuclei and two socalled pulsating vacuoles. These pulsating vacuoles (Amaba has one) seem to aid in discharging waste products from the body. When the Paramocium touches some foreign substance or is otherwise irritated it swims away, and it shoots out from the surface of its body some fine long threads which when at rest are probably coiled up in little sacs on the surface of the body. When the Paramacium has taken in enough food and grown so that it has reached the limit of its size, it divides transversely into halves as the Amoba does. Both nuclei divide first, and then the cytoplasm constricts and divides (Fig. 6). Thus two new Paramacic are formed. One of them has to develop a new mouth opening and groove, so that there is in 
the case of the reproduction of Paramacium the beginnings of developmental changes during the course of the growth of the young. The young Amabos have only to add substance to their bodies, to grow larger, in order to be exactly like their parent.

The new Paramosia attain full size and then divide, each into two. And so on for many generations. But it has been discovered that this simplest kind of reproduction can not go on indefinitely. After a number of generations the Paramoecia, instead of simply dividing in two, come together in pairs, and a part of

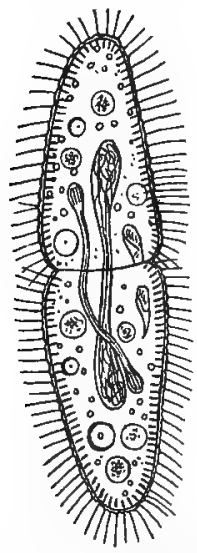

Fre. 6.-Paramacium putorinum dividing. The two nuclei become very elongate before dividing.-After BütscuLI. one of the nuclei of each member of a pair passes into the body of and fuses with a part

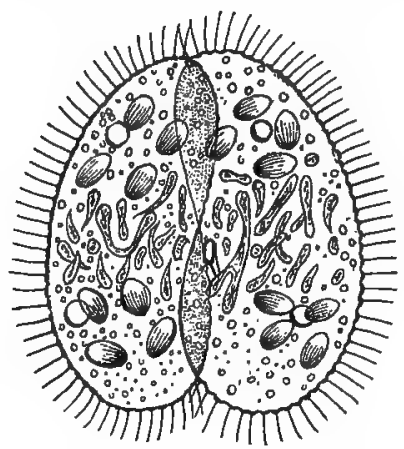

Fig. 7.-Parancecium caudatun; two individuals separating after conjugation.

of one of the nuclei of the other member of the pair. In the meantime the second nucleus in each Paramoecium has broken up into small pieces and disappeared. The new nucleus composed of parts of the nuclei from two animals divides, giving each animal two nuclei just as it had before this extraordinary process, which is called conjugation, began (Fig. 7). Each Paramerium, with its nuclei composed of parts of the nuclei from two distinct individuals. 
now simply divides in two, and a large number of generations by simple fission follow.

Paramocium in the character of its body and in the manner of the performance of its life processes is distinctly less simple than the $A m a b a$, but its body is composed of a single structural unit, a single cell, and it is truly one of the "simplest animals."

6. Vorticella,-Another interesting and readily found protozoan is Vorticella (Fig. 8). While the Amocba can crawl and Paramocium swim, Vorticella, except when very young,
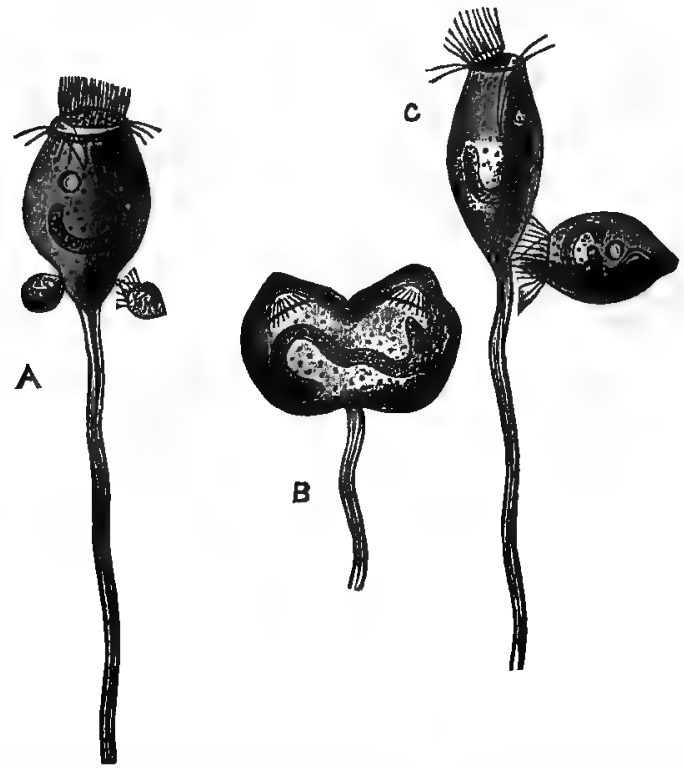

FIt. 8.-Vorticella microstoma (after STriv). A, small, free-8wimming individuals conjugating with a large, stalked individual; B, a stalked individual dividing longitudinally; $\mathbf{C}$, after division is completed one part severs itself from the other, forms a ring of cilla, and ewims away.

is attached by tiny stems to dead leaves or sticks in the water, and can change its position only to a limited extent. 
The body is pear-shaped or bell-shaped, with a mouth opening at the broad end, and a delicate stem at the narrow end. This stem is either hard and stiff, or is flexible and capable of being suddenly contracted in a close spiral. In the body mass there is one pulsating vacuole and one nucleus. Usually many Vorticellee are found together on a common stalk, thus forming a protozoun colony.

The life processes of Vorticella are of the simple kind already observed in Amoba and Paramocium. Vorticella shows, however, some modifications of the process of reproduction which are interesting. The plane of division of Vorticella is parallel to the long axis of the pear-shaped body, so that when fission is complete there are two Vorticelloe on a single stalk. One of the two becomes detached, and by means of a circle of fine hairs or cilia which appear around its basal end leads a free swimming life for a short time. Finally it settles down and develops a stalk. Vorticella shows two kinds of fission-one the usual division into equal parts, and another division into unequal parts. In this latter kind, called reproduction or multiplication by budding, a small part of the parent body separates, develops a basal circle of cilia, and swims away. The process of conjugation also takes place among the Vorticella, but they are never two equal forms which conjugate, but always one of the ordinary stalked forms and one of the small free-swimming forms produced by budding.

Here, then, in the life of Vorticella, are new modifications of the life processes; but, after all, these.life processes are very simply performed, and the body is like the body of the Amoeba, a single cell. Vorticella is plainly one of "the simplest animals."

7. Gregarina.-A fourth kind of protozoan to which we can profitably give some special attention is Gregarina (Fig. 9), the various species of which live in the alimentary 
canal * of crayfishes and centipeds and certain insects. Gregarina is a parasite, living at the expense of the host in whose body it lies. It has no need to swim about quickly,
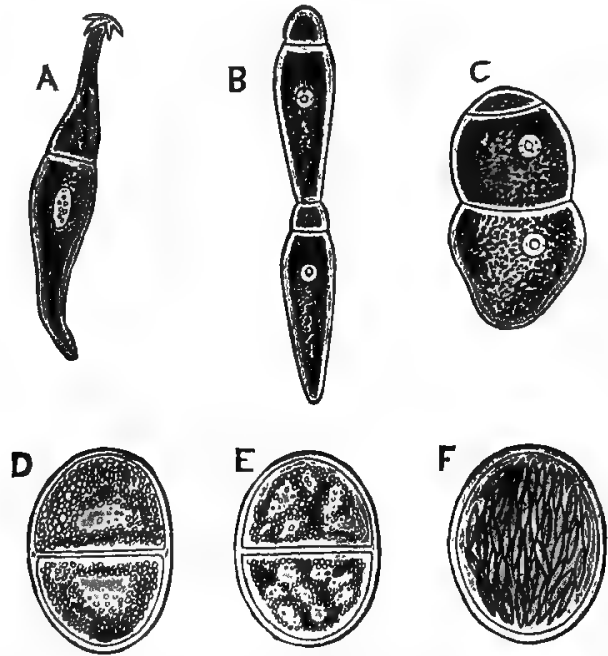

Fri. 9.-Gregarinidg. A, a Gregarinid (Actinocephalus oligacanthus) from the intestine of an insect (after STEIN); B and C, spore forming by a Gregarinid (Coccidium oviforme) from the liver of a guinea-pig (after LEUCKART); D, E, and $F$, successive stages in the conjugation and spore forming of Gregarina polymorpha (after KOELLIKER).

and hence has no swimming cilia like Paramocium and the young Vorticella. It does need to cling to the inner wall of the alimentary canal of its host, and the body of some species is provided with hooks for that purpose. The

* Specimens of Gregarina can be abundantly found in the alimentary canal of meal worms, the larve of the black beetle (Tenebrio molitor), common in granaries, mills, and brans. "Snip off with small scissors both ends of a larva, seize the protruding (white) intestine with forceps, draw it out, and tease a portion in normal salt solution (water will do) on a slide. Cover, find with the low power (minute, oblong, transparent bodies), and study with any higher objective to suit,"Murbaca. 
food of Gregaring is the liquid food of the host as it exists in the intestine, and which is simply absorbed anywhere through the surface of the body of the parasite. There is no mouth opening nor fixed point of ejection of waste material, nor is there any contractile vacuole in the body.

In the method of multiplication or reproduction Gregarina shows an interesting difference from $A m a b a$ and Paramacium and Vorticella. When the Gregarina is ready to multiply, its body, which in most species is rather elongate and flattened, contracts into a ball-shaped mass and becomes encysted-that is, becomes inclosed in a tough, membranous coat. This may in turn be covered externally by a jelly-like substance. The nucleus and the protoplasm of the body inside of the coat now divide into many small parts called spores, each spore consisting of a bit of the cytoplasm inclosing a small part of the original nucleus. Later the tough outer wall of the cyst breaks and the spores fall out, each to grow and develop into a new Gregarina. In some species there are fine ducts or canals leading from the center of the cyst through the wall to the outside, and through these canals the spores issue. Sometimes two Gregarince come together before encystation and become inclosed in a common wall, the two thus forming a single cyst. This is a kind of conjugation. In some species each of the young or new Gregarince coming from the spores immediately divides by fission to form two individuals.

8. Marine Protozoa.-If called upon to name the characteristic animals of the ocean, we answer readily with the names of the better-known ocean fishes, like the herring and cod, which we know to live there in enormous numbers; the seals and sea lions, the whales and porpoises, those fish-like animals which are really more like land animals than like the true fishes; and the jelly-fishes and corals and star-fishes which abound along the ocean's edge. But in naming only these we should be omitting certain animals which in point 
of abundance of individuals vastly outnumber all other animals, and which in point of importance in helping maintain the complex and varied life of the ocean distinctly outclass all other marine forms. These animals are the marine Protozoa, those of the "simplest animals" which live in the ocean.

Although the water at the surface of the ocean appears clear, and on superficial examination devoid of life, yet a drop of this water taken from certain ocean regions examined under the microscope reveals the fact that this water is inhabited by Protozoa. Not only is the water at the very surface of the ocean the home of the simplest animals, but they can be found in all the water from the surface to a great depth beneath it. In a pint of this ocean water from the surface or near it there may be millions of these animals. In the oceans of the world the number of them is inconceivable. Dr. W. K. Brooks says that the "basis of all the life in the modern ocean is found in the microorganisms of the surface." By micro-organisms he means the one-celled animals and the one-celled plants. For the simplest plants are, like the simplest animals, onecelled. "Modern microscopical research," he says, "has shown that these simple plants, and the Globigerinæ and Radiolaria [kinds of Protozoa] which feed upon them, are so abundant and prolific that they meet all demands and supply the food for all the animals of the ocean."

9. The Globigerinæ and Radiolaria.-The Globigerinæ (Fig. 10) and Radiolaria (Fig. 11) are among the most interesting of all the simplest animals. Their simple onecelled body is surrounded by a microscopic shell, which among the Globigerinæ is usually made of lime (calcium carbonate), in the case of Radiolaria of silica. These minute shells present a great variety of shape and pattern, many being of the most exquisite symmetry and beauty. The shells are usually perforated by many small holes, through which project long, delicute, protoplasmic threads. These 
fine threads interlace when they touch each other, thus forming a sort of protoplasmic network outside of the shell. In some cases there is a complete layer of protoplasmpart of the body protoplasm of the protozoan - surround-

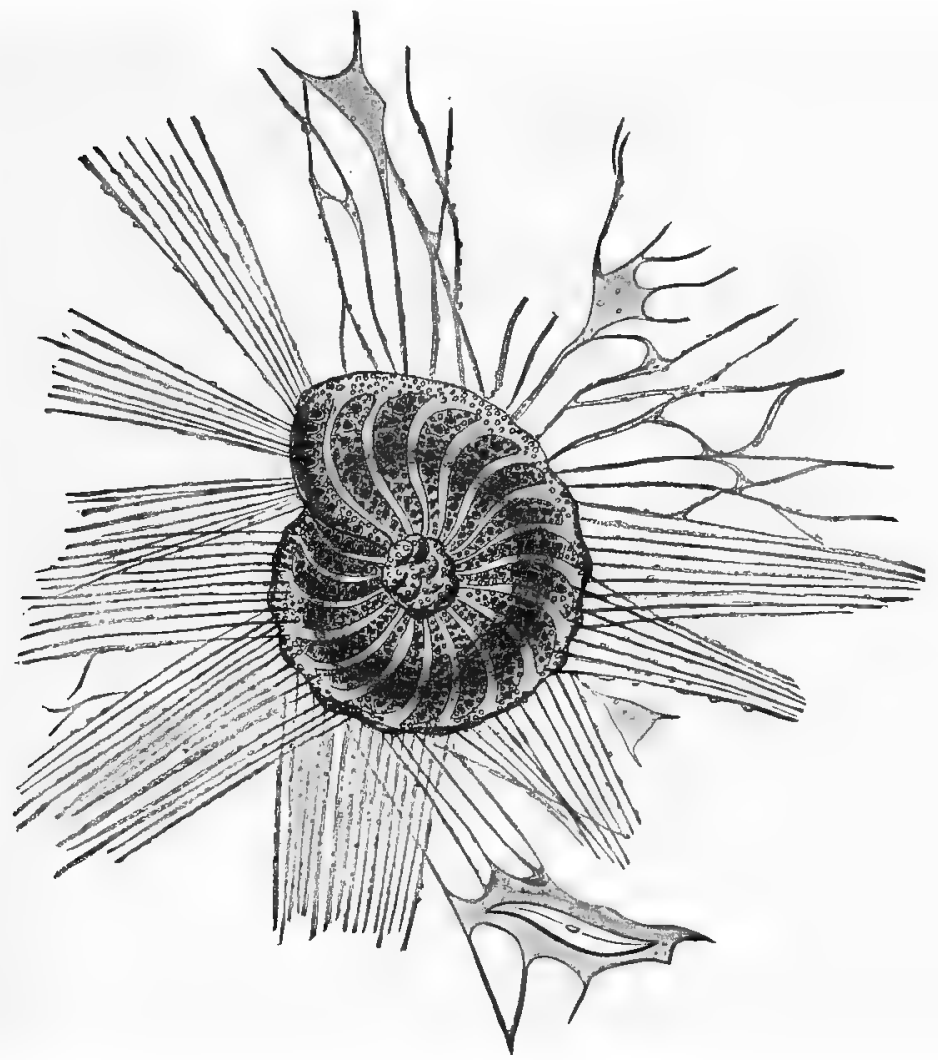

Fra. 10.-Polystomella strigillata, one of the Globigerinæ.-After Max SchuLtzE.

ing the cell externally. The Radiolaria, whose shells are made of silica, possess also a perforated membranous sac called the central capsule, which lies imbedded in the protoplasm, dividing it into two portions, one within and 
one outside of the capsule. In the protoplasm inside of the capsule lies the nucleus or nuclei ; and from the protoplasm outside of the capsule rise the numerous fine, threadlike pseudopods which project through the apertures in the shell, and enable the animal to swim and to get food.

Most of the myriads of the simplest animals which swarm in the surface waters of the ocean belong to a few kinds of these shell-bearing Globigerinæ and Radiolaria. Large areas of the bottom of the Atlantic Ocean are covered with a slimy gray mud, often of great thickness, which is called globigerina-ooze, because it is made up chiefly of the microscopic shells of Globigerinæ. As death comes to the minute protoplasmic animals their hard shells sink slowly to the bottom, and accumulate in such vast quantities as to form a thick layer on the ocean floor. Nor is it only in present times and in the oceans we know that the Globigerinæ have flourished. All over the world there are thick rock strata which are composed chiefly of the fossilized shells of these simplest animals. Where the strata are made up exclusively of these shells the rock is chalk. Thus are composed the great chalk cliffs of Kent, which gave to England the early name of Albion, and the chalk beds of France and Spain and Greece. The existence of these chalk strata means that where now is land, in earlier geologic times were oceans, and that in the oceans Globigerinæ lived in countless numbers. Dying, their shells accumulated to form thick layers on the sea bottom. In later geologic ages this sea bottom has been uplifted and is now land, far perhaps from any ocean. The chalk strata. of the plains of the United States, like those in Kansas, are more than a thousand miles from the sea, and yet they are mainly composed of the fossilized shells of marine Protozoa. Indeed, we are acquainted with more than twice as many fossil species of Globigerinæ as species living at the present time. The ancestors of these Globigerinæ, from which the present Globigerinæ differ but little, can be 
traced far back in the geologic history of the world. It is an ancient type of animal structure.

The Radiolaria, too, which live abundantly in the present oceans, especially in the marine waters of the tropical and temperate zones, are found as fossils in the rocks from the time of the coal age on. The siliceous shells of the

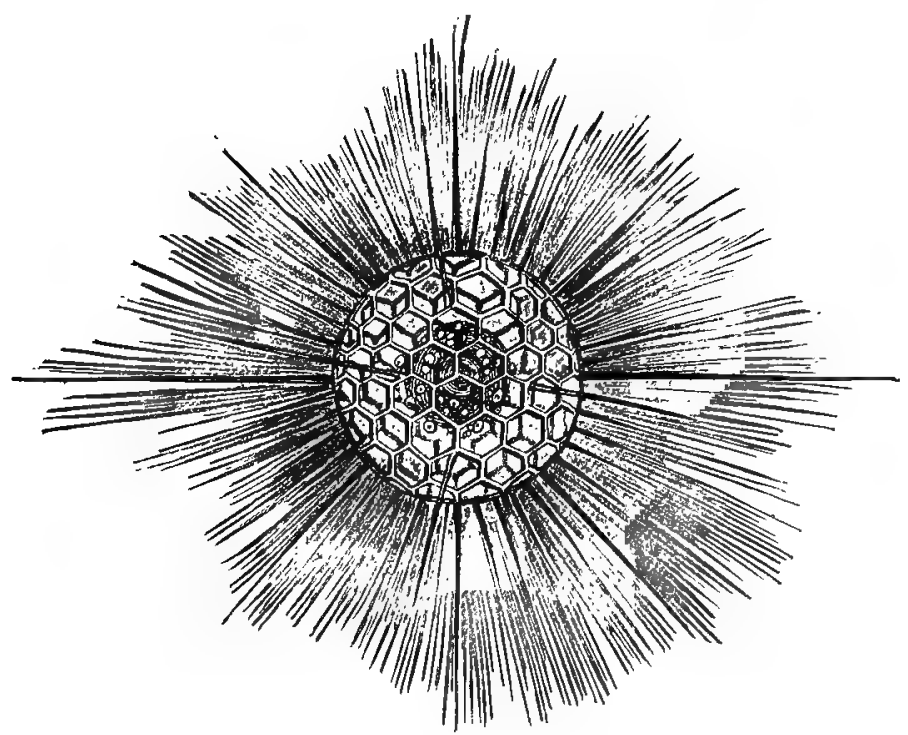

Fra. 11.-IIeliosphara actinota (nfter HAECKEL); a radiolarian with symmetrical shell.

Radiolaria sinking to the sea bottom and accumulating there in great masses form a radiolaria-ooze similar to the globigerinæ-ooze; and just as with the Globigerinæ, the remains of the ancient Radiolaria formed thick layers on the floor of the ancient oceans, which have since been up' 'lifted and now form certain rock strata. That kind of rock called Tripoli, found in Sicily, and the Barbados earth from the island of Barbados, both of which are used 
as polishing powder, are composed almost exclusirely of the siliceous shells of ancient and long-extinct Radiolaria.

10. Antiquity of the Protozoa.-All the animals of the ocean depend upon the marine Protozoa (and the marine Protophyta, or one-celled plants) for food. Either they prey upon these one-celled organisms directly, or they prey upon animals which do prey on these simplest animals. The great zoölogist. already quoted says: "The food supply of marine animals consists of a few species of microscopic organisms which are inexhaustible and the only source of food for all the inhabitants of the ocean. The supply is primeval as well as inexhaustible, and all the life of the ocean has gradually taken shape in direct dependence upon it." That is, the marine simplest animals are the only marine animals which live independently; they alone can live or could have lived in earlier ages without depending on other animals. They must therefore be the oldest of marine animals. By oldest we mean that their kind appeared earliest in the history of the world. As it is certain that marine life is older than terrestrial life-that is, that the first animals lived in the ocean-it is obvious that the marine Protozoa are the most ancient of animals. This is an important and interesting fact. Zoölogists try to find out the relationships and the degrees of antiquity or modernness of the various kinds of animals. We have seen that the Protozoa, those animals which have the simplest body structure and perform the necessary life pro- cesses in the simplest way, are the oldest, the first animals. This is just what we would expect.

11. The primitive form.-We find among the simplest animals a considerable variety of shape and some manifest variation in habit. But the points of resemblance are far more pronounced than the points of difference, and are of fundamental importance. The composition of the body of one cell, as opposed to the many-celled structure of the bodies of all other animals, is the fact to be most distinctly 
emphasized. The shape of this one-celled body varies. With the most primitive or simplest of the "simplest animals," like Amcba, for example, there is no "distinction of ends, sides, or surfaces, such as we are familiar with in in the higher animals. Anterior and posterior ends, right and left sides, dorsal and ventral surfaces are terms which have no meaning in reference to an $A$ moeba, for any part of the animal may go first in locomotion, and when crawling the animal moves along on whatever part of its surface happens to be in contact with foreign bodies." The one shape most often seen among the Protozoa, or most nearly fairly to be called the typical shape, is the spherical or subspherical shape. Why this is so is readily seen. Most of the Protozoa are aquatic and free swimming. They live in a medium, the water, which supports or presses on the body equally on all sides, and the body is not forced to assume any particular form by the environment. The body rests suspended in the water with any part of its surface uppermost or any part undermost. As any part of the surface serves equally well in many of the Protozoa for breathing or eating or excreting, it is obvious that the spherical form is the simplest and most convenient shape for such a body. It is interesting to note that the spherical form is the common shape of the egg cell of the higher animals. Each one of the higher, multicellular animals begins life (as we shall find it explained in another chapter of this book) as a single cell, the egg cell, and these egg cells are usually spherical in shape. The full significance of this we need not now attempt to understand, but it is interesting to note that normally the whole body of the simplest animals is a single spherical cell, and that every one of the higher animals, however complex it may become by growth and development, begins life as a single spherical cell.

12. The primitive but successful life.-Living consists of the performing of certain so-called life processes, such as 
eating, breathing, feeling, and multiplying. These processes are performed among the higher animals by various organs, special parts of the body, each of which is fitted to do some one kind of work, to perform some one of these processes. There is a division or assignment of labor here among different parts of the body. Such a division of labor, and special fitting of different parts of the body for special kinds of work does not exist, or exists only in slightest degree among the simplest animals. The Amoba eats or feels or moves with any part of its body; all of the body exposed to the air (air held in the water) breathes; the whole body mass takes part in the process of reproduction.

Only very small organisms can live in this simplest way. So all of the Protozoa are minute. When the only part of the body which can absorb oxygen is the simple external surface of a spherical body, the mass of that body must be very small. With any increase in size of the animal the mass of the body increases as the cube of the diameter, while the surface increases only as the square of the diameter. Therefore the part of the body (inside) which requires to be provided with oxygen increases more rapidly than the part (the outside) which absorbs oxygen. Thus this need of oxygen alone is sufficient to determine the limit of size which can be attained by the spherical or subspherical Protozoa.

That the simplest animals, despite the lack of organs and the primitive way of performing the life processes, live successfully is evident from their existence in such extraordinary numbers. They outnumber all other animals. Although serving as food for hosts of ocean animals, the marine Protozoa are the most abundant in individuals of all living animals. The conditions of life in the surface waters of the ocean are easy, and a simple structure and simple method of performance of the life processes are wholly adequate for successful life under these conditions. 
That the character of the body structure of the Protozoa has changed but little since early geologic times is explained by the even, unchanging character of their surroundings. The oceans of former ages have undoubtedly been essentially like the oceans of to-day-not in extent and position, but in their character of place of habitation for animals. The environment is so simple and uniform that there is little demand for diversity of habits and consequent diversity of body structure. Where life is easy there is no necessity for complex structure or complicated habits of living. So the simplest animals, unseen by us, and so inferior to us in elaborateness of body structure and habit, swarm in countless hordes in all the oceans and rivers and 'akes, and live successfully their simple lives. 


\section{CHAPTER II}

\section{THE LIFE OF THE SLIGHTLY COMPLEX ANIMALS}

13. Colonial Protozoa, - When one of the simplest animals multiplies by fission, the halves of the one-celled body separate wholly from each other, more apart, and pursue their lives independently. The original parent cell divides to form two cells, which exist thereafter wholly apart from each other. There are, however, certain simple animals which are classed with the Protozoa, which show an interesting and important difference from the great majority of the simplest animals. These are the so-called colony-forming or colonial Protozoa.

These colonial Protozoa belong to a group of organisms called the * Volvocinæ. The simplest of the Volvocinæ are single cells, which live wholly independently and are in structure and habit essentially like the other Protozoa we have studied. They have, however, imbedded in the onecelled body a bit of chlorophyll, the green substance which gives the color to green plants and is so important in their physiology. In this respect they differ from the other Protozoa. Among the other Volvocinæ, however, a few or many cells live together, forming a small colony-that is,

* These colonial organisms, the Volvocine, are the objects of some contention between botanists and zoölogists. The botanists call them plants because they possess a cellulose membrane and green chromatophores, and exhibit the melabolism characteristic of most plants; but most zoölogists consider them to he animals belonging to the order Flagellata of the Proto\%or. In the latest authoritative text-book of zoölogy, that of Parker and Iaswell (1897), they are so elassed. 
there is formed a group of a few or many cells, each cell having the structure of the simpler unicellular forms. These cells are held together in a gelatinous envelope, and the mass is usually spherical in shape. In most of the colonies each of the cells possesses two or three long, protoplasmic, whiplash-like hairs, called flagella, and by the lashing of these flagella in the water the whole group swims about.

14. Gonium.-If, when one of the simplest animals divided to form two darighter cells, these two cells did not move apart, but remained side by side and each divided to form two more, and each of these divided. to form two more, and these eight divided each into two, each cell complete and independent but all remaining together in a group - if this process should take place we should have produced a group or colony of sixteen cells, each cell a complete animal capable of living independently like the other simplest animals, but all holding together to form a tiny, flat, platelike colony. Now, this is precisely what takes place
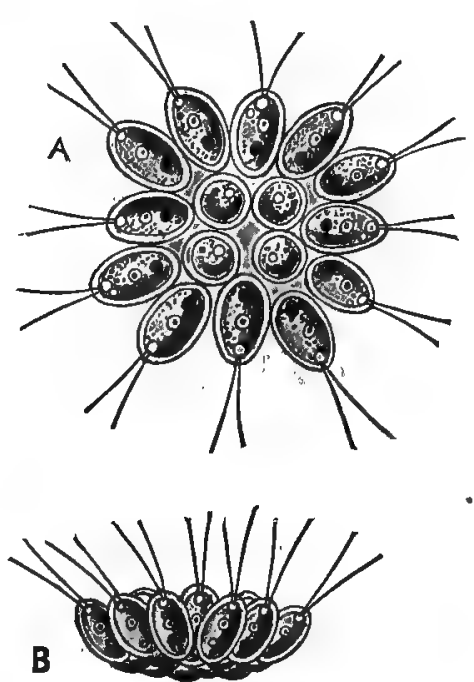

FIG. 12. Gonium pectorale (after STEIN). A, colony seen from above; $\mathbf{B}$, colony seen from the side.

in the case of those colonial Protozoa belonging to the genus Gonium (Fig. 12). When the mother cell of Conium divides, the daughter cells do not swim apart, but remain side by side, and by repeated fission, until there are sixteen cells side by side, the colony is formed. Each cell of the 
colony eats anil breathes and feels for itself; each can and does perform all the processes, necessary to keep it alive. When ready to multiply, the sixteen cells of the. Gonium colony separate, and each cell becomes the ancestor of a new colony.

15. Pandorina - Another colony usually composed of sixteen cells is Pandorina, but the cells are arranged to form a spherical instead of a plate-like colony (Fig. 13). In Pandorina morum the colony consists of sixteen ovoid cells in a spherical jelly-like mass. Each cell has two flagella, and by the lashing of all the flagella the whole colony moves through the water. Food is taken by any of the cells, is assimilated, and the cells increase in size. When Pandorina is ready to multiply, each cell divides repeatedly until it has formed sixteen daughter cells. The inclosing gelatinous mass which holds the colony together dissolves,

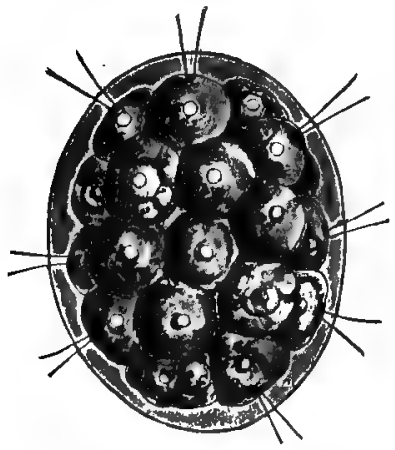

Fig. 13.-Pandorina 8). (from $\mathrm{Na}$ ture). The cells romposing the colony are beginning to divide to form danghter colonips. and the daughter colonies become free and swim apart. Each colony soon grows to the size of the original colony. This kind of multiplication or reproduction may be continued for several generations. But it does not go on indefinitely. After a number of these generations has been produced by simple division, the cells of a colony divide each into eight instead of sixteen daughter cells. The daughter cells are not all of the same size, but the difference is hardly noticeable. The eight cells resulting from the repeated division of one of the original cells separate and swim about independently by means of their flagella. If one of these cells comes near a similar free-swimming cell from another 
colony, the two cells conjugate (Fig. 14) - that is, fuse to form a single cell. This new cell formed by the fusion of two, develops a tough enveloping membrane of cellulose and passes into what is called the "resting stage." That is, the cell remains dormant for a shorter or longer time. It may thus tide over a drought or a winter. It may become dry or be frozen, yet when suitable conditions of moisture or temperature are again present the outer wall breaks and the protoplasm issues as a large freeswimming cell, which soon divides into sixteen daughter cells which constitute a new colony.

16. Eudorina, - Another colonial protozoan which much resembles Pandorina, but differs from it in one interesting and suggestive thing, is Eudorina. In Eudorina elegans (Fig. 15) the colony is spherical and is composed of sixteen or thirtytwo cells. Each of these cells can become the parent of a new colony by simple repeated division. But this simple mode of reproduction, just as with $\mathrm{Pan}$ dorina, can not persist indefinitely. There must be conjugation. But the process of mul-

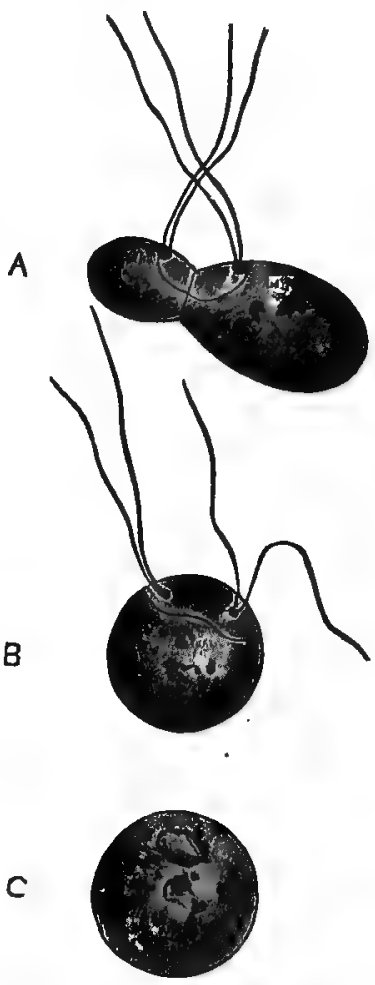

FTa. 14. - Pandorina morum (after GoeBex). Three stages in the conjugation and formation of the resting spore. $\mathrm{A}$, two cells just fused; B. the two cells completely fused, but with flagella still persisting; $\mathrm{C}$, the resting spore.

tiplication, which includes conjugation, is different from that process in Pandorina, in that in Eudorina the coniu- 
gating cells are of two distinctly different kinds. When this kind of multiplication is to take place in the case of Eudorina elegans, to choose a common species, some of the cells of a colony divide into sixteen or thirty-two

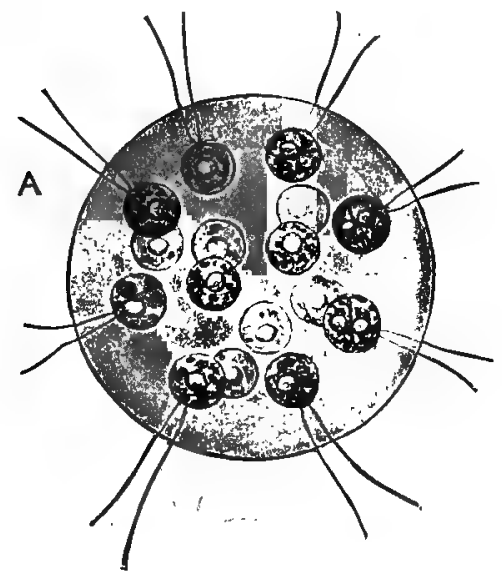
minute elongated cells, each provided with two flagella. These small cells escape

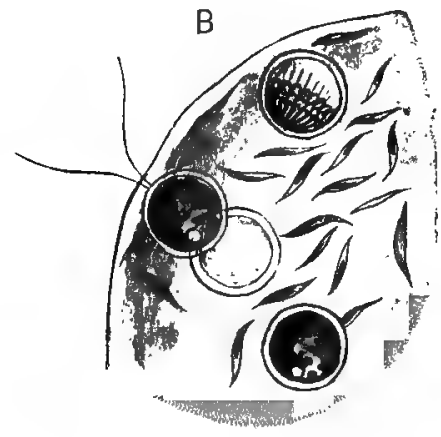

Fig. 15.-Endorina tegrus. $\Lambda$, a muture colony (froin Nature); B, formation of the two kinds of reproductive cells.

from the envelope of the parent cell, remaining for some time united in small bundles. Other cells of the colony do not divide, but increase slightly in size and become spherical in shape. When a bundle of the small cells comes into contact with some of these large spherical cells the bundle breaks up, and conjugation takes place between the small flagellated free-swimming cells and the large non-flagellate spherical cells. Each new cell formed by the fusion of one of the small and one of the large cells develops a cellulose wall and assumes a resting stage. After a time from each of these resting spores a new colony of sixteen or thirty-two cells is formed by direct, repeated division.

1\%. Volvox-Another interesting colonial protozoan is Volvox. The large sphericul colonies of Volvox globator 
(Fig. 16) are composed of several thousand cells, arranged in a single peripheral layer about the hollow center of the ball. The cells are ovoid, and each is provided with two long flagella which project out into the water. The lashing of the thousands of the flagella give the balllike colony a rotary motion. The cells are held together by a jelly-like intercellular substance and are connected with each other by fine protoplasmic threads which extend from the body protoplasm of one cell to the cells surrounding it. When the colony is full grown and ready to reproduce itself certain cells of the colony undergo great changes. Some of them increase in size enormously, having reserve food material stored in them, and they may be called the egg cells of the colony. Reproduction may now occur by simple division of one of these great egg cells into many small cells, all held together in a
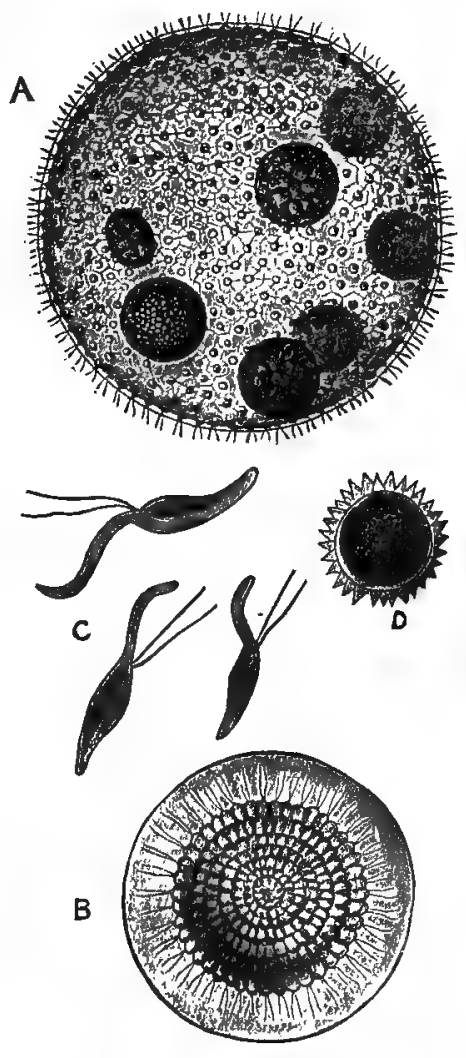
common envelope. These form a daughter colony which escapes from the

Fig. 16.-A, Volvox minor, entire colony (from Nature). B, C, and D, reproductive cells of Volvox globator.

mother colony and by growth and further division comes to be a new full-sized colony. Or reproduction may occur in another, more complex, way. Certain cells of the colony 
divide into bundles of very small, slender cells, each of which is provided with flagella. The remaining cells of the colony (that is, those which have not swollen into egg cells or divided into many-sixty-four to one hundred and twenty-eight—minute, flagellate cells) remain unchanged for a while and finally die. They take absolutely no part in reproducing the colony. One of the minute free-swimming cells fuses with one of the enormous egg cells, the new cell thus formed being a resting spore. From this resting spore a new colony develops by repeated division.

18. Steps toward complexity. - Within the group of Volvocince there are plainly several steps on the way from simplicity of structure to complexity of structure. Gonium, Pandorina, Eudorina, and Volvox form a series proceeding from the simplest animals toward the complex animals. In Gonium the cells composing the colony are all alike in structure, and each one is capable of performing all the processes or functions of life. In Pandorina and Eudorina the cells are at first alike, but there is, as the time for reproduction approaches, a differentiation of structure; the cells of the colony, all of which take part in the process of reproduction, come to be in certain generations of two kinds-an inactive large kind which may be called the egg cells, and a small, active, free-swimming kind which seeks out and conjugates with, or, we may say, fertilizes the egg cells. In Volvox there is a new differentiation. Only certain particular and relatively few cells take part in reproducing the colony; most of the cells have given up the power or function of reproduction. These cells, when the time of multiplication comes, simply support the special reproductive cells. They continue to waft the great colony through the water by lashing their flagella; they continue to take in food from the outside. The reproductive cells devote themselves wholly to the business of producing new colonies, of perpetuating the species. And this matter of reproduction is less simple than in the other Volvocince. 
At least there is much more difference between the two kinds of reproductive cells. The egg cells are comparatively enormous, and they are stored with a mass of food material. The fertilizing cells are very small, but very active and very different from the egg cells. We have in Volvox the beginnings of a distinct division of labor and an accompanying differentiation of structure. Certain cells of the colony do certain things, and are modified in structure to fit them specially for their particular duties. The steps from the simplest structure toward a complex structure are plainly visible.

19. Individual or colony.-Is the Gonium colony, the Pandorina colony, or the Volvox colony a group of several or many distinct organisms, or is it to be considered as a single organism? With Gonium, which we may call the simplest of these colonial organisms, the colony is composed of a few wholly similar cells or one-celled animals, each fully capable of performing all the life processes, each wholly competent to lead an independent life. In fact, each does, for part of its life, live independently, as we have already described. In the case of Pandorina and Eudorina, while all the cells are for most of the lifetims, of the colony alike and each is capable of living indeprndently, at the time of reproduction the cells become of two kinds. A difference of structure is apparent, and for the perpetuation of the species the co-operation of these different kinds of cells is necessary. That is, it is impossible for a single one of the members of the colony to reproduce the colony, except for a limited number of generations. With Volvox this giving up of independence on the part of the individual members of the colony is more marked. There is a real interdependence among the thousands of cells of the colony. The function of reproduction rests with a few particular cells, and for the perpetuation of the species there is demanded a co-operation of two distinct kinds of reproductive cells. The great majority of the cells take no part in reproduc- 
tion. They can perform all the other life processes; they move the colony by lashing the water with their flagella; they take in food and assimilate it; they can feel. All the cells of the great colony, too, are intimately connected by means of protoplasmic threads. The protoplasm of one cell can mingle with that of another cell; food can go from cell to cell. The question whether the Volvox colony is a group of distinct organisms or is a single organism made up of cells among which there is a simple but obvious difference in structure and function; in other words, whether Volvox is a colony of one-celled animals, of Protozoa, or is a multicellular animal, one of the Metazoa (for so all the many-celled animals are called), is a difficult one to decide. Most zoölogists class the Volvocinæ with the Protozoa-that is, they incline to consider Gonium, Pandorina, Volvox, and the other Volvocinæ as groups or colonies of one-celled animals.

20. Sponges.-If the Volvocina be considered to belong to the Protozoa, the sponges are the simplest of all the many-celled animals. Sponges are not free-swimming anirals, except for a short time in their young stage, but are fixed, like plants. They live attached to some solid substance on the sea bottom. They resemble plants, too, in the way. in which the body is modified during growth by the environment. If the rock to which the young sponge is attached is rough and uneven, the body of the sponge will grow so as to fit the unevenness; if the rock surfaco is smooth, the body of the sponge will be more regular. Thus a sponge may be said to have no fixed shape of body ; individuals of the same species of sponge differ much in form. The typical form of the sponges is that of a short cylinder or vase attached by one end and with the upper free end open (Fig. 17). Many individuals of one kind ustally live together in a close group or colony, and they may be so attached to each other as to appear like a branching plant. This branching may be very diffuse, and the branches 
may become so interwoven with each other as to form a very complex group. A sponge is composed of many cells arranged in three layers-that is, the body of a sponge is a cylinder closed at one end whose wall is composed of three layers of cells. The outer layer of cells is called the ectoderm, and the cells composing it are flat and are all closely attached to each other. The inner layer is called the endoderm, and its cells are thicker than those of the ectoderm; they are also closely attached to each other. Sometimes they are provided with flagella like the flagellate Protozoa. The flagella are, however, not for the purpose of locomotion, but for creating currents in the water, which bathes the interior of the open cylindrical body. The middle layer, called the mesoderm, is composed of numerous separate cells lying in a jelly-like matrix. From these mesoderm cells fine needles or spicules of lime or silica often project out through the ectoderm. These minute sponge spicules are of a great variety of shapes, and they form a sort of skeleton for the support of the soft body mass. All over the outer surface of the body are scattered fine openings or pores, which

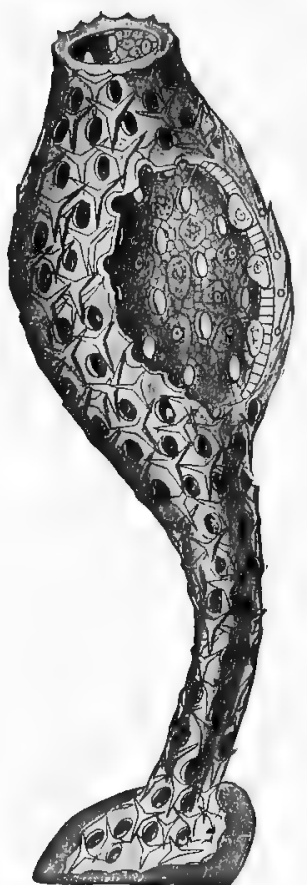

FIG. 17,-One of the simplest sponges, Calcolynthus pri. migenius (after HABCKzL). A part of the outer wall is cut away to show the in. side. lead through the walls of the body into the inner cavity. This cavity is of course also connected with the outside by the large opening at the free or apical end of the body.

There is hardly any differentiation of parts among the 
sponges. As in the P'rotozoa, there are no special organs for the performance of special functions. The sponge feeds by creating, with its flagella, water currents which

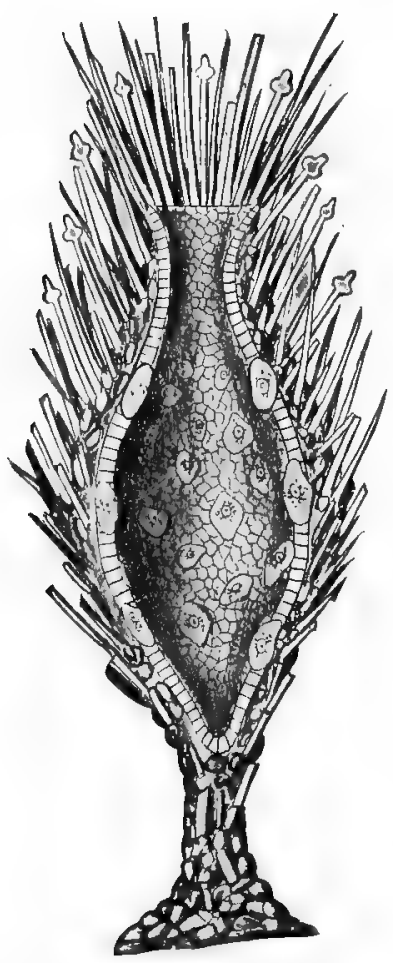

Fici. 18. - Une of the simple sponges, Prophysema primordiale (after

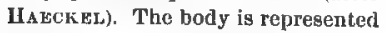
as cut in two longitudinaliy. The large celle of the inner layer are the egg cells.

flow in through the many fine pores of the body and out from the inner body cavity through the large opening at the free end of the body. These currents of water bear fine particles of organic matter which are taken up by the cells lining the pores and body cavity, and assimilated. There are no special organs of digestion. Each cell takes up food and digests it. The water currents also bring air to these same cells, and thus the sponge breathes. Although the sponge as a whole can not move, does not possess the power of locomotion, yet the protoplasm of the cells has the power of contracting, just as with the Protozoa, and the pores can be opened or closed by this cellular movement. Practically, thus, the only movements the sponge can make are the movements made by the individual cells.

Reproduction is accomplished by a process of division, or by a process of conjugation and subsequent division. In its simplest way multiplication takes place by a group of cells separating from the body of the parent sponge, 
becoming inclosed in a common capsular envelope, and by repeated division and consequent increase in number of cells becoming a new sponge. This is reproduction by "budding." The "buds," or small groups of cells which separate from the parent sponge, are called gemmules. Reproduction in the more complex way occurs as follows: Some of the free amoeboid cells of the mesoderm (the middle one of the three layers of the body wall) become enlarged and spherical in form. These are the egg cells. Other mesodermic cells divide into many small cells, which are oval with a long, tapering, tail-like projection. These cells are active, being able to swim by the lashing of the tapering tail. These are the fertilizing cells. The two kinds of reproductive cells may be formed in one sponge; if so, they are formed at different times. Or one sponge may produce only egg cells, another only fertilizing or, as they are called, sperm cells. Conjugation takes place between a sperm cell and an egg cell. That is, one of the small active sperm cells finds one of the large, spherical, inactive cells and penetrates into the protoplasm of its body. The two cells fuse and form a single cell, which may be called the fertilized or impregnated egg. This fertilized egg, remaining in the body mass of the parent sponge, divides repeatedly, the new cells formed by this division remaining together. The young or embryo sponge finally escapes from the body of the parent sponge, and lives for a short time as an active free-swimming animal. Its body consists of an oval mass of cells, of which those on one side are provided with cilia or swimming hairs. The cells of the body continue to divide and to grow, and the body shape gradually changes. The young sponge finally becomes attached to some rock, the body assumes the typical cylindrical shape, an aperture appears at the free end, and small perforations appear on the surface. The sponge becomes full grown.

Those of us who do not live in the vicinity of the sear 
shore where sponges are found can not observe the structure and life history of living specimens. There are, however, among the thousand and more kinds of sponges a few kinds that live in fresh water, and these are so widely spread over the earth that examples of them can be found in almost any region. They belong to the genus Spongilla, and thirty or more species or kinds of Spongilla are known. In standing or slowly flowing water, Spongilla grows erect and branching, like a shrub or miniature tree; in swift water it grows low and spreading, forming a sort of mat over the surface to which it is attached. Reproduction takes place very actively by the process of budding. The budded-off gemmules are spherical in shape, and the cells of each gemmule are inclosed in an envelope composed of siliceous spicules of peculiar shape. These gemmules are formed in the body substance of the parent sponge toward the end of the year, and are set free by the decaying of that part of the body of the parent sponge in which they lie. They sink to the bottom of the pond or brook, and lie there dormant until the following spring. Then they develop rapidly by repeated division of the cells and growth.

It is not the purpose here to describe the many and interesting kinds of sponges which inhabit the ocean. The sponge of the bathroom is simply the skeleton of a large sponge or group of sponges. The skeleton here is not composed of lime or silica, but of a tough, horny substance, which is secreted by cells of the mesodermal layer of the body wall of the sponge. This substance is called spongin, and is a substance allied to silk in its chemical composition. All the commercial sponges, the spongin skeletons, belong to one genus-Spongia. These sponges grow especially abundantly in the Mediterranean and Red Seas, and in the Atlantic Ocean off the Florida reefs, and on the shores of the Bahama Islands. The sponges are pulled up by divers, or by means of hooks or dredges. The 
living matter soon dies and decays, leaving the horny skeleton, which when cleaned and trimmed is ready for use.

The most beautiful sponges are those with siliceous skeletons. The fine needles or threads of glass, arranged often in delicate and intricate pattern, make these sponges objects of real beauty.

21. Polyps, corals, and jelly-fishes.-The general or typical plan of body structure of those animals which come next in degree of complexity to the sponges can be best understood by imagining the typical cylindrical body of a sponge modified in the following way: The middle one of the three layers of the body wall not to be composed of cells in a gelatinous mass, but to be simply a thin noncellular membrane; the body wall to be pierced by no fine openings or pores, so that the interior cavity of the body is connected with the outside only by the single large opening at the free end, and this opening to be surrounded by a circlet of arm-like processes or tentacles, continuations of the body wall and similarly composed. Such a body structure is the general or fundamental one for all polyps, corals, sea-anemones, and jelly-fishes. The variety in shape and the superficial modifications of this type-plan are many and striking; but, after all, the typeplan is recognizable throughout the whole of this great group of animals. Perhaps the simplest representative of the group is a tiny polyp which grows abundantly in the fresh-water streams and pools, and can be readily obtained for observation. It is called Hydra.

22. Hydra.-The body of Hydra (Fig. 19), which is very small and appears to the unaided eye as a tiny white or greenish gelatinous particle attached to some subme rged stone, bit of wood, or aquatic plant, is a simple cyinder attached by one end to the stone or weed. The other free end is contracted so as to be conical, and it is narrowly open. Around the opening are six or eight small waving 
tentacles. The wall of the cylinder is composed of an outer and an inner layer of cells and a thin non-cellular membranous layer between them. The tentacles are hollow and are simple extensions of the body wall. The cells of the outer layer, or ectoderm, are not all alike. Some are smaller than the others and appear to be crowded in

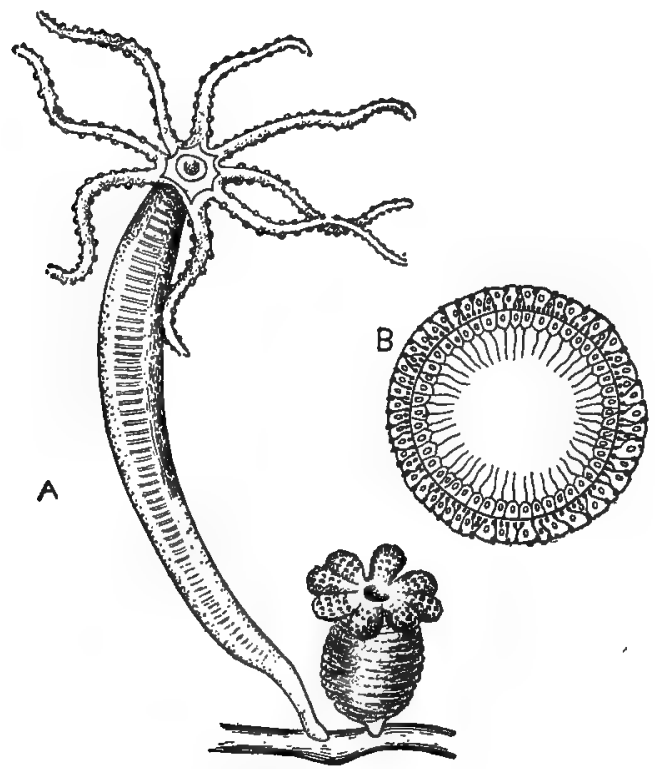

Fia. 19.-The fresh-water polyp, Hyara vulgaris. A, in expanded condition, and in contracted condition; $\mathbf{B}$, cross section of body, showing the two layers of cells which make up the body wall.

between the bases or inner ends of the larger ones. The inner ends of the large cells are extended as narrow-pointed prolongations directed at right angles with the rest of the cell. These processes are very contractile and are called muscle processes. Each one is simply a continuation of the protoplasm of the cell body, which is especially contractile. Some of the smaller ectoderm cells are very 
irregular in shape and possess specially large nuclei. These cells are more irritable or sensitive than the others and are called nerve cells. The ectoderm cells of the base or foot of the Hydra are peculiarly granular, and secrete a sticky substance by which the Hydra holds fast to the stone or weed on which it is found. These cells are called gland cells. Imbedded in many of the larger ectoderm cells, especially those of the tentacles, are small oval sacs, in each of which lies folded or coiled a fine long thread. When the tentacles touch one of the small animals which serve Hydra as food, these fine threads shoot out from their sacs and so poison or sting the prey that it is paralyzed. The tentacles then contract and bend inward, forcing the captured animal into the mouth opening in the center of the circle of tentacles. Through the mouth opening the prey enters the body cavity of Hydra and is digested by the cells lining this cavity. These cells belonging to the inner layer of the body wall or endoderm are mostly large, and each contains one or more contractile vacuoles. From the free ends-the ends which are next to the body cavity - of these cells project pseudopods or fine flagella. These projections are constantly changing: now two or three short, blunt pseudopods are projecting into the body cavity; now they are withdrawn, and a few fine, long flagella are projected. In addition to these cells there are in the endoderm, especially abundant near the mouth opening and wholly lacking in the tentacles and at the base of the body, many long, narrow, granular cells. They are gland cells which secrete a digestive fluid. The food captured by the tentacles and taken in through the mouth opening disintegrates in the body cavity, or digestive cavity, as it may be called. The digestive fluid secreted by the gland cells of the endoderm acts upon it, so that it becomes broken into small parts. These particles are probably seized by the pseudopods of the other endoderm cells and are taken into the body protoplasm 
of these cells. The ectoderm cells do not take food directly, but receive nourishment only through the endoderm cells.

Hydra is not permanently attached. It holds firmly to the submerged stone or weed by means of the sticky secretion from the ectodermal gland cells of its base, but it can loosen itself, and by a slow creeping or gliding move along the surface of the stone to another spot. Even when attached, the form of the body changes; it extends itself longitudinally, or it contracts into a compact globular mass. The tentacles move about in the water, and are continually contracting or extending.

Like Volvox and the sponges, those other slightly complex animals we have already considered, Hydra has two methods of multiplication. In the simpler way, there appears on the outer surface of the body a little bud which is composed, at first, of ectoderm cells alone; but soon it is evident that it is a budding, or outpushing, of the whole body wall, ectoderm, endoderm, and middle membrane. In a few hours the bud has six or eight tiny, blunt tentacles, a mouth opening appears at the free end, and the little Hydra breaks off from the parent body and leads an independent existence. In the more complex way, two kinds of special reproductive cells are produced by each individual, viz., large, inactive, spherical egg cells, and small, active sperm cells, each with an oval part or head (consisting of the nucleus) and a slender, tapering tail-like part (consisting of the cytoplasm). The egg cell lies inclosed in a layer of thin, surrounding cells, which compose a capsule for it. When the egg cell is ready for fertilization this capsule breaks, and one of the active sperm cells finds its way to and fuses with the egg cell. The fertilized egg cell now divides into several cells, which remain together. The outer ones form a liard capsule, and thus protected the embryo falls to the bottom, and after lying dormant for awhile develops into a Hydra. 
23. Differentiation of the body cells.-In IFydra we have the heginnings of complexity of structure carried a step further than in the sponges. The division of labor among the cells composing the body is more pronounced, and the structural modification of the different cells to enable them better to perform their special duties is obvious. Some of the cells of the body specially devote themselves to foodtaking; some specially to the digestion of the food; some are specially contractile, and on them the movements of the body depend, while others are specially irritable or sensitive, and on them the body depends for knowledge of the contact of prey or enemies. In the lasso cells-those with the stinging threads-there is a very wide departure from the simple primitive type of cells. There is in Hydra a manifest differentiation of the cells into various kinds of cells. The beginnings of distinct tissues and organs are foreshadowed.

The individuals of Hydra live, usually, distinct from each other. There is no tree-like colony, as with the sponges. But most of the other polyps do live in this colonial manner. The new polyps which develop as buds from the body of the parent do not separate from the parent, but remain attached by their bases. They, in turn, produce new polyps which remain attached, so that in time a branching, tree-like colony is formed.

24. Medusæ or jelly-fishes-Most of the other polyps differ from Hydra also in producing, in addition to ordinary polyp buds, buds which develop into bell-shaped structures called medusa (Fig. 20). These medusæ consist of a soft gelatinous bell- or umbrella-shaped body, with a short clapper or stem which has an opening at its free end. From the edge of the bell or umbrella four pairs of tentacles project. The medusæ usually separate from the parent polyp and live an independent, free-swimming life. These are the beautiful animals commonly known as jelly-fishes. The medusæ or jelly-fishes produce special reproductive 
cells, a single medusa producing only one kind of such cells -that is, producing either egg cells alone or sperm cells alone. The active sperm cells produced by one medusa find their way to an egg cell producing medusa, and fuse

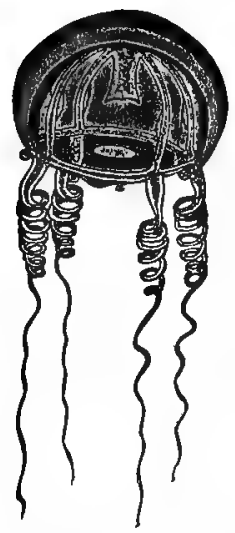

Frg. 20.-A medusa, Eucope. - After Habcirer.

with or fertilize these egg cells. The fertilized egg develops into a small, oval, free-swimming embryo called a planula, which finally attaches itself to a stone or bit of wood or seaweed, and grows to be a simple cylindrical polyp attached at its base and with mouth and tentacles at its free end. This polyp gives rise by budding to new polyps, which remain attached to it, and gradually a new tree-like colony is formed. From this polyp or this colony new medusæ bud off, swim away, and finally produce new polyps. Thus there is in the life of the polyps what is called an alternation of generations. There are two kinds of individuals which evidently belong to the same species of animal, or, put in another way, one kind of animal has two distinct forms. This appearance of one kind of animal in two forms is called dimorphism. We shall see later that one kind of animal may appear in more than two forms; such a condition is called polymorphism. In alternation of generations we have the polyp animal appearing in one generation as a fixed cylindrical polyp, while in the next generation it is a free-swimming, umbrella-shaped medusa or jelly-fish.

The polyps which are dimorphic-that is, have a polyp form of individual and a medusa form of individual-show more differentiation in structure than the simple Hydra. This further differentiation is especially apparent in the medusæ or jelly-fishes. Here the nerve cells are aggregated in little groups arranged along the edge of the umbrella 
to form distinct sense organs. The muscle processes are better developed, and the digestive cavity is differentiated into central and peripheral portions. In these dimorphic polyps the fixed polyp individuals reproduce by the simple way of budding, while the medusa individuals reproduce by producing special reproductive cells of two kinds, which must fuse to form a cell capable of developing into a new polyp.

25. Corals.-There are many kinds of polyps and jellyfishes, and they present a great variety of shape and size and general appearance. Many polyps exist only in the true polyp form, never producing medusæ. Others have

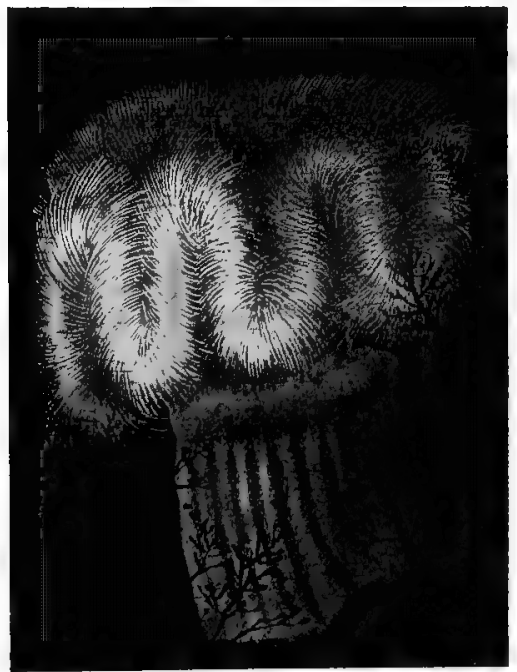

Fia. 21.-A polyp, or aea-nnemone (Metridium dianthus).

only the medusa form. Some live in colonies, and others are always solitary. The animals we know as corals are polyps which live in enormous colonies, and which exist only in the true polyp form, not producing medusæ. They 


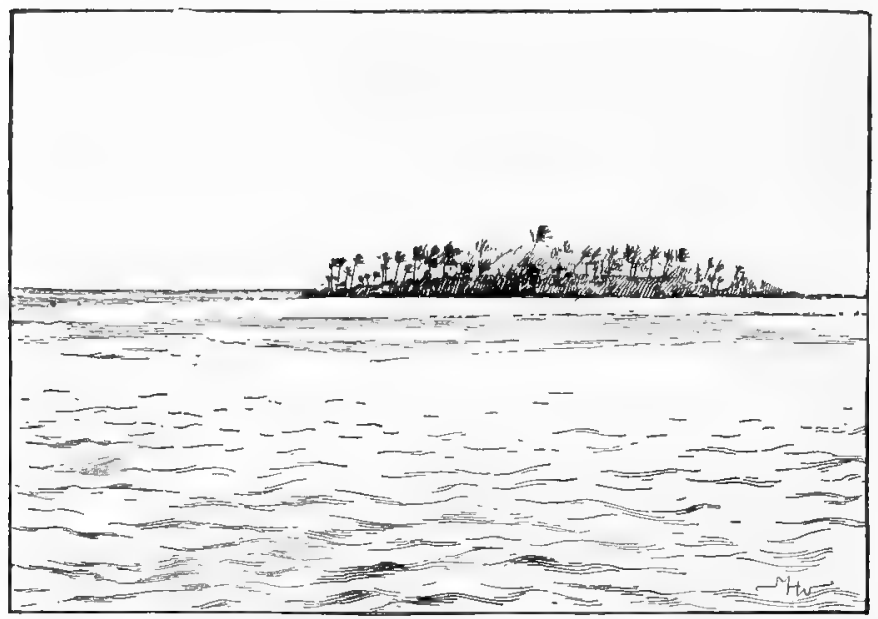

Fig. 22.-Coral islund (Nanukn Levn, of the Fiji gronp). (After a photograph by MaX Agagsiz.)

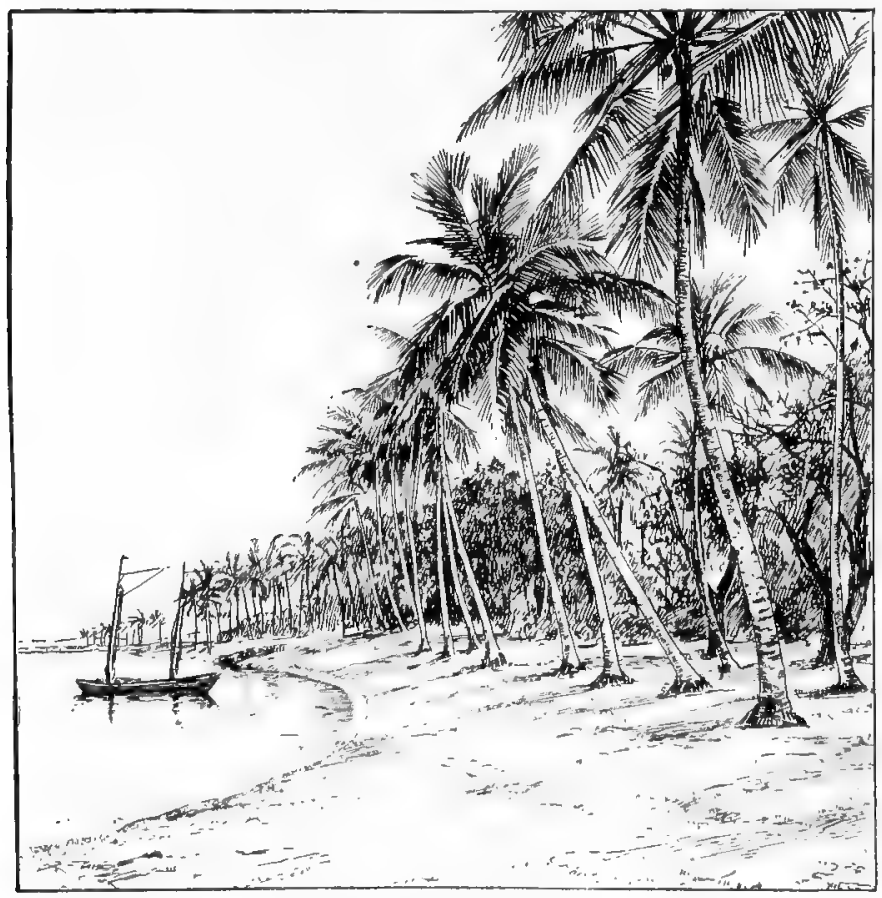

FIG. 88. -Shore of a coral island, with cocounut palms. (A fter a photograph.) 
form a firm skeleton of lime (calcium carbonate), and after their death these skeletons persist, and because of their abundance and close massing form great reefs or banks and islands. Coral islands occur only in the warmer oceans. In the Atlantic they are found along the coasts of southern Florida, Brazil, and the West Indies; in the Pacific and Indian Oceans there are great coral reefs on the coast of Australia, Madagascar, and elsewhere, and certain large

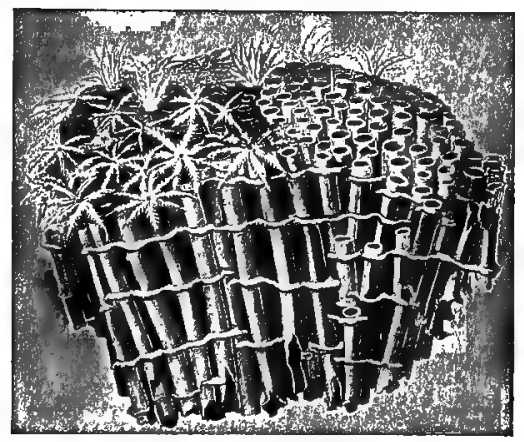

Fia. 24.-Organ-pipe coral.

groups of inhabited islands like the Fiji, Society, and Friendly Islands are composed exclusively of coral islands. More than two thousand kinds of living corals are known, and their skeletons offer much variety in structure and appearance. Brain coral, organ-pipe coral (Fig. 24), the well-known red coral from Italy and Sicily, used as jewelry, and the sea pens and sea fans are among the better known and more beautiful kinds of coral skeletons.

26. Colonial jelly-fishes. - While many of the medusæ or jelly-fishes are another form of individual of a true fixed polyp, many of the larger and more beautiful jelly-fishes do not exist in any other form. Some of these larger jellyfishes are several feet in diameter, and when cast up on the beach form a great shapeless mass of soft, jelly-like sub- 
stance. The bodics of all jelly-fishes are soft and gelatinous, the body substance containing hardly one per cent of solid matter. It is mostly water. Many jelly-fishes are beautifully and strikingly colored, and as they swim slowly about near the surface of the ocean, lazily opening and shutting their iridescent, umbrella-like bodies, they are among the most beautiful of marine organisms. When one of the jelly-fishes is taken from the water, however, it quickly loses its brilliant colors, and dries away to a shapeless, shriveling, sticky mass.

Some of the most beautiful of the jelly-fishes belong to a group called the Siphonophora. These jelly-fishes are elongate and tube-like rather than umbrella- or bell-shaped, and they are polymorphic-that is, there are several different forms of individuals belonging to a single kind or species. The Siphonophora are all free-swimming, but nevertheless form small colonies. In the Mediterranean Sea and in other southern ocean waters the surface may be covered for great areas by these brilliantly colored jelly-fish colonies, each of which looks, as a celebrated German naturalist has said, like a swimming flower cluster whose parts, flowers, stems, and leaves seem to be made of transparent crystal, but which possess the life and soul of an animal. An abundant species of these Siphonophora (Fig. 25) is composed of a slender, flexible, floating, central stem several feet long, to which are attached thousands of medusa and polyp individuals representing several different kinds of forms, each kind of individual being specially modified or adapted to perform some one duty. The central stem is a greatly elongated polyp individual, whose upper end is dilated and filled with air to form a float. This individual holds up the whole colony. Grouped around this central stem just below the float are many bell-shaped bodies which alternately open and close, and by thus drawing in and expelling water from their cavities impel the whole colony through the water. These bell-shaped structures are attached me- 
dusa individuals, whose business it is to be the locomotive organs for the colony. These medusæ are without tentacles, and take no food and prodnce no young. They have given up the power of performing these other life processes, and devote themselves wholly to the business of locomotion. From the lower end of the central stem rises a host of structures, among which several distinct kinds are readily perceived. One kind is composed of a pearshaped hollow body open at its free end, and bearing a long tentacle which is furnished with numerous groups of stinging cells. These are the polyp individuals whose especial business it is to capture and sting prey and to eat it. These individuals are the food-getters for the colony. Scattered among these stinging, feeding polyps, are numerous smaller individuals with oval, closed body, each bearing a long, slender thread. These threads

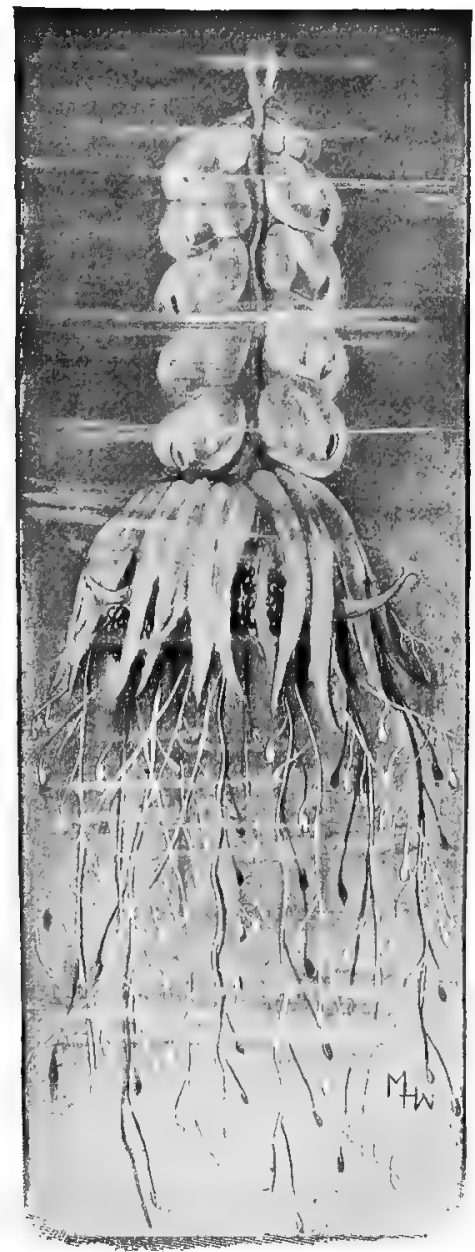

Fia. 25.-A colonial jelly-fish, Physophora (after $H_{A B C K E L}$ ). At the top is the float polyp, around its stem the swimming medusa, and below are the feeding, feeling, protecting, and reproducing polyps and meduax. 
are very sensitive, and the polyps hearing them have for special function that of feeling or being sensible of stimuli from without. They are the sense organs or sense individuals of the colony. Finally, there are two other kinds of structures or individuals which produce the special reproductive cells for the perpetuation of the species. These are the modified medusa individuals, and one kind, larger than the other, produces the active sperm cells, while the other produces the inactive egg cells.

2\%. Increase in the degree of complexity.-In the corals, sea-anemones, and jelly-fishes there is plainly much more of a division of labor among the various parts of an individual and much more modification of these parts-that is, much more structural complexity than among the sponges and Hydra. And these, in their turn, are more complex than are the colonial Protozoa, the Volvocinæ. There is a great difference in degree of complexity among the slightly complex animals. But the various groups of these animals which we have studied can all be arranged roughly in a series beginning with the least complex among them and ascending to the most complex. And in this series, and in the always accompanying division of labor among the different parts, the gradual increase in complexity is beautifully shown.

From an animal composed of many structurally similar cells, each cell capable of performing all the life processes, we pass to an animal composed of cells of a few different kinds, of slight structural diversity. Each kind of cell devotes itself especially to a certain few life processes or functions. Next we find an animal in which the cells of one kind are specially aggregated to form a single part of the body which is specially devoted to the performance of a single function. This diversity among the cells increases, this aggregation of similar cells to form special parts or organs increases, and the division of labor or assignment of special functions to special organs becumes 
more and more pronounced. Among the more complex polyps and jelly-fishes the contractile cells form distinct muscle fibers and muscles; the sensitive cells form distinct nerve cells and nerve fibers which are arranged in a primitive nervous system; the digestive cavity becomes complex and composed of different portions ; the reproductive cells are formed by special organs, and the distinction between the egg cells and the sperm cells-that is, between the female reproductive elements and the male reproductive elements-becomes more pronounced.

We have followed this increase or development of structural and physiological complexity from simplest animals to fairly somplex ones. The principle of this development of complexity is evident. It will not be profitable to attempt to follow in detail this development among the higher animals. The complex animals are complex because their life processes are performed by special parts of their body, which parts are specially modified so as to perform these processes well. The animals which are more complex than those we have studied differ from these simply in the degree of complexity attained. In order to understand this better we shall not further consider special groups of animals, but special processes or functions, and attempt to see how the modification and increase in complexity of structure goes hand in hand with the increase of elaborateness or complexity in the performance of function. 


\section{CHAPTER III}

\section{THE MULTIPLICATION OF ANIMALS AND SEX}

28. All life from life.-On the performance of the func. tion of reproduction or multiplication depends the exist. ence or perpetuation of the species. Although an animal may take food and perform all the functions necessary to its own life, it does not fulfill the demands of successful existence unless it reproduces itself. Some individuals of every species must produce offspring or the species becomes extinct. We have seen in our study of the simple animals that the function of reproduction is the first function to become differentiated in the ascent from simplest animals to complex animals. The first division of labor among the cells composing the bodies of the slightly complex animals and the first structural differences among the cells are connected with the performance of the function of reproduction or multiplication.

We are all so familiar with the fact that a kitten comes into the world only through being born, as the offspring of parents of its kind, that we shall likely not appreciate at first the full significance of the statement that all life comes from life; that all organisms are produced by other organisms. Nor shall we at first appreciate the importance of the statement. This is a generalization of modern times. It has always been easy to see that cats and horses and chickens and the other animals we familiarly know give birth to young or new animals of their own kind; or, put conversely, that young or new cats and horses and chickens come into existence only as the off- 
spring of parents of their kind. And in these latter days of microscopes and mechanical aids to observation it is even easy to see that the smaller animals, the microscopic organisms, come into existence only as they are produced by the division of other similar animals, which we may call their parents. But in the days of the earlier naturalists the life of the microscopic organisms, and even that of many of the larger but unfamiliar animals, was shrouded in mystery. And what seem to us ridiculous beliefs were held regarding the origin of new individuals.

29. Spontaneous generation.-The ancients believed that many animals were spontaneously generated. The early naturalists thought that flies arose by spontaneous generation from the decaying matter of dead animals; from a dead horse come myriads of maggots which change into flesh flies. Frogs and many insects were thought to be generated spontaneously from mud. Eels were thought to arise from the slime rubbed from the skin of fishes. Aristotle, the Greek philosopher, who was the greatest of the ancient naturalists, expresses these beliefs in his books. It was not until the middle of the seventeenth centuryAristotle lived three hundred and fifty years before the birth of Christ-that these beliefs were attacked and began to be given up. In the beginning of the seventeenth century William Harvey, an English naturalist, declared that every animal comes from an egg, but he said that the egg might " proceed from parents or arise spontaneously or out of putrefaction." In the middle of the same century Redi proved that the maggots in decaying meat which produce the flesh flies develop from eggs laid on the meat by flies of the same kind. Other zoölogists of this time were active in investigating the origin of new individuals. And all their discoveries tended to weaken the belief in the theory of spontaneous generation.

Finally, the adherents of this theory were forced to restrict their belief in spontaneous generation to the case 
of a few kinds of animals, like parasites and the animalcules of stagnant water. It was maintained that parasites arose spontaneously from the matter of the living animal in which they lay. Many parasites have so complicated and extraordinary a life history that it was only after long and careful study that the truth regarding their origin was discovered. But in the case of every parasite whose life history is known the young are offespring of parents, of other individuals of their kind. No case of spontaneous generation among parasites is known. The same is true of the animalcules of stagnant water. If some water in which there are apparently no living organisms, however minute, be allowed to stand for a few days, it will come to be swarming with microscopic plants and animals. Any organic liquid, as a broth or a vegetable infusion exposed for a short time, becomes foul through the presence of innumerable bacteria, infusoria, and other one-celled animals and plants, or rather through the changes produced by their life processes. But it has been certainly proved that these organisms are not spontaneously produced by the water or organic liquid. A few of them enter the water from the air, in which there are always greater or less numbers of spores of microscopic organisms. These spores (embryo organisms in the resting stage) germinate quickly when they fall into water or some organic liquid, and the rapid succession of generations soon gives rise to the hosts of bacteria and Protozoa which infest all standing water. If all the active organisms and inactive spores in a glass of water are killed by boiling the water, "sterilizing " it, as it is called, and this sterilized water or organic liquid be put into a sterilized glass, and this glass be so well closed that germs or spores can not pass from the air without into the sterilized liquid, no living animals will ever appear in it. It is now known that flesh will not decay or liquids ferment except through the presence of living animals or plants. To sum up, we may say that we know of no instance of the 
spontaneous generation of organisms, and that all the animals whose life history we know are produced from other animals of the same kind. "Omne vivum ex vivo," All life from life.
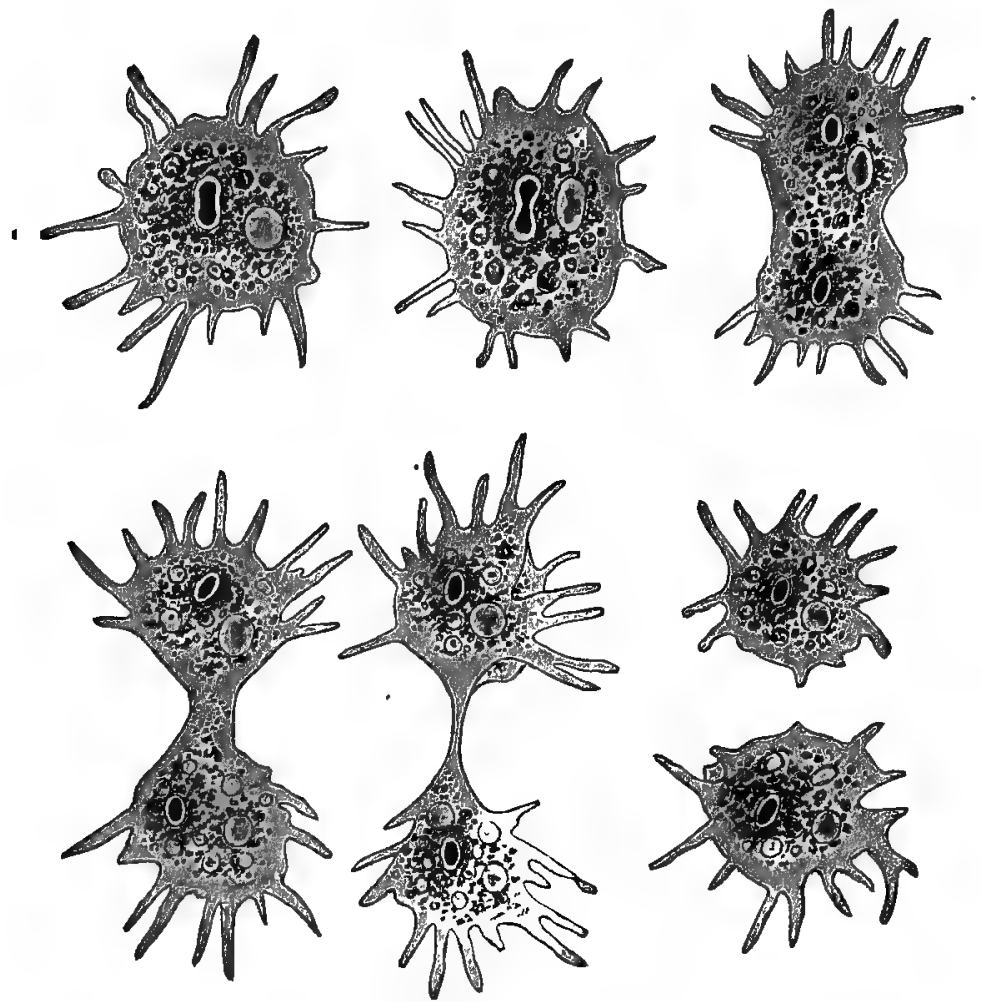

Fio. 26.-The multiplication of Amoba by simple fission.

30. The simplest method of multiplication.-In our study of the simplest and the slightly complex animals we became acquainted with the simplest methods of multiplication and with methods which are more complex. The method 
of simple fission or splitting-binary fission it is often called, because the division is always in two-by which the body of the parent becomes divided into two equal parts-into halves-is the simplest method of multiplication. This is the usual method of Amoeba (Fig. 26) and of many other of the simplest animals. In this kind of reproduction it is hardly exact to speak of parent and children. The children, the new Amobce, are simply the parent cut into halves. The parent persists; it does not produce offspring and die. Its whole body continues to live. The new Amobce take in and assimilate food and add new matter to the original matter of the parent body; then each of them divides in two. The grandparent's body is now divided into four parts, one fourth of it forming one half of each of the bodies of the four grandchildren. The process of assimilation, growth, and subsequent division takes place again, and again, and again. Each time there is given to the new $A m a b a$ an ever-lessening part of the actual body substance of the original ancestor. Thus an Amoba never dies a natural death, or, as has been said, "no Amœba ever lost an ancestor by death." It may be killed outright, but in that case it leaves no descendants. If it is not killed before it produces new $A m a b c e$ it never dies, although it ceases to exist as a single individual. The $A m c e b a$ and other simple animals which multiply by direct binary fission may be said to be immortal, and the "immortality of the Protozoa" is a phrase which you will be sure to meet if you begin to read the writings of the modern philosoph. ical zoölogists.

31. Flightly complex methods of multiplication.-Most of the Protozoa multiply or reproduce themselves in two ways-by simple fission and by conjugation. Paramoacium, for example, reproduces itself for many generations by fission, but a generation finally appears in which a different method of reproduction is followed. Two individuals come together and each exchanges with the other a part 
of its nucleus. Then the two individuals separate and each divides into two. The result of this conjugation is to give to the new Paramoecia produced by the conjugating individuals a body which contains part of the body substance of two distinct individuals. The new Paramocia are not simply halves of a single parent; they are parts of two parents. If the two conjugating individuals differ at all-and they always do differ, because no two individual animals, although belonging to the same species, are exactly alike-the new individual, made up of parts of each of them, will differ from both. We shall, as we study further, see that Nature seems intent on making every new individual differ slightly from the individual which produces it; and the method of multiplication or the production of new individuals which Nature has adopted to produce the result is the method which we have seen exhibited in its simplest form among the simplest animals-the method of having two individuals take part in the production of a new one. The further study of multiplication among animals is the study of the development and elaboration of this method.

32. Differentiation of the reproductive cells.-Among the colonial Protozoa the first differentiation of the cells or members composing the colony is the differentiation into two kinds of reproductive cells. Reproduction by simple division, without preceding conjugation, can and does take place, to a certain extent, among all the colonial Protozoa. Indeed, this simple method of multiplication, or some modification of it, like budding, persists among many of the complex animals, as the sponges, the polyps, and even higher and more complex forms. But such a method of singleparent reproduction can not be used alone by a species for many generations, and those animals which possess the power of multiplication in this way always exhibit also the other more complex kind of multiplication, the method of double-parent reproduction. Conjugation takes place between different members of a single colony of one of the 
colonial Protozoa, or between members of different colonies of the same species. These conjugating individuals in the simpler kinds of colonies, like Gonium, are similar; in Pandorina they appear to be slightly different, and in Eudorina and Volvox the conjugating cells are very different from each other (Figs. 15 and 16). One kind of cell, which is called the egg cell, is large, spherical, and inactive, while the other kind, the sperm cell, is small, with ovoid head and tapering tail, and free-swimming. In the simpler colonial Protozoa all the cells of the body take part in reproduction, but in Volvox only certain cells perform this function, and the other cells of the body die. Or we may say that the body of Volvox dies after it has produced special reproductive cells which shall fulfill the function of multiplication.

Beginning with the more complex Volvocinæ, which we may call either the most complex of the one-celled animals or the simplest of the many-celled animals, all the complex animals show this distinct differentiation between the reproductive cells and the cells of the rest of the body. Of course, we find, as soon as we go up at all far in the scale of the animal world, that there is a great deal of differentiation among the cells of the body: the cells which have to do with the assimilation of food are of one kind; those on which depend the motions of the body are of another kind; those which take oxygen and those which excrete waste matter are of other kinds. But the first of this cell differentiation, as we have already often repeated, is that shown by the reproductive cells; and with the very first of this differentiation between reproductive cells and the other body cells appears a differentiation of the reproductive cells into two kinds. These two kinds, among all animals, are always essentially similar to the two kinds shown by Volvox and the simplest of the many-celled animals-namely, large, inactive, spherical egg cells, and small, active, elongate or " tailed" sperm cells. 
33. Sex, or male and female.-In the slightly complex animals one individual produces both egg cells and sperm cells. But in the Siphonophora, or colonial jelly-fishes, studied in the last chapter, certain nembers of the colony produce only sperm cells, and certain other members of the colony produce only egg cells. If the Siphonophora be considered an individual organism and not a colony composed of many individuals, then, of course, it is like the others of the slightly complex animals in this respect. But as soon as we rise higher in the scale of animal life, as soon as we study the more complex animals, we find that the egg cells and sperm cells are almost always produced by different individuals. Those individuals which produce egg cells are called female, and those which produce sperm cells are called male. There are two sexes. Male and female are terms usually applied only to individuals, but it is evidently fair to call the egg cells the female reproductive cells, and the sperm cells the male reproductive cells. A single individual of the simpler kinds of animals produces both male and female cells. But such an individual can not be said to be either. male or female; it is sexlessthat is, sex is something which appears only after a certain degree of structural and physiological differentiation is reached. It is true that even among many of the higher or complex animals certain species are not represented by male and female individuals, any individual of the species being able to produce both male and female cells. But this is the exception.

34. The object of sex-Among almost all the complex animals it is necessary that there be a conjugation of male and female reproductive cells in order that a new individual may be produced. This necessity first appears, we remember, among very simple animals. This intermixing of body substance from two distinct individuals, and the development therefrom of the new individual, is a phenomenon which takes place through the whole scale of animal life. 
The object of this intermixing is the production of va. riation. Nature demands that the offspring shall differ slightly from its parents. By having the beginnings of its body, the single cell from which the whole body develops, composed of parts of two different individuals, this difference, although slight and nearly imperceptible, is insured. Sex is a provision of Nature which insures variation.

35. Sex dimorphism.-As we have seen, almost every species of animal is represented by two kinds of individuals, males and females. In the case of many animals, espe-

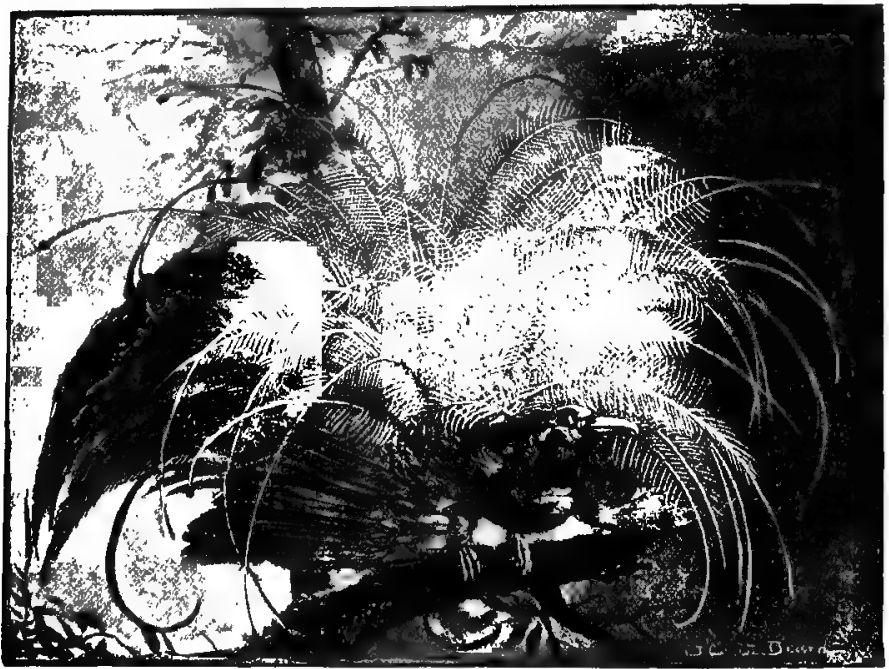

l'a. 2t.-Bird of paradine, male.

cially the simpler ones, these two kinds of individuals do not differ in appearance or in structure apart from the organs concerned with multiplication. But with many animals the sexes can be readily distinguished. The male and female individuals often show marked differences, especially in external structural characters. We can read- 
ily tell the peacock, with its splendidly ornamental tail feathers, from the unadorned peafowl, or the horned ram from the bleating ewe. There is here, plainly, a dimorphism-the existence of two kinds of individuals belonging to a single species. This dimorphism is due to sex, and the condition may be called sex dimorphism. Among some animals this sex dimorphism, or difference between the sexes, is carried to extraordinary extremes. This is especially true among polygamous animals, or those in which the males mate with many females, and are forced to fight for their possession. The male bird of paradise, with its gorgeous display of brilliantly colored and fantastically shaped feathers (Fig. 27 ), seems a wholly different kind of bird from the modest brown female. The male golden and silver pheasants, and allied species with their elaborate plumage, are very unlike the dull-colored females. The great, rough, warlike male fur seal, roaring like a lion, is three times as large as the dainty, soft-furred female, which bleats like a sheep.

Among some of the lower animals the differences between male and female are even greater. The males of the common cankerworm moth (Fig. 28) have four wings;
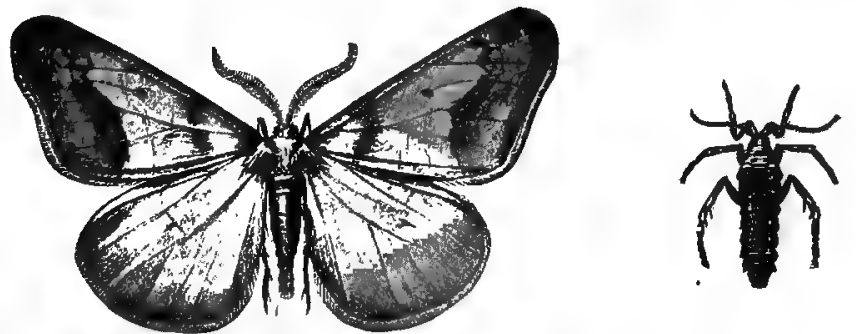

FIG. 28.-Cankerworm moth; the winged male and winglesg female.

the females are wingless, and several other insect species show this same difference. Among certain species of white ants the females grow to be fire or six inches long, while the males do not exceed half an inch in length. In the 
case of some of the parasitic worms which live in the bodies of other animals, the male has an extraordinarily degraded, simple body, much smaller than that of the female and differing greatly from that of the female in structure.

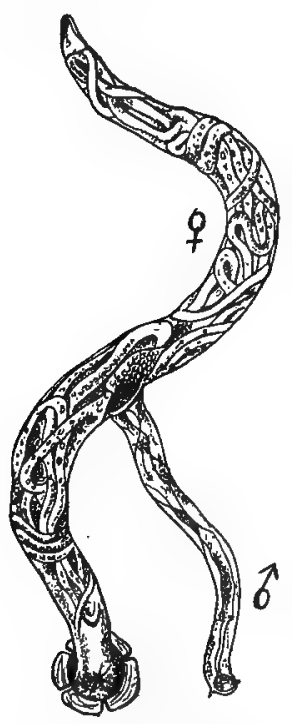

Frg. 29.-The parasitic worm (Syngamus traclealis), which causes the "gapes" in fowls. The male is attached to the female, and lives as a parasite on her.

In some cases even-as, for example, the worm which causes "gapes" in chickens - the male lives parasitically on the female, being attached to the body of the female for its whole lifetime, and drawing its nourishment from her blood (Fig. 29).

A condition known as parthenogenesis is found among certain of the complex animals. Although the species is represented by individuals of both sexes, the female can produce young from eggs which have not been fertilized. For example, the queen bee lays both fertilized and unfertilized eggs. From the fertilized eggs hatch the workers, which are rudimentary females, and other queens, which are fullydeveloped females; from the unfertilized eggs hatch only males-the drones. Many generations of plant lice are produced each year parthenogenetically - that is, by unfertilized females. But there is at least one generation each year produced in the normal way from fertilized eggs.

Some of the complex animals are hermaphroditic-that is, a single individual produces both egg cells and sperm cells. The tapeworm and many allied worms show this condition. This is the normal condition for the simplest animals, as we have already learned, but it is an exceptional condition among the complex animals. 
36. The number of young.-There is great variation in the number of young produced by different species of animals. Among the animals we know familiarly, as the mammals, which give birth to young alive, and the birds, which lay eggs, it is the general rule that but few young are produced at a time, and the young are born or eggs are laid only once or perhaps a few times in a year. The robin lays five or six eggs once or twice a year; a cow may produce a calf each year. Rabbits and pigeons are more prolific, each having several broods a year. But when we observe the multiplication of some of the animals whose habits are not so familiar to us, we find that the production of so few young is the exceptional and not the usual habit. A lobster lays ten thousand eggs at a time; a queen bee lays about five million eggs in her life of four or five years. A female white ant, which after it is full grown does nothing but lie in a cell and lay eggs, produces eighty thousand eggs a day steadily for several months. A large codfish was found on dissection to contain about eight million eggs.

If we search for some reason for this great difference in fertility among different animals, we may find a promising clew by attending to the duration of life of animals, and to the amount of care for the young exercised by the parents. We find it to be the general rule that animals which live many years, and which take care of their young, produce but few young; while animals which live but a short time, and which do not care for their young, are very prolific. The codfish produces its millions of eggs; thousands are eaten by sculpins and other predatory fishes before they are hatched, and other thousands of the defenseless young fish are eaten long before attaining maturity. Of the great number produced by the parent, a few only reach maturity and produce new young. But the eggs of the robin are hatched and protected, and the helpless fledglings are fed and cared for until able to cope with their natural 
enemies. In the next year another brood is carefully reared, and so on for the few years of the robin's life.

Under normal conditions in any given locality the number of individuals of a certain species of animal remains about the same. The fish which produces tens of thousands of eggs and the bird which reproduces half a dozen eggs a year maintain equally well their numbers. In one case a few survive of many born; in the other many (relatively) survive of the few born; in both cases the species is effectively maintained. In general, no agency for the perpetuation of the species is so effective as that of care for the young. 


\section{CHAPTER IV}

\section{FUNCTION AND STRUCTURE}

3\%. Organs and functions,-An animal does certain things which are necessary to life. It eats and digests food, it breathes in air and takes oxygen from it and breathes out carbonic-acid gas; it feels and has other sensations; it produces offspring, thus reproducing itself. These things are done by the simplest animals as well as by the complex animals. But while with the simplest animals the whole body (which is but a single cell) takes part in doing each of these things, among the complex animals only a part of the body is concerned with any one of these things. Only a part of the body has to do with the taking in of oxygen. Another part has to do with the digestion of food, and another with the business of locomotion. These parts of the body, as we know, differ from each other, and they differ because they have different things to do. These different parts are called argans of the body, and the things they do are called their functions. The nostrils, tracheæ, and lungs are the organs which have for function the process of respiration. The legs of a cat are the organs which perform for it the function of locomotion. The structure of one of the higher animals is complex because the body is made up of many distinct organs having distinct functions. The things done by one of the complex animals are many; around each of the principal functions or necessary processes, as a center, are grouped many minor accessory functions, all helping to make more successful the accom- 
plishment of the principal functions. While many of the lower animals have no eyes and no ears, and trust to more primitive means to discover food or avoid enemies, the higher animals have extraordinarily complex organs for seeing and hearing, two functions which are accessory only to such a principal function as food-taking.

38. Differentiation of structure-We have seen, in our study of the slightly complex animals, how the body becomes more and more complex in proportion to the degree in which the different life processes are divided or assigned to different parts of it for performance. With the gradually increasing division of labor the body becomes less homogeneous in structure; a differentiation of structure becomes apparent and gradually increases. The extent of the division of labor and the extent of the differentiation of structure, or division of the body into distinct and different parts and organs, go hand in hand. An animal in which the division of labor is carried to an extreme is an animal in which complexity of structure is extreme.

39. Anatomy and physiology.-Zoölogy, or the study of animals, is divided for convenience into several branches or phases. The study of the classification of animals is called systematic zoölogy; the study of the development of animals from their beginning as a single cell to the time of their birth is called animal embryology; the study of the structure of animals is called animal anatomy, and the study of the performance of their life processes or functions is called physiology. Because the whole field of zoölogy is so great, some zoölogists limit themselves exclusively to one of these phases of zoölogical study, and those who do not so definitely limit their study, at least give their special attention to a single phase, although all try to keep in touch with the state of knowledge in other phases. In earlier days the study of the anatomy of animals and of their physiology were held to be two very distinct lines of investigation, and the anatomists paid little attention to 
physiology and the physiologists little to anatomy. But we have seen how inseparably linked are structure and function. The structure of an animal is as it is because of the work it has to do, and the functions of an animal are performed as they are performed because of the special structural condition of the organs which perform them. The study of the anatomy and the study of the physiology of animals can not be separated. To understand aright the structure of an animal it is necessary to know to what use the structure is put; to understand aright the processes of an animal it is necessary to know the structure on which the performance of the processes depends.

40. The animal body a machine.-The body of an animal may be well compared with some machine like a locomotive engine. Indeed, the animal body is a machine. It is a machine composed of many parts, each part doing some particular kind of work for which a particular kind of structure fits it; and all the parts are dependent on each other and work together for the accomplishment of the total business of the machine. The locomotive must be provided with fuel, such as coal or wood or other readily combustible substance, the consumption of which furnishes the force or energy of the machine. The animal body must be provided with fuel, which is called food, which furnishes similarly the energy of the animal. Oxygen must be provided for the combustion of the fuel in the locomotive and the food in the body. The locomotive is composed of special parts: the firebox for the reception and combustion of fuel; the steam pipes for the carriage of steam; the wheels for locomotion; the smoke stack for throwing off of waste. The animal body is similarly composed of parts : the alimentary canal for the reception and assimilation of food; the excretory organs for the throwing off of waste matter; the arteries and veins for the carriage of the oxygen and food-holding blood; the legs or wings for locomotion. 
The locomotive is an inorganic machine; the animal is an organic machine. There is a great and real difference between an organism, a living animal, and a locomotive, an inorganic structure. But for a good understanding of the relation between function and structure, and of the composition of the body of the complex animals, the comparison of the animal and locomotive is very instructive.

41. The specialization of organs.-The organ for the performance of some definite function in one of the higher animals may be very complex. The corresponding organ in one of the lower animals for the performance of the same function may be comparatively simple. For example, the organ for the digestion of food is, in the case of the polyp, a simple cylindrical cavity in the body into which food enters through a large opening at the apical or free end of the body. The digestive organ of a cow is a long coiled tube, comprising many regions of distinct structural and physiological character and altogether extremely complicated. An organ in simple or primitive condition is said to be generalized; in complex or highly modified condition it is said to be specialized. That is, an organ may be modified and complexly developed to perform its function in a special way, in a way differing in many particulars from the way the corresponding organ in some other animal performs the same general function. The specialization of organs, or their modification to perform their functions in special ways, is what makes animal bodies complex, for specialization is almost always in the line of complexity. Later we shall see more clearly how specialization is brought about. For the present we may study one of the more important organs of the animal body for the sake of having concrete examples of some of the general statements made in this discussion of function and structure.

42. The alimentary canal.-The organ which has to do with the taking and digesting of food is called the ali- 
mentary canal. In some of the higher animals this is a very complex organ. In the cow, one of the cud-chewing mammals or ruminants, it consists of several distinct por tions, which differ among themselves very much (Fig. 30). First, there is the mouth, or opening for the entrance of the food. The mouth is supplied with teeth for tearing off and chewing the food, with a tongue for manipulating it; and with taste papillæ situated on the tongue and palate for determining the desirability of the food. Into the mouth a peculiar fluid (the saliva) is poured by certain glands, organs accessory to the alimentary eanal. The herbage bitten off, mixed with saliva, and rolled by the tongue into a ball, passes back through a narrow tube, the oesophagus, and into a sac called the rumen, or paunch. Here it ies until the cow ceases for the while to take in food, when it passes back again through the osophagus and into the mouth for mastica-

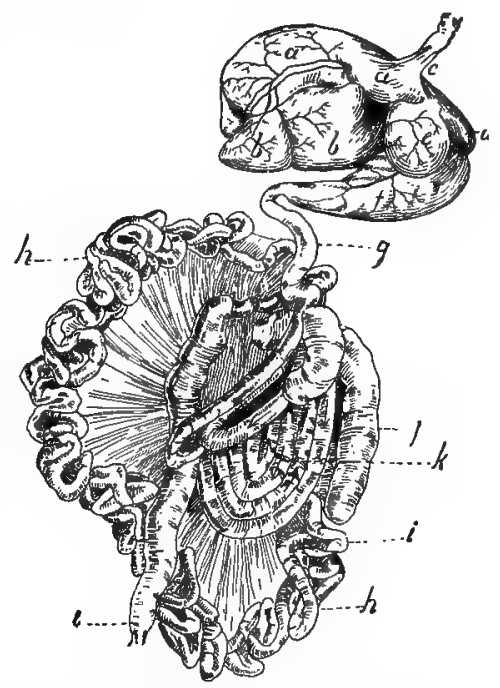

Fig. 30.-Alimentary canal of the ox (after ColiN and MǗLter), $a$, rumen (left hemsiphere) ; $b$, rumen (right hemisphere) ; $c$, insertion of cesophagus ; $d$, reticulum ; $e$, omasum; $f$, abomasum ; $g$, duodenum ; $h$ and $i$, jejunum and ileum ; $j$, cæcum; $k$, colon, with its various convolutions ; $l$, rectum. tion. After being masticated it again passes downward through the oesophagus, and enters this time another sac called the reticulum, lying next to the rumen. From here it passes into another sac-like portion of the alimentary canal called the omasum, where it is strained through numerous leaf-like folds which line the walls of this part of the canal. From here the food passes into a fourth 
sac-like part of the canal, called the abomasum. Here the process of digestion goes on. The four sacs-rumen, reticulum, omasum, and abomasum-are called stomachs, or they may be considered to be four chambers forming one large stomach. In the abomasum, or digesting stomach, digestive fluids are poured from glands lining its walls, and the food becomes converted into a liquid called chyle. The chyle passes from the stomach into a long, narrow, tubular portion of the canal called the intestine. The intestine is very long, and lies coiled in a large mass in the body of the cow. The intestine is divided into distinct regions, which vary in size and in the character of the inner wall. These parts of the intestine have names, as duodenum, jejunum, ileum, cæcum, colon, etc. Part of the intestine is lined inside with fine papillæ, which take up the chyle (the digeated food) and pass it through the walls of the intestine to other special organs, which pass it on to the blood, with which it becomes mixed and carried by an elaborate system of tubes to all parts of the body. Part of the grass taken into the alimentary canal by the cow can not be digested, and must be got rid of. This passes on into a final posterior part of the intestine called the rectum, and leaves the body through the anus or posterior opening of the alimentary canal. The whole canal is more than twenty times as long as the body of the cow; it is composed of parts of different shape; its walls are supplied with muscles and blood-vessels ; the inner lining is covered with folds, papillæ, and gland cells. It is altogether a highly specialized organ, a structurally complex and elaborately functioning organ.

Let us now examine the alimentary canal, or organ of digestion, in some of the simpler animals.

The Protozoa, or simplest animals, have no special organ at all. When the surface of the body of an Amceba comes into contact with an organic particle which will serve as food, the surface becomes bent in at the point of its con- 
tact with the food particle, and the body substance simply incloses the food (Fig. 3). Food is taken in by the surface. The whole outer surface of the body is the foodtaking organ. In the simplest many-celled animals, the sponges, there is no special food-taking and digestive organ. Each of the cells of the body takes in and assimilates food for itself. The sponge is like a great group of Ancobe holding fast to each other, but each looking out for its own necessities. Among the polyps, however, there is a definite organ of digestion-that is, food is only taken and digested by certain parts of the body. The simple polyp's body (Fig. 31 ) is a cylinder or vase closed at one end and open at the other end, and attached by the closed end to a rock. The opening is usually of less diameter than the diameter of the body, and it is surrounded by a number of tentacles, whose

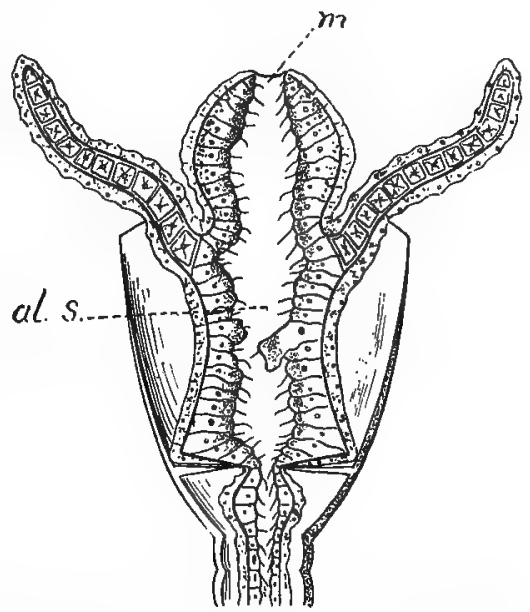

Frg. 31.-Obelia $s p .$, a simple polyp; vertical section, highly magnified. $m$, mouth opening; al. s., alimentary sac.-After ГАлкек and HABWELL.

function it is to seize the food and convey it to the mouth opening. There are, of course, no teeth, no tongue, none of the various parts which are in or are part of the mouth of the higher animals. The polyp's mouth is simply a hole or opening into the inside of the body. This body cavity, or simplest of all stomachs, is simply the cylindrical or vase-shaped hollow space inclosed by the body wall. This space extends also into the tentacles. There is no other opening, no posterior or anal opening. We can not 
speak of an cesophagus or intestine in connection with this most primitive of alimentary sacs. The cells which line the sacs show some differentiation; some are gland cells and secrete digestive fiuids; some are amceboid and are provided with pseudopods or flagella for seizing bits of food. The food caught by the tentacles comes into the alimentary sac through the opening or primitive mouth, and

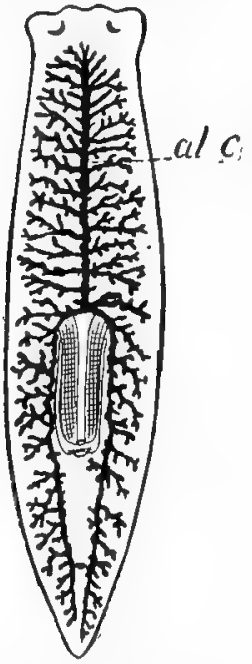

Fia. 32.-Diagrammatic sketch of a flatworm (Planaria), showing the branched alimentary canal, al. c.After JiJima and HatbohrK.

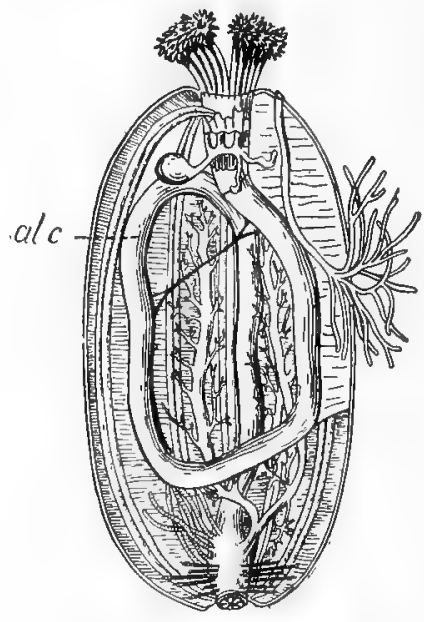

Fic. 33.-Sea-cucumber (Holothurian) dissected to show alimentary canal, al. c.-After LrbokanT.

what of it is digestible is, by the aid of the gland cells and the amoboid cells, taken up and assimilated, while the rest of it is carried out by water currents again through the single opening.

In the flatworms (Fig. 32) like Planaria (small, thin, flattened worms to be found in the mud at the bottom of fresh-water ponds) the mouth opens into a short, narrow tube which may be called an osophagus. The csophagus 
connects the mouth with the rest of the alimenttary canal, which gives out many side branches or diverticula, which are themselves branched, so that the alimentary sac or stomach is a system of ramifying tubes extending from a central main tube to all parts of the body of the worm. There is no anal opening. In the round or thread worms, of which the deadly Trichina is an example, the alimentary canal is a simple straight tube with both anterior or mouth opening and posterior or anal opening. In the seaurchins and sea-cucumbers (Fig. 33) the alimentary canal is a simple tube with two openings, but it is longer than the body between mouth and anus, and so is more or less bent or coiled. In the earthworm the alimentary canal (Fig. 34), although a simple straight tube running through the body, plainly shows a differentiation into particular regions. Behind the mouth opening the alimentary tube is large and thick - walled and is called the pharynx; behind the pharynx it is narrower and is called the cesophagus. Behind the cesophagus it expands to form a rounded, thin-walled chamber called the crop, and just behind this there is another rounded but very thick-walled cham- Fis.34.-Earthworm dissected ber called the gizzard. From the gizzard back the alimentary canal is

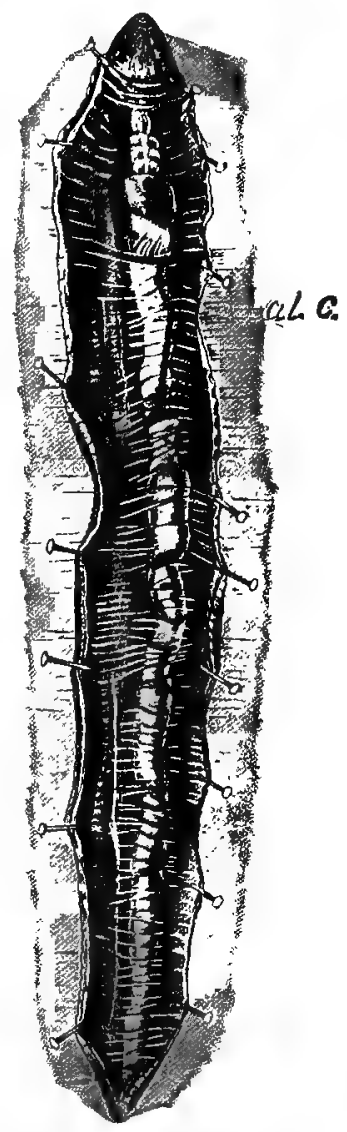
to show alimentary canal, al. $c$. about uniform in size, being rather wide and having thick, soft walls. This portion of it is called the intestine. The 
posterior part of the intestine, called the rectum, leads to the anal opening. There is some differentiation of the inner surface of the canal. In the great group of mollusks, of which the common fresh-water clam or mussel is an example, the alimentary canal (Fig. 35) shows much variation. The microscopic plants, which are the food of the mussel, are taken in through the mouth and pass into a short oesophagus, thence into a wide stomach and there digested. Behind the stomach is a long, much-folded, narrow intestine which winds about through the fleshy "foot" and finally reaches the surface of the body, and has an anal opening at a point opposite the position of the mouth.

Among the insects there is a great range in degree of complexity of the alimentary canal. The digestive organs are, however, in most insects in a condition of high specialization. The month opening is provided with well-developed

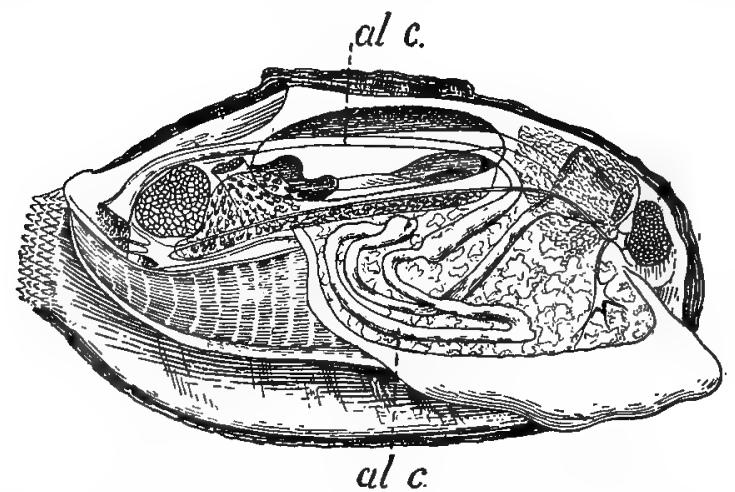

FiG. 35.-Pond massel dissected to show alimentary canal, al. c.-After НА твснвк and Corr.

biting and masticating or piercing and sucking mouth parts; pharynx, osophagus, strm:ıch, and intestine are always differentiated and sometincs greatly modified. In the common cockroach, for eximplo (Fig. 36), the mouth has a complicated food-getting apparatus, and the canal, which 
is much longer than the body of the insect, and hence much bent and coiled, consists of a pharynx, esophagus, fore-stomach or proventriculus, true digesting stomach or ventriculus, intestine, and rectum which opens at the posterior tip of the body. The inner lining of the canal shows much differentiation in the different parts of the canal, and there are numerous accessory glands connected with various parts of the canal.

Finally, among the highest animals, the vertebrates, we find still more elaborate specialization of the alimentary canal. As an example the alimentary canal of a cow has already been described in detail.

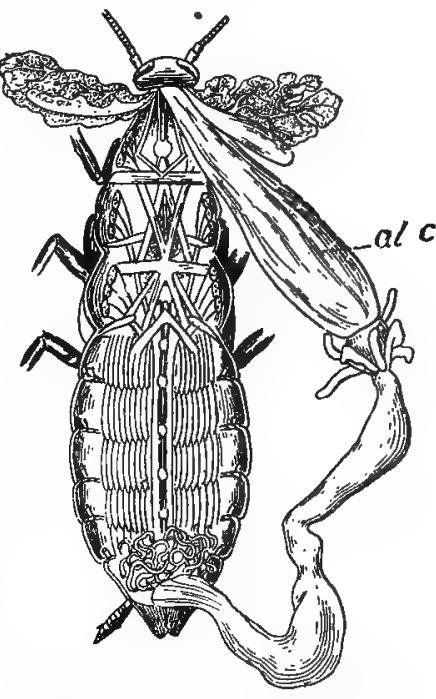

43. Stable and variable characteristics of an organ. - In spite of all this variation in the structure and general character of the alimentary canal, there are certain characteristics which are features of all alimentary canals. In the examination of an organ we must ever distinguish between its so-called constant or stable characteristics and its inconstant or variable characteristics. The constant characteristics are the fundamentally essential ones of the organ; the variable ones are the special characteristics which adapt the organ for the peculiar habits of the animal possessing it-habits which may differ very much from those of some other animal of similar size, similar distribution, similar abundance.

44. Stable and variable characteristics of the alimentary canal_-A tiger or a lion has an alimentary canal not more 
than three or four times the length of its body, while a sheep has an alimentary canal twenty-eight times as long as its body. The tiger is carnivorous; the sheep herbivorous. Associated with the different food habits of the two animals is a striking difference in the alimentary canals. Animals like the horse or cat, which chew their food before swallowing it, have a slender cesophagus ; animals like snakes which swallow their food whole have a wide œsophagus. Birds, that have no teeth and hence can not masticate or grind their food in their mouths, usually have a special grinding stomach, the gizzard, for this purpose. And so we might cite innumerable examples of these inconstant or variable characteristics of the alimentary canal. On the other hand, the alimentary canals of all the many-celled animals except the lowest agree in certain important characteristics. Each alimentary canal has two openings, one for the ingress of food and one for the exit of the indigestible portions of the matter taken in, and the canal itself stretches through the body from mouth to anus as a tube, now narrow, now wide, now suddenly expanding into a sac or giving off lateral diverticula, but always simply a lumen or hollow inclosed by a flexible muscular wall. The inner lining of the wall is provided with secreting and absorbing structures. Indeed, we can reduce the essential characters of the alimentary canal to even more simple features. The organ of digestion or assimilation of all the many-celled animals is merely a surface with which food is brought into contact, and which has the power of digesting this food by means of digestive secretions, and of absorbing the food when digested. This surface is small or great in extent, depending upon the amount of food necessary to the life of the animal and the difficulty or readiness with which the food can be digested. This surface might just as well be on the outside of the animal's body as on the inside, if it were convenient. In fact, it is on the outside of some animals. Among the Protozoa the 
digesting surface is simply the external surface of the body. And not alone among the one-celled animals. Many of the parasitic worms which live in the bodies of other animals, and the larvæ or "grubs" of many insects which lie in the tissues of plants bathed by the sap, have no inner alimentary canal, but take food through the outer surface of the body. But in these cases the food is ready for immediate absorption, so that no special treatment of it is necessary, hence no complex structures are required.

Even were no such special treatment of the food necessary in the case of the larger animals, it would still be im-

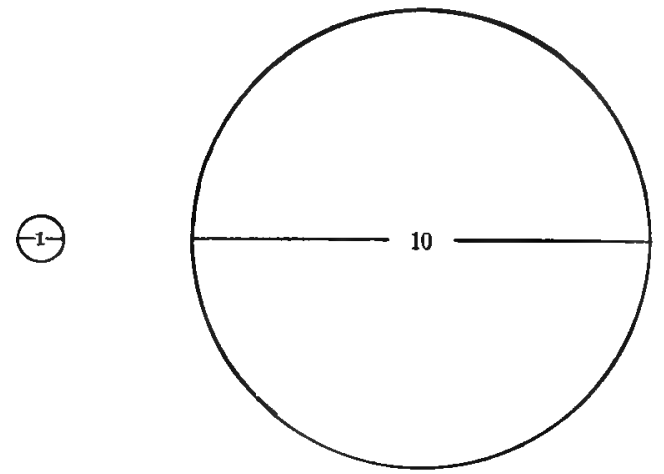

FiG. 37.-Diagram illustrating increase of volume and surface with increase of diameter of sphere.

possible for the simple external surface of the body to serve for food absorption, because of the well-known relation between the surface and the mass of a solid body. When a solid body in the form of a sphere increases in size, its mass or volume increases as the cube of the diameter, while the surface increases only as the square of the diameter (Fig. 37). The external surface of minute animals a few millimeters in diameter can take up enough food to supply the whole body mass. But among large animals this foodgetting surface is increased as the square of the diameter of 
the body, while the volume or food-using surface of the body is increased as the cube of its diameter. The food supplying can not keep pace with the food using. Hence it is absolutely essential that among large animals the food-taking surface be increased so that it will remain in the same favorable proportion to the mass of the animal as is the case among the minute animals, where the simple external body surface is sufficient to obtain all the food necessary. This increase of surface, without an accompanying increase of size of the animal, is accomplished by having the digesting and assimilating surface inside the body and by having it greatly folded. The surface of the alimentary canal is, after all, simply a bent-in continuation of the outer surface of the body. It is open to the outside of the body by two openings, and wholly closed (except by its porosity) to the true inside of the body. By the bending and coiling of the alimentary canal, and by the repeated folding of its inner wall, the alimentary surface is greatly increased. The necessity for this increase accounts largely for the complexity of the alimentary canal.

But it is not alone this necessity for increased surface that accounts for the great specialization of the alimentary canal in such animals as the insects and the vertebrates. The structural differences in different portions of the canal, resulting in the differentiation of the canal into distinct parts, or the differentiation of the whole organ into distinct subordinate organs, each with a special work or function to perform, are the result of the necessity for the special manipulation of the special kinds of foods taken. Animals which feed on other animals must have mouth structures fit for seizing and rending their prey, and the alimentary canal must be specially modified for the digestion of flesh. Animals which feed on vegetable substances must have special modifications of the alimentary canal quite different from those of the carnivores. Some insects, like the mosquito, take only liquid food, the sap of plants, or the blood 
of animals; others, like the weevils, feed on the hard, dry substance of seeds and grains; others, like the grasshoppers and caterpillars, eat green leaves; and still others eat other insects. The alimentary canal of each of these kinds of insects differs more or less from that of the other kinds. The specialization of the alimentary canal depends then upon the necessity for a large food-digesting and absorbing surface, and on the complex treatment of the food. The character of this specialization in each case depends upon the special kind or quality of food taken by the animal in question.

45. The mutual relation of function and structure.-The structure of an animal depends upon the manner in which the life processes or functions of the animal are performed. If the functions are performed in a complex manner, the structure of the body is complex; if the functions are performed in simple manner, the body will be simple in structure. With the increase in degree of the division of labor among various parts of the body, there is an increase in definiteness and extent of differentiation of structure. Each part or organ of the body becomes more modified and better fitted to perform its own special function. A peculiar structural condition of any part of the body, or of the whole body of any animal, is not to be looked on as a freak of Nature, or as a wonder or marvel. Such a structure has a significance which may be sought for. The unusual structural condition is associated with some special habit or manner of performance of a function. Function and structure are always associated in Nature, and should always be associated in our study of Nature. 


\section{CHAPTER V}

\section{THE LIFE CYCLE}

46. Birth, growth and development, and death,-Certain phenomena are familiar to us as occurring inevitably in the life of every animal. Each individual is born in an immature or young condition; it grows (that is, it increases in size), and develops (that is, changes more or less in structure), and dies. These phenomena occur in the succession of birth, growth and development, and death. But before any animal appears to us as an independent individualthat is, outside the body of the mother and outside of an egg (i. e., before birth or hatching, as we are accustomed to call such appearance)-it has already undergone a longer or shorter period of life. It has been a new living organism hours or days or months, perhaps, before its appearance to us. This period of life has been passed inside an egg, or as an egg or in the egg stage, as it is variously termed. The life of an animal as a distinct organism begins in an egg. And the true life cycle of an organism is its life from egg through birth, growth and development, and maturity to the time it produces new organisms in the condition of eggs. The life cycle is from egg to egg. Birth and growth, two of the phenomena readily apparent to us in the life of every animal, are two phenomena in the true life cycle. Death is a third inevitable phenomenon in the life of each individual, but it is not a part of the cycle. It is something outside.

4\%. Life cycle of simplest animals.-The simplest animals have no true egg stage, nor perhaps have they any true 
death. The new Amobos are from their beginning like the full-grown $A m a b a$, except as regards size. And the old $A m a e b a$ does not die, because its whole body continues to live, although in two parts - the two new Amoebce. The life cycle of the simplest animals includes birth (usually by simple fission of the body of the parent), growth, and some, but usually very little, development, and finally the reproduction of new individuals, not by the formation of eggs, but by direct division of the body.

48. The egg.-In our study of the multiplication of animals (Chapter III) we learned that it is the almost univer-

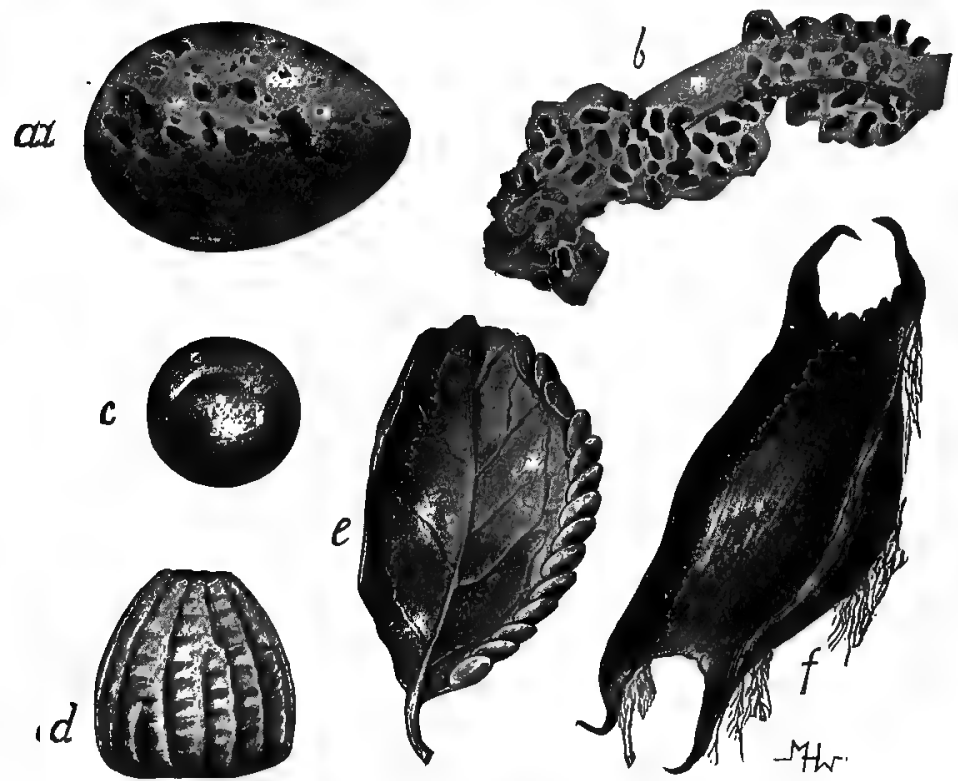

FIG. 38.-Eggs of different animals showing variety in external appearance, $a$, egg of bird; $b$, eggs of toad; $c$, egg of fish; $d$, egg of butterfly; $e$, eggs of katydid on leaf; $f$, egg-case of skate.

sal rule among many-celled animals that each individual begins life as a single cell, which has been produced by the 
fusion of two germ cells, a sperm cell from a nrale individual of the species and an egg cell from a female indiridual of the species. The single cell thus formed is called the fertilized egg cell, and its subsequent development results in the formation of a new individual of the same species with its parents. Now, in the development of this cell into a new animal, food is necessary, and sometimes a certain amount of warmth. So with the fertilized egg cell there is, in the case of all animals that lay eggs, a great".. or less amount of food matter-food yolk, it is called-gathered about the germ cell, and both germ cell and food yolk are inclosed in a soft or hard wall. Thus is composed the egg as we know it. The hen's egg is as large as it is because of the great amount of food yolk it contains. The egg of a fish as large as a hen is much smaller than the hen's egg; it contains less food yolk. Eggs (Fig. 38) may vary also in their external appearance, because of the different kinds of membrane or shells which may inclose and protect them. Thus the frog's eggs are inclosed in a thin membrane and imbedded in a soft, jolly-like substance; the skate's egg has a tough, dark-brown leathery inclosing wall; the spiral egg of the bull-head sharks is leathery and colored like the dark-olive seaweeds among which it lies; and a bird's egg has a hard shell of carbonate of lime. But in each case there is the essential fertilized germ cell; in this the eggs of hen and fish and butterfly and cray-fish and worm are alike, however much they may differ in size and external appearance.

49. Embryonic and post-embryonic development.--Some animals do not lay eggs, that is they do not deposit the fertilized egg cell outside of the body, but allow the development of the new individual to go on inside the body of the mother for a longer or shorter period. The mammals and some other animals have this habit. When such an animal issues from the body of the mother, it is said to be born. When the developing animal issues from an egg 
which has been deposited outside the body of the mother, it is suid to hatch. The animal at birth or at time of hatching is not yet fully developed. Only part of its development or period of immaturity is passed within the egg or within the body of the mother. That part of its life thus passed within the egg or mother's body is called the embryonic life or embryonic stages of development; while that period of development or immaturity from the time of birth or hatching until maturity is reached is called the post-embryonic life or post-embryonic stages of development.

50. First stages in development.-The embryonic development is from the beginning up to a certain point practically identical for all many-celled animals-that is, there are cer-

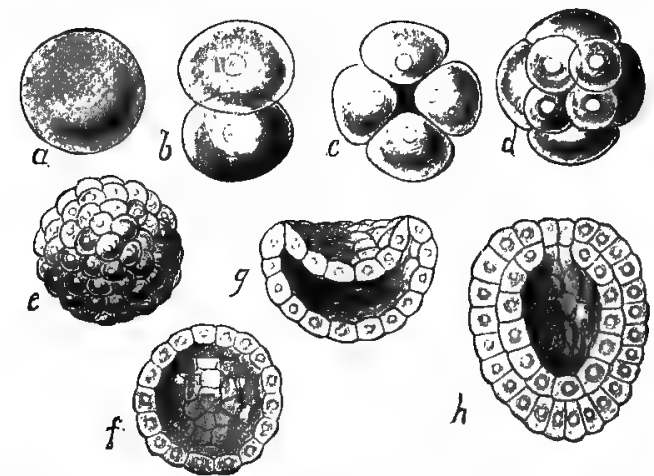

FIG. 39.-First stages in embryonic development of the pond snail (Lymnaus). a. egg ccll ; $b$, first cleavage ; $c$, second cleavage ; $d$. thurd cleavage ; $e$, after numerous cleavages; $f$, blastula (in section); $g$, gastrula, just forming (in section); $h$, gastrula, completed (in section).-After RABL.

tain principal or constant characteristics of the beginning development which are present in the development of all many-celled animals. The first stage or phenomenon of development is the simple fission of the germ cell into halves (Eig. 39, b). These two daughter cells next divide so that there are four cells (Fig. 39, c); each of these divides, and this division is repeated until a greater or lesser num- 
ber (varying with the various species or groups of animals) of cells is produced (Fig. 39, $d$ ). The phenomenon of repeated division of the germ cell, and usually the surrounding yolk, is called cleavage, and this cleavage is the first stage of development in the case of all many-celled animals. The first division of the germ cell produces usually two equal cells, but in some of the later divisions the new cells formed may not be equal. In some animals all the cleavage cells are of equal size; in some there are two sizes of cells. The germ or embryo animal consists now of a mass of few or many undifferentiated primitive cells lying together and usually forming a sphere (Fig. 39,e), or perhaps separated and scattered through the food yolk of the egg. The next stage of development is this: the cleavage cells arrange themselves so as to form a hollow sphere or ball, the cells lying side by side to form the outer circumferential wall of this hollow sphere (Fig. 39, $f$ ). This is called the blastula or blastoderm stage of development, and the embryo itself is called the blastula or blastoderm. This stage also is common to all the manycelled animals. The next stage in embryonic development is formed by the bending inward of a part of the blastoderm cell layer, as shown in Fig. 39, $g$. This bending in may produce a small depression or groove; but whaterer the shape or extent of the sunken-in part of the blastoderm, it results in distinguishing the blastoderm layer into two parts, a sunken-in portion called the endoblast and the other unmodified portion called the ectoblast. Endo-means "within," and the cells of the endoblast often push so far into the original blastoderm cavity as to come into contact with the cells of the ectoblast and thus obliterate this cavity (Fig. 39, h). This third well-marked stage in the embryonic development is called the gastrula* stage, and it also

* This gastrula stage is not always formed by a bending in or invagination of the blastoderm, but in some animals is formed by the splitting off or delamination of cells from a definite limited region of 
occurs in the development of all or nearly all many-colled animals.

51. Continuity of development.-In the case of a few of the simple many-celled animals the embryo hatches-that is, issues from the egg at the time of or very soon after reaching the gastrula stage. In the higher animals, however, development goes on within the egg or within the body of the mother until the embryo becomes a complex body, composed of many various tissues and organs. Almost all the development may take place within the egg,

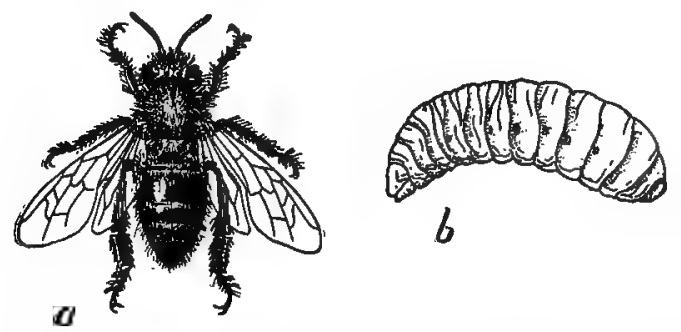

Fia. 40.-Honey-bee. $a$, adult worker ; $b$, young or larval worker.

so that when the young animal hatches there is necessary little more than a rapid growth and increase of size to make it a fully developed, mature animal. This is the case with the birds : a chicken just hatched has most of the tissues and organs of a full-grown fowl, and is simply a little hen. But in the case of other animals the young hatches from the egg before it has reached such an advanced stage of development; a young star-fish or young crab or young honey-bee (Fig. 40) just hatched looks very different from its parent. It has yet a great deal of development to undergo before it reaches the structural condition of a fully developed and fully grown star-fish or crab or bee. Thus the development of some animals is almost

the blastoderm. Our knowledge of gastrulation and the gastrula stage is yet far from complete. 
wholly embryonic development-that is, development within the egg or in the body of the mother-while the development of other animals is largely post-embryonic or larval development, as it is often called. There is no important difference between embryonic and post-embryonic development. The development is continucus from egg cell to mature animal, and whether inside or outside of an egg it goes on regularly and uninterruptedly.

52. Development after the gastrula stage.-The cells which compose the embryo in the cleavage stage and blastoderm stage, and even in the gastrula stage, are all similar; there is little or no differentiation shown among them. But from the gastrula stage on development includes three important things: the gradual differentiation of cells into various kinds to form the various kinds of animal tissues; the arrangement and grouping of these cells into organs and body parts; and finally the developing of these organs and body parts into the special condition characteristic of the species of animal to which the developing individual belongs. From the primitive undifferentiated cells of the blastoderm, development leads to the special cell types of muscle tissue, of bone tissue, of nerve tissue; and from the generalized condition of the embryo in its early stages development leads to the specialized condition of the body of the adult animal. Development is from the general to the special, as was said years ago by the first great student of development.

53. Divergence of development.-A star-fish, a beetle, a dove, and a horse are all alike in their beginning-that is, the body of each is composed of a single cell, a single structural unit. And they are all alike, or very much alike, through several stages of development; the body of each is first a single cell, then a number of similar undifferentiated cells, and then a hollow sphere consisting of a single layer of similar undifferentiated cells. But soon in the course of development the embryos begin to differ, and as 
the young animals get further and further along in the course of their development, they become more and more different until each finally reaches its fully developed mar ture form, showing all the great structural differences between the star-fish and the dove, the beetle and the horse. That is, all animals begin development alike, but gradually diverge from each other during the course of development.

There are some extremely interesting and significant things about this divergence to which attention should be given. While all animals are alike structurally* at the beginning of development, so far as we can see, they do not all differ at the time of the first divergence in development. This first divergence is only to be noted between two kinds of animals which belong to different great groups or classes. But two animals of different kinds, both belonging to some one great group, do. not show differences until later in their development. This can best be understood by an example. All the butterflies and beetles and grasshoppers and flies belong to the great group of animals called Insecta, or insects. There are many different kinds of insects, and these kinds can be arranged in subordinate groups, such as the Diptera, or flies, the Lepidoptera, or butterflies and moths, and so on. But all have certain structural characteristics in common, so that they are comprised in one great group or class-the Insecta. Another great group of animals is known as the Vertebrata, or back-boned animals. The class Vertebrata includes the fishes, the batrachians, the reptiles, the birds, and the mammals, each composing a subordinate group, but all characterized by the possession of a back-

* They are alike structurally, when we consider the cell as the unit of animal structure. That the egg cells of different animals may differ in their fine or ultimate structure, seems certain. For each one of these egg cells is destined to become some one kind of animal, and no other; each is, indeed, an indivilual in simplest, least developed condition of some one kind of animal, and we must believe that difference in kind of animals depends upon difference in structure in the egg itself. 
bone, or, more accurately speaking, of a notochord, a back. bone-like structure. Now, an insect and a vertebrate diverge very soon in their development from each other; but two insects, such as a beetle and a honey-bee, or any two vertebrates, such as a frog and a pigeon, do not diverge from each other so soon. That is, all vertebrate animals diverge in one direction from the other great groups, but all the members of the great group keep together for some time longer. Then the subordinate groups of the Vertebrata, such as the fishes, the birds, and the others diverge, and still later the different kinds of animals in each of these groups diverge from each other. In the illustration (Fig. 41) on the opposite page will be seen pictures of the embryos of various vertebrate animals shown as they appear at different stages or times in the course of development. The embryos of a fish, a salamander, a tortoise, a bird, and a mammal, representing the five principal groups of the Vertebrata, are shown. In the upper row the embryos are in the earliest of all the stages figured, and they are very much alike. They show no obvious characteristics of fish or bird. Yet there are distinctive characteristics of the great class Vertebrata. Any of these embryos could readily be distinguished from an embryonic insect or worm or sea-urchin. In the second row there is beginning to be manifest a divergence among the different embryos, although it would still be a difficult matter to distinguish certainly which was the young fish and which the young salamander, or which the young tortoise and which the young bird. In the bottom row, showing the animals in a later stage of development, the divergence has proceeded so far that it is now plain which is a fish, which batrachian, which reptile, which bird, and which mammal.

54. The laws or general facts of development. -That the course of development of any animal from its beginning to fully developed adult form is fixed and certain is readily seen. Every rabbit develops in the same way; every grass- 

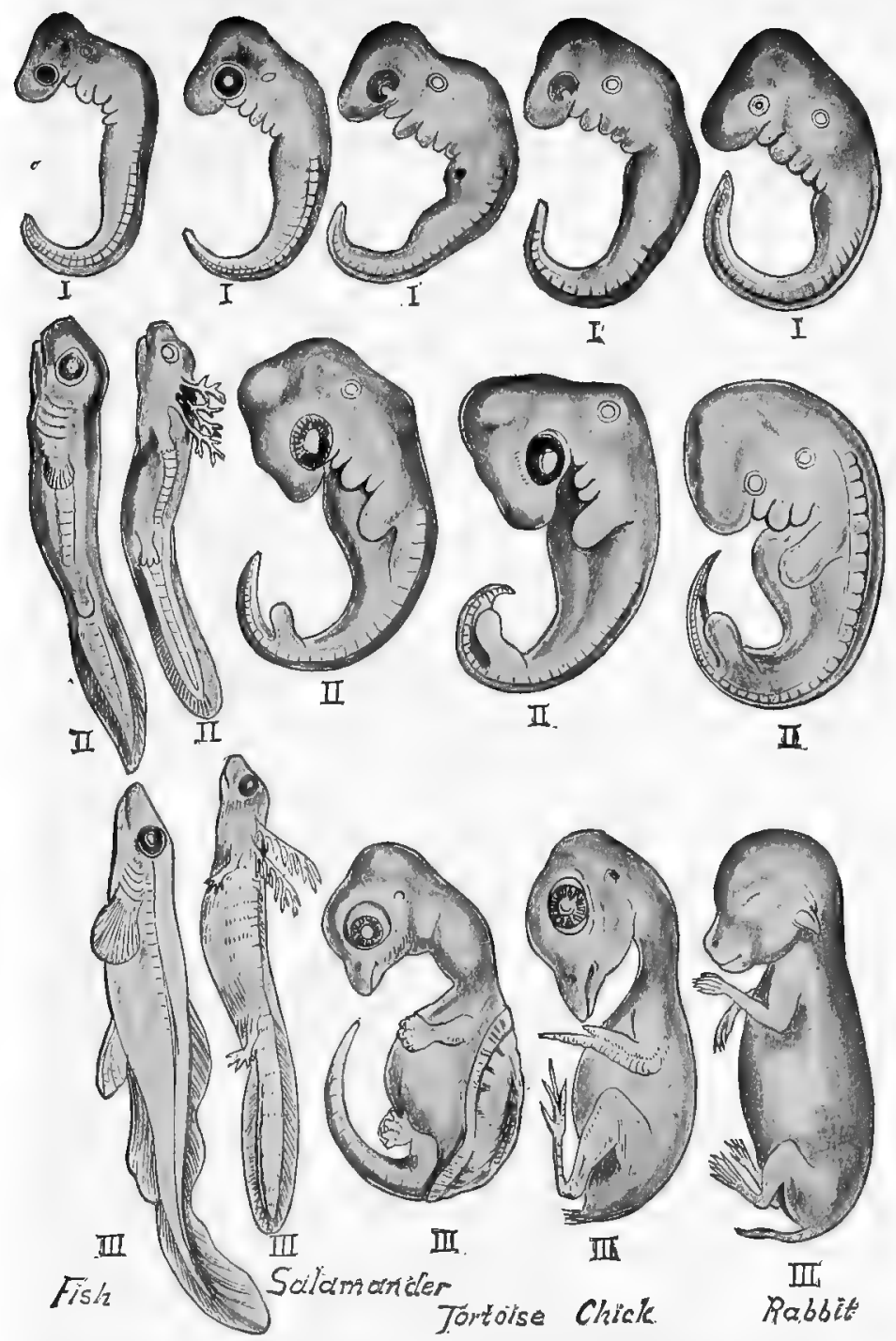

FIG. 41.-Different vertebrate animal in successive embryonic stages, I, frrst or earliest of the stiges figured; II, second of the stages; III, third or latest of the stages,-After Hafokm. 
hopper goes through the same developmental changes from single egg cell to the full-grown active hopper as every other grasshopper of the same kind-that is, development takes place according to certain natural laws, the laws of animal development. These laws may be roughly stated as follows : All many-celled animals begin life as a single cell, the fertilized egg cell ; each animal goes through a certain orderly series of developmental changes which, accompanied by growth, leads the animal to change from single cell to the many-celled, complex form characteristic of the species to which the animal belongs; this development is from simple to complex structural condition; the development is the same for all individuals of one species. While all animals begin development similarly, the course of development in the different groups soon diverges, the divergence being of the nature of a branching, like that shown in the growth of a tree. In the free tips of the smallest branches we have represented the various species of animals in their fully developed condition, all standing clearly apart from each other. But in tracing back the development of any kind of animal, we soon come to a point where it very much resembles or becomes apparently identical with some other kind of animal, and going further back we find it resembling other animals in their young condition, and so on until we come to that first stage of development, that trunk stage, where all animals are structurally alike. To be sure, any animal at any stage in its existence differs absolutely from any other kind of animal, in that it can develop into only its own kind of animal. There is something inherent in each developing animal that gives it an identity of its own. Although in its young stages it may be hardly distinguishable from some other kind of animal in similar stages, it is sure to come out, when fully developed, un individual of the sume kind as its parents were or are. The young fish and the young salamander in the upper row in Fig. 41 seem very much alike, but one embryo is sure to 
develop into a fish and the other into a salamander. This certainty of an embryo to become an individual of a certain kind is called the law of heredity.

55. The significance of the facts of development. - The significance of the developmental phenomena is a matter about which naturalists have yet very much to learn. It is believed, however, by practically all naturalists that many of the various stages in the development of an animal correspond to or repeat the structural condition of the animal's ancestors. Naturalists believe that all backboned or vertebrate animals are related to each other through being descended from a common ancestor, the first or oldest backboned animal. In fact, it is because all these backboned animals - the fishes, the batrachians, the reptiles, the birds, and the mammals-have descended from a common ancestor that they all have a backbone. It is believed that the descendants of the first backboned animal have in the course of many generations branched off little by little from the original type until there have come to exist very real and obvious differences among the backboned animals-differences which among the living backboned animals are familiar to all of us. The course of development of an individual animal is believed by many naturalists to be a very rapid, and evidently much condensed and changed, recapitulation of the history which the species or kind of animal to which the developing individual belongs has passed through in the course of its descent through a long series of gradually changing ancestors. If this is true, then we can readily understand why the fish and the salamander and tortoise and bird and rabbit are all so much alike in their earlier stages of development, and gradually come to differ more and more as they pass through later and later developmental stages.

Some naturalists believe that the ontogenetic stages are not as significant in throwing light upon the evolutionary history of the species as just indicated. Some think that 
when the earlier stages of one species correspond pretty closely with the early stages of another, we have a good basis for making up our minds about relationship between the two species. But it is certainly not obvious why we should have a similarity among the younger stages of different animals and no correspondence among the older stages of more recent animals with the younger stages of more ancient ones. But on the other hand it is certainly true that a too specific application of the broad generalization that ontogeny repeats phylogeny has led to numerous errors of interpreting genealogic relationship.

56. Metamorphosis. - While a young robin when it hatches from the egg or a young kitten at birth resembles its parents, a young star-fish or a young crab or a young butterfly when hatched does not at all resemble its parents. And while the young robin after hatching becomes a fully grown robin simply by growing larger and undergoing comparatively slight developmental changes, the young star-fish or young butterfly not only grows larger, but undergoes some very striking developmental changes; the body changes very much in appearance. Marked changes in the body of an animal during post-embryonic or larval development constitute what is called metamorphic development, or the animal is said to undergo or to show metamorphosis in its derelopment. Metamorphosis is one of the most interesting features in the life history or development of animals, and it can be, at least as far as its external aspects are concerned, very readily observed and studied.

5\%. Metamorphosis among insects, - All the butterflies and moths show metamorphosis in their development. So do many other insects, as the ants, bees, and wasps, and all the flies and beetles. On the other hand, many insects do not show metamorphosis, but, like the birds, are hatched from the egg in a condition plainly resembling the parents. A grasshopper (Fig. 42) is a convenient example of an insect without metamorphosis, or rather, as there are, after all, 
a few easily perceived changes in its post-embryonic development, of an insect with an "incomplete metamorphosis." The eggs of grasshoppers are laid in little packets of several score half an inch below the surface of the ground. When the young grasshopper hatches from the egg it is of course very small, but it is plainly recognizable as a grasshopper. But in one important character it differs from the adult, and that is in its lack of wings. The adult grasshopper has two pairs of wings; the just hatched young or larval grasshopper has no wings at all. The young grasshopper feeds voraciously and grows rapidly.
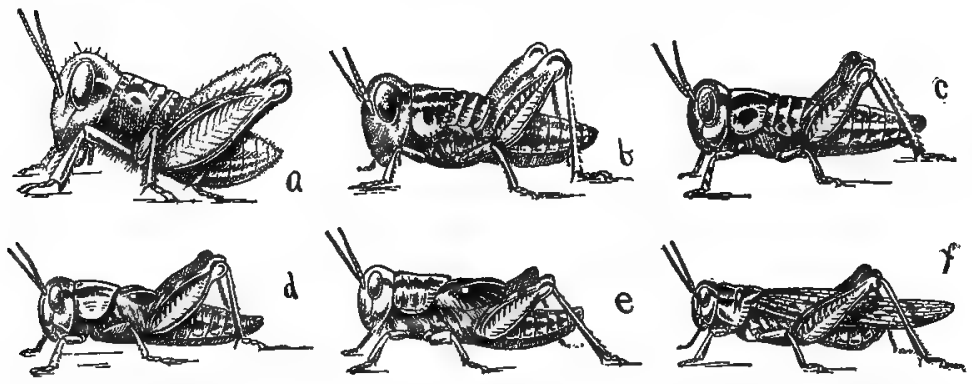

Fig. 42.-Post-embryonic development (incomplete metamorphosis) of the Rocky Mountain locust (Melanoplus spretus). $a, b, c, d, e$, and $f$, anccessive developmental stages from just hatched to adult individual.-After EmERToN.

In a few days it molts, or casts its outer skin (not the true skin, but a thin, firm covering or outer body wall composed of a substance called chitin, which is secreted by the cells of the true skin). In this second larval stage there can be seen the rudiments of four wings, in the condition of tiny wing pads on the back of the middle part of the body (the thorax). Soon the chitinous body covering is shed again, and after this molt the wing pads are markedly larger than before. Still another molt occurs, with another increase in size of the developing wings, and after a fifth and last molt the wings are fully developed, and 
the grasshopper is no longer in a larval or immature condition, but is full grown and adult.

For example of complete metamorphosis among insects we may choose a butterfly, the large red-brown butterfly

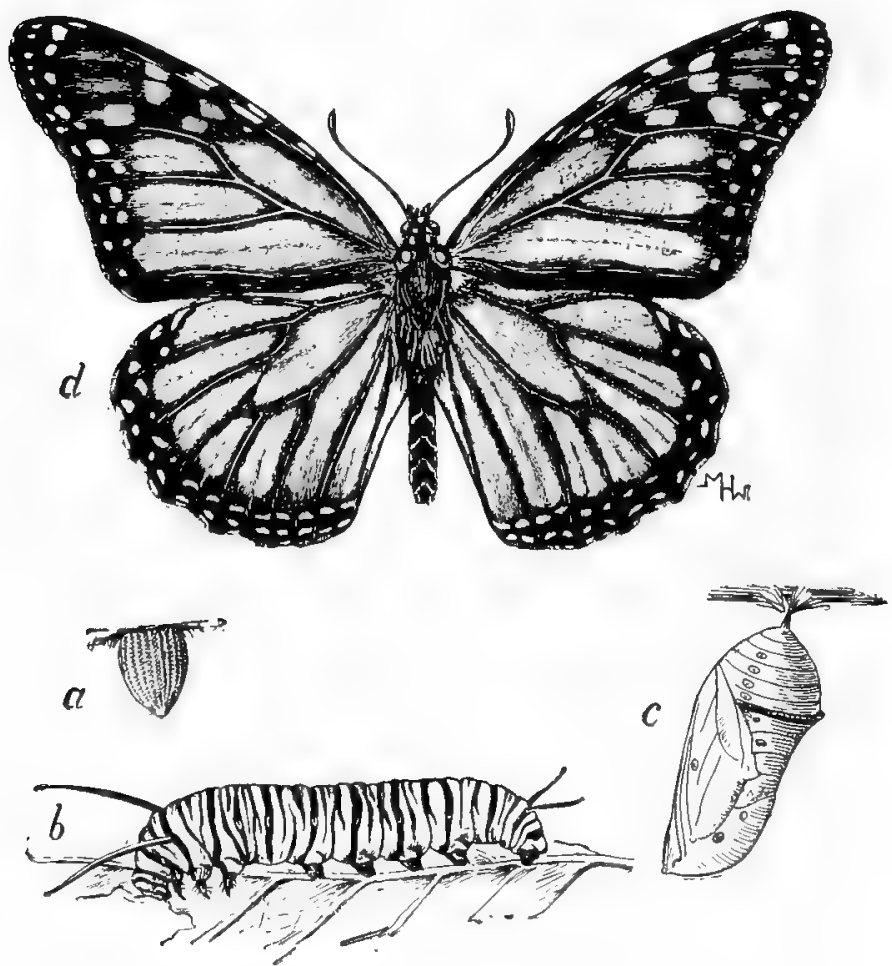

Fra. 43.-Metamorphosis of monarch butterfly (Anosia plexïppus). u, egg; $\delta$, larva ; c, pupa; $d$, imago or adult.

common in the United States and called the monarch or milkweed butterfly (Anosia plexippus). The eggs (Fig. $43, a)$ of this butterfly are laid on the leaves of various kinds of milkweed (Asclepias). The larval butterfly or butterfly larva or caterpillar (as the first young stage of the butter- 
flies and moths is usually called), which hatches from the ogg in.three or four days, is a creature bearing little or no resemblance to the beautiful winged adult. The larva is worm-like, and instead of having three pairs of legs like the butterfly it has eight pairs; it has biting jaws in its mouth with which it nips off bits of the green milkweed leaves, instead of having a long, slender, sucking proboscis for drinking flower nectar as the butterfly has. The body of the crawling worm like larva (Fig. $43, b$ ) is greenish yollow in color, with broad rings or bands of shining black. It has no wings, of course. It eats voraciously, grows rapidly and molts. But after the molting there is no appearance of rudimentary wings; it is simply a larger wormlike larva. It continues to feed and grow, molting several times, until after the fourth molt it appears no longer as an active, crawling, feed-

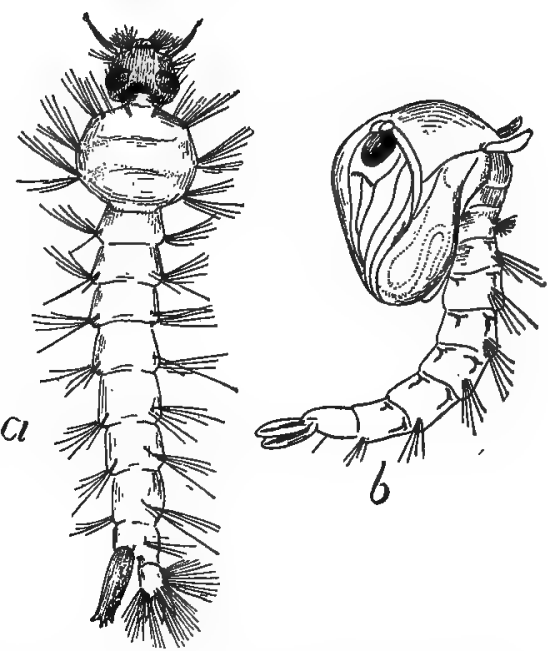

Fig. 44.--Metamorphosis of mosquito (Oulex). $a$, larva ; $b$, pupa. ing, worm-like larva, but as a quiescent, non-feeding pupa or chrysalis (Fig. 43,c). The immature butterfly is now greatly contracted, and the outer chitinous wall is very thick and firm. It is bright green in color with golden dots. It is fastened by one end to a leaf of the milkweed, where it hangs immovable for from a few days to two weeks. Finally, the chitin wall of the chrysalis splits, and there issues the full-fledged, great, four-winged, red-brown butterfly (Fig. 43, d). Truly this is a metamorphosis, and a start- 
ling one. But we know that development in other animals is a gradual and continuous process, and so it is in the

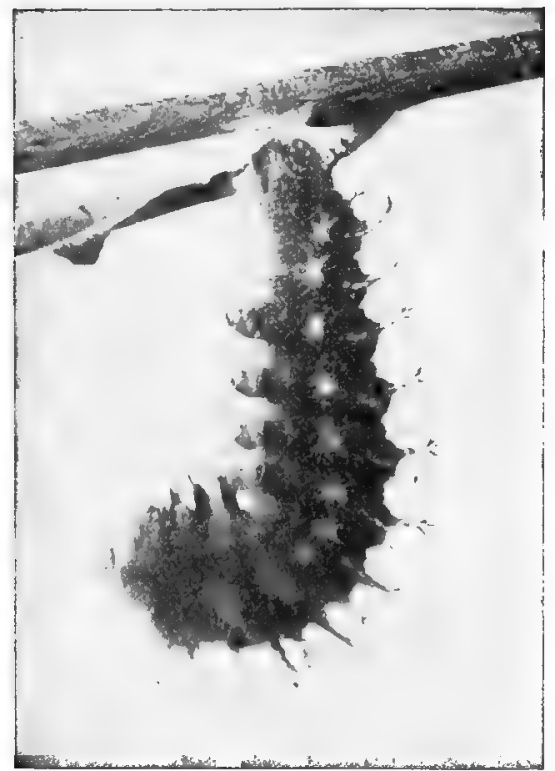

Fig. 45-Larva of a butterfly just changing into pupa (making last larval molt). Photograph from Nature. case of the butterfly. The gradual changing is masked by the outer covering of the body in both larva and pupa. It is only at each molting or throwing off of this unchanging, unyielding chitin armor that we perceive how far this change has gone. The longest time of concealment is that during the pupal or chrysalis stage, and the results of the changing or development when finally revealed by the splitting of the pupal case are hence the most striking.

58. Metamorphosis of the toad-Metamorphosis is found in the development of numerous other animals, as well as among the insects. Certain cases are familiar to all-the metamorphosis of the frogs and toads (Fig. 46). The eggs of the toad are arranged in long strings or ribbons in a transparent jelly-like substance. These jelly ribbons with the small, black, bead-like eggs in them are wound around the stems of submerged plants or sticks near the shores of the pond. From each egg hatches a tiny, wriggling tadpole, differing neurly as much from in full-grown toad as a caterpillar differs from a butterfly. The tadpoles feed on 
the microscopic plants to be found in the water, and swim easily about by means of the long tail. The very young tadpoles remain underneath the surface of the water all the time, breathing the air which is mixed with water by means of gills. But as they become older and larger they come often to the surface of the water. Lungs are developing inside the body, and the tadpole is beginning to breathe as a land animal, although it still breathes partly by means of gills, that is, as an aquatic animal. Soon it is apparent that although the tadpole is steadily and rapidly growing larger, its tail is growing shorter and smaller instead of larger. At the same time, fore and hind legs bud out and rapidly take

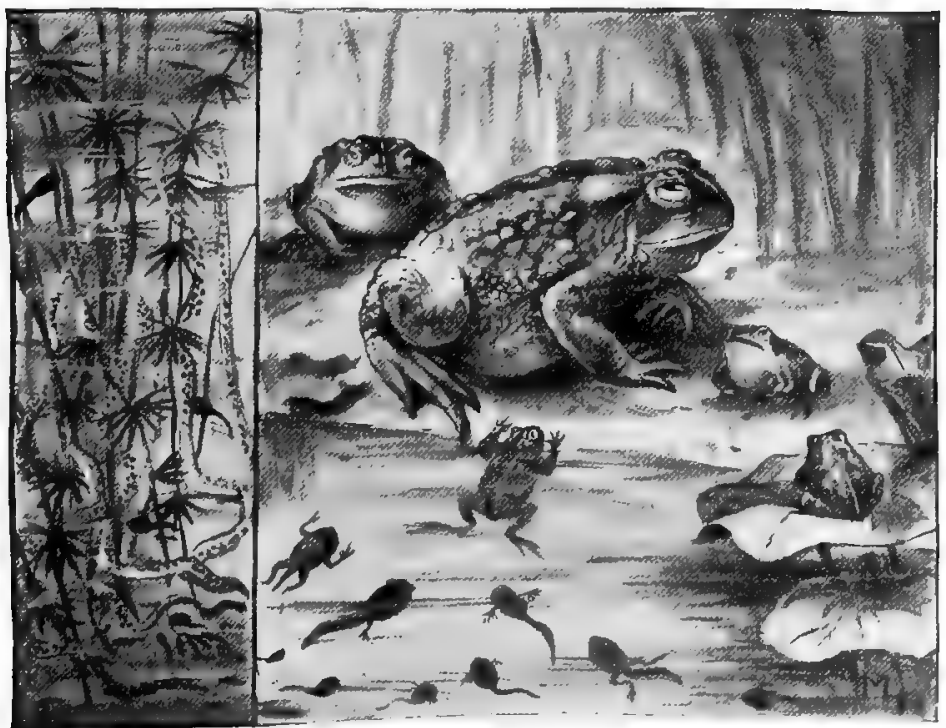

F1G. 46.-Metamorphosis of the toad (partly after GAGE). At left the strings of eggs, in water the various tadpole or larval stages, and on bank the adult toads.

form and become functional. By the time that the tail gets very short, indeed, the young toad is ready to leave the water and live as a land animal. On land the toad lives, as 
we know, on insects and snails and worms. The metamorphosis of the toad is not so striking as that of the butterfly, but if the tadpole were inclosed in an unchanging opaque body wall while it was losing its tail and getting its legs, and this wall were to be shed after these changes were made, would not the metamorphosis be nearly as extraordi-

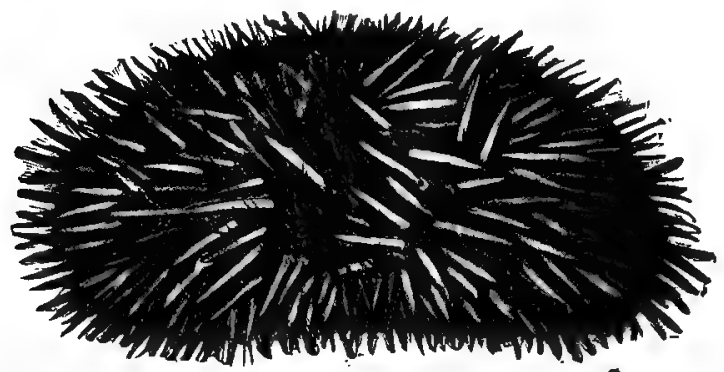

Fra. 47.-Metamorphosis of seaurchin. Upper figure the adult, lower figure the pluteus larva.

nary as in the case of the butterfly? But in the metamorphosis of the toad we can see the gradual and continuous character of the change.

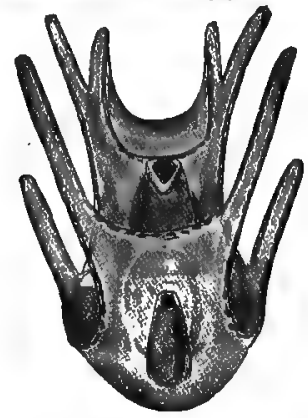

59. Metamorphosis among other animals,-Many other animals, besides insects and frogs and toads, undergo metamorphosis. The just-hatched sea-urchin does not resemble a fully developed sea-urchin at all. It is a minute wormlike creature, provided with cilia or vibratile hairs, by means of which it swims freely about. It changes next into a curious bootjack-shaped body called the pluteus stage (Fig 47). In the pluteus a skeleton of lime is formed, and the final true sea-urchin body begins to appear inside the pluteus, 
developing and growing by using up the body substance of the pluteus. Star-fishes, which are closely related to seaurchins; show a similar metamorphosis, except that there is no pluteus stage, the true star-fish-shaped body forming, within and at the expense of the first larval stage, the ciliated free-swimming stage.

A young crab just issued from the egg (Fig. 48) is a very different appearing creature from the adult or fully developed crab. The body of the crab in its first larval stage is composed of a short, globular portion, fur-
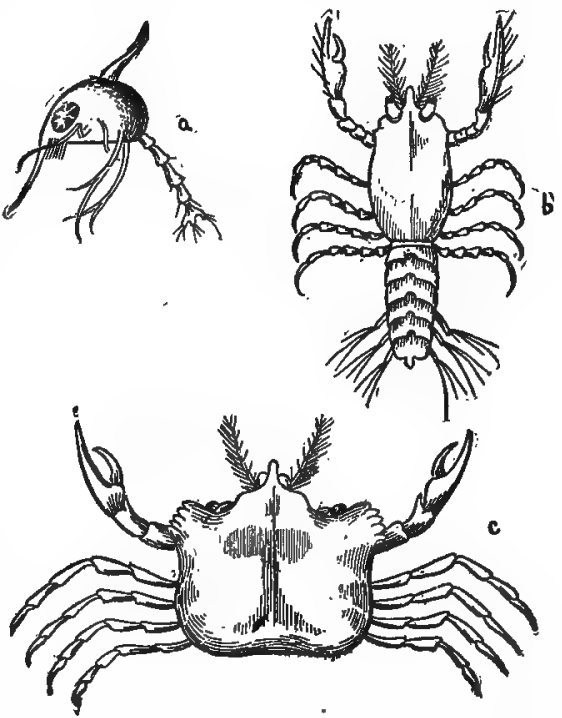

FıG. 48.-Metamorphosis of the crab. $a$, the zoena stage; $b$, the megalops; $c$, the adult.

nished with conspicuous long spines and a relatively long, jointed tail. This is called the zoëa stage. The zoëa changes into a stage called the megalops, which has many characteristics of the adult crab condition, but differs especially from it in the possession of a long, segmented tail, and in having the front half of the body longer than wide. The crab in the megalops stage looks very much like a tiny lobster or shrimp. The tail soon disappears and the body widens, and the final stage is reached.

In many families of fishes the changes which take place in the course of the life cycle are almost as great as in the case of the insect or the toad. In the lady-fish (Albula vulpes) the very young (Fig. 49) are ribbon-like in form, 
with small heads and very loose texture of the tissues, the body substance being jelly-like and transparent. As the fish grows older the body becomes more compact, and therefore
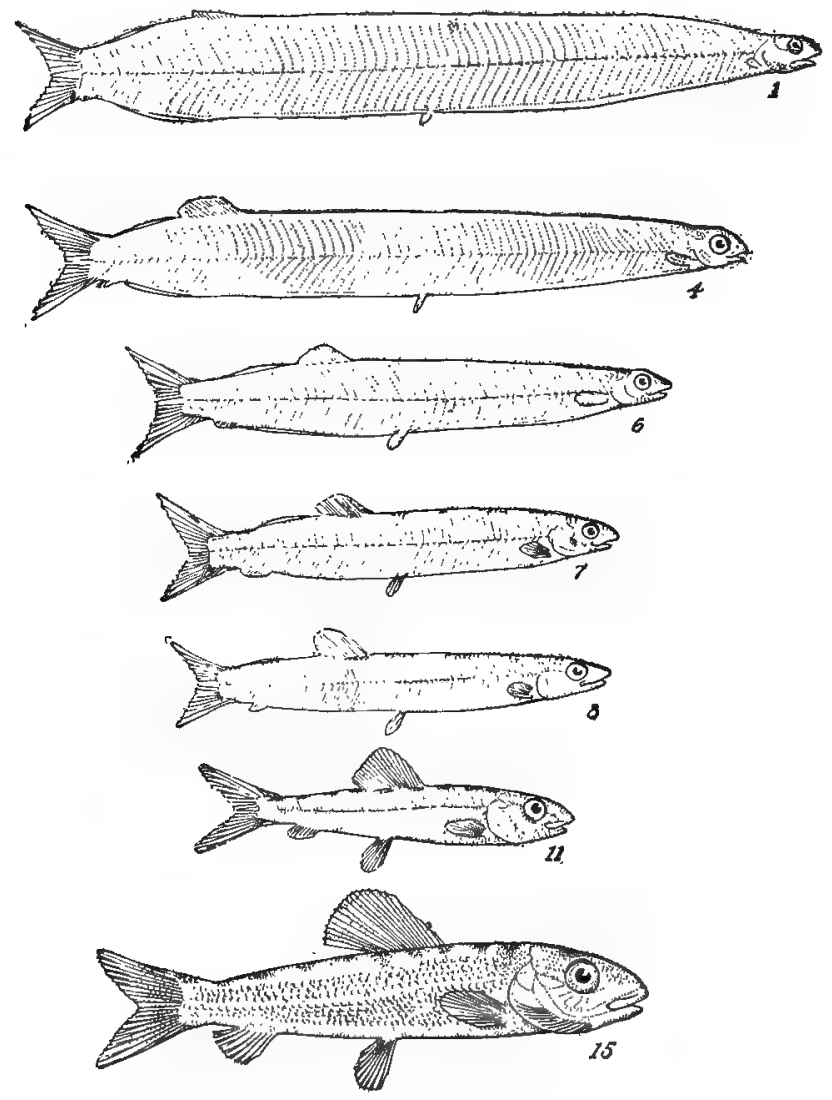

Fia. 49.-Stages in the post-embryonic development of the lady-fish (Albula vulpes), showing metamorphosis, -After C. H. GILBERT.

shorter and slimmer. After shrinking to the texture of an ordinary fish, its growth in size begins normally, although 
it has steadily increased in actual weight. Many herring, eels, and other soft-bodied fishes pass through stages similar to those seen in the lady-fish. Another type of development is illustrated in the sword-fish. The young has a bony head, bristling with spines. As it grows older the spines disappear, the skin grows smoother, and, finally, the bones of the upper jaw grow together, forming a prolonged sword, the teeth are lost and the fins become greatly modified. Fig. 50 shows three of these stages of growth. The
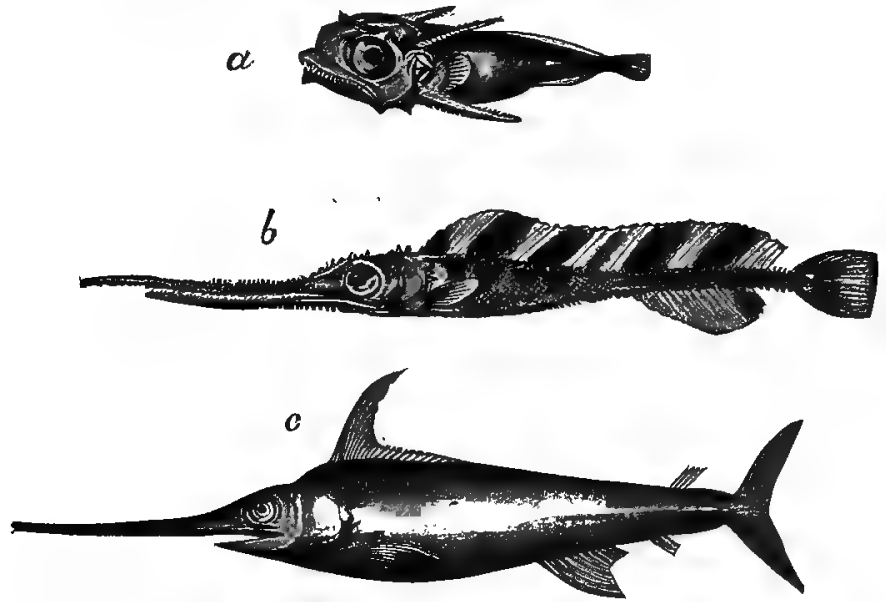

Fic. 50.-Three stages in the development of the sword-fish (Xiphias gladius). $a$, very young ; $b$, older ; $c$, adult.-Partly after Lütren.

flounder or flat-fish (Fig. 51) when full grown lies flat on one side when swimming or when resting in the sand on the bottom of the sea. The eyes are both on the upper side of the body, and the lower side is blind and colorless. When the flounder is hatched it is a transparent fish, broad and flat, swimming vertically in the water, with an eye on each side. As its development (Fig. 52) goes on it rests itself obliquely on the bottom, the eye of the lower side turns upward, and as growth proceeds it passes gradually 
around the forehead, its socket moving with it, until both eyes and sockets are transferred by twisting of the skull to

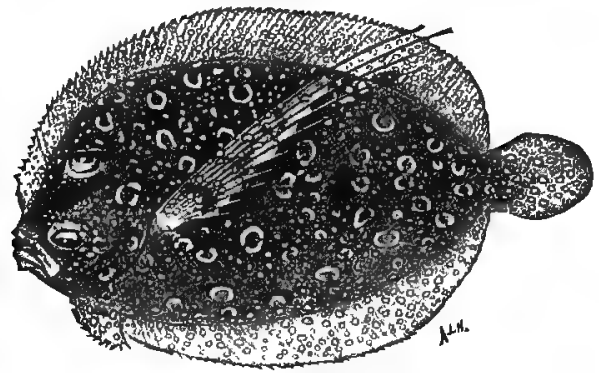

FIG. 51.-The wide-eyed flounder (Platophry/s lunatus). Adult, showing both eyes on upper side of head.

the upper side. In some related forms or soles the small eye passes through the head and not around it, appearing finally in the same socket with the other eye.

Thus in almost all the great groups of animals we find certain kinds which show metamorphosis in their postembryonic development. But metamorphosis is simply development; its striking and extraordinary features are usually due to the fact that the orderly, gradual course of the development is revealed to us only occasionally, with the result of giving the impression that the development is proceeding by leaps and bounds from one strange stage to
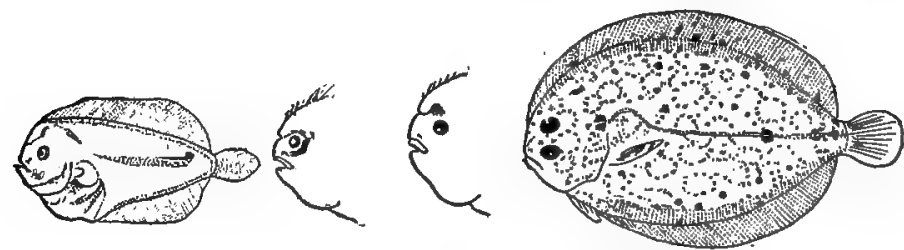

Fra. 52.-Development of a flounder (after EMERY). The eyes in the young flounder are arranged normally, one on each side of head.

another. If metamorphosis is carefully studied it loses its aspect of marvel, although never its great interest. 
60. Duration of life.-After an animal has completed its development it has but one thing to do to complete its life cycle, and that is the production of offspring. When it has laid eggs or given birth to young, it has insured the beginning of a new life cycle. Does it now die? Is the business of its life accomplished? There are many animals which die immediately or very soon after laying eggs. The May-flies-ephemeral insects which issue as winged adults from ponds or lakes in which they have spent from one to three years as aquatic crawling or swimming larvæ, flutter about for an evening, mate, drop their packets of fertilized eggs into the water, and die before the sunrise - are extreme examples of the numerous kinds of animals whose adult life lasts only long enough for mating and egglaying. But elephants live for two hundred years. Whales probably live longer. A horse lives about thirty years, and so nny a cat or toad. A sea-

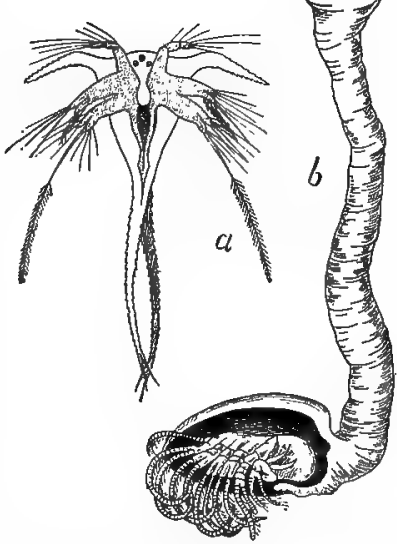

Fig. 53.-Metamorphosis of a barnacle (Leysas). $u$, larva; $b$, adult.

mone, which was kept in an aquarium, lived sixty-six '3. Cray-fishes may live twenty years. A queen bee ; kept in captivity for fifteen years. Most birds have lung lives-the small song birds from eight to eighteen years, and the great eagles and vultures up to a hundred years or more. On the other hand, among all the thousands of species of insects, the individuals of very few indeed live more than a year; the adult life of most insects being but a few days or weeks, or at best months. Even among the higher animals, some are very short-lived. In Japan is a small fish (Solaux) which probably lives 
but a year, ascending the rivers in numbers when young in the spring, the whole mass of individuals dying in the fall after spawning.

Naturalists have sought to discover the reason for these extraordinary differences in the duration of life of different animals, and while it can not be said that the reason or reasons are wholly known, yet the probability is strong that the duration of life is closely connected with, or dependent upon, the conditions attending the production of offspring. It is not sufficient, as we have learned from our study of the multiplication of animals (Chapter III), that an adult animal shall produce simply a single new individual of its kind, or even only a few. It must produce many, or if it produces comparatively few it must devote great care to the rearing of these few, if the perpetuation of the species is to be insured. Now, almost all long-liven animals are species which produce but few offspring at a time, and reproduce only at long intervals, while most short-lived animals produce a great many eggs, and these all at one time. Birds are long-lived animals; as we know, most of them lay eggs but once a year, and lay only a few eggs each time. Many of the sea birds which swarm in countless numbers on the rocky ocean islets and great sea cliffs lay only a single egg once each year. And these birds, the guillemots and murres and auks, are especially long-lived. Insects, on the contrary, usually produce many eggs, and all of them in a short time. The May-fly, with its one evening's lifetime, lets fall from its body two packets of eggs and then dies. Thus the shortening of the period of reproduction with the production of a great many offspring seem to be always associated with a short adult lifetime; while a long period of reproduction with the production of few offspring at a time and care of the offspring are associated with a long adult lifetime.

There seems also to be some relation between the size of animals and the length of life. As a general rule 
large animals are long-lived and small animals have short iives.

61. Death.-At the end comes death. After the animal has completed its life cycle, after it has done its share toward insuring the perpetuation of its species, it dies. It may meet a violent death, may be killed by accident or by enemies, before the life cycle is completed. And this is the fate of the vast majority of animals which are born or hatched. Or death may come before the time for birth or hatching. Of the millions of eggs laid by a fish, each egg a new fish in simplest stage of development, how many or rather how few come to maturity, how few complete the cycle of life!

Of death we know the essential meaning. Life ceases and can never be renewed in the body of the dead animal. It is important that we include the words "can never be renewed," for to say simply that "life ceases," that is, that the performance of the life processes or functions ceases, is not really death. It is easy to distinguísh in most cases between life and death, between a live animal and a dead one, yet there are cases of apparent death or a semblance of death which are very puzzling. The test of life is usually taken to be the performance of life functions, the assimilar tion of food and excretion of waste, the breathing in of oxygen, and breathing out of carbonic-acid gas, movement, feeling, etc. But some animals can actually suspend all of these functions, or at least reduce them to such a minimum that they can not be perceived by the strictest examination, and yet not be dead. That is, they can renew again the performance of the life processes. Bears and some other animals, among them many insects, spend the winter in a state of death-like sleep. Perhaps it is but sleep; and yet hibernating insects can be frozen solid and remain frozen for weeks and months, and still retain the power of actively living again in the following spring. Even more remarkable is the case of certain minute animals called $R \sigma$ - 
tatoria and of others called Tardigrada, or bear-animalcules. These bear-animalcules live in water. If the water dries up, the animalcules dry up too; they shrivel up into formless little masses and become desiccated. They are thus simply dried-up bits of organic matter; they are organic dust. Now, if after a long time-years even-one of these organic dust particles, one of these dried-up bear-animal. cules is put into water, a strange thing happens. The body swells and stretches out, the skin becomes smooth instead of all wrinkled and folded, and the legs appear in normal shape. The body is again as it was years before, and after a quarter of an hour to several hours (depending on the length of time the animal has lain dormant and dried) slow movements of the body parts begin, and soon the animalcule crawls about, begins again its life where it had been interrupted. Various other small animals, such as vinegar eels and certain Protozoa, show similar powers. Certainly here is an interesting problem in life and death.

When death comes to one of the amimals with which we are familiar, we are accustomed to think of its coming to the whole body at some exact moment of time. As we stand beside a pet which has been fatally injured, we wait until suddenly we say, "It is dead." As a matter of fact, it is difficult to say when death occurs. Long after the heart ceases to beat, other organs of the body are alivethat is, are able to perform their special functions. The muscles can contract for minutes or hours (for a short time in warm-blooded, for a long time in cold-blooded animalii) after the animal ceases to breathe and its heart to beat. Even longer live certain cells of the body, especially the amœboid white blood-corpuscles. These cells, very like the $A m \infty b a$ in character, live for days after the animal is, as we say, dead. The cells which line the tracheal tube leading to the lungs bear cilia or fine hairs which they wave back and forth. They continue this movement for days after the heart has ceased beating. Among cold. 
blooded animals, like snakes and turtles, complete cessation of life functions comes very slowly, even after the body has been literally cut to pieces.

Thus it is essential in defining death to speak of a complete and permanent cessation of the performance of the life processes.

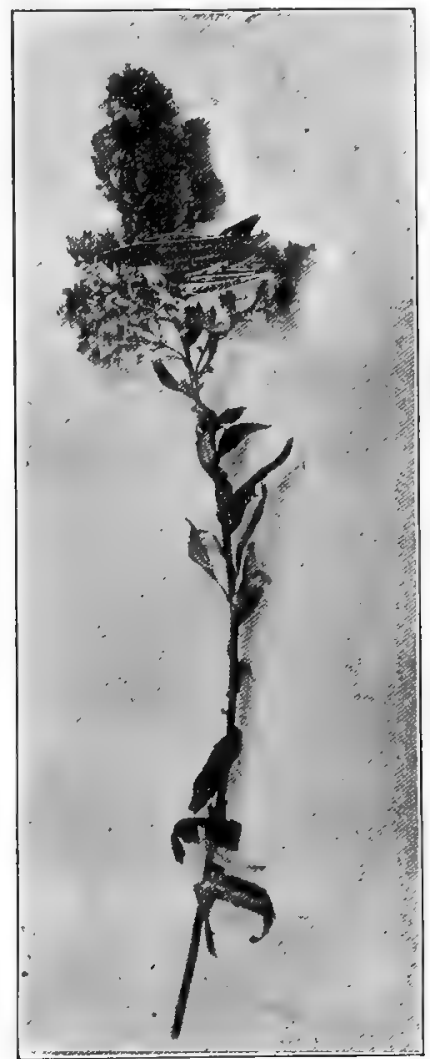

A grasshopper (Melanoplus differentialis) killed by disease caused by a parasitic fungus. On golden-rod. 


\section{CHAPTER VI}

\section{THE PRIMARY CONDITIONS OF ANMMAL LIFE}

62. Primary conditions and special conditions-Certain primary conditions are necessary for the existence of all animals. We know that fishes can not live very long out of water, and that birds can not live in water. These, howerer, are special conditions which depend on the special structure and habits of these two particular kinds of backboned animals. But the necessity of a constant and sufficient supply of air is a necessity common to both; it is one of the primary conditions of their life. All animals must have air. Similarly both fishes and birds, and all other animals as well, must have food. This is another one of the primary conditions of animal life. That backboned animals must find somehow a supply of salts or compounds of lime to form into bones is a special condition peculiar to these animals. Other animals having shells or teeth composed of carbonate or phosphate of lime are subject to the same special demand, but many animals have no hard parts, and therefore need no lime.

63. Food.-All the higher plants, those that are green (chlorophyll-bearing), can make their living substance out of inorganic matter alone-that is, use inorganic substances as food. But animals can not do this. They must have already formed organic matter for food. This organic matter may be the living or dead tissues of plants, or the living or dead tissues of animals. For the life of animals it is necessary that other organisms live, or have lired. It is this need which primarily distinguishes an animal from a 
plant. Animals can not exist without plants. The plants furnish all animals with food, either directly or indirectly. The amount of food and the kinds of food required by various kinds of animals are special conditions depending on the size, the degree of activity, the structural character of the body, etc., of the animal in question. Those which do the most need most. Those with warmest blood, greatest activity, and most rapid change of tissues are most dependent on abundance, regularity, and fitness of their food. As we well know, an animal can live for a longer or shorter time without food. Men have fasted for a month, or even two months. Among cold-blooded animals, like the reptiles, the general habit of food taking is that of an occasional gorging, succeeded by a long period of abstinence. Many of the lower animals can go without food for surprisingly long periods without loss of life. But the continued lack of food results inevitably in death. Any animal may be starved in time.

If water be held not to be included in the general conception of food, then special mention must be made of the necessity of water as one of the primary conditions of animal life. Protoplasm, the basis of life, is a fluid, although thick and viscous. To be fluid its components must be dissolved or suspended in water. In fact, all the truly living substance in an animal's body contains water. The water necessary for the animal may be derived from the other food, all of which contains water in greater or less quantity, or may be taken apart from the other food, by drinking or by absorption through the skin. Sheep are seldom seen to drink, for they find almost enough water in their green food. Fur seals never drink, for they absorb the water needed through pores in the skin.

64. Oxygen--Animals must have air in order to live, but the essential element of the air which they need is its oxygen. For the metabolism of the body, for the chemical 
changes which take place in the body of every living animal, a supply of oxygen is required. This oxygen is derived directly or indirectly from the air. The atmosphere of the earth is composed of 79.02 parts of nitrogen (including argon), .03 parts of carbonic acid, and 20.95 parts of oxygen. Thus all the animals which live on land are enveloped by a substance containing nearly 21 per cent of oxygen. But animals can live in an atmosphere containing much less oxygen. Certain mammals, experimented on, lived without difficulty in an atmosphere containing only 14 per cent of oxygen; when the oxygen was reduced to 7 per cent serious disturbances were caused in the animal's condition, and death by suffocation ensued when 3 per cent of oxygen was left in the atmosphere. Animals which live in water get their oxygen, not from the water itself (water being composed of hydrogen and oxygen), but from air which is mechanically mixed with the water. Fishes breathe the air which is mixed with or dissolved in the water. This scanty supply therefore constitutes their atmosphere, for in water from which all air is excluded no animal can breathe. Whatever the habits of life of the animal, whether it lives on the land, in the ground, or in the water, it must have oxygen or die.

65. Temperature, pressure, and other conditions,-Some physiologists include among the primary or essential general conditions of animal life such conditions as favorable temperature and favorable pressure. It is known from observation and experiment that animals die when a too low or a too high temperature prevails. The minimum or maximum of temperature between which limits an animal can live varies much among different kinds of animals. It is familiar knowledge that many kinds of animals can be frozen and yet not be killed. Insects and other small animals may lie frozen through a winter and resume active life again in the spring. An experimenter kept certain fish frozen in blocks of ice at a temperature of $-15^{\circ} \mathrm{C}$. 
for some time and then gradually thawed them out unhurt. Only very hardy kinds adapted to the cold would, however, survive such treatment. There is no doubt that every part of the body, all of the living substance, of these. fish was frozen, for specimens at this temperature could be broken and pounded up into fine ice powder. But a temperature of $-20^{\circ} \mathrm{C}$. killed the fish. Frogs lived after being kept at a temperature of $-28^{\circ} \mathrm{C}$., centipeds at $-50^{\circ} \mathrm{C}$., and certain snails endured a temperature of $-120^{\circ} \mathrm{C}$. without dying. At the other extreme, instances are known of animals living in water (hot springs or water gradually heated with the organisms in it) of a temperature as high as $50^{\circ} \mathrm{C}$. Experiments with $A m o c b c e$ show that these simplest animals contract and cease active motion at $35^{\circ} \mathrm{C}$., but are not killed until a temperature of $40^{\circ}$ to $45^{\circ} \mathrm{C}$. is reached. The little fish called blob or miller's thumb (Cottus ictalops) has been seen lying boiled in the bottom of the hot springs in the Yellowstone Park; but it must have entered these springs through streams of a temperature little below the boiling point.

The pressure or weight of the atmosphere on the surface of the earth is nearly fifteen pounds on each square inch. This pressure is exerted equally in all directions, so that an object on the earth's surface sustains a pressure on each square inch of its surface exposed to the air of fifteen pounds. Thus all animals living on the earth's surface or near it live under this pressure, and know no other condition. For this reason they do not notice it. The animals that live in water, however, sustain a much greater pressure, this pressure increasing with the depth. Certain ocean fishes live habitually at great depths, as two to five miles, where the pressure is equivalent to that of many hundred atmospheres. If these fishes are brought to the surface their eyes bulge out fearfully, being pushed out through reduced expansion; their scales fall off because of the great expansion of the skin, and the stomach is pushed 
out from the mouth till it is wrong side out. Indeed, the bodies sometimes burst. Their bodies are accustomed to this great pressure, and when this outside pressure is suddenly removed the body may be bursted. Sometimes such a fish is raised from its proper level by a struggle with its prey, when both captor and victim may be destroyed by the expansion of the body. Some fishes die on being taken out of water through the swelling of the air bladder and the bursting of its blood-vessels. If an animal which lives normally on the surface of the earth is taken up a very high mountain or is carried up in a balloon to a great altitude where the pressure of the atmosphere is much less than it is at the earth's surface, serious consequences may ensue, and if too high an altitude is reached death occurs. This death may be in part due to the difficulty in breathing in sufficient oxygen to maintain life, but it is probably chiefly due to disturbances caused by the removal of the pressure to which the body is accustomed and is structurally adapted to withstand. A famous balloon ascension was made in Paris in 1875 by three men. After the balloon had reached a height of nearly 24,000 feet (almost five miles) the men began to lose consciousness. On the sinking of the balloon to about 20,000 feet the men regained consciousness again and threw out ballast so that the balloon rose to a height of over 25,000 feet. This time all three became wholly unconscious, and on the balloon sinking again only one regained consciousness. The other two died in the foolhardy experiment. All living animals are accustomed to live under a certain pressure, and there are evidently limits of maximum or minimum pressure beyond which no animal at present existing can go and remain alive.

But in the case both of temperature and pressure conditions it is easy to conceive that animals might exist which could live under temperature and pressure conditions not included between the minimum and maximum limits of each 
as determined by animals so existing. But it is impossible to conceive of animals which could live without oxygen or without organic food. The necessities of oxygen and organic food (and water) are the primary or essential conditions for the existence of any animals.

Of course, we might include such conditions, among the primary conditions, as the light and heat of the sun, the action of gravitation, and other physical conditions without which existence or life of any kind would be impossible on this earth. But we here consider by "primary conditions of animal life" rather those necessities of living animals as opposed to the necessities of living plants. Neither animals nor plants could exist without the sun, whence they derive directly or indirectly all their energy.

66. Difference between animals and plants.-It is easy to distinguish between the animal and plant when a butterfly is fluttering about a blossoming cherry tree or a cow feeding in a field of clover. It is not so easy, if it is, indeed, possible, to say which is plant and which is animal when the simplest plants are compared with the simplest animals. It is almost impossible to so define animals as to distinguish all of them from all plants, or so to define plants as to distinguish all of them from all animals. While most animals have the power of locomotion, some, like the sponges and polyps and barnacles and numerous parasites, are fixed. While most plants are fixed, some of the low aquatic forms have the power of spontaneous locomotion, and all plants have some power of motion, as especially exemplified in the revolution of the apex of the growing stem and root, and the spiral twisting of tendrils, and in the sudden closing of the leaves of the sensitive plant when touched. Among the green or chlorophyllbearing plants the food consists chiefly of inorganic substances, especially of carbon which is taken from the carbonic-acid gas in the atmosphere, and of water. But some green-leaved plants feed also in part on organic food. 
Such are the pitcher-plants and sun-dews, and Venus-flytraps, which catch insects and use them for food nutrition. But there are many plants, the fungi, which are not green - that is, which do not possess chlorophyll, the substance on which seems to depend the power to make organic matter out of inorganic substances. These plants feed on organic matter as animals do. The cells of plants (in their young stages, at least) have a wall composed of a peculiar carbohydrate substance called cellulose, and this cellulose W is for a long time believed not to occur in the body of animals. But now it is known that certain sea-squirts (Tunicata) possess cellulose. It is impossible to find any set of characteristics, or even any one characteristic, which is possessed only by plants or only by animals. But nearly all of the many-celled plants and animals may be easily distinguished by their general characteristics. The power of breaking up carbonic-acid gas into carbon and oxygen and assimilating the carbon thus obtained, the presence of chlorophyll, and the cell walls formed of cellulose, are characteristics constant in all typical plants. In addition, the fixed life of plants, and their general use of inorganic substances for food instead of organic, are characteristics readily observed and practically characteristic of manycelled plants. When the thousands of kinds of one-celled organisms are compared, however, it is often a matter of great difficulty or of real impossibility to say whether a given organism should be assigned to the plant kingdom or to the animal kingdom. In general the distinctive characters of plants are grouped around the loss of the power of losomotion and related to or dependent upon it.

6\%. Living organic matter and inorganic matter.-It would seem to be an easy matter to distinguish an organism-that is, a living animal or plant-from an inorganic substance. It is easy to distinguish a dove or a sunflower from stone, and practically there never is any difficulty in making such distinctions. But when we try to define living organic matter, 
and to describe those characteristics which are peculiar to it, which absolutely distinguish it from inorganic matter, we meet with some difficulties. At least many of the characteristics commonly ascribed to organisms, as peculiar to them, are not so. The possession of organs, or the composition of the body of distinct parts, each with a distinct function, but all working together, and depending on each other, is as true of a steam-engine as of a horse. That the work done by the steam-engine depends upon fuel is true; but: so it is that the work done by the horse depends upon fuel, or food as we call it in the case of the animal. The oxidation or burning of this fuel in the engine is wholly comparable with the oxidation of the food, or the muscle and fat it is turned into, in the horse's body. The composition of the bodies of animals and plants of tiny structural units, the cells, is in many ways comparable with the composition of some rocks of tiny structural units, the crystals. But not to carry such rather quibbling comparisons too far, it may be said that organisms are distinguished from organic substances by the following characteristics: Organization; the power to make over inorganic substances into organic matter, or the changing of organic matter of one kind, as plant matter, into another kind, as animal matter; motion, the power of spontaneous movement in response to stimuli; sensation, the power of being sensible of external stimuli; reproduction, the power of producing new beings like themselves; and adaptation, the power of responding to external conditions in a way useful to the organism. Through adaptation organisms continue to exist despite the changing of conditions. If the conditions surrounding an inorganic body change, even gradually, the inorganic body does not change to adapt itself to these conditions, but resists them until no longer able to do so, when it loses its identity or integrity. 


\section{CHAPTER VII}

\section{THE CROWD OF ANIMALS AND THF STRUGGLF FOR BXISTENCE}

68. The crowd of animals. - All animals feed upon living organisms, or on their dead bodies. Hence each animal throughout its life is busy with the destruction of other organisms, or with their removal after death. If those creatures upon which others feed are to hold their own, there must be enough born or developed to make good the drain upon their numbers. If the plants did not fill up their ranks and make good their losses, the animals that feed on them would perish. If the plant-eating animals were destroyed, the flesh-eating animals would in turn disappear. But, fortunately, there is a vast excess in the process of reproduction. More plants sprout than can find room to grow. More animals are born than can possibly survive. The process of increase among animals is correctly spoken of as multiplication. Each species tends to increase in geometric ratio, but as it multiplies its members it finds the world already crowded with other species doing the same thing. A single pair of any species whatsoever, if not restrained by adverse conditions, would soon increase to such an extent as to fill the whole world with its progeny. An annual plant producing two seeds only would have $1,048,5 \% 6$ descendants at the end of twenty-one years, if each seed sprouted and matured. The ratio of increase is therefore a matter of minor importance. It is the ratio of net increase above loss which determines the fate of a species. Those species increase in numbers whose gain exceeds 
the death rate, and those which "live beyond their means" must sooner or later disappear. One of the most abundant of birds is the fulmar petrel, which lays but one egg yearly. It has but few enemies, and this low rate of increase suffices to cover the seas within its range with petrels.

It is difficult to realize the inordinate numbers in which each species would exist were it not for the checks produced by the presence of other animals. Certain Protozoa at their normal rate of increase, if none were devoured or destroyed, might fill the entire ocean in about a week. The congerecl lays, it is said, $15,000,000$ eggs. If each egg grew up to maturity and reproduced itself in the same way in less than ten years the sea would be solidly full of congereels. If the eggs of a common house-fly should develop, and each of its progeny should find the food and temperature it needed, with no loss and no destruction, the people of a city in which this might happen could not get away soon enough to escape suffocation from a plague of flies. Whenever any insect is able to develop a large percentage of the eggs laid, it becomes at once a plague. Thus originate plagues of grasshoppers, locusts, and caterpillars. But the crowd of life is such that no great danger exists. The seavenger destroys the decaying flesh where the fly would lay its eggs. Minute creatures, insects, bacteria, Protozoa are parasitic within the larva and kill it. Millions of flies perish for want of food. Millions more are destroyed by insectivorous birds, and millions are slain by parasites. The final result is that from year to year the number of flies does not increase. Linnæus once said that "three flies would devour a dead horse as quickly as a lion." Equally soon would it be devoured by three bacteria, for the decay of the horse is due to the decomposition of its flesh by these microscopic plants which feed upon it. "Even slow-breeding man," says Darwin, "has doubled in twenty-five years. At this rate in less than a thousand years there would literally not be standing room for his progeny. The elephant is reckoned the slow- 
est breeder of all known animals. It begins breeding when thirty years old and goes on breeding until ninety years old, bringing forth six young in the interval, and surviving till a hundred years old. If this be so, after about eight hundred years there would be 19,000,000 elephants alive, descended from the first pair." A few years more of the unchecked multiplication of the elephant and every foot of land on the earth would be covered by them.

Yet the number of elephants does not increase. In generai, the numbers of every species of animal in the state of Nature remain about stationary. Under the influence of man most of them slowly diminish. There are about as many squirrels in the forest one year as another, about as many butterflies in the field, about as many frogs in the pond. Wolves, bears, deer, wild ducks, singing birds, fishes, tend to grow fewer and fewer in inhabited regions, because the losses from the hand of man are added to the losses in the state of Nature.

It has been shown that at the normal rate in increase of English sparrows, if none were to die save of old age, it would take but twenty years to give one sparrow to every square inch in the State of Indiana. Such an increase is actually impossible, for more than a hundred other species of similar birds are disputing the same territory with the power of increase at a similar rate. There can not be food and space for all. With such conditions a struggle is set up between sparrow and sparrow, between sparrow and other birds, and between sparrow and the conditions of life. Such a conflict is known as the struggle for existence.

69. The struggle for existence.-The struggle for existence is threefold: $(\alpha)$ among individuals of one species, as sparrow and sparrow; $(b)$ between individuals of different species, as sparrow with bluebird or robin ; and $(c)$ with the conditions of life, as the effort of the sparrow to keep warm in winter and to find water in summer. All three forms of this struggle are constantly operative and with 
every species. In some regions the one phase may be more destructive, in others another. Where the conditiuns of life are most easy, as in the tropics, the struggle of species with species, of individual with individual, is the most severe.

No living being can escape from any of these three phases of the struggle for existence. For reasons which we shall see later, it is not well that any should escape, for "the sheltered life," the life withdrawn from the stress of effort, brings the tendency to degeneration.

Because of the destruction resulting from the struggle for existence, more of every species are born than can possibly find space or food to mature. The majority fuil to reach their full growth because, for one reason or another, they can not do so. All live who can. Each strives to feed itself, to save its own life, to protect its young. But with all their efforts only a portion of each species succeed.

70. Selection by Nature.-But the destruction in Nature is not indiscriminate. In the long run those least fitted to resist attack are the first to perish. It is the slowest animal which is soonest overtaken by those which feed upon it. It is the weakest which is crowded away from the feeding-place by its associates. It is the least adapted which is first destroyed by extremes of heat and cold. Just as a farmer improves his herd of cattle by destroying his weakest or roughest calves, reserving the strong and fit for parentage, so, on an inconceivably large scale, the forces of Nature are at work purifying, strengthening, and fitting to their surroundings the various species of animals. This process has been called natural selection, or the survival of the fittest. But by fittest in this sense we mean only best adapted to the surroundings, for this process, like others in Nature, has itself no necessarily moral element. The songbird becomes through this process more fit for the song-bird life, the hawk becomes more capable of killing and tear- 
ing, and the woodpecker better fitted to extract grubs from the tree.

In the struggle of species with species one may gain a little one year and another the next, the numbers of each species fluctuating a little with varying circumstances, but after a time, unless disturbed by the hand of man, a point will be reached when the loss will almost exactly balance the increase. This produces a condition of apparent equilibrium. The equilibrium is broken when any individial or group of individuals becomes capable of doing something more than hold its own in the struggle for existence.

When the conditions of life become adverse to the existence of a species it has three alternatives, or, better, one of three things happens, namely, migration, adaptation, extinction. The migration of birds and some other animals is a systematic changing of environment when conditions are unfavorable to life. When the snow and ice come, the furseal forsakes the islands on which it breeds, and which are its real home, and spends the rest of the year in the open sea, returning at the close of winter. Some other animals migrate irregularly, removing from place to place as conditions become severe or undesirable. The Rocky Mountain locusts, which breed on the great plateau along the eastern base of the Rocky Mountains, sometimes increase so rapidly in numbers that they can not find enough food in the scanty vegetation of this region. Then great hosts of them fly high into the air until they meet an air current moving toward the southeast. The locusts are borne by this current or wind hundreds of miles, until, when they come to the great grain-growing Mississippi Valley, they descend and feed to their hearts' content, and to the dismay of the Nebraska and Kansas farmer. These great forced migrations used to occur only too often, but none has taken place since 1878 , and it is probable that none will ever occur again. With the settlement of the Rocky Mountain plateau by farmers, food is plenty at home. And the constant fight- 
ing of the locusts by the farmers, by plowing up their eggs, and crushing and burning the young hoppers, keeps down their numbers.

Another animal of interesting migratory habits is the lemming, a mouse-like animal nearly as large as a rat, which lives in the arctic regions. At intervals varying from five to twenty years the cultivated lands of Norway and Sweden, where the lemming is ordinarily unknown, are overrun by vast numbers of these little animals. They come as an army, steadily and slowly advancing, always in the same direction, and "regardless of all obstacles, swimming across streams and even lakes of several miles in breadth, and committing considerable devastation on their line of march by the quantity of food they consume. In their turn they are pursued and harassed by crowds of beasts and birds of prey, as bears, wolves, foxes, dogs, wild cats, stoats, weasels, eagles, hawks, and owls, and never spared by man; even the domestic animals not usually predaceous, as cattle, foals, and reindeer, are said to join in the destruction, stamping them to the ground with their feet and even eating their bodies. Numbers also die from disease apparently produced from overcrowding. None ever return by the course by which they came, and the onward march of the survivors never ceases until they reach the sea, into which they plunge, and swimming onward in the same direction as before perish in the waves." One of these great migrations lasts for from one to three years. But it always ends in the total destruction of the migrating army. But the migration may be of advantage to the lemmings which remain in the original breeding grounds, leaving them with enough food, so that, on the whole, the migration results in gain to the species.

But most animals can not migrate to their betterment. In that case the only alternatives are adaptation or destruction. Some individuals by the possession of slight advantageous variations of structure are able to meet the new 
demands and survive, the rest die. The survivors produce young similarly wdvantageously different from the general type, and the adaptation increases with successive generar tions.

71. Adjustment to surroundings a result of natural selection.-To such causes as these we must ascribe the nice adjustment of each species to its surroundings. If a species or a group of individuals can not adapt itself to its environment, it will be crowded out by others that can do so. The former will disappear entirely from the earth, or else will be limited to surroundings with which it comes into perfect adjustment. A partial adjustment must with time become a complete one, for the individuals not adapted will be exterminated in the struggle for life. In this regard very small variations may lead to great results. A side issue apparently of little consequence may determine the fate of a species. Any advantage, no matter how small, will turn the scale of life in favor of its possessor and his progeny. "Battle within battle," says a famous naturalist, "must be continually recurring, with varying success. Yet in the long run the forces are so nicely balanced that the face of Nature remains for a long time uniform, though assuredly the merest trifle would give the victory to one organic being over another."

72. Artificial selection.-It has been long known that the nature of a herd or race of animals can be materially altered by a conscious selection on the part of man of these individuals which are to become parents. To "weed out" a herd artificially is to improve its blood. To select for reproduction the swiftest horses, the best milk cows, the most intelligent dogs, is to raise the standard of the herd or race in each of these respects by the simple action of heredity. Artificial selection has been called the "magician's wand," by which the breeder can summon up whatever animal form he will. If the parentage is chosen to a definite end, the process of heredity will develop the form 
desired by a force as unchanging as that by which a stream turns a mill.

From the wild animals about him man has developed the domestic animals which he finds useful. The dog which man trains to care for his sheep is developed by selection from the most tractable progeny of the wolf which once devoured his flocks. By the process of artificial selection those individuals that are not useful to man or pleasing to his fancy have been destroyed, and those which contribute to his pleasure or welfare have been preserved and allowed to reproduce their kind. The various fancy breeds of pigeons-the carriers, pouters, tumblers, ruff-necks, and fan-tails-are all the descendants of the wild dove of Europe (Columba livia). These breeds or races or varieties hare been produced by artificial selection. So it is with the various breedis of cattle and of hogs and of horses and dogs.

In this artificial selection new variations are more rapidly produced than in Nature by means of intercrossing different races, and by a more rapid weeding out of unfavorable-that is, of undesirable-variations. The rapid production of variations and the careful preservation of the desirable ones and rigid destruction of undesirable ones are the means by which many races of domestic animals are produced. This is artificial selection.

73. Dependence of species on species, -There was introduced into California from Australia, on young orange trees, a few years ago, an insect pest called the cottony cushion scale (Icerya purchasi). This pest increased in numbers with extraordinary rapidity, and in four or five years threatened to destroy completely the great orange orchards of California. Artificial remedies were of little avail. Finally, an entomologist was sent to Australia to find out if this scale insect had not some special natural enemy in its native country. It was found that in Australia a certain species of lady-bird beetle attacked and fed on the cottony 
cushion scales and kept them in check. Some of these lady-birds (Vedalia cardinalis) were brought to California and released in a scale-infested orchard. The lady-birds, having plenty of food, thrived and produced many young. Soon the lady-birds were in such numbers that numbers of them could be distributed to other orchards. In two or three years the Vedalias had become so numerous and widely distributed that the cottony cushion scales began to diminish perceptibly, and soon the pest was nearly wiped out. But with the disappearance of the scales came also a disappearance of the lady-birds, and it was then discovered that the Vedalias fed only on cottony cushion scales and could not live where the scales were not. So now, in order to have a stock of Vedalias on hand in California it is necessary to keep protected some colonies of the cottony cushion scale to serve as food. Of course, with the disappearance of the predaceous lady-birds the scale began to increase again in various parts of the State, but with the sending of Vedalias to these localities the scale was again crushed. How close is the interdependence of these two species!

Similar relations can be traced in every group of animals. When the salmon cease to run in the Sacramento River in California the otter which feeds on them takes, it is said, to robbing the poultry-yards; and the bear, which also feeds on fish, strikes out for other game, taking fruit or chickens or bee-hives, whatever he may find. 


\section{CHAPTER VIII}

\section{ADAPTATIONS}

74. Origin of adaptations. - The strife for place in the crowd of animals makes it necessary for each one to adjust itself to the place it holds. As the individual becomes fitted to its condition, so must the species as a whole. The species is therefore made up of individuals that are fitted or may become fitted for the conditions of life. As the stress of existence becomes more severe, the individuals fit to continue the species are chosen more closely. This choice is the automatic work of the conditions of life, but it is none the leas effective in its operations, and in the course of centuries it becomes unerring. When conditions change, the perfection of adaptation in a species may be the cause of its extinction. If the need of a special fitness can not be met immediately, the species will disappear. For example, the native sheep of England have developed a long wool fitted to protect them in a cool, damp climate. Such sheep transferred to Cuba died in a short time, leaving no descendants. The warm fleece, so useful in England, rendered them wholly unfit for survival in the tropics. It is one advantage of man, as compared with other forms of life, that so many of his adaptations are external to his structure, and can be cast aside when necessity arises.

75. Classification of adaptations. - The various forms of adaptations may be roughly divided into five classes, as follows: $(a)$ food securing, $(b)$ self-protection, $(c)$ rivalry, $(d)$ defense of young, $(e)$ surroundings.

The few examples which are given under each class, 123 
some of them striking, some not especially so, are mostly chosen from the vertebrates and from the insects, because these two groups of animals are the groups with which beginning students of zoölogy are likely to be familiar, and the adaptations referred to are therefore most likely to be best appreciated. Quite as good and obvious examples could be selected from any other groups of animals. The student

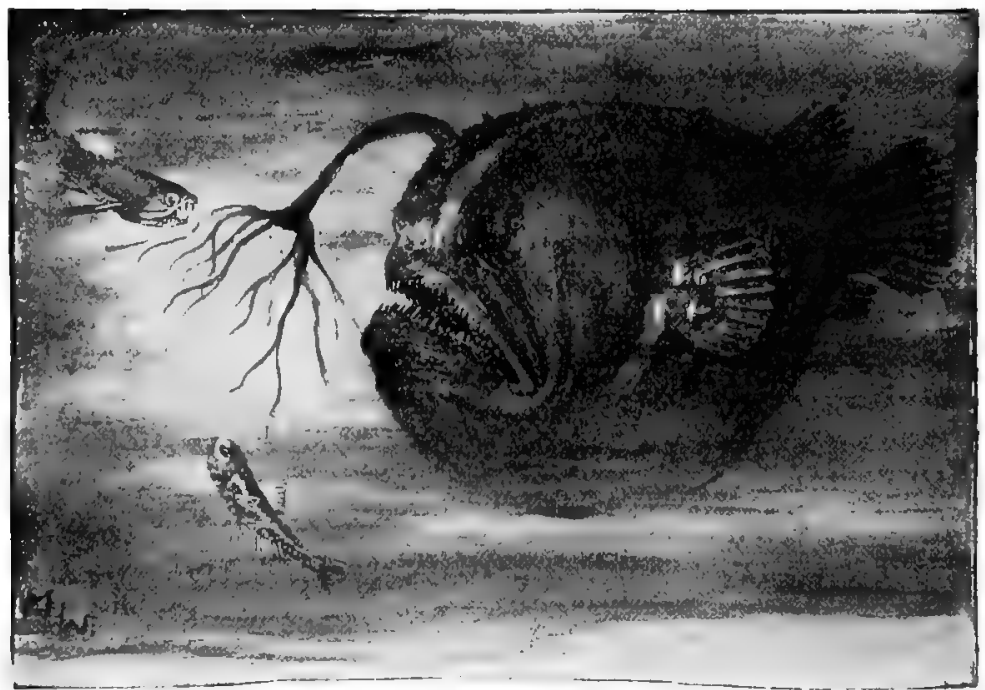

Fı, 34.-The deep-sea angler (Corynolophus reinhardti), which has a dorsal spine modified to be a Inminou "flahing rod and lure," nttrncting lantern-fishes (Echiostoma and Ethophora). An extraordinary adaptution for securing food. (The angler is drawn ufter a figure of Lotrkn's.)

will find good practice in trying to discover examples shown by the animals with which he may be familiar. That all or any part of the body structure of any animal can be called with truth an example of adaptation is plain from what we know of how the various organs of the animal body have come to exist. But by giving special attention to such adaptations as are plainly obvious, beginning stu- 
dents may be put in the way of independent observation along an extremely interesting and attractive line of zoölogical study.

76. Adaptations for securing food - For the purpose of capture of their prey, some carnivorous animals are provided with strong claws, sharp teeth, hooked beaks, and other structures familiar to us in the lion, tiger, dog, cat, owl, and eagle. Insecteating mammals have contrivances especially

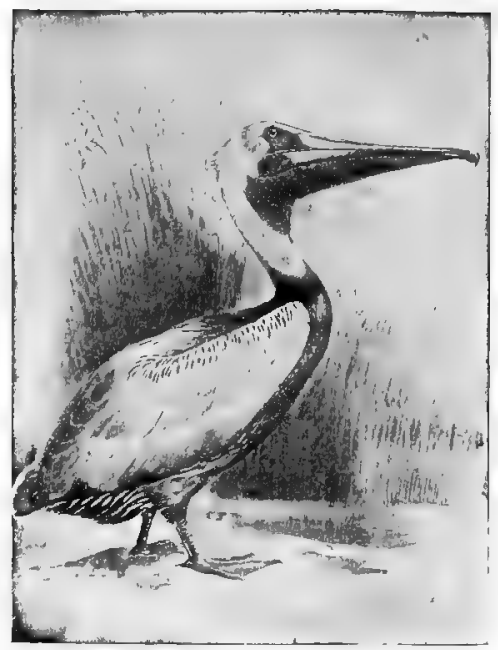

Fis. 55.-The brown pelican, showing gular sinc. which it uses in catching and holding thehes that form its food.

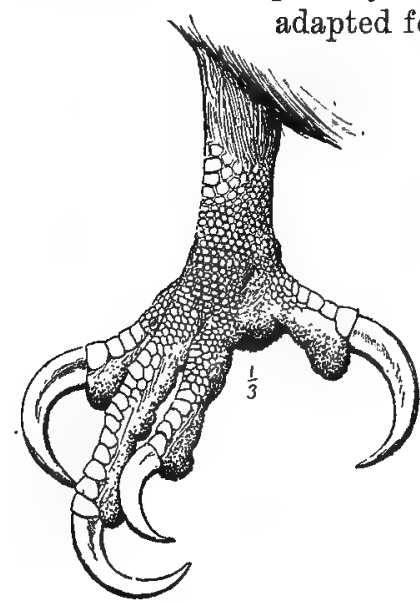

Fig. 56.-Foot of the bald eagle, showing claws for seizing its prey. (Chapman.) or the catching of insects. The ant-eater, for example, has a curious, long sticky tongue which it thrusts forth from its cylindrical snout deep into the recesses of the anthill, bringing it out with its sticky surface covered with ants. Animals which feed on nuts are fitted with strong teeth or beaks for cracking them. Similar teeth are found in those fishes which feed on crabs, snails, or sea-urchins. Those mammals like the horse and cow, that feed on plants, have usually 


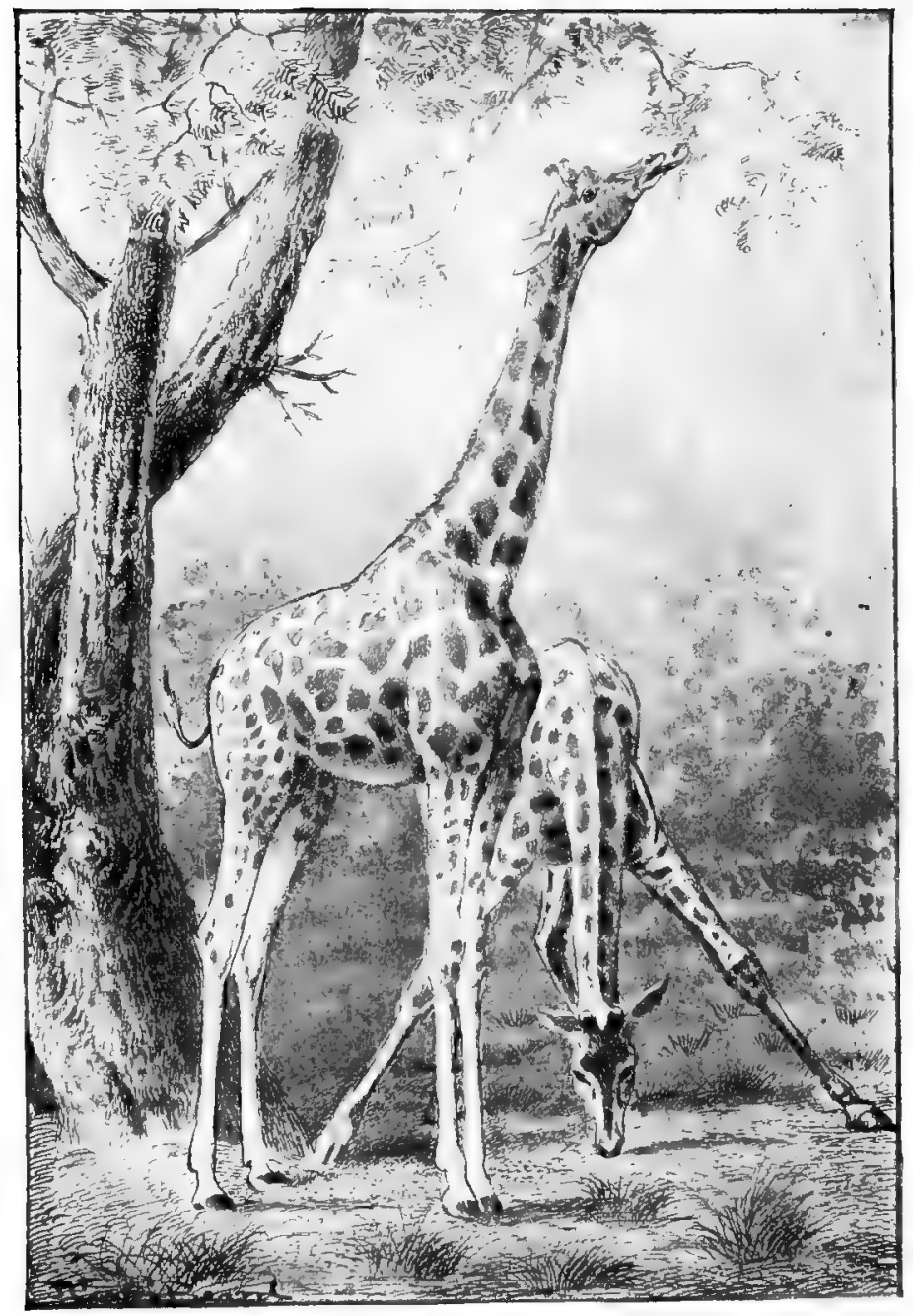

F'ca. 57.--Giralfer Peeding. 
broad chisel-like incisor teeth for cutting off the foliage, and teeth of very similar form are developed in the dif-

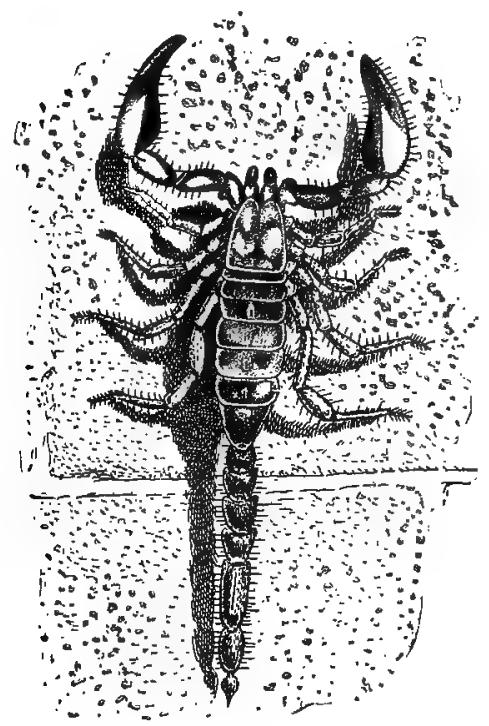

Fis. 58.-Scorpion, showing the special development of certain month parts (the maxillary palpi) as pincer-like organs for grasping prey. At the posterior tip of the body is the poisonous sting. ferent groups of planteating fishes. inolar teeth are found when it

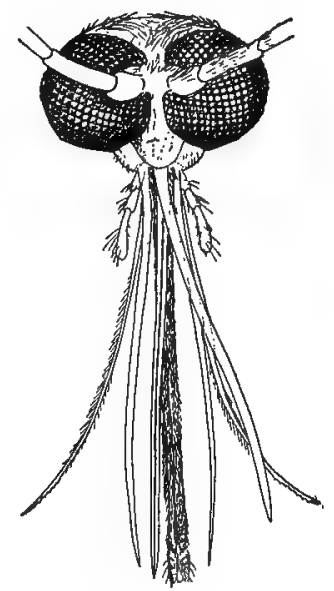

Fig. 59.-Head of mosquito (female), showing the piercing ncedle-like month parta which compose the "bill."

is necessary that the food should be crushed or chewed, and the sharp canine teeth go with a flesh diet. The long neck of the giraffe (Fig. 57) enables it to browse on the foliage of trees.

Insects like the leafbeetles and the grasshoppers, that feed on the foliage of plants, have a pair of jaws, broad but

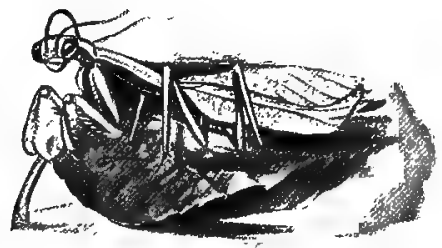

FIa. 60.-The praying-horse (Mantis) with fore legs developed as grasping orguns. 
sharply edged, for cutting off bits of leaves and stems. Those which take only liquid food, as the butterflies and sucking-bugs, have their mouth parts modified to form a slender, hollow sucking beak or proboscis, which can be

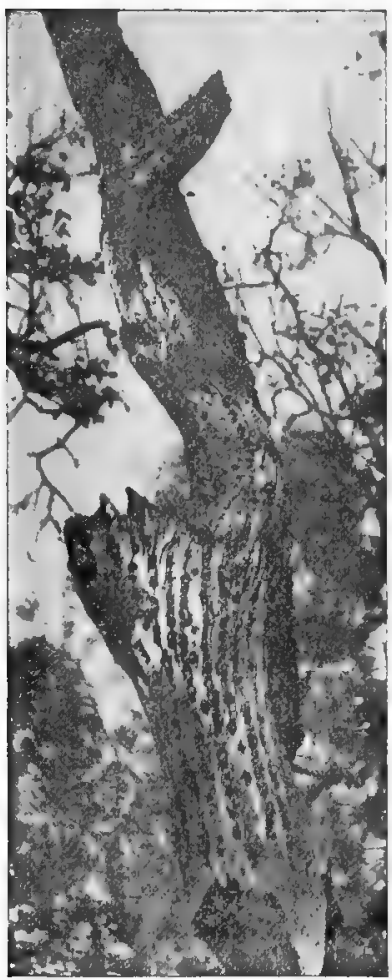

Fig, 61,-Acorns put into bark of tree by the Californian woodpecker (Melanerpes formicivorus bairdïi). -From photograph, Stanford Univereity, California. thrust into a flower nectary, or into the green tissue of plants or the flesh of animals, to suck up nectar or plant sap or blood, depending on the special food habits of the insect. The honey-bee has a very complicated equipment of mouth parts fitted for taking either solid food like pollen, or liquid food like the nectar of flowers. The mosquito has a "bill" (Fig. 59) composed of six sharp, slender needles for piercing and lacerating the flesh, and a long tubular under lip through which the blood can flow into the mouth. Some predaceous insects, as the praying-horse (Fig. 60), have their fore legs developed into formidable grasping organs for seizing and holding their prey.

77. Adaptation for self-defense.-For self-protection, carnivorous animals use the same weapons to defend themselves which serve to secure their prey; but these as well as other animals may protect themselves in other fashions. Most of the hoofed animals are provided with horns, struc- 


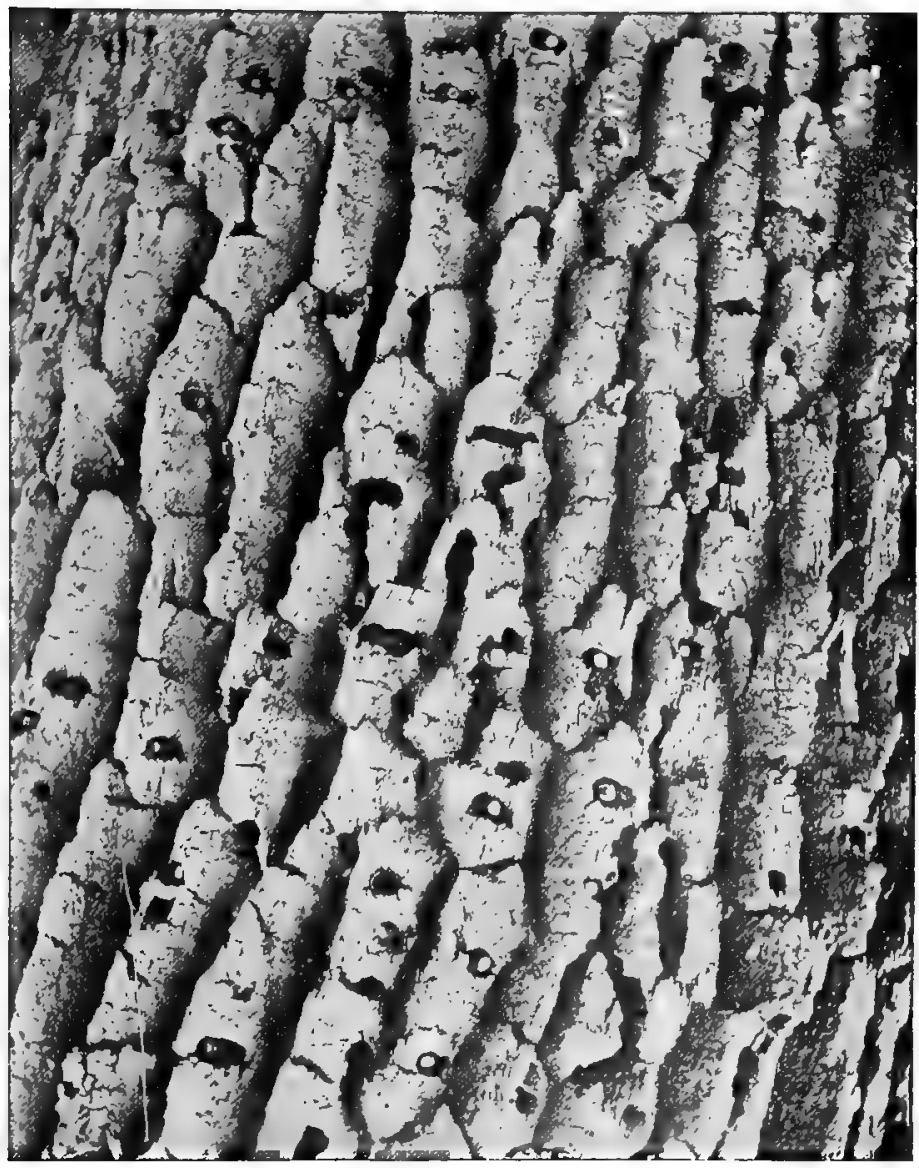

Fro. 62.-Section of bark of live oak tree with acorns placed in it by the Californian woodpecker (Melanerpes formicivorus bairdii).-From photograph, Stanford University, California.

tures useless in procuring food but often of great effectiveness as weapons of defense. To the category of structures useful for self-defense belong the many peculiarities of coloration known as "recognition marks." These are marks, 
not otherwise useful, which are supposed to enable members of any one species to recognize their own kind among the mass of animal life. To this category belongs the

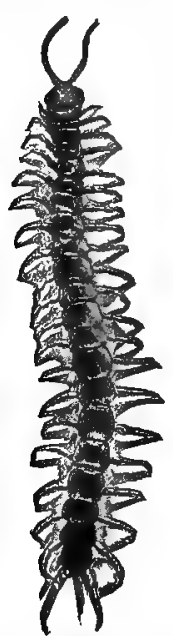

FIG. 63.-Centiped. The foremost pair of legs is modified to be a pair of scizing and stinging organs. An adaptation for self-defense and for securing food. black tip of the weasel's tail, which remains the same whatever the changes in the outer fur. Another example is seen in the white outer feathers of the tail of the meadow-lark as well as in certain sparrows and warblers. The white on the skunk's back and tail serves the same purpose and also as a warning. It is to the skunk's advan." tage not to be hidden, for to be seen in the crowd of animals is to be avoided by them. The songs of birds and the calls of various creatures serve also as recognition marks. Each species knows and heeds its own characteristic song or cry, and it is a source of mutual protection. The fur-seal pup knows its mother's call, even though ten thousand other mothers are calling on the rookery.

The ways in which animals make themselves disagreeable or dangerous to their captors are almost as varied as the animals themselves. Besides the teeth, claws, and horns of ordinary attack and defense, we find among the mammals many special structures or contrivances which serve for defense through making their possession unpleasant. The scent glands of the skunk and its relatives are noticed above. The porcupine has the bristles in its fur specialized as quills, barbed and detachable. These quills fill the mouth of an attacking fox or wolf, and serve well the purpose of defense. The hedgehog of Kurope, an animal of different nature, being related rather to the mole than to 
the squirrel, has a similar armature of quills. The armadillo of the tropics has movable shields, and when it withdraws its

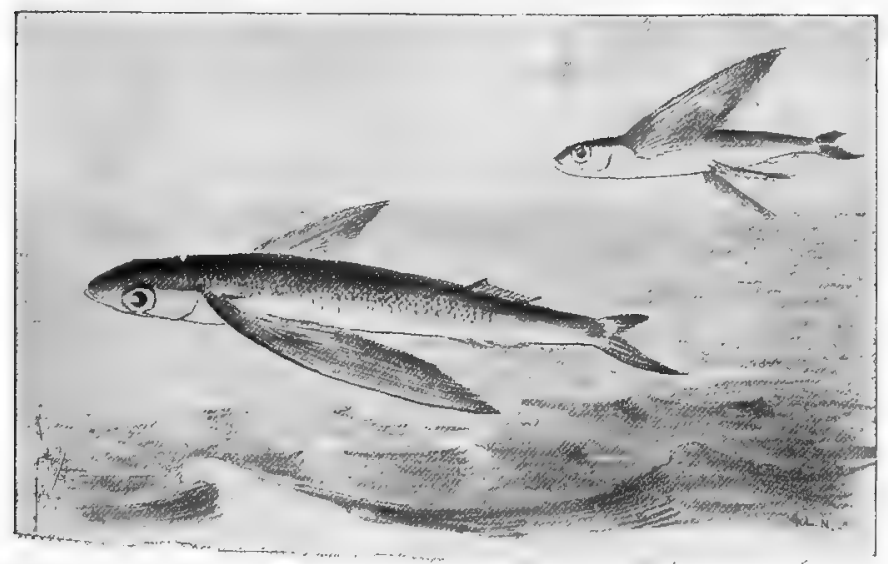

Fia. 64.-Flying fishes. (The upper one a species of Cypselurus, the lower of Exocotus.) These fishes escape from their enemies by leaping into the air and sailing or "flying" long distances.

head (which is also defended by a bony shield) it is as well protected as a turtle.

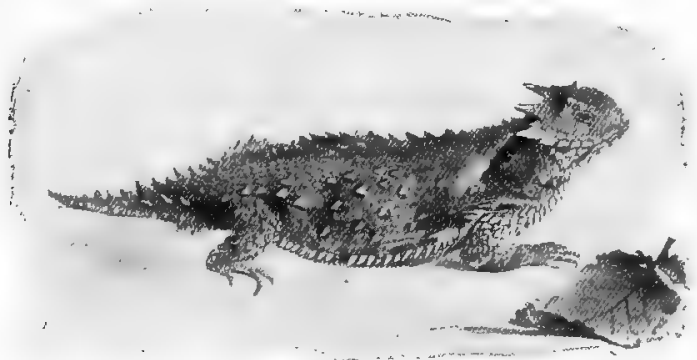

Fig. 65.-The horned toad (Phrynosoma blainvillei). The spiny covering repels many enemies.

Special organs for defense of this nature are rare among birds, but numerous among reptiles. The turtles are all 
protected by bony shields, and some of them, the box-turtles, may close their shields almost hermetically. The snakes broaden their heads, swell their necks, or show their forked tongues to frighten their enemies. Some of them

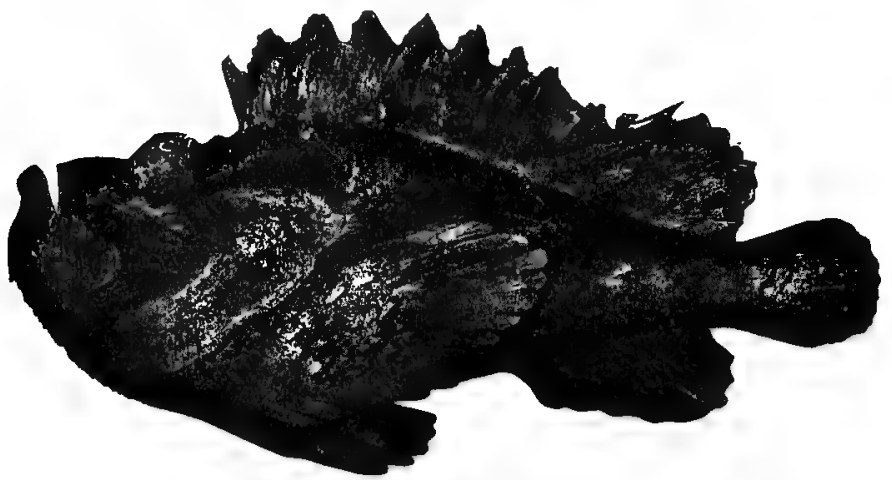

Fro. 66.-Nokee or poisonous scorpion-fish (Emmydrichthys vulcanus) with poisonous spines, from Tahiti.

are further armed with fangs connected with a venom gland, so that to most animals their bite is deadly. Besides its fangs the rattlesnake has a rattle on the tail made up of a

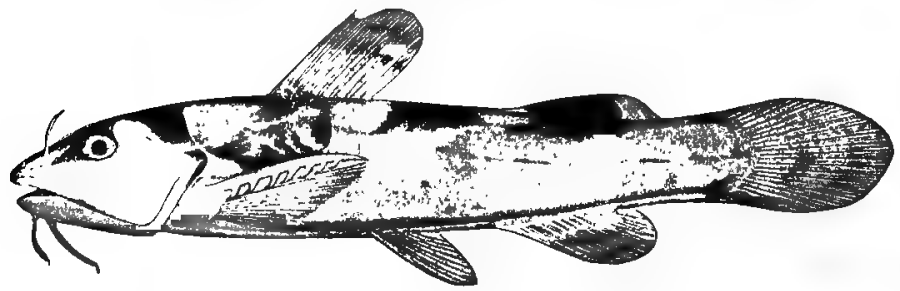

Fit. 67.-Mad tom (Schilbeodes furiosus) with poisoned pectoral spine.

succession of bony clappers, modified vertebræ, and scales, by which intruders are warned of their presence. This sharp and insistent buzz is a warning to animals of other species and a recognition signal to those of its own kind. 
Even the fishes have many modes of self-defense through giving pain or injury to those who would swallow them. The cat-fishes or horned pouts when attacked set immorably the sharp spine of the pectoral fin, inflicting a jagged wound. Pelicans who have swallowed a catfish have been known to die of the wounds inflicted by the fish's spine. In the group of scorpionfishes and toad-fishes are certain genera in which these spines are provided with poison glands. These may inflict very serere wounds to other fishes, or even to birds or man. One of this group of poison-fishes is the nokee (Emmydrichthys, Fig. 66). A group of small freshwater cat-fishes, known as the mad toms (Fig. 67), have also a poison gland attached to the pectoral spine, and its sting is most exasperating, like the sting of a wasp. The sting-rays (Fig. 68) of many species Fra. 68.-A sting.ray have a strong, jagged spine on the tail, (Urolophus goodei), covered with slime, and armed with broad from Panama. saw-like teeth. This inflicts a dangerous wound, not through the presence of specific renom, but from the danger of blood poisoning arising from the slime, and the ragged or unclean cut.

Many fishes are defended by a coat of mail or a coat of sharp thorns. The globe-fishes and porcupine-fishes (Fig: 69) are for the most part defended by spines, but their instinct to swallow air gives them an additional safeguard. When one of these fishes is disturbed it rises to the surface, 
gulps air until its eapacious stomach is filled, and then floats belly upward on the surface. It is thus protected from other fishes, though easily taken by man. The torpedo, electric eel, electric cat-fish, and star-gazer, surprise and

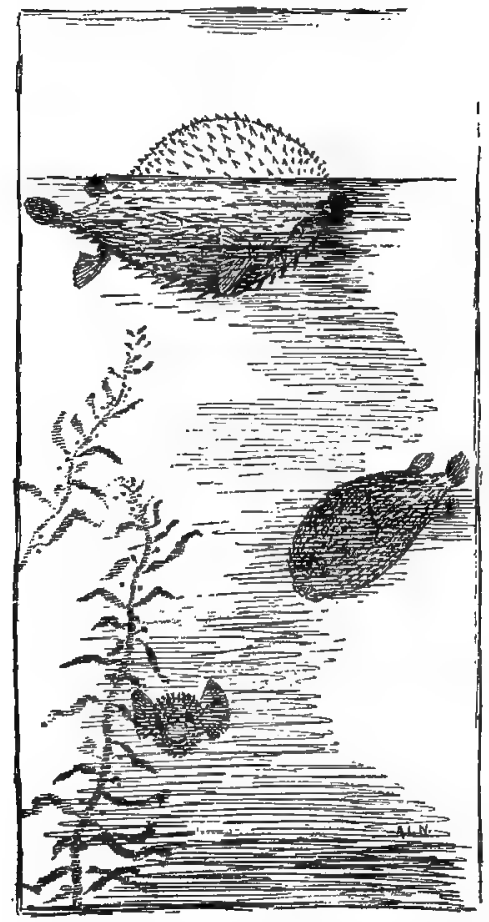

Fra. 69.-Porcupine-fish (Diodon hystrix), the lower ones swimming normally, the upper one floating belly upward, with inflated otomach.-Drawn from apecimens from the Floride Keys. stagger their captors by means of electric shocks. In the torpedo or electric ray (Fig. 70 ), found on the sandy shores of all warm seas, on either side of the head is a large honeycomb-like structure which yields a strong electric shock whenever the live fish is touched. This shock is felt severely if the fish be stabbed with a knife or metallic spear. The electric eel of the rivers of Paraguay and southern Brazil is said to give severe shocks to herds of wild horses driven through the streams, and similar accounts are given of the electric cat-fish of the Nile.

Among the insects, the possession of stings is not uncommon. The wasps and bees are familiar examples of stinging insects, but many other kinds, less familiar, are similarly protected. All insects have their bodies covered with a coat of armor, composed of a horny substance called chitin. In some cases this chitin- 
ous coat is very thick and serves to protect them effectually. This is especially true of the beetles. Some insects are inedible (as mentioned in Chapter XII), and are conspicuously colored so as to be readily recognized by insectivorous birds. The birds, knowing by experience that these insects are ill-tasting, avoid them. Others are effectively concealed from their enemies by their close resemblance in color and marking to their surroundings. These protective resemblances are discussed in Chapter XII.

78. Adaptation for rivalry. -In questions of attack and defense, the need of meeting animals of their own kind as well as animals of other races must be considered. In struggles of species with those of their own kind, the term rivalry may be applied. Actual warfare is confined mainly to males in the breeding season and to polygamous animals. Among those in which the male mates with many females, he must struggle with other males for their possession. In all the groups of vertebrates the scxes are about equal in numbers. Where mating exists, either for the season or for

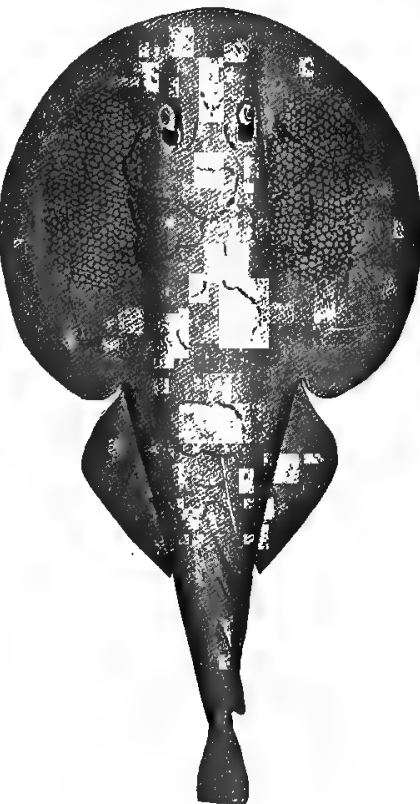

Fra. 70.-Torpedo or electric ray ( $\mathrm{Nar}$ cine brasiliensis), showing electric cells. life, this condition does not involve serious struggle or destructive rivalry.

Among monogamous birds, or those which pair, the male courts the female of his choice by song and by display 


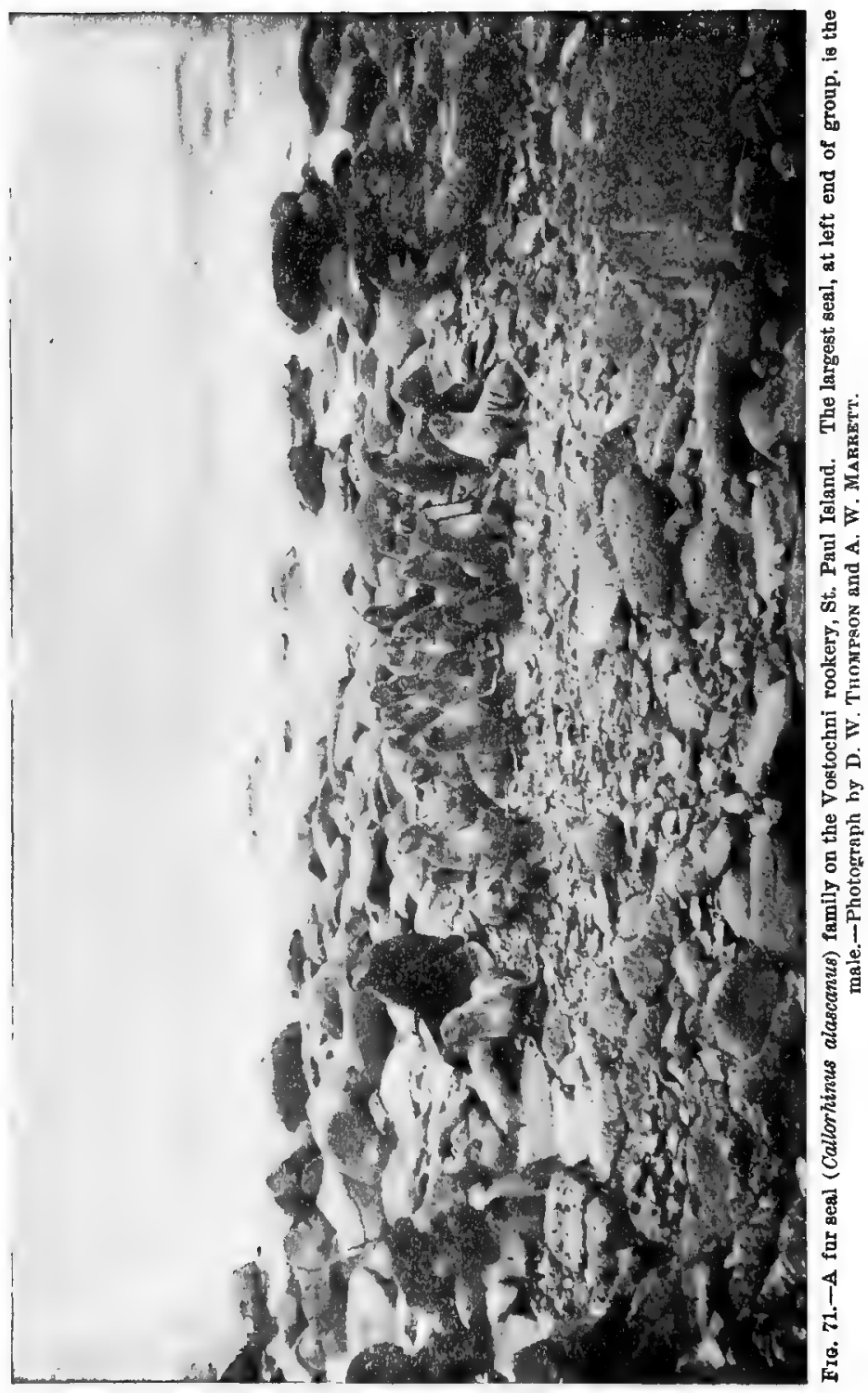


of his bright feathers. The female consents to be chosen by the one which pleases her. It is believed that the handsomest, most viracious, and most musical males are the ones most successful in such courtship. With polygamous animals there is intense rivalry among the males in the mating season, which in almost all species is in the spring. The strongest males survive and reproduce their strength. The most notable adaptation is seen in the superior size of teeth, horns, mane, or spurs. Among the polygamous fur seals (Fig. " r1) and sea lions the male is about four times

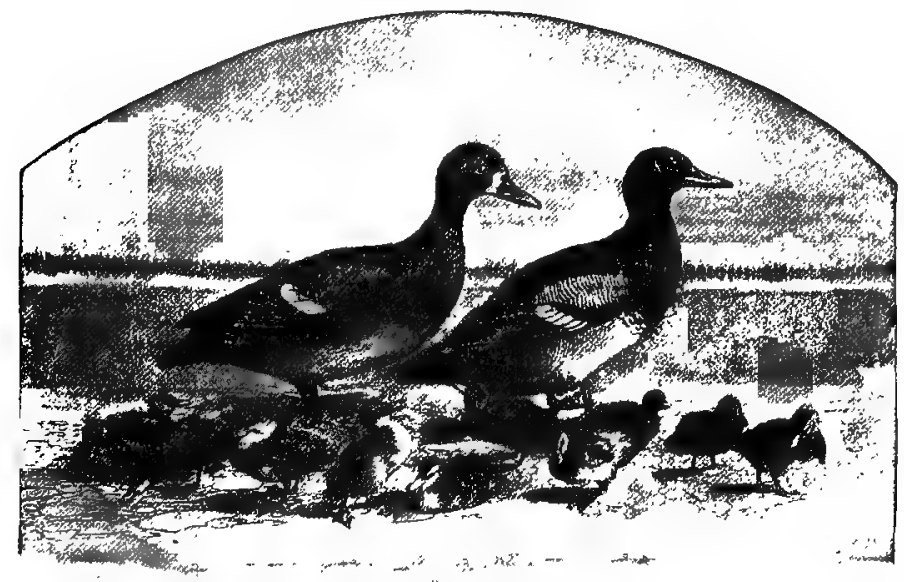

Fra. 72,-A wild duck (Aythya) family. Male, female, and præcocial young.

the size of the female. In the polygamous family of deer, buffalo, and the domestic cattle and sheep, the male is larger and more powerfully armed than the female. In the polygamous group to which the hen, turkey, and peacock belong the males possess the display of plumage, and the structures adapted for fighting, with the will to use them.

79. Adaptations for the defense of the young.-The protection of the young is the source of many adaptive structures as well as of the instincts by which such structures are 
ntilized. In general, those animals are highest in derelopment, with best means of holding their own in the struggle

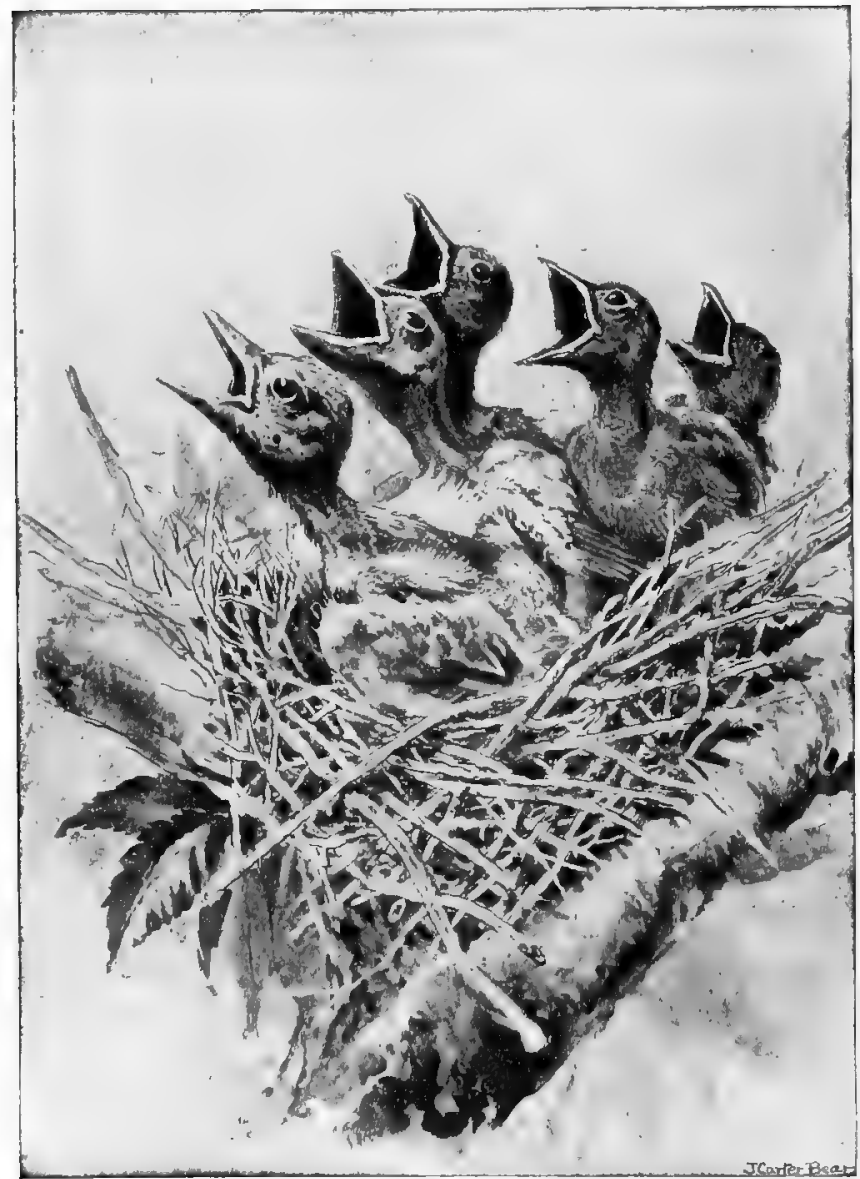

E16. 73.-The altricial nestlinge of the Blue jay (Cyanocitla cristula).

for life, that take best care of their young. The homes of animals are elsewhere specially discussed (see Chapter 
$X V)$, but those instincts which lead to home-building may all be regarded as useful adaptations in preserving the young. Among the lower or more coarsely organized

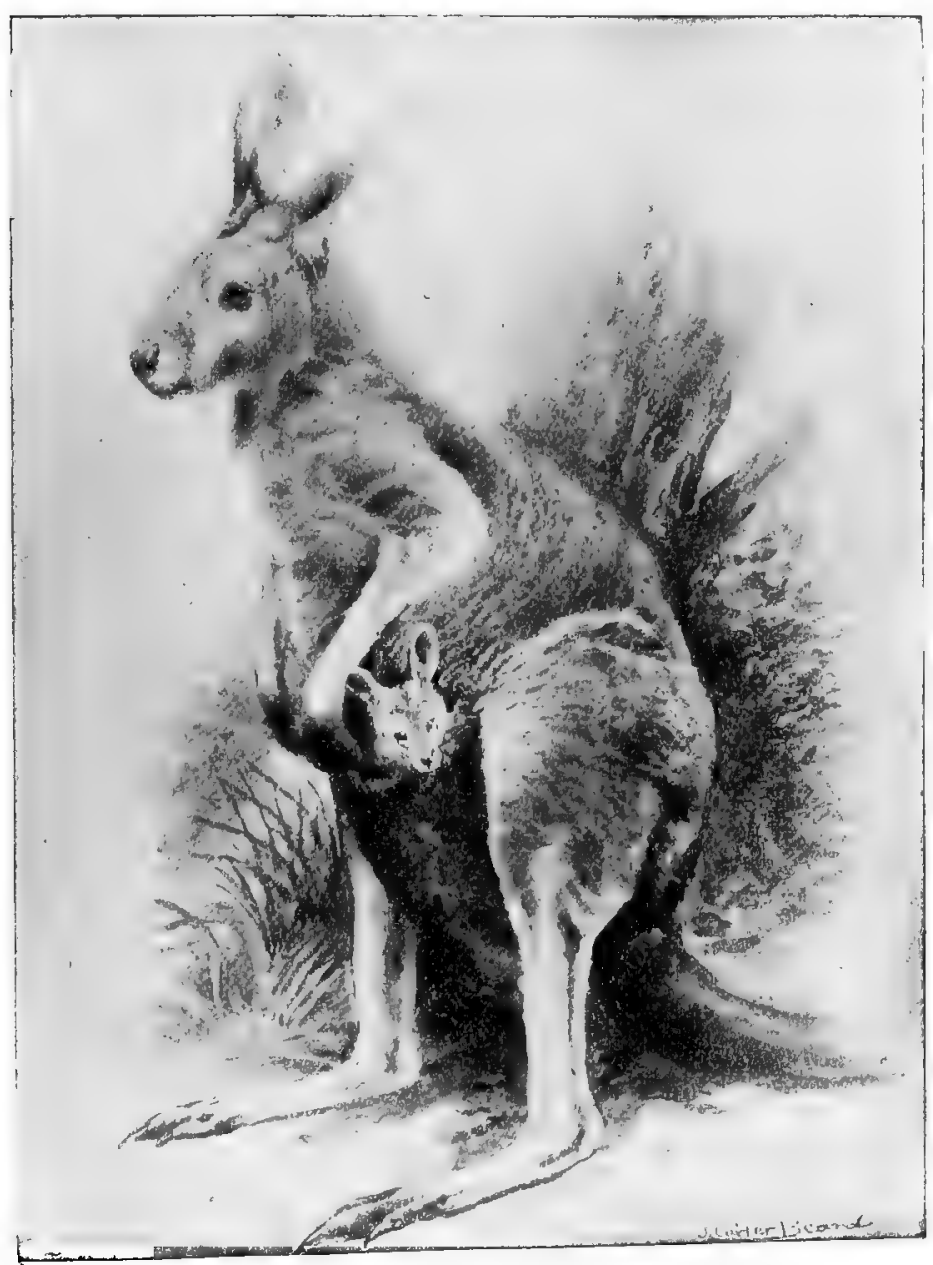

Fiu. 74.-Kangaroo (Macropus mufus) with young in pouch. 
birds, such as the chicken, the duck, and the auk, as with the reptiles, the young animal is hatched with well-developed muscular system and sense

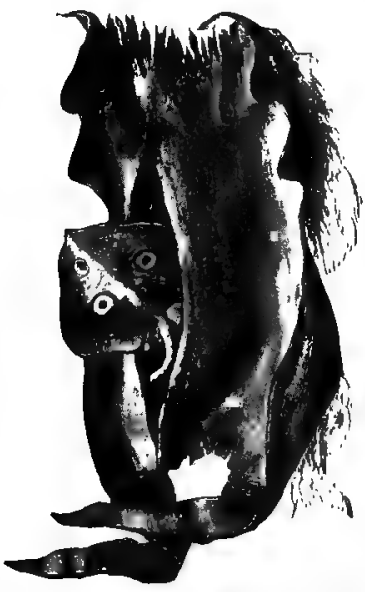

Fig. 75.-Egg-case of Califorviu barn-door skate (Raja binoculata) cut open to show young inside. (Young issues naturally at one end of the case.) organs, and is capable of running about, and, to some extent, of feeding itself. Birds of this type are known as prococial (Fig. 72 ), while the name altricial (Fig. 73 ) is applied to the more highly organized forms, such as the thrushes, doves, and song-birds generally. With these the young are hatched in a wholly helpless condition, with ineffective muscles, deficient senses, and dependent wholly upon the parent. The altricial condition demands the building of a nest, the establishment of a home, and the continued care of one or both of the parents.

The very lowest mammals known, the duck-bills (Monotremes) of Australia, lay large eggs in a strong shell like those of a turtle, and guard them with great jealousy. But with almost all mammals the egg is very small and without much food-yolk. The egg begins its development within the body. It is nourished by the blood of the mother, and after birth the young is cherished by her, and fed by milk secreted by specialized glands of the skin. All these features are adaptations tending toward the preservation of the young. In the

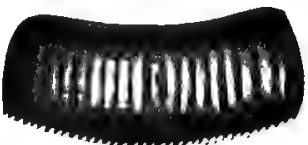

Frg. 76.-Egg-case of the cockroach.

division of mammals next lowest to the Monotremes-the kangaroo, opossum, etc.- the young are born in a very immature state and are at once seized by the mother and 
thrust into a pouch or fold of skin along the abdomen, where they are kept until they are able to take care of themselves (Fig. 74). This is an interesting and ingenious adaptation, but less specialized and less perfect an adaptation than the conditions found in ordinary mammals.

Among the insects, the special provisions for the protection and care of the eggs and the young are wide-spread and various. Some of those adaptations which take the special form of nests or "homes" will be described in a later chapter (see Chapter XV). The eggs of the common cockroach are laid in small packets inclosed in a firm wall

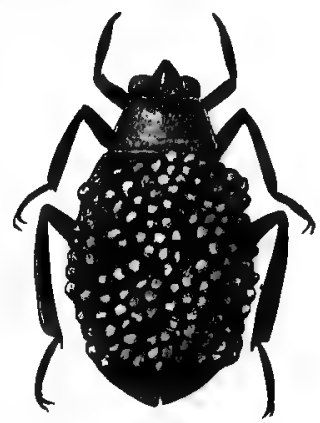

Fig. 77,-Giant water.bug \{Serphus). Mule carrying egys on its back.

(Fig. 16). The eggs of the great water-bugs are carried on the back of the male (Fig. (7) $^{4}$ ) and the spiders lay their eggs in a silken sac or cocoon, and some of the ground or

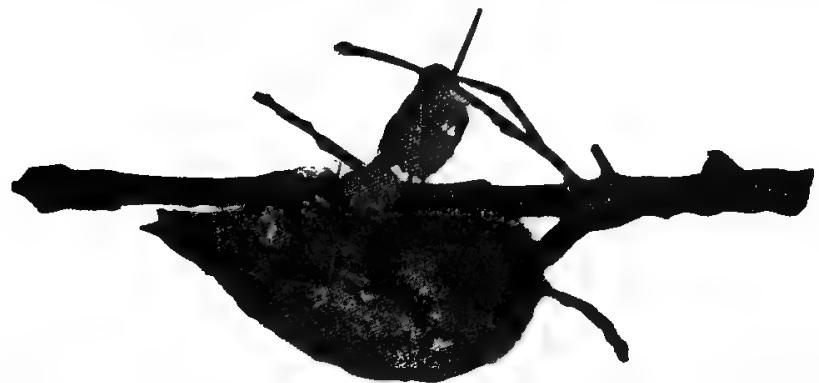

Fig. 78.-Cocoon inclosing the pupa of the great Ceanothus moth. Spun of silk by the larva before pupation.

running spiders (Lycosida) drag this egg-sac, attached to the tip of the abdomen, about with them. The young spiders when hatched live for some days inside this sac, feeding on each other! Many insects have long, sharp, 
piercing ovipositors, by means of which the eggs are deposited in the ground or in the leaves or stems of green plants, or even in the hard wood of tree-trunks. Some of

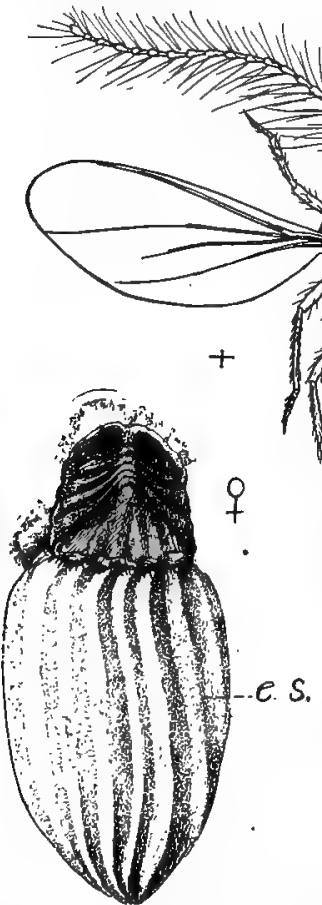

Fig. 79,-The cottony cushion scale insect (Icerya purchasi), from California. The male is winged, the female wingless and with a large waxen egg-sac (e.s.) attached to her body. (The lines at the left of each figure indicate the size of the insects.)

gnaws its way out. Such insect galls are especially abundant on oak trees (Fig. 80). The care of the eggs and the young of the social insects, as the bees and ants, are described in Chapter IX, and nearly covering the body in which eggs are deposited (Fig. 79). The various gall insects lay their eggs in the soft tissue of plants, and on the hatching of the larvæ an abnormal growth of the plant occurs about the young insect, forming an inclosing gall that serves not only to protect the insect within, but to furnish it with an abundance of plant-sap, its food. The young insect remains in the gall until it completes its development and growth, when it the scale insects se-
crete wax from their bodies and form a large, often beautiful egg-case, attached to e. 
80. Adaptations concerned with surroundings in life.-A large part of the life of the animal is a struggle with the environment itself; in this struggle only those that are adapted live and leave descendants fitted like themselves. The fur of mammals fits them to their surroundings. As the fur differs, so may the habits change. Some animals are active in winter; others, as the bear, hibernate, sleeping in caves or hollow trees or in burrows until conditions are favorable for their activity. Most snakes and lizards hibernate in cold weather. In the swamps of Louisiana,

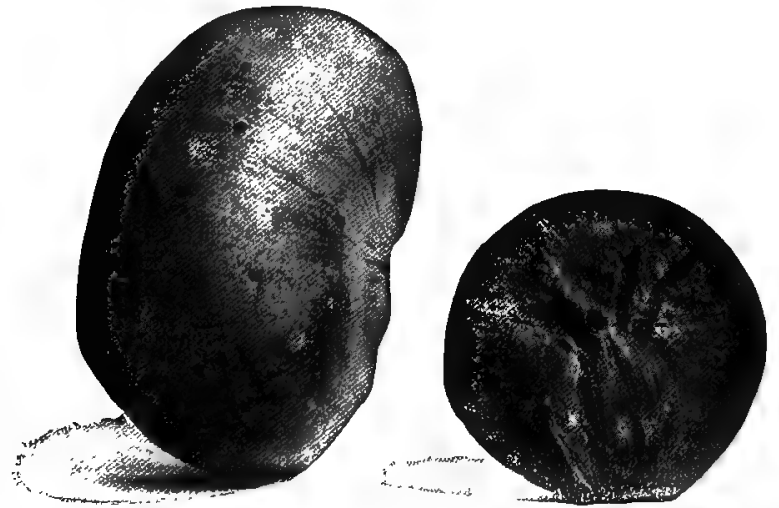

Fra. 80.-The giant gall of the white oak (California), made by the gall insect Andricus califorricus. The gall at the right cut open to show tunnels made by the insects in escaping from the gall.-From photograph.

in winter, the bottom may often be seen covered with water snakes lying as inert as dead twigs. Usually, however, hibernation is accompanied by concealment. Some animals in hibernation may be frozen alive without apparent injury. The blackfish of the Alaska swamps, fed to dogs when frozen solid, has been known to revive in the heat of the dog's stomach and to wriggle out and escape. As animals resist heat and cold by adaptations of structure or habits, so may they resist dryness. Certain fishes hold reservoirs 
of water above their gills, by means of which they can breathe during short excursions from the water. Still others (mud-fishes) retain the primitive lung-like structure of the swim-bladder, and are able to breathe air when, in the dry season, the water of the pools is reduced to mud.

Another series of adaptations is concerned with the places chosen by animals for their homes. The fishes that

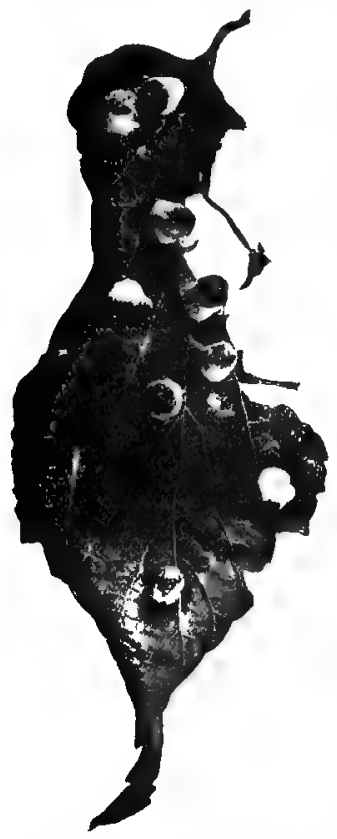

- FIa. 81.-Insert galls on lear.

live in water have special organs for breathing under water (Fig. 82). Many of the South American monkeys have the tip of the tail adapted for clinging to limbs of trees or to the bodies of other monkeys of its own kind. The hooked claws of the bat hold on to rocks, the bricks of chimneys, or to the surface of hollow trees where the bat sleeps through the day. The tree-frogs (Fig. 83) or tree-toads have the tips of the toes swollen, forming little pads by which they cling to the bark of trees.

Among other adaptations relating to special surroundings or conditions of life are the great cheek pouches of the pocket gophers, which carry off the soil dug up by the large shovel-like feet when the gopher excavates its burrow.

Those insects which live underground, making burrows or tunnels in the soil, have their legs or other parts adapted for digging and burrowing. 'The mole cricket (Fig. 84) has its legs stout and short, with broad, shovel-like feet. Some water-beetles (Fig. 85) and water-bugs have one or more of the pairs of legs flattened and broad to serve as oars or pad. dles for swimming. The grasshoppers or locusts, who leap, 
have their hind legs greatly enlarged and elongated, and provided with strong muscles, so as to make of them "leaping legs." The grubs

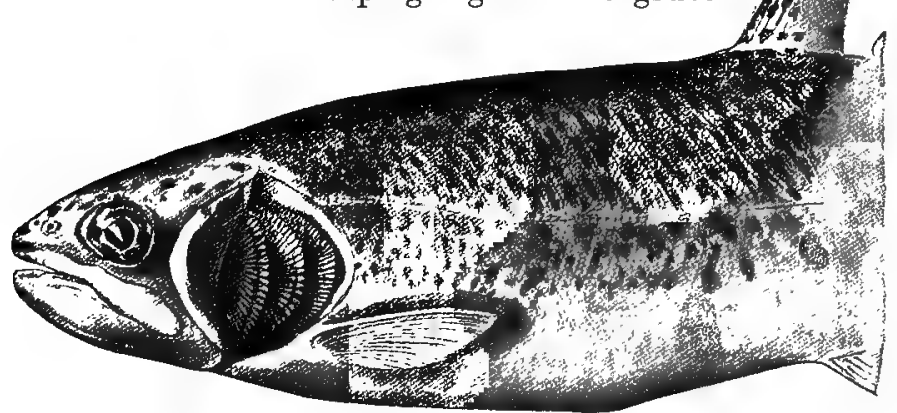

FiG. 82.-Head of rainbow trout (Salmo irideus) with gill cover bent back to show gills, the breathing organs.

or larvæ of beetles which live as "borers" in tree-trunks have mere rudiments of legs, or none at all (Fig. 86). They have great, strong, biting jaws for cutting away the hard wood. They move simply by wriggling along in their burrows or tunnels.

Insects that live in water either come up to the surface to breathe or take down air underneath their wings, or in some other way, or have gills for breathing the air which is mixed with the water. These gills are special adap-

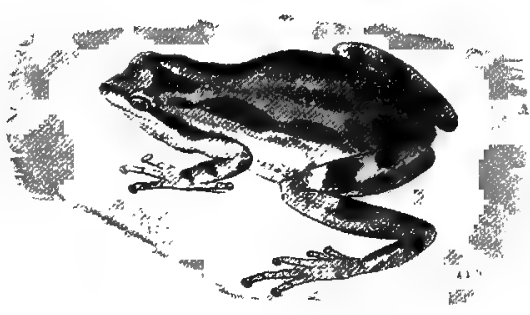

FIG. 83.-T'ree-toad ( Hyla regilla). tive structures which present a great variety of form and appearance. In the young of the May-flies they are delicate plate-like flaps projecting from the sides of the body. They are kept in constant motion, gently waving back and 
forth in the water so as to maintain currents to bring fresh water in contact with them. Young mosquitoes (Fig. 87)

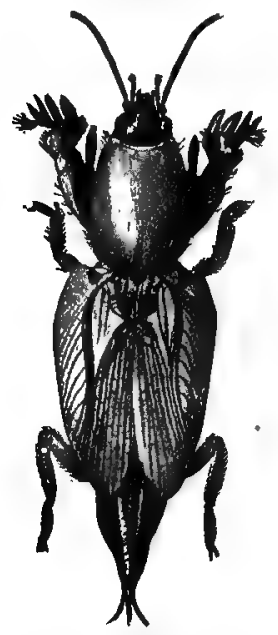

Fig. 84.-The mole cricket (Gryllotalpa), with fore feet modified for digging. do not have gills, but come up to the surface to breathe. The larvæ, or wrigglers, breathe through a special

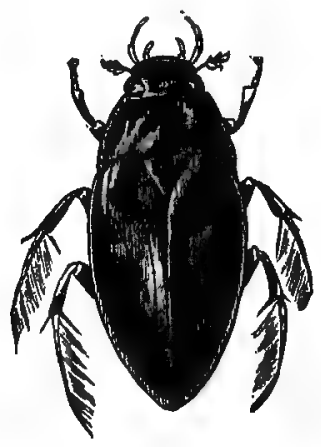

FrG. 85.-A water-beetle (Hydrophilus).

tube at the posterior tip of the body, while the pupæ have a pair of horn-like tubes on the back of the head end of the body.

81. Degree of structural change in adaptations.-While among the higher or vertebrate animals, especially the fishes and reptiles, most remarkable cases of adaptations occur, yet the structural changes are for the most part external, never seriously affecting the development of the internal organs other than the skeleton. The organization of these higher animals is much less plastic than among the invertebrates. In

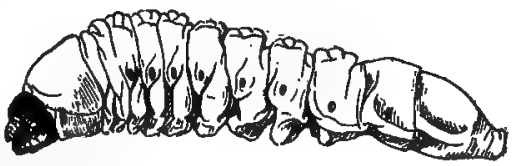

FIG. 86.-Wood-boring beetle larva (Prionus). general, the higher the type the more persistent and unchangeable are those structures not immediately exposed 
to the influence of the struggle for existence. It is thus the outside of an animal that tells where its ancestors have lived. The inside, suffering little change, whatever the surroundings, tells the real nature of the animal.

82. Vestigial organs.-In general, all the peculiarities of animal structure find their explanation in some need of adaptation. When this need ceases, the structure itself tends to disappear or else to serve some other need. In the bodies of most animals there are certain incomplete or rudimentary organs or structures which serve no distinct useful purpose. They are structures which, in the ancestors of the animals now possessing them, were fully developed functional organs, but which, because of a change in habits or conditions of living, are of no further need, and are gradually dying out. Such organs are called vestigial organs. Examples are the disused ear muscles of man, the vermiform appendix in

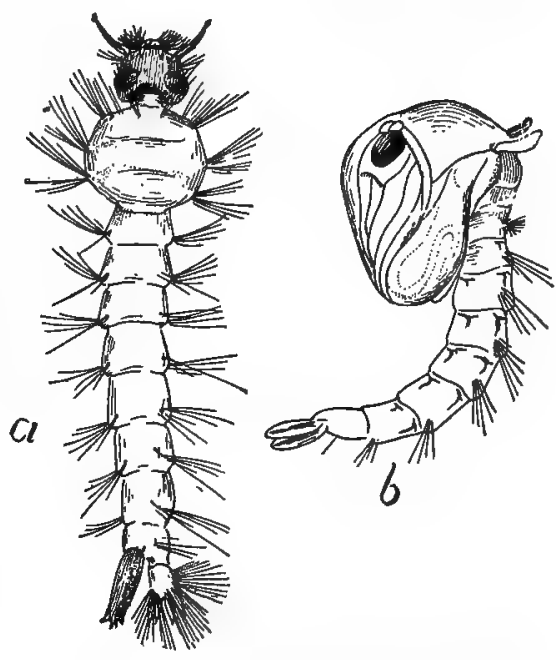

Fre. 87.- Young stages of the mosquito. $a$, larva (wriggler) ; $b$, pupa. man, which is the reduced and now useless anterior end of the large intestine. In the lower animals, the thumb or degenerate first finger of the bird with its two or three little quills serves as an example. So also the reduced and elevated hind toe of certain birds, the splint bones or rudimentary side toes of the horse, the rudimentary eyes of blind fishes, the minute barbel or beard of the horned dace or chub, and the rudimentary teeth of the right whales and sword-fish. 
Fach of thesc restigial organs tells a story of some past adaptation to conditions, one that is no longer needed in the life of the species. They have the same place in the study of animals that silent letters have in the study of words. For example, in our word knight the $k$ and $g h$ are no longer sounded; but our ancestors used them both, as the Germans do to-day in their cognate word Knecht. So with the French word temps, which means time, in which both $p$ and $s$ are silent. The Romans, from whom the French took this word, needed all its letters, for they spelled and pronounced it tempus. In general, every silent letter in every word was once sounded. In like manner, every vestigial structure was once in use and helpful or necessary to the life of the animal which possessed it.

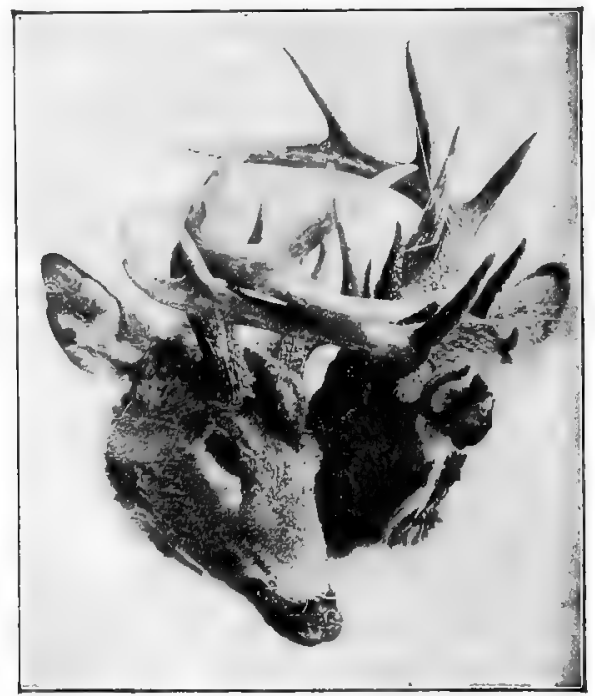

Jorns of two male deer interlocked while fighting. Permission of $\mathrm{G}$ O. SuresDs, publisher of Recrentiun. 
CHAPTER IX

ANIMAL COMIMUNITIES AND SOCIAL LIFE

83. Man not the only social animal_-Man is commonly called the social animal, but he is not the only one to which this term may be applied. There are many others which possess a social or communal life. A moment's thought brings to mind the familiar. facts of the communal life of the honey-bee and of the ants. And there are many other kinds of animals, not so well known to us, that live in communities or colonies, and live a life which in greater or less degree is communal or social. In this connection we may use the term communal for the life of those animals in which the division of labor is such that the individual is dependent for its continual existence on the community as a whole. The term social life would refer to a lower degree of mutual aid and mutual dependence.

84. The honey-bee.-Honey-bees live together, as we know, in large communities. We are accustomed to think of honey-bees as the inhabitants of bee-hives, but there were bees before there were hives. The ", bee-tree" is familiar to many of us. The bees, in Nature, make tieir home in the hollow of some dead or decaying tree-trunk, and carry on there all the industries which characterize the busy communities in the hives. A honey-bee community comprises three kinds of individuals (Fig. 88)namely, a fertile female or queen, numerous males or drones, and many infertile females or workers. These three kinds of individuals differ in external appearance sufficiently to be readily recognizable. The workers are 
smaller than the queens and drones, and the last two differ in the shape of the abdomen, or hind body, the abdomen of the queen being longer and more slender than that of the
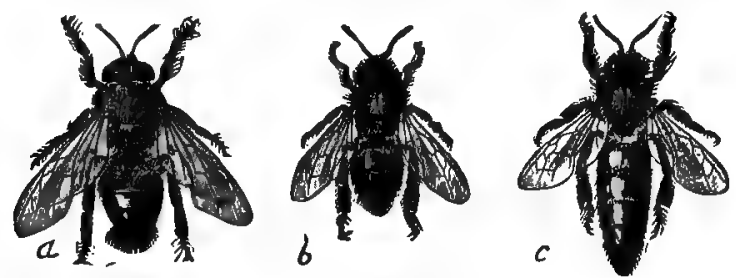

Fia. 88.-Honey-bee, $a$, drone or male; $b$, worker or infertile female; $c$, queen or fertile female.

male or drone. In a single community there is one queen, a few hundred drones, and ten to thirty thousand workers. The number of drones and workers varies at different times of the year, being smallest in winter. Each kind of individual has certain work or business to do for the whole community. The queen lays all the eggs from which new bees are born; that is, she is the mother of the entire community. The drones or males have simply to act as royal consorts; upon them depends the fertilization of the eggs. The workers undertake all the food-getting, the care of the young bees, the comb-building, the honey-making-all the industries with which we are more or less familiar that are carried on in the hive. And all the work done by the workers is strictly work for the whole community; in no case does the worker bee work for itself alone; it works for itself only in so far as it is a member of the community.

How varied and elaborately perfected these industries are may be perceived from a brief account of the life history of a bee community. The interior of the hollow in the bee-tree or of the hive is filled with "comb" - that is, with wax molded into hexagonal cells and supports for these cells. The molding of these thousands of symmet- 
rical cells is accomplished by the workers by means of their specially modified trowel-like mandibles or jaws. The wax itself, of which the cells are made, comes from the bodies of the workers in the form of small liquid drops which exude from the skin on the under side of the abdomen or hinder body rings. These droplets run together, harden and become flattened, and are removed from the wax plates, as the peculiarly modified parts of the skin which produce the wax are called, by means of the hind legs, which are furnished with scissor-like contrivances for cutting off the wax (Fig. 89). In certain of the cells are stored the pollen and honey, which serve as food for the community. The pollen is gathered by the workers from certain favorite flowers and is carried by them from the flowers to the hive in the "pollen baskets," the slightly soncave outer surfaces of one of the segments of the broadened and flattened hind legs. This concave surface is lined on each margin with a row of incurved stiff hairs which hold the pollen mass securely in place (Fig. 89). The "honey" is the nectar of flowers which has been sucked up by the workers by means of their elaborate lapping and sucking mouth parts and swallowed into a sort of honey-sac or stomach, then brought to the hive and regurgitated into the

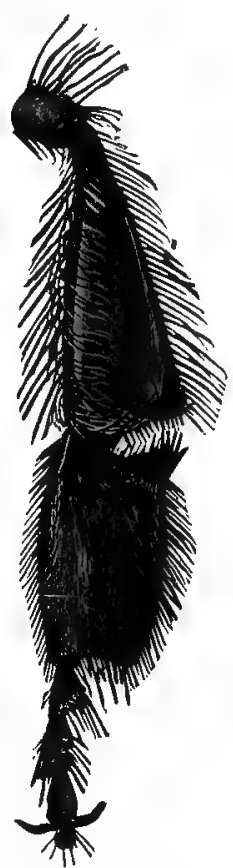

Fig. 89.-Posterior leg of worker honey-bee. The concave aurface of the upper large joint with the marginal hairs is the pollen basket; the wax shears are the cutting surfaces of the angle between the two large segments of the leg.

cells. This nectar is at first too watery to be good honey, so the bees have to evaporate some of this water. Many of the workers gather above the cells containing 
nectar, and buzz-that is, vibrate their wings violently. This creates currents of air which pass over the exposed nectar and increase the evaporation of the water. The violent buzzing raises the temperature of the bees' bodies, and this warmth given off to the air also helps make evaporation more rapid. In addition to bringing in food the workers also bring in, when necessary, "propolis," or the resinous gum of certain trees, which they use in repairing the hive, as closing up cracks and crevices in it.

In many of the cells there will be found, not pollen or honey, but the eggs or the young bees in larval or pupal

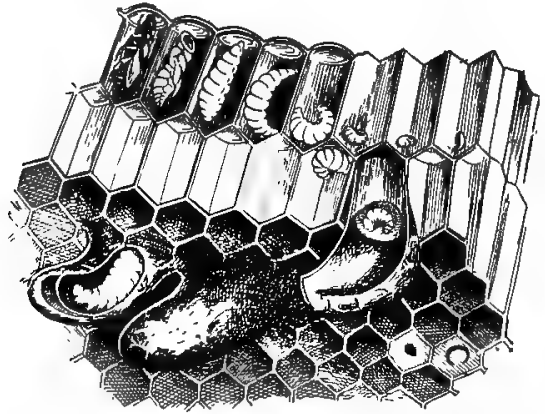

Fí. 90.-Cells containing eggs, larvæ, and pupre of the honey-bee. The lower large, irregular cells are queen cells.-After BFNTON. condition (Fig. 90). The queen moves about through the hive, laying eggs. She deposits only one egg in a cell. In three days the egg hatches, and the young bee appears as a helpless, soft, white, footless grub or larva. It is cared for by certain of the workers, that may be called nurses. These nurses do not differ structurally from the other workers, but they have the special duty of caring for the helpless young bees. They do not go out for pollen or honey, but stay in the hive. They are usually the new bees-i. e., the youngest or most recently added workers. After they act as nurses for a week or so they take their places with the food-gathering workers, and other new bees act as nurses. The nurses feed the young or larval bees at first with a highly nutritious food called bee-jelly, which the nurses malie in their stomach, and regurgitate for the larvæ. After the larvæ are two or three days old 
they are fed with pollen and honey. Finally, a small mass of food is put into the cell, and the cell is "capped" or covered with wax. The larva, after eating all the food, in two or three days more changes into. a pupa, which lies quiescent without eating for thirteen days, when it changes into a full-grown bee. The new bee breaks open the cap of the cell with its jaws, and comes out into the hive, ready to take up its share of the work for the community. In a few cases, however, the life history is different. The nurses will tear down several cells around some single one, and enlarge this inner one into a great irregular vase-shaped cell. When the egg hatches, the grub or larva is fed beejelly as long as it remains a larva, never being given ordinary pollen and honey at all. This larva finally pupates, and there issues from the pupa not a worker or drone bee, but a new queen. The egg from which the queen is produced is the same as the other eggs, but the worker nurses by feeding the larva only the highly nutritious bee-jelly make it certain that the new bee shall become a queen instead of a worker. It is also to be noted that the male bees or drones are hatched from eggs that are not fertilized, the queen having it in her power to lay either fertilized or unfertilized eggs. From the fertilized eggs hatch larvæ which develop into queens or workers, depending on the manner of their nourishment; from the unfertilized egge hatch the males.

When several queens appear there is much excitement in the community. Each community has normally a single one, so that when additional queens appear some rearrangement is necessary. This rearrangement comes about first by fighting among the queens until only one of the new queens is left alive. Then the old or mother queen issues from the hive or tree followed by many of the workers. She and her followers fiy away together, finally alighting on some tree branch and massing there in a dense swarm. This is the familiar phenomenon of "swarming." The 
swarm finally finds a new hollow tree, or in the case or the hive-bee (Fig. 91) the swarm is put into a new hive, where the bees build cells, gather food, produce young, and thus

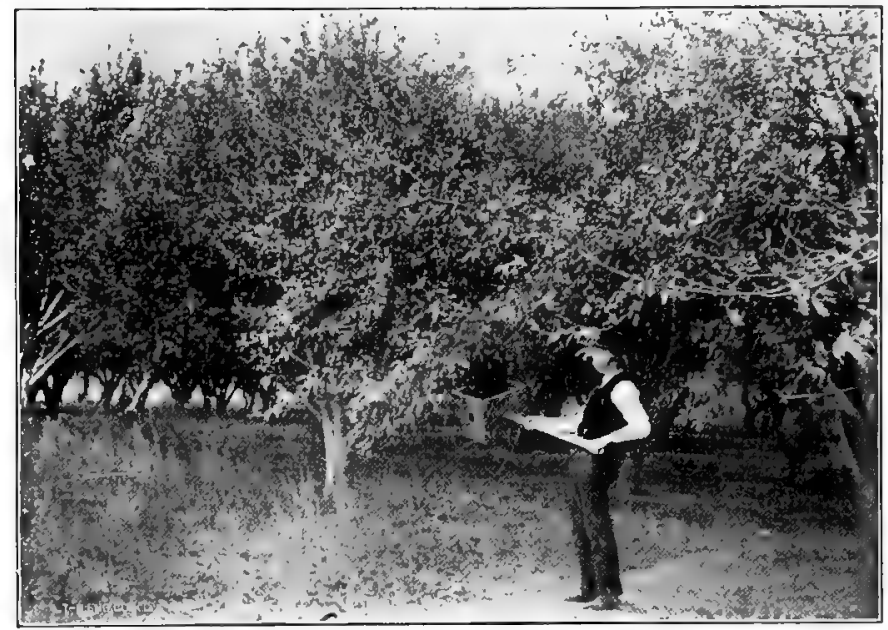

Fia. 91.-Hiving a swarm of honey-bees. Photograph by S. J. Hunter.

found a new community. This swarming is simply an emigration, which results in the wider distribution and in the increase of the number of the species. It is a peculiar but effective mode of distributing and perpetuating the species.

There are many other interesting and suggestive things which might be told of the life in a bee community: how the community protects itself from the dangers of starvation when food is scarce or winter comes on by killing the useless drones and the immature bees in egg and larval stage; how the instinct of home-finding has been so highly developed that the worker bees go miles away for honey and nectar, flying with unerring accuracy back to the hive; of the extraordinarily nice structural modifications which adapt the bee so perfectly for its complex and varied businesses; and of the tireless persistence of the workers until 
they fall exhausted and dying in the performance of their duties. The community, it is important to note, is a persistent or continuous one. The workers do not live long, the spring broods usually not over two or three months, and the fall broods not more than six or eight months; but new ones are hatching while the old ones are dying, and the community as a whole always persists. The queen may live several years, perhaps as many as five.* She lays about one million eggs a year.

85. The ants.-There are many species of ants, two thousand or more, and all of them live in communities and show a truly communal life. There is much variety of habit in the lives of different kinds of ants, and the degree in which the communal or social life is specialized or elaborated varies much. But certain general conditions prevail in the life of all the different kinds of individuals-
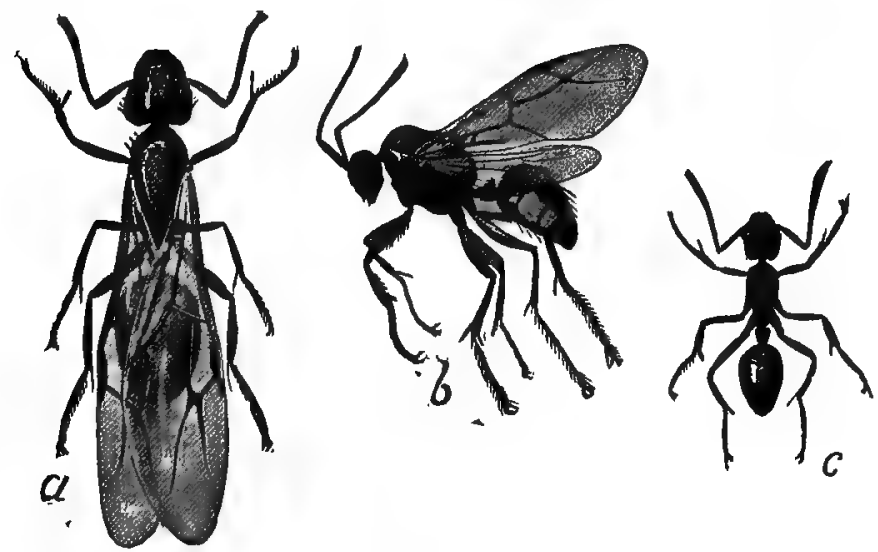

FrG. 92.-Female (a), male (b), and worker (c) of an ant (Camponotus sp.).

sexually developed males and females that possess wings, and sexually undereloped workers that are wingless (Fig. 92). In some kinds the workers show structural differ-

* A queen bee has been kept rive for fifteen years. 
ences among themselves, being divided into small workers, large workers, and soldiers. The workers are not, as with the bees, all infertile females, but they are both male and female, both being infertile. Although the life of the ant communities is much less familiar and fully known than that of the bees, it is even more remarkable in its specializations and claborateness. The ant home, or nest, or formicary, is, with most species, a very elaborate underground, many-storied labyrinth of galleries and chambers. Certain rooms are used for the storage of food; certain others as "nurseries" for the reception and care of the young; and others as stables for the ants' cattle, certain plant-lice or scale-insects which are sometimes collected and cared for by the ants. The food of ants comprises many kinds of vegetable and animal substances, but the favorite food, or "national dish," as it has been called, is a sweet fluid which is produced by certain small insects, the plant-lice (Aphidæ) and scale-insects (Coccidr). These insects live on the sap of plants ; rose-bushes are especially favored with their presence. The worker ants (and we rarely see any ants but the wingless workers, the winged males and females appearing out of the nest only at mating time) find these honeysecreting insects, and gently touch or stroke them with their feelers (antennæ), when the plant-lice allow tiny drops of the honey to issue from the body, which are eagerly drunk by the ants. It is manifestly to the advantage of the ants that the plant-lice should thrive; but they are soft-bodied, defenseless insects, and readily fall a prey to the wandering predaceous insects like the lady-birds and aphis lions. So the ants often guard small groups of plant-lice, attacking, and driving away the would-be ravagers. When the branch on which the plant-lice are gets withered and dry, the ants have been observed to carry the plant-lice carefully to a fresh, green branch. In the Mississippi Valley a certain kind of plant-louse lives on the roots of corn. Its eggs are deposited in the ground in the autumn and hatch 
the following spring before the corn is planted. Now, the common little brown ant lives abundantly in the cornfields, and is specially fond of the honey secreted by the corn-root plant-louse. So, when the plant-lice hatch in the spring before there are corn roots for them to feed on, the little brown ants with great solicitude carefully place the plant-lice on the roots of a certain kind of knotweed which grows in the field, and protect them until the corn germinates. Then the ants remove the plant-lice to the roots of the corn, their favorite food plant. In the arid lands of New Mexico and Arizona the ants rear their scale-insects on the roots of cactus. Other kinds of ants carry plant lice into their nests and provide them with food there. Because the ants obtain food from the plant-lice and take care of them, the plant-lice are not inaptly called the ants' cattle.

Like the honey-bees, the young ants are helpless little grubs or larva, and are cared for and fed by nurses. The so-called ants' eggs, little white, oval masses, which we often see being carried in the mouths of ants in and out of an ants' nest, are not eggs, but are the pupæ which are being brought out to enjoy the warmth and light of the sun or being taken back into the nest afterward.

In addition to the workers that build the nest and collect food and care for the plant-lice, there is in many species of ants a kind of individuals called soldiers. These are wingless, like the workers, and are also, like the workers, not capable of laying or of fertilizing eggs. It is the business of the soldiers, as their name suggests, to fight. They protect the community by attacking and driving away predaceous insects, especially other ants. The ants are among the most warlike of insects. The soldiers of a community of one species of ant often sally forth and attack a community of some other species. If successful in battle the workers of the victorious community take possession of the food stores of the conquered and carry 
them to their own nest. Indeed, they go even further; they may make slaves of the conquered ants. There are numerous species of the so-called slave-making ants. The slavemakers carry into their own nest the eggs and larvæ and pupæ of the conquered community, and when these come to maturity they act as slaves of the victors-that is, they collect food, build additions to the nests, and care for the young of the slave-makers. This specialization goes so far in the case of some kinds of ants, like the robber-ant of South America (Eciton), that all of the Eciton workers have become soldiers, which no longer do any work for themselves. The whole community lives, therefore, wholly by pillage or by making slaves of other kinds of ants. There are four kinds of individuals in a robber-ant communitywinged males, winged females, and small and large wingless soldiers. There are many more of the small soldiers than of the large, and some naturalists believe that the few latter, which are distinguished by heads and jaws of great size, act as officers. On the march the small soldiers are arranged in a long, narrow column, while the large soldiers are scattered along on either side of the column and appear to act as sentinels and directors of the army. The observations made by the famous Swiss students of ants, Huber and Forel, and by other naturalists, read like fairy tales, and yet are the well-attested and often reobserved actual phenomena of the extremely specialized communal and social life of these animals.

86. Other communal insects.-The termites or white ants (not true ants) are communal insects. Some species of termites in Africa live in great mounds of earth, often fifteen feet high. The community comprises hundreds of thousands of individuals, which are of eight kinds (Fig 93), viz., sexually active winged males, sexually active winged females, other fertile males and females which are wingless, wingless workers of both sexes not capable of reproduction, and wingless soldiers of both sexes also incapable of 
reproduction. The production of new individuals is the sole business of the fertile males and females; the workers build the nest and collect food, and the soldiers protect the community from the attacks of marauding insects. The egg-laying queen grows to monstrous size, being sometimes
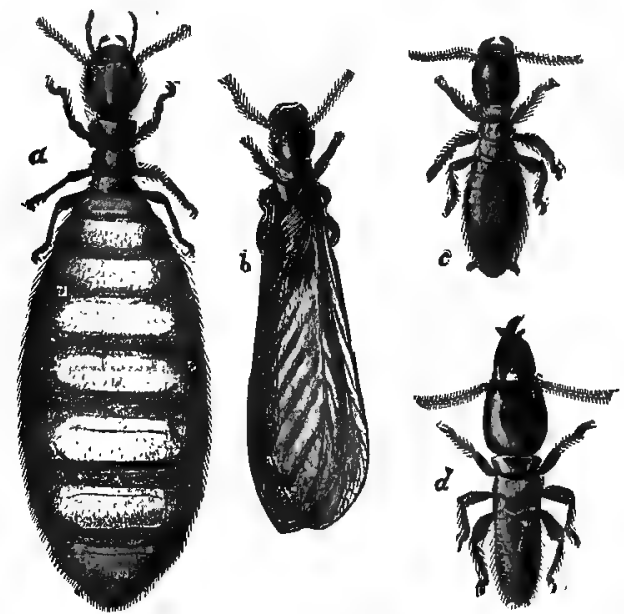

Fıt. 93.-Termites. $a$, queen ; $b$, male; $c$, worker ; $d$, soldier.

five or six inches long, while the other individuals of the community are not more than half or three quarters of an inch long. The great size of the queen is due to the enormous number of eggs in her body.

The bumble-bees live in communities, but their social arrangements are very simple ones compared with those of the honey-bee. There is, in fact, among the bees a series of gradations from solitary to communal life. The interesting little green carpenter-bees live a truly solitary life. Each female bores out the pith from five or six inches of an elder branch or raspberry cane, and divides this space into a few cells by means of transverse partitions (Fig. 94). In each cell she lays an egg, and puts with it enough food - flower pollen-to last the grub or larva through its life. 
She then waits in an upper cell of the nest until the ynung bees issue from their cells, when she leads them off, and each begins active life on its own account. The mining-

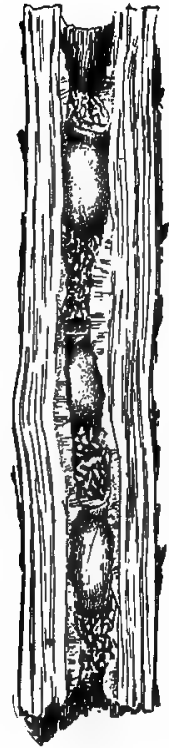

Fia. 94.-Nest of carpenter-bee.

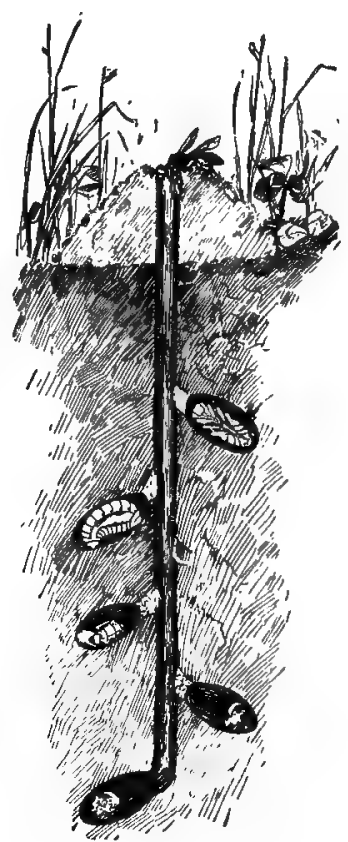

Fia. 95.-Nest of Andrena. the mining-bee.

bees (Andrena), which make little burrows (Fig. 95) in a clay bank, live in large colonies-that is, they make their nest burrows close together in the same clay bank, but each female makes her own burrow, lays her own eggs in it, furnishes it with food-a kind of paste of nectar and pollenand takes no further care of her young. Nor lias she at any time any special interest in her neighbors. But with the smaller mining-bees, belonging to the genus Halictus, several females unite in making a common burrow, after which each female makes side passages of her own, extend- 
ing from the main or public entrance burrow. As a wellknown entomologist has said, Andrena builds villages composed of individual homes, while Halictus makes cities composed of apartment houses. The bumble-bee (Fig. 96), however, establishes a real community with a truly communal life, although a very simple one. The few bumblebees which we see in winter time are queens; all other bumble-bees die in the autumn. In the spring a queen selects some deserted nest of a field-mouse, or a hole in the ground, gathers pollen which she molds into a rather large irregular mass and puts into the hole, and lays a few eggs on the pollen mass. The young grubs or larvæ which soon hatch feed on the pollen, grow, pupate, and issue as workers-winged bees a little smaller than the queen. These workers bring more pollen, enlarge the nest, and make irregular cells in the pollen mass, in each of which the queen lays an egg. She gathers no more pollen, does no more work except that of egg-laying. From these new eggs are produced more workers, and so on until the community may come to be pretty large. Later in the summer males and females are produced and mate. With the approach of winter all the workers and males die, leaving only the fertilized females, the queens, to live through the winter and found new communities in the spring.

The sucial wasps show a communal life like that of the bumble-bees. The only yellow-jackets and hornets that live through the winter are fertilized females or queens. 
When spring comes each queen builds a small nest suspended from a tree branch, and consisting of a small comb inclosed in a covering or envelope open at the lower end. The nest is composed of "wasp paper," made by chewing bits of weather-beaten wood taken from old fences or outbuildings. In each of the cells the queen lays an egg. She deposits in the cell a small mass of food, consisting of some chewed insects or spiders. From these eggs hatch grubs which eat the food prepared for them, grow, pupate, and issue as worker bees, winged and slightly smaller than the queen (Fig. 97). The workers enlarge the nest, adding more combs and making many cells, in each of which the queen lays an egg. The workers provision the cell with chewed insects, and other broods of workers are
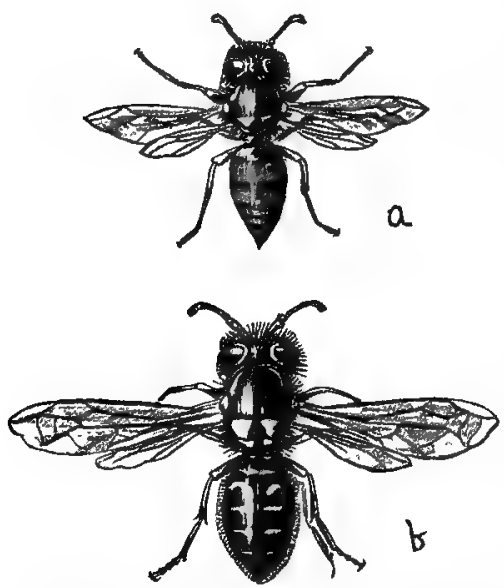

FIG, 97,-The yellow-jacket (Vespa), a social wasp. $a$, worker; $b$, queen. rapidly hatched. The community grows in numbers and the nest grows in size until it comes to be the great ball-like oval mass which we know so well as a hornets' nest (Figs. 98 and 99), a thing to be left untouched. Sometimes the nest is built underground. When disturbed, they swarm out of the hole and fiercely attack any invading foe in sight. After a number of broods of workers has been produced, broods of males and females appear and mating takes place. In the late fall the males and all of the many workers die, leaving only the new queens to live through the winter. 
The bumble-bees and social wasps show an intermediate condition between the simply gregarious or neighborly

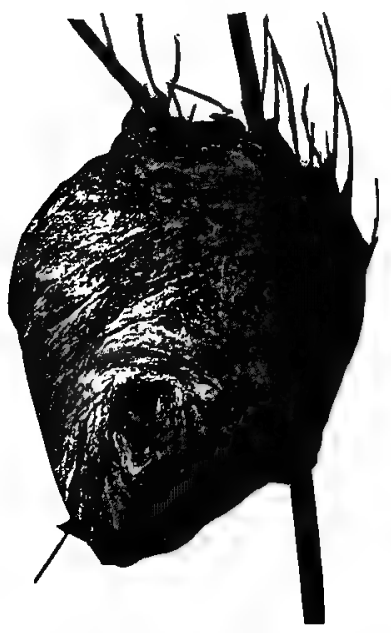

Fra. 98.-Nest of Vespa, a social wasp. From photograph.

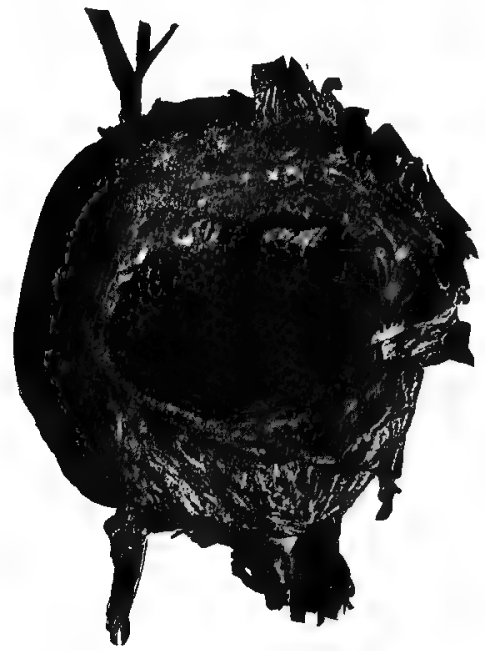

Fig. 99.-Nest of Vespa opened to show combs within.

mining-bees and the highly developed, permanent honeybee community. Naturalists believe that the highly organized communal life of the honey-bees and the ants is a development from some simple condition like that of the bumble-bees and social wasps, which in its turn has grown out of a still simpler, mere gregarious assembly of the individuals of one species. It is not difficult to see how such a development could in the course of a long time take place.

8\%. Gregariousness and mutual aid-The simplest form of social life is shown among those kinds of animals in which many individuals of one species keep together, forming a great band or herd. In this case there is not much division of labor, and the safety of the individual is not wholly bound up in the fate of the herd. Such animals are 
said to be gregarious in habit. The habit undoubtedly is advantageous in the mutual protection and aid afforded the individuals of the band. This mutual help in the case of many gregarious animals is of a very positive and obvious character. In other cases this gregariousness is reduced to a matter of slight or temporary convenience, possessing but little of the element of mutual aid. The great herds of reindeer in the north, and of the bison or buffalo which once ranged over the Western American plains, are examples of a gregariousness in which mutual protection from enemies, like wolves, seems to be the principal advantage gained. The bands of wolves which hunted the buffalo show the advantage of mutual help in aggression as well as in protection. In this banding together of wolves there is active co-operation among individuals to obtain a common food supply. What one wolf can not do-that is, tear down a buffalo from the edge of the herd-a dozen can do, and all are gainers by the operation. On the other hand, the vast assembling of sea-birds (Fig. 100) on certain ocean islands and rocks is a condition probably brought about rather by the special suitableness of a few places for safe breeding than from any special mutual aid afforded; still, these seabirds undoubtedly combine to drive off attacking eagles and hawks. Eagles are usually considered to be strictly solitary in habit (the unit of solitariness being a pair, not an individual); but the description, by a Russian naturalist, of the hunting habits of the great white-tailed eagle (Halicetos albicilla) on the Russian steppes shows that this kind of eagle at least has adopted a gregarious habit, in which mutual help is plainly obvious. This naturalist once saw an eagle high in the air, circling slowly and widely in perfect silence. Suddenly the eagle screamed loudly. "Its cry was soon answered by another eagle, which approached it, and was followed by a third, a fourth, and so on, till nine or ten eagles came together and soon disappeared." The naturalist, following them, soon discovered them gathered 


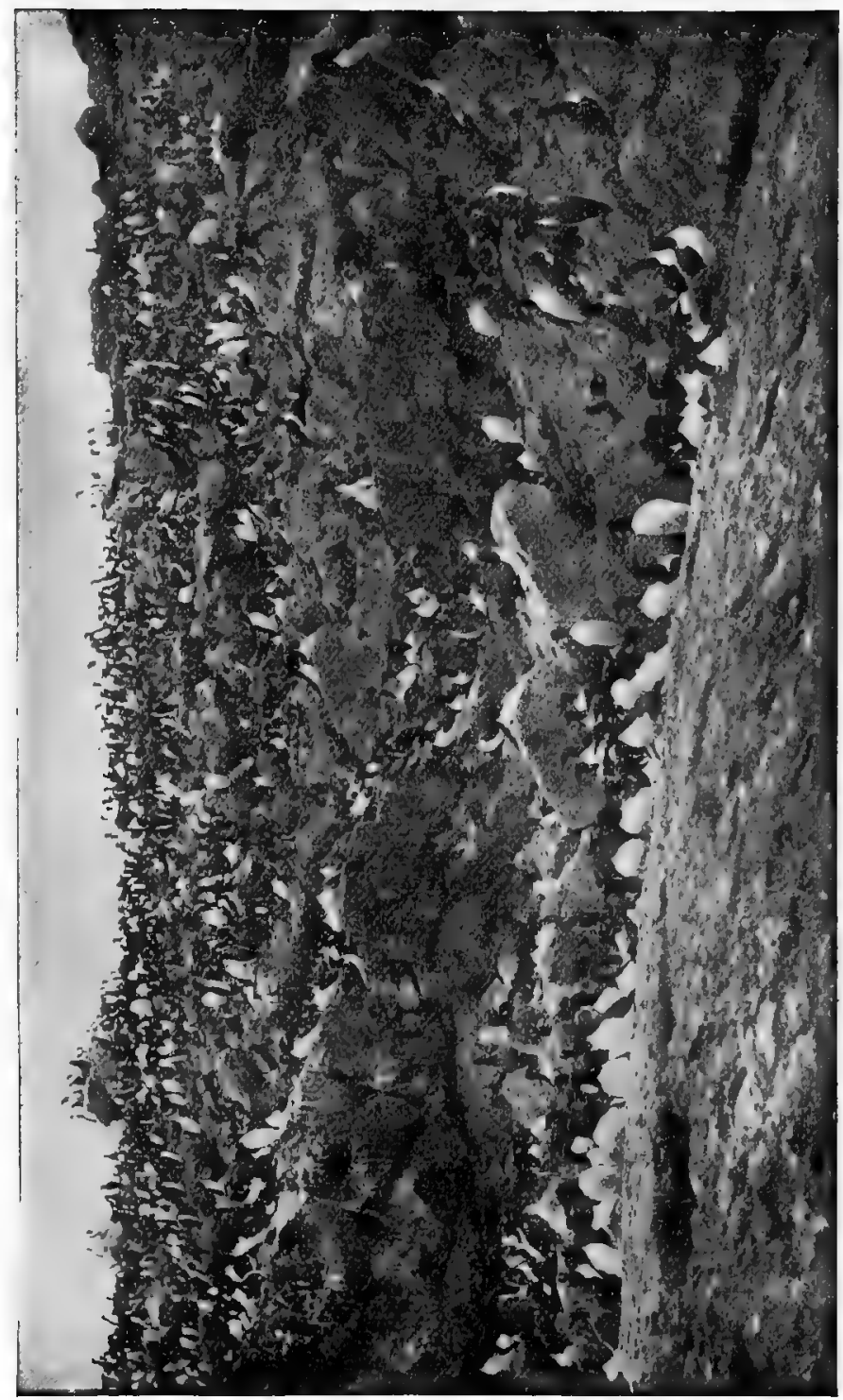

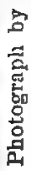

迥

范

모

最

$-15 x^{2}+2$

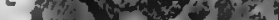

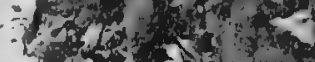
C. $\rightarrow \times 1$

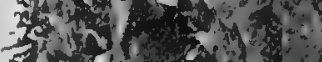
$5 x+4$ a

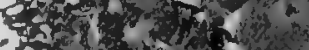

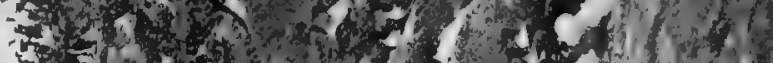

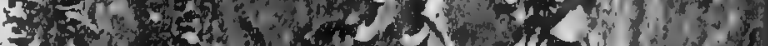

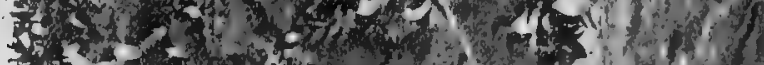

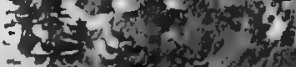
$+2 c^{2}$

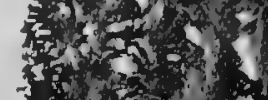
$=2 x+2$

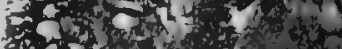

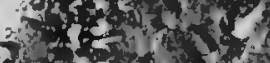

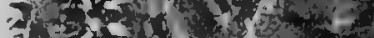

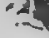


about the dead body of a horse. The food found by the first was being shared by all. The association of pelicans in fishing is a good example of the advantage of a gregarious and mutually helpful habit. The pelicans sometimes go fishing in great bands, and, after having chosen an appropriate place near the shore, they form a wide half-circle facing the shore, and narrow it by paddling. toward the land, catching the fish which they inclose in the ever-narrowing circle.

The wary Rocky Mountain sheep (Fig. 101) live together in small bands, posting sentinels whenever they are feeding or resting, who watch for and give warning of the approach of enemies. The beavers furnish a wellknown and very interesting example of mutual help, and they exhibit a truly communal life, although a simple one. They live in "villages" or communities, all helping to build the dam across the stream, which is necessary to form the broad marsh or pool in which the nests or houses are built. Prairie-dogs live in great villages or communities which spread over many acres. They tell each other by shrill cries of the approach of enemies, and they seem to visit each other and to enjoy each other's society a great deal, although that they afford each other much actual active help is not apparent. Birds in migration are gregarious, although at other times they may live comparatively alone. In their long flights they keep together, often with definite leaders who seem to discover and decide on the course of flight for the whole great flock. The wedgeshaped flocks of wild geese flying high and uttering their sharp, metallic call in their southward migrations are well known in many parte of the United States. Indeed, the more one studies the habits of animals the more examples of social life and mutual help will be found. Probably most animals are in some degree gregarious in habit, and in all cases of gregariousness there is probably some degree of mutual aid. 


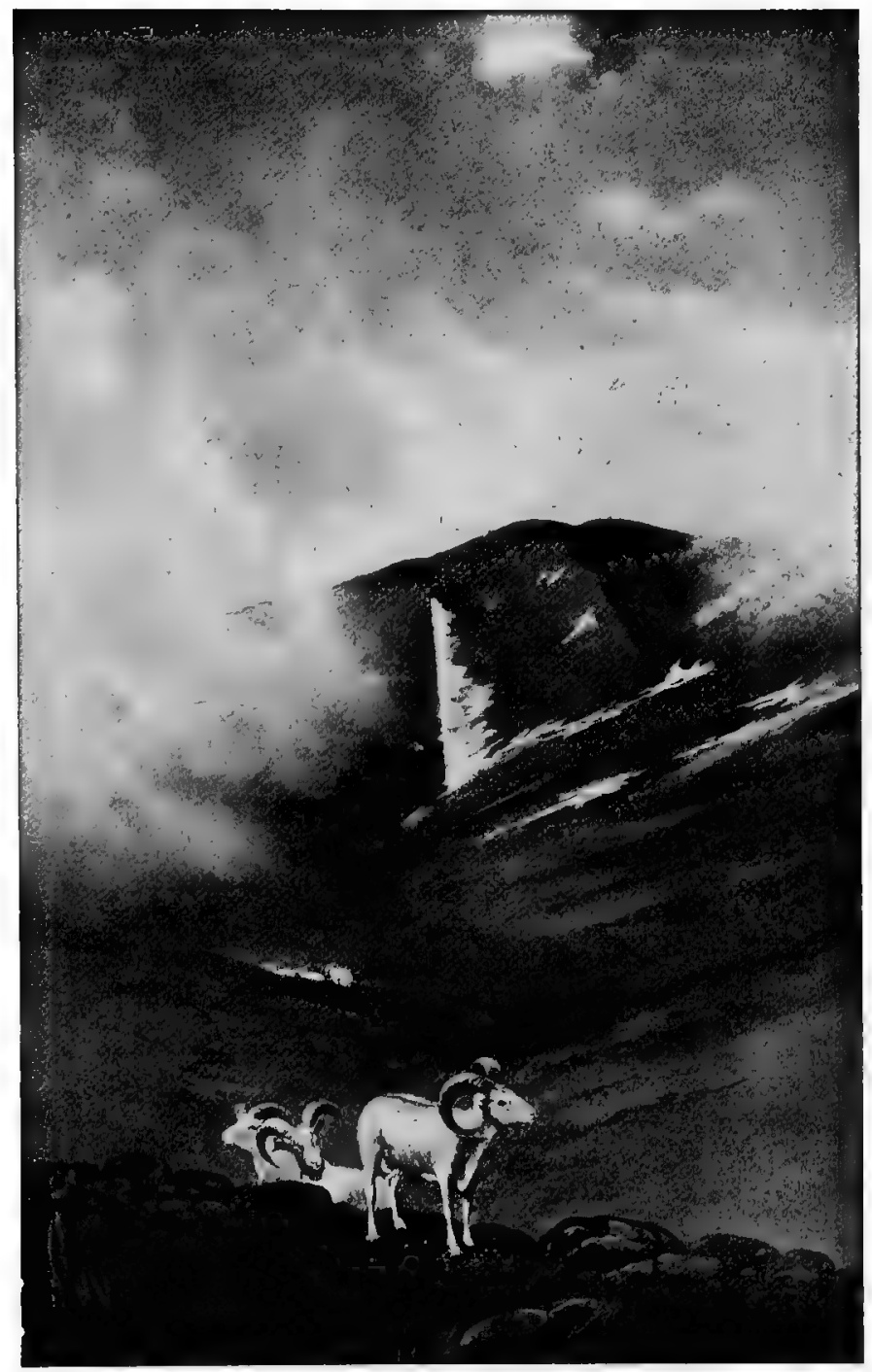

FIa. 101.-Rocky Mountain or bighorn sheep. By permission of the publishers of Outing. 
88. Division of labor and basis of communal life.-We have learned in Chapters II and IV that the complexity of the bodies of the higher animals depends on a specialization or differentiation of parts, due to the assumption of different functions or duties by different parts of the body; that the degree of structural differentiation depends on the degree or extent of division of labor shown in the economy of the animal. It is obvious that the same principle of division of labor with accompanying modification of structure is the basis of colonial and communal life. It is simply a manifestation of the principle among individuals instead of among organs. The division of the necessary labors of life among the different zooids of the colonial jelly-fish is plainly the reason for the profound and striking, but always reasunable and explicable modifications of the typical polyp or medusa body, which is shown by the swimming zooids, the feeding zooids, the sense zooids, and the others of the colony. And similarly in the case of the termite community, the soldier individuals are different structurally from the worker individuals because of the different work they have to do. And the queen differs from all the others, because of the extraordinary prolificacy demanded of her to maintain the great community.

It is important to note, however, that among those animals that show the most highly organized or specialized communal or social life, the structural differences among the individuals are the least marked, or at least are not the most profound. The three kinds of honey-bee individuals differ but little; indeed, as two of the kinds, male and female, are to be found in the case of almost all kinds of animals, whether communal in habit or not, the only unusual structural specialization in the case of the honey bee, is the presence of the worker individual, which differs from the usual individuals-in- but little more than the rudimentary condition of the reproluctive glands. Finally, in the case of man, with whom the communal or social habit is so 


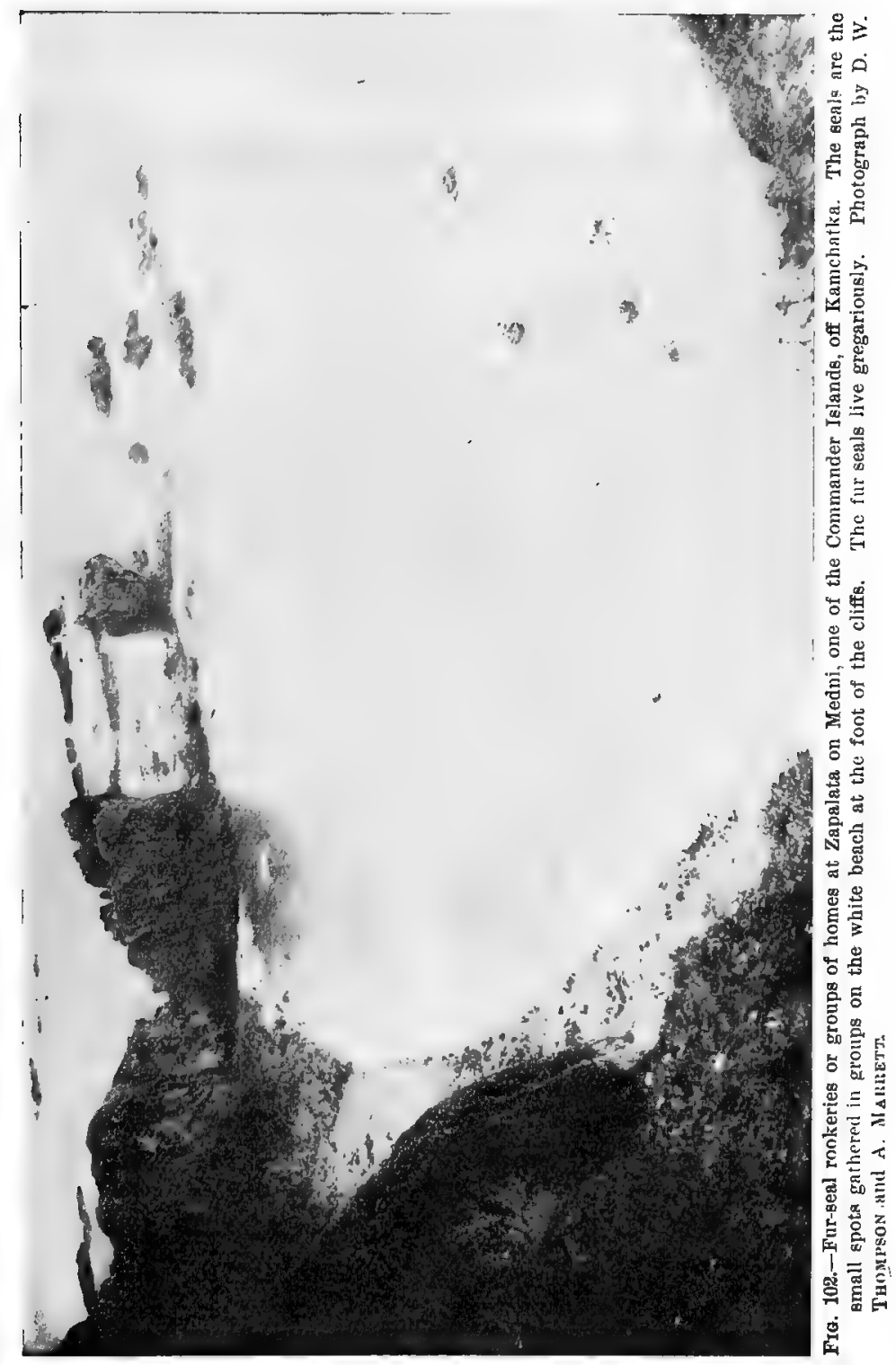


all-important as to gain for him the name of "the social animal," there is no differentiation of individuals adapted only for certain kinds of work. Among these highest examples of social animals, the presence of an advanced mental endowment, the specialization of the mental power, the power of reason, have taken the place of and made unnecessary the structural differentiation of individuals. The honey-bee workers do different kinds of work: some gather food, some care for the young, and some make wax and build cells, but the individuals are interchangeable; each one knows enough to do these various things. There is a structural differentiation in the matter of only one special work or function, that of reproduction.

With the ants there is, in some cases, a considerable structural divergence among individuals, as in the genus Atta of South America with six kinds of individualsnamely, winged males, winged females, wingless soldiers, and wingless workers of three distinct sizes. In the case of other kinds with quite as highly organized a communal life there are but three kinds of individuals, the winged males and females and the wingless workers. The workers gather food, build the nest, guard the "cattle" (aphids), make war, and care for the young. Each one knows enough to do all these various distinct things. Its body is not so modified that it can do but one kind of thing, which thing it must always do.

The increase of intelligence, the development of the power of reasoning, is the most potent factor in the development of a highly specialized social life. Man is the example of the highest development of this sort in the animal kingdom, but the highest form of social development is not by any means the most perfectly communal.

89. Advantages of communal life.-The advantages of communal or social life, of co-operation and mutual aid, are real. The animals that have adopted such a life are among the most successful of all animals in the struggle for exist- 
ence. The termite individual is one of the most defenseless, and, for those animals that prey on insects, one of the most toothsome luxuries to be found in the insect world. But the termite is one of the most abundant and widespread and successfully living insect kinds in all the tropics. Where ants are not, few insects are. The honeybee is a popular type of a successful life. The artificial protection afforded the honey-bee by man may aid in its struggle for existence, but it gains this protection because of certain features of its communal life, and in Nature the honey-bee takes care of itself well. The Little Bee People of Kipling's Jungle Book, who live in great communities in the rocks of Indian hills, can put to rout the largest and fiercest of the jungle animals. Co-operation and mutual aid are among the most important factors which help in the struggle for existence. Its great advantages are, however, in some degree balanced by the fact that mutual help brings mutual dependence. The community or society can accomplish greater things than the solitary individuals, but co-operation limits freedom, and often sacrifices the individual to the whole. 


\section{CHAPTER $\mathrm{X}$ \\ COMMENSALISM AND SYMBIOSIS}

90. Association between animals of different species,-The living together and mutual help discussed in the last chapter concerned in each instance a single species of animal. All the various members of a pack of wolves or of a community of ants are individuals of the same species. But there are many instances of an association of individuals of different kinds of animals. The number of individuals concerned, however, is usually but two-that is, one of each of the two kinds of animals. In many cases of an association of individuals of different species one kind derives great benefit and the other suffers more or less injury from the association. One kind lives at the expense of the other. This association is called parasitism, and is discussed in the next chapter. In some cases, however, neither kind of animal suffers from the presence of the other. The two live together in harmony and presumably to their mutual advantage. - In some cases this mutual advantage is obvious. This kind of association is called rommensulism or symbiosis. The term commensalism may be used to denote a condition where the two animals are not so intimately associated nor derive such obvious mutual advantage from the association, as in that condition of very intimate and permanent association with obvious co-operative and marked advantage that may be called. symbiosis. A few examples of each of these interesting conditions of atsisoriation hetwen which it is impossible to make any sharp distinction, will be given. 
91. Commensalism. - A curious example of commensalism is afforded by the different species of Remoras (Echeridida) which attach themselves to sharks, barracudas, and other large fishes by means of a sucking disk on the top of the head (Fig. 103). This disk is made by a modification of

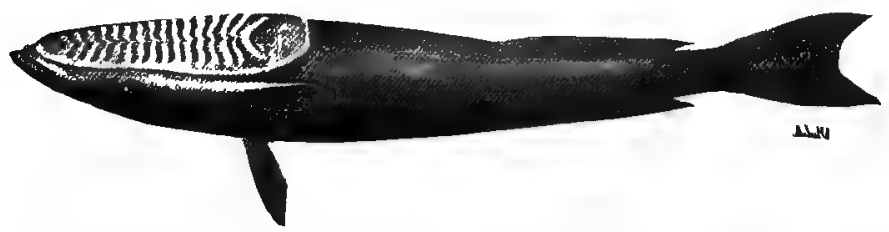

Frg. 103.-Remora, with dorsal fin modified to be a sucking plate by which the fish attaches itself to a shark.

the dorsal fin. The Remora thus attached to a shark may be carried about for weeks, leaving its host only to secure food. This is done by a sudden dash through the water. The Remora injures the shark in no way save, perhaps, by the slight check its presence gives to the shark's speed in swimming.

Whales, similarly, often carry barnacles about with them. These barnacles are permanently attached to the skin of the whale just as they would be to a stone or wooden pile. Many small crustaceans, annelids, mollusks, and other invertebrates burrow into the substance of living sponges, not for the jurpose of feeding on them, but for shelter. On the other hand, the little boring sponge (Cliona) burrows in the shells of oysters and other bivalves for protection. These are hardly true cases of even that lesser degree of mutually advantageous association which we are calling commensalism. But some species of sponge "are never found growing except on the backs or legs of certain crabs." In these cases the sponge, with its many plant-like branches, protects the crab by concealing it from its enemies, while the sponge is benefited by being carried about by the crab to new food supplies. Certain sponges 
and polyps are always found growing in close association, though what the mutual advantage of this association is has not yet been found out.

Among the coral reefs near Thursday Island (between New Guinea and Australia) there lives an enormous kind of sea-anemone or polyp. Individuals of this great polyp measure two feet across the disk when fully expanded. In the interior, the stomach cavity, which communicates freely with the outside by means of the large mouth opening at the free end of the polyp, there may often be found a small fish (Amphiprion percula). That this fish is purposely in the gastral cavity of the polyp is proved by the fact that when it is dislodged it invariably returns to its singular lodging-place. The fish is brightly colored, being of a brilliant vermilion hue with three broad white cross bands. The discoverer of this peculiar habit suggests that there are mutual benefits to fish and polyp from this habit. "The fish being conspicuous, is liable to attacks, which it escapes by a rapid retreat into the sea-anemone; its enemies in hot pursuit blunder against the outspread tentacles of the anemone and are at once narcotized by the 'thread cells' shot out in innumerable showers from the tentacles, and afterward drawn into the stomach of the anemone and digested."

Small fish of the genus Nomeus may often be found accompanying the beautiful Portuguese man-of-war (Physalia) as it sails slowly about on the ocean's surface (Fig. 104). These little fish lurk underneath the float and among the various hanging thread-like parts of the Physalia, which are provided with stinging cells. The fish are protected from their enemies by their proximity to these stinging threads, but of ' what advantage to the man-ofwar their presence is is not understood. Similarly, several kinds of medusæ are known to harbor or to be accompanied by young or small adult fishes.

In the nests of the various species of ants and termites 
many different kinds of other insects have been found. Some of these are harmful to their hosts, in that they feed on the food stores gathered by the industrious and provident ant, but others appear to feed only on refuse or useless substances in the nest. Some may even be of help to their hosts. Over one thousand species of these myrmecophilous (ant-loving) and termitophilous (termite-loving) insects have been recorded by collectors as living habitually in the nests of ants and termites. The owls and rattlesnakes which live with the prairie-dogs in their villages afford a familiar example of commensalism.

92. Symbiosis.-Of a more intimate character, and of more obvious and certain mutual advantage, is the wellknown case of the symbiotic association of some of the numerous species of hermitcrabs and certain species of sea-anemones. The hermitcrab always takes for his habitation the shell of another animal, often that of the common whelk. All of

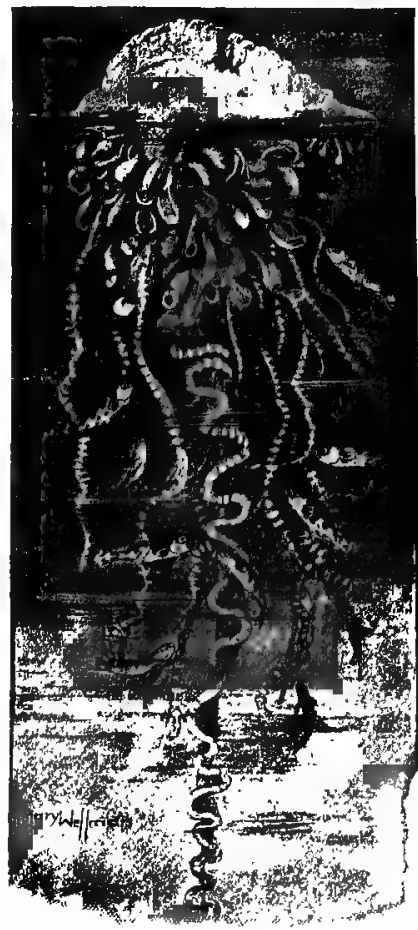

Fra 104.-A Portuguese man-of-war (Physalia), with man-of-war fishes (Nompus gronovii) living in the shelter of the stinging feelers. Specimens from off Tampa, Fla.

the hind part of the crab lies inside the shell, while its head with its great claws project from the opening of the shell. On the surface of the shell near the opening there is often to be found a sea-anemone, or sea-rose (Fig. 105). 
This sen-anemone is fastened securely to the shell, and las its mouth opening and tentacles near the head of the crab. The sea-anemone is carried from place to place by the hermit-crab, and in this way is much aided in obtaining food. On the other hand, the crab is protected from its enemies by the well-armed and dangerous tentacles of the sea-anem-

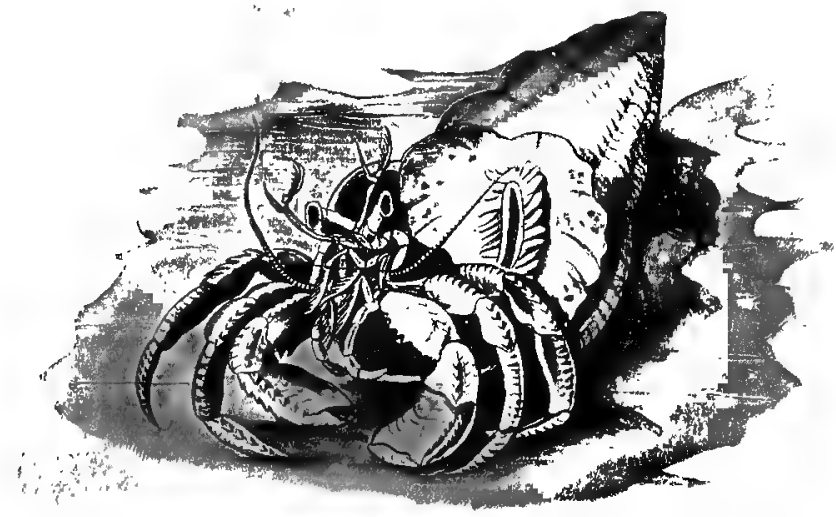

Fra. 105.-Hermit-crab (P(tgurus) in shell, with a set-anemone (Adamsia palliata) attached to the shel1.-After HerTwig.

one. In the tentacles there are many thousand long, slender stinging threads, and the fish that would obtain the hermit-crab for food must first deal with the stinging anemone. There is no doubt here of the mutual advantage gained by these two widely different but intimately associated companions. If the sea-anemone be torn away from the shell inhabited by one of these crabs, the crab will wander about, carefully seeking for another anemone. When he finds it he struggles to loosen it from its rock or from whatever it may be growing on, and does not rest until he has torn it loose and placed it on his shell.

There are numerous small crabs called pea-crabs (Pinnotheres) which live habitually inside the shells of living 
mussels. The mussels and the crabs live together in perfect harmony and to their mutual benefit.

There are a few extremely interesting cases of symbiosis in which not different kinds of animals are concerned, but animals and plants. It has long been known that'some sea-anemones possess certain body cells which contain chlorophyll, that green substance characteristic of the green plants, and only in few cases possessed by animals. When these chlorophyll - be aring sea-anemones were first found, it was believed that the chlorophyll cells really belonged to the animal's body,

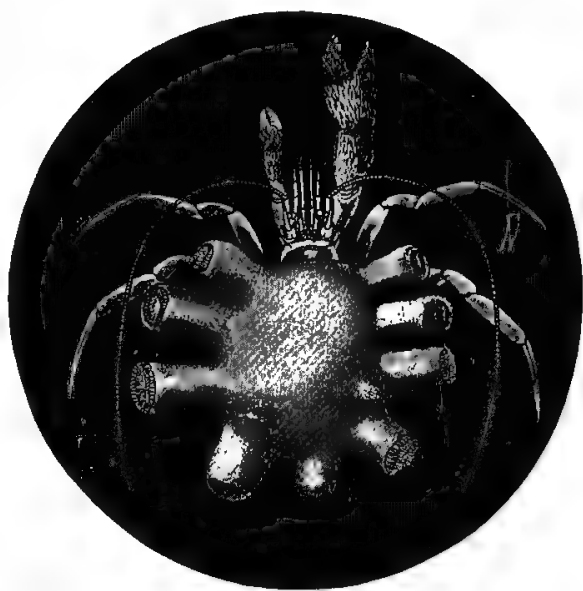

Fia. 106.-The crab Epitoanthus paguriphilus, with the sea-anemone Parapagurus pilosiramus on its shell. and that this con-

dition broke down one of the chiefest and most readily apparent distinctions between animals and plants. But it is now known that these chlorophyll-bearing cells are microscopic, one-celled plants, green algæ, which live habitually in the bodies of the sea-anemone. It is a case of true symbiosis. The algæ, or plants, use as food the carbonic-acid gas which is given off in the respiratory processes of the sea-anemone, and the sea-anemone breathes in the oxygen given off by the algæ in the process of extracting the curbon for food from the carbonic-acid gas. 'These algæ, or one-celled plants, lie regularly only in the innermost of the three cell layers which compose the wall 
or body of the sea-anemone (Fig. 10\%). They penetrate into and lie in the interior of the cells of this layer whose special function is that of digestion. They give this inner-

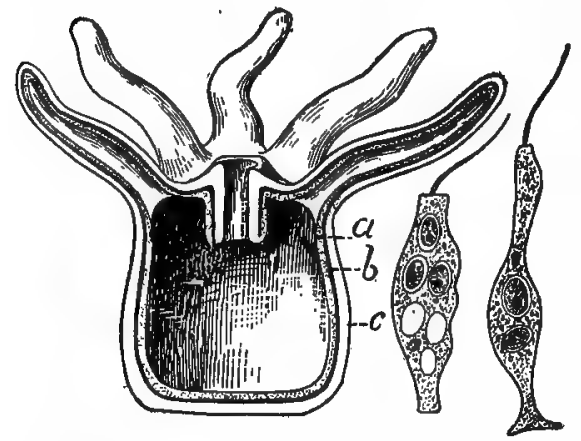

Frg. 107.-Diagrammatic section of sea-anemone. $a$, the inner cell layer containing alga cells, the two isolated cells at right being cells of this layer with contained algæ; $b$, middle body wall layer; $c$, outer body wall layer.-After HERTwre. most layer of cells a distinct green color.

There are other examples known of the symbiotic association of plants and animals; and if we were to follow the study of symbiosis into the plant kingdom we should find that in one of the large groups of plants, the familiar lichens which grow on rocks and tree trunks and old fences, every member lives symbiotically. A lichen is not a single plant, but is always composed of two plants, an alga (chlorophyll-bearing) and a fungus (without chlorophyll) living together in a most intimate, mutually advantageous association. 


\section{CHAPTER XI}

\section{PARASITISM AND DEGENERATION}

93. Relation of parasite and host.-In addition to the various ways of living together of animals already described, namely, the social life of individuals of a single species and the commensal and symbiotic life of individuals of different species, there is another kind of association among animals that is very cornmon. In cases of symbiosis the two animals living together are of mutual advantage to each other; both profit by the association. But tinere are many instances in the animal kingdom of an association between two animals by which one gains advantages great or small, sometimes even obtaining all the necessities of life, while the other gains nothing, but suffers corresponding disadvantage, often even the loss of life itself. This is the association of parasite and host; the relation between two animals whereby one, the parasite, lives on or in the other, the host, and at the expense of the host. Parasitism is a common phenomenon in all groups of animals, although the parasites themselves are for the most part confined to the classes of invertebrates. Among the simplest animals or Protozoa there are parasites, as Gregarina, which lives in the bodies of insects and crustaceans; there are parasitic worms, and parasitic crustaceans and mollusks and insects, and a few vertebrates. When an animal can get along more safely or more easily by living at the expense of some other animal and takes up such a life, it becomes a parasite. Parasitism is naturally, therefore, not confined to any one group or class of animals. 
94. Kinds of parasitism.-The bird-lice (Mallophaga), which infest the bodies of all kinds of birds and are found especially abundant on domestic fowls, live upon the outside of the bodies of their hosts, feeding upon the feathers and dermal scales. They are examples of external parasites. Other examples are fleas and ticks, and the crustaceans called fish-lice and whale-lice, which are attached to marine animals. On the other hand, almost all animals are infested by certain parasitic worms which live in the alimentary canal, like the tape-worm, or imbedded in the muscles, like the trichina. These are examples of internal parasites. Such parasites belong mostly to the class of worms, and some of them are very injurious, sucking the blood from the tissues of the host, while others feed solely on the partly digested food. There are also parasites that live partly within and partly on the outside of the body, like the Sacculina, which lives on various kinds of crabs. The body of the Sacculina consists of a soft sac which lies on the outside of the crab's body, and of a number of long, slender root-like processes which penetrate deeply into the crab's body, and take up nourishment from within. The Sacculina is itself a crustacean or crab-like creature. The classification of parasites as external and internal is purely arbitrary, but it is often a matter of convenience.

Some parasites live for their whole lifetime on or in the body of the host, as is the case with the bird-lice. Their eggs are laid on the feathers of the bird host; the young when hatched remain on the bird during growth and development, and the adults only rarely leave the body, usually never. These mav be called permanent parasites. On the other hand, fleas leap off or on a dog as caprice dictates; or, as in other cases, the parasite may pass some definite part of its life as a free, non-parasitic organism, attaching itself, after development, to some animal, and remaining there for the rest of its life. These parasites may be called temporary parcsites. But this grouping or classification, 
like that of the external and internal parasites, is simply a matter of convenience, and does not indicate at all any blood relationship among the members of any one group.

95. The simple structure of parasites, - In all cases the body of a parasite is simpler in structure than the body of other animals which are closely related to the parasitethat is, animals that live parasitically have simpler bodies than animals that live free active lives, competing for food with the other animals about them. This simplicity is not primitive, but results from the loss or atrophy of the structures which the mode of life renders useless. Many parasites are attached firmly to their host, and do not move about. They have no need of the power of locomotion. They are carried by their host. Such parasites are usually without wings, legs, or other locomotory organs. Becanse they have given up locomotion they have no need of organs of orientation, those special sense organs like eyes and ears and feelers which serve to guide and direct the moving animal; and most non-locomotory parasites will be found to have no eyes, nor any of the organs of special sense which are accessory to locomotion and which serve for the detection of food or of enemies. Because these important organs, which depend for their successful activity on a highly organized nervous system, are lacking, the nervous system of parasites is usually very simple and undeveloped. Again, because the parasite usually has for its sustenance the already digested highly nutritious food elaborated by its host, most parasites have a very simple alimentary canal, or even no alimentary canal at all. Finally, as the fixed parasite leads a wholly sedentary and inactive life, the breaking down and rebuilding of tissue in its body go on very slowly and in minimum degree, and there is no need of highly developed respiratory and circulatory organs; so that most fixed parasites have these systems of organs in simple condition. Altogether the body of a fixed, permanent parasite is so simplified and so want- 
ing in all those special structures which characterize the higher, active, complex animals, that it often presents a very different appearance from those animals with which we know it to be nearly related.

The simplicity of parasites does not indicate that they all belong to the groups of primitive simple animals. Parasitism is found in the whole range of animal life, from primitive to highest. 'Their simplicity is something that has resulted from their mode of life. It is the result of a change in the body-structure which we can often trace in the development of the individual parasite. Many parasites in their young stages are free, active animals with a better or more complex body than they possess in their fully developed or adult stage. The simplicity of parasites is the result of degeneration-a degeneration that has been brought about by their adoption of a sedentary, non-competitive parasitic life. And this simplicity of degeneration, and the simplicity of primitiveness should be sharply distinguished. Animals that are primitively simple have had only simple ancestors; animals that are simple by degeneration often have had highly organized, complex ancestors. And while in the life history or development of a primitively simple animal all the young stages are simpler than the adult, in a degenerate animal the young stages may be, and usually are, more complex and more highly organized than the adult stage.

In the examples of parasitism that are described in the following pages all these general statements are illustrated.

96. Gregarina, - In the intestines of cray-fishes, centipeds, and several kinds of insects may often be found certain one-celled animals (Protozoa) which are living as parasites. Their food, which they take into their minute body by absorption, is the intestinal fluids in which they lie. These parasitic Protozoa belong to the genus Gregarina (Fig. 9) (see Chapter I). Because the body of any 
protozoan is as simple as an animal's body can be, being composed of but a single cell, degeneration can not occur in the cases of these parasites. There are, besides Gregarina, numerous other parasitic one-celled animals, several kinds living inside the cells of their host's body. One kind lives in the blood-corpuscles of the frog, and another in the cells of the liver of the rabbit.

9\%. The tape-worm and other flat-worms, -In the great group of flat-worms (Platyhelminthes), that group of animals which of all the principal animal groups is widest in its distribution, perhaps a majority of the species are parasites. Instead of being the exception, the parasitic life is the rule among these worms. Of the three classes into which the flat-worms are divided almost all of the members of two of the classes are parasites. The common tape-worm (Tcenia) (Fig. 108), which lives parasitically in the intestine of man, is a good example of one of these classes. "It has the form of a narrow ribbon, which may attain the length of several yards, attached at one end to the wall of the intestine, the remainder hanging freely in the interior." Its body is composed of segments or serially

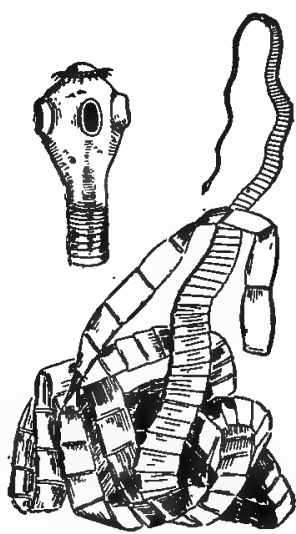

FIG. 108.-Tape-worm (Tania solium). In upper lefthand corner of figure the head much magnified, After LEUCK.ART. arranged parts, of which there are about eight hundred and fifty altogether. It has no mouth nor alimentary canal. It feeds simply by absorbing into its body, through the surface, the nutritious, already digested liquid food in the intestine. There are no eyes nor other special sense organs, nor any organs of locomotion. The body is very degenerate. The life history of the tape-worm is interesting, because of the necessity of 
two hosts for its completion. The eggs of the tape-worm pass from the intestine with the excreta, and must be taken into the body of some other animal in order to develop. In the case of one of the several species of tapeworms that infest man this other host must be the pig. In the alimentary canal of the pig the young tape-worm develops, and later bores its way through the walls of the canal and becomes imbedded in the muscles. There it lies, until it finds its way into the alimentary canal of man by his eating the flesh of the pig. In the intestine of man

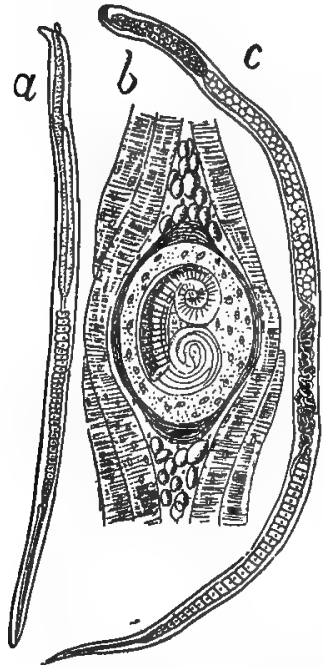

Fia. 109. - Trichina spiralis (after Claus). $a$, male; $b$, encysted form in muscle: $c$, female. the tape-worm continues to develop until it becomes full grown.

In a lake in Yellowstone Park the suckers are infested by one of the flat-worms (Ligula) that attains a size of nearly one fourth the size of the fish in whose intestines it lives. If the tape-worm of man attained such a comparative size, a man of two hundred pounds' weight would be infested by a parasite of fifty pounds' weight.

98. Trichina and other roundworms.-Another group of animals, many of whose numbers are parasites, are the round-worms or threadworms (Nemathelminthes). The free-living round-worms are active, well-organized animals, but the parasitic kinds all show a greater or less degree of degeneration. One of the most terrible parasites of man is a round-worm called Trichina spiralis (Fig. 109). It is a minute worm, from one to three millimetres long, which in iis adult condition lives in the intestine of man or of the pig or other mammals. The young are born alive and bore through the walls 
of the intestine. They migrate to the voluntary muscles of the hosts, especially those of the limbs and back, and here each worm coils itself up in a muscle fiber and becomes inclosed in a spindle-shaped cyst or cell (Fig. 109, b). A single muscle may be infested by hundreds of thousands of these minute worms. It has been estimated that fully one hundred million encysted worms have existed in the muscles of a "trichinized" human body. The muscles undergo more or less degeneration, and the death of the host may occur. It is necessary, for the further development of the worms, that the flesh of the host be eaten by another mammal, as the flesh of the pig by man, or the flesh of man by a pig or rat. The Trichinae in the alimentary canal of the new host develop into active adult worms and produce new young.

In the Yellowstone Lake the trout are infested by the larvæ or young of a round-worm (Bothriocephalus cordiceps) which reaches a length of twenty inches, and which is often found stitched, as it were, through the viscera and the muscles of the fish. The infested trout become feeble and die, or are eaten by the pelicans which fish in this lake. In the alimentary canal of the pelican the worms become adult, and parts of the worms containing eggs escape from the alimentary canal with the excreta. These portions of worms are eaten by the trout, and the eggs give birth to new worms which develop in the bodies of the fish with disastrous effects. It is estimated that for each pelican in Yellowstone Lake over five million eggs of the parasitic worms are discharged into the lake.

The young of various carnivorous animals are often infested by one of the species of round-worms called "pupworms" (Uncinaria). Recent investigations show that thousands of the young or pup fur-seals are destroyed each year by these parasites. The eggs of the worm lie through the winter in the sands of the breeding grounds of the furseal. The young receive them from the fur of the mother 


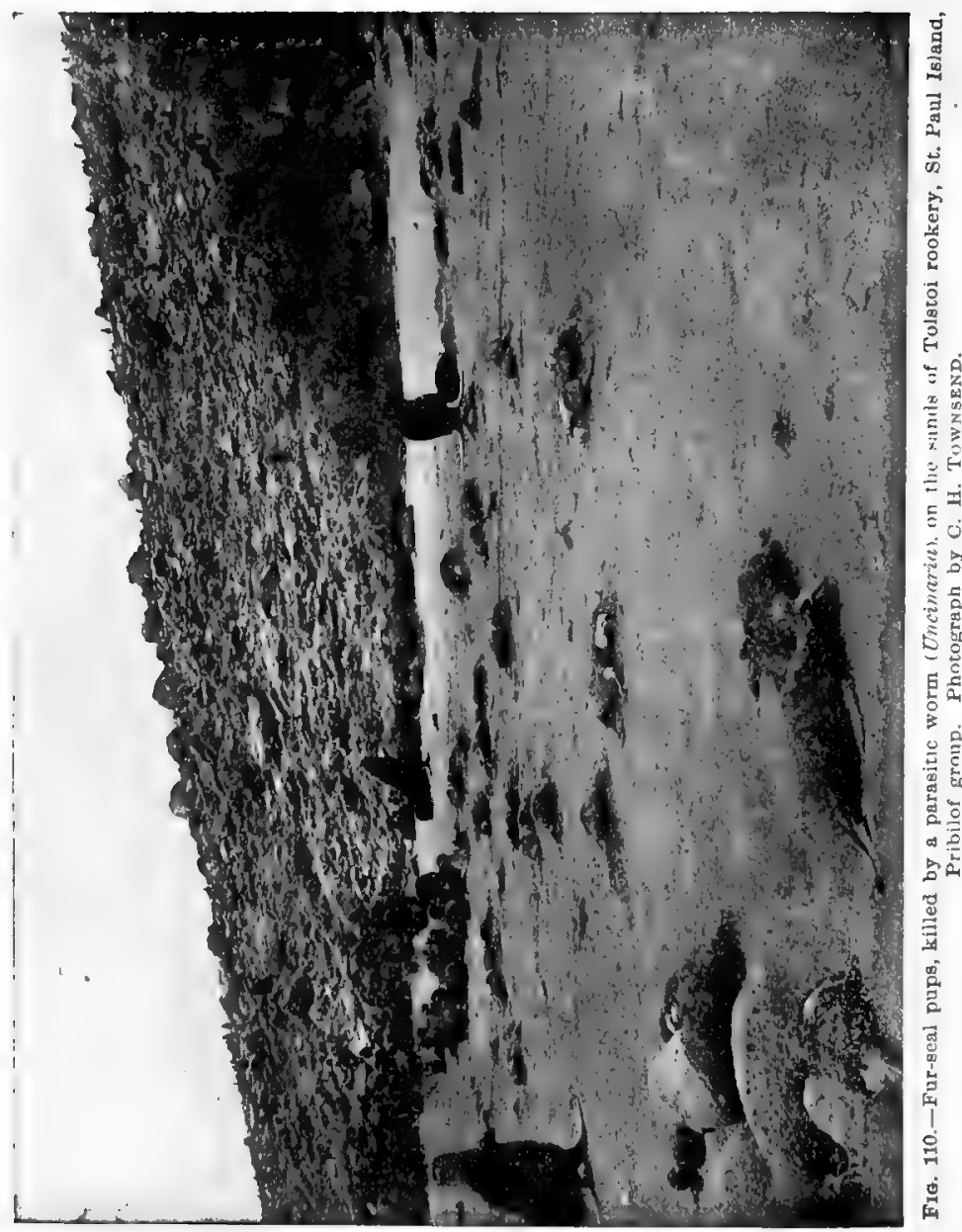


and the worm develops in the upper intestine. It feeds on the blood of the young seal, which finally dies from anæmia. On the beaches of the seal islands in Bering Sea there are sometimes hundreds of dead seal pups which have been killed by this parasite (Fig. 110).

99. Sacculina.-Among the more highly organized animals the results of a parasitic life, in degree of structural degeneration, can be more readily seen. A well-known parasite, belonging to the crustacea-the class of shrimps, crabs, lobsters, and cray-fishes-is Sacculina. The young Sacculina is an active, free-swimming larva much like a young prawn or young crab. But the adult bears absolutely no resemblance to such a typical crustacean as a cray-fish or crab. The Sacculina after a short period of independent existence attaches itself to the abdomen of a crab, and there completes its development while living as a parasite. In its adult condition (Fig. 111) it is simply a great tumor-like sac, bearing many
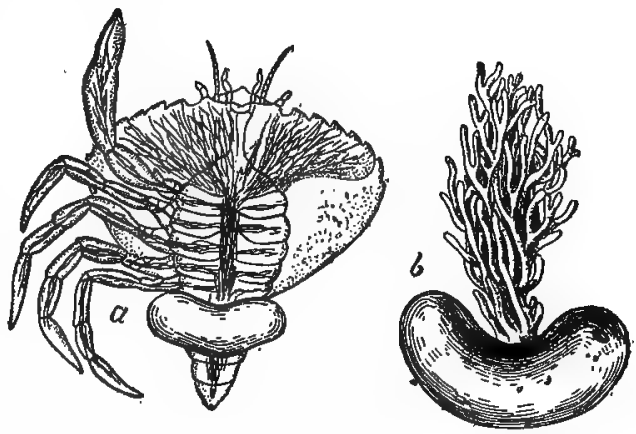

F1a. 111.-Sacculina, a crustacean parasite of crabs. a, attached to a crab, with root-like processes penerrating the crab's body ; $b$, removed from the crab. delicate root-

like suckers which penetrate the body of the crab host and absorb nutriment. The Sacculina has no eyes, no mouth parts, no legs, or other appendages, and hardly any of the usual organs except reproductive organs. Degeneration here is carried very far.

Other parasitic crustacea, as the numerous kinds of fish-lice (Fig. 112) which live attached to the gills or to 
other parts of fish, and derive all their nutriment from the body of the fish, show various degrees of degeneration. With

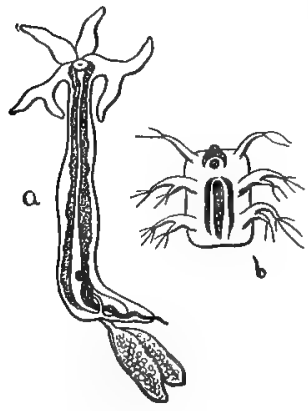

Fia. 112. - Fish-louge (Lernoecera). $u$, adult; $b$, larva. some of these fish-lice the female, which looks like a puffed-out worm, is attached to the fish or other aquatic animal, while the male, which is perhaps only a tenth of the size of the female, is permanently attached to the female, living parasitically on her.

100. Parasitic insects. - Among the insects there are many kinds that live parasitically for part of their life, and not a few that live as parasites for their whole life. The true sucking lice (Fig. 113) and the bird-lice (Fig. 114) live for their whole lives as external parasites on the bodies of their host, but they are not fixed - that is, they retain their legs and power of locomotion, although they have lost their wings through degeneration. The eggs of the lice are deposited on the hair of the mammal or bird that

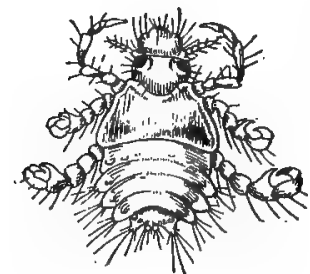

Fra. 118.-Sucking louse (Pediculus) of human body.

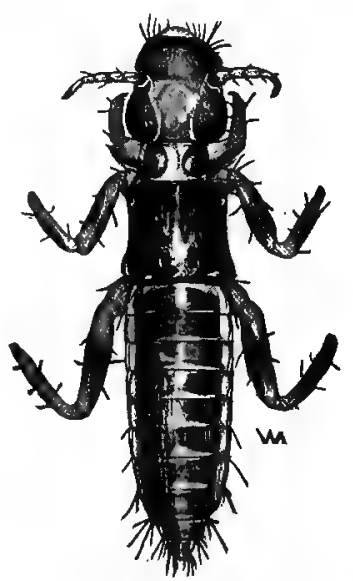

F1a. 114.-Bird louse (Lipeurus densus).

serves as host; the young hatch and immediately begin to live as parasites, either sucking the blood or feeding on the 
hair or feathers of the host. In the order Hymenoptera there are several families, all of whose members live during their larval stage as parasites. We may call all these hymenopterous parasites ichneumon flies. The ichneumon flies are parasites of other insects, especially of the larvæ of beetles and moths and butterflies. In fact, the ichneumon flies do more to keep in check the increase of injurious and destructive caterpillars than do all our artificial remedies for these insect pests. The adult ichneumon fly is fourwinged and lives an active, independent life. It lays its eggs either in or on or near some caterpillar or beetle grub, and the young ichneumon, when hatched, burrows about in the body of its host, feeding on its tissues, but not attacking such organs as the heart or nervous ganglia, whose injury would mean immediate death to the host. The caterpillar lives with the ichneumon grub within it, usually until nearly

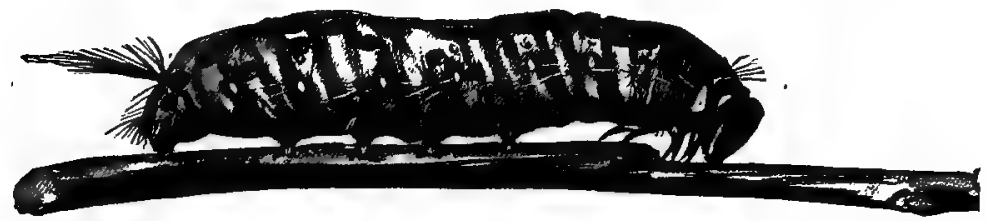

Frg. 115.-Parasitized caterpillar from which the icbneumon fly parusites huve issued, showing the circular holes of exit in the skin.

time for its pupation. In many instances, indeed, it pupates, with the parasite still feeding within its body, but it never comes to maturity. The larval ichneumon fly pupates either within the body of its host (Fig. 115) or in a tiny silken cocoon outside of its body (Fig. 116). From the cocoons the adult winged ichneumon flies emerge, and after mating find another host on whose body to lay their eggs.

One of the most interesting ichneumon flies is Thalessa (Fig. 119), which has a remarkably long, slender, flexible ovipositor, or egg-laying organ. An insect known as the 
pigeon horn-tail (Tremex columba) (Fig. 117) deposits its eggs, by means of a strong, piercing ovipositor, half an inch deep in the trunk wood of growing trees. The young or
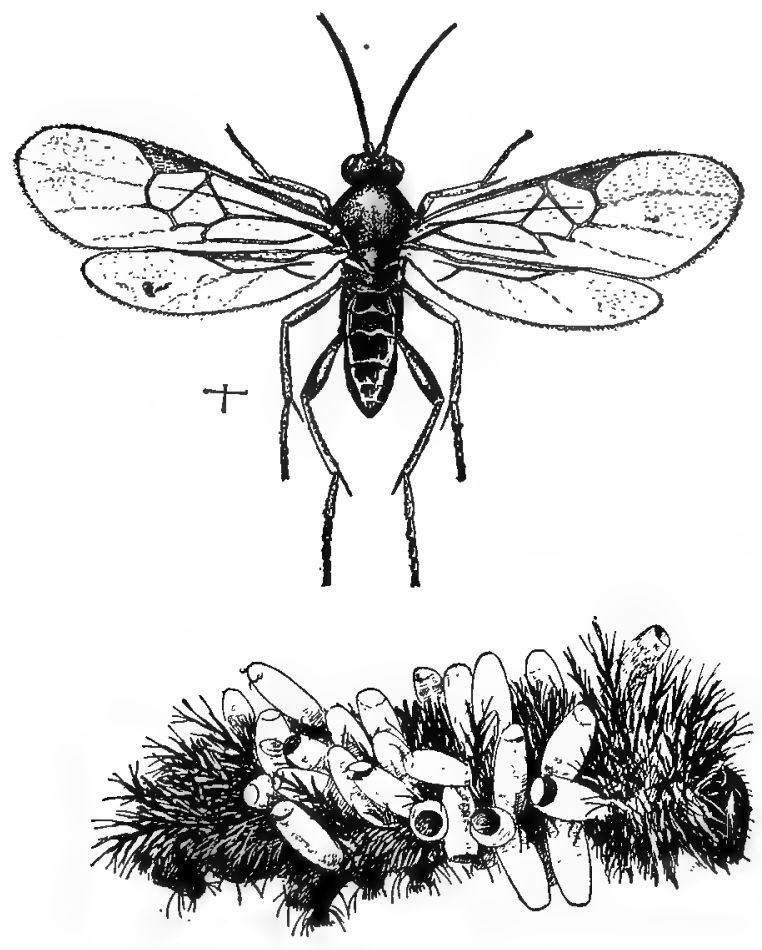

Fra. 116.-Caterpillar with cocoons of the pupæ of ichneumon fly parasites, and (above) one of the adult ichneumon flies. The lines indicate natural dimensions.

larval Tremex is a soft-bodied white grub, which bores deeply into the trunk of the tree, filling up the burrow behind it with small chips. The Thalessa is a parasite of the Tremex, and "when a female Thalessa finds a tree infested by Tremex, she selects a place which she judges is opposite 
a Tremex burrow, and, elevating her long ovipositor in a loop over her back, with its tip on the bark of the tree (Fig.

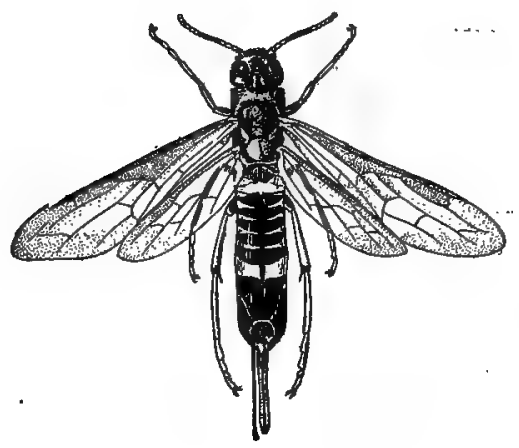

Fia. 11\%.-The pigeon horn-tail (Tremex columba), with strong boring ovipositor.
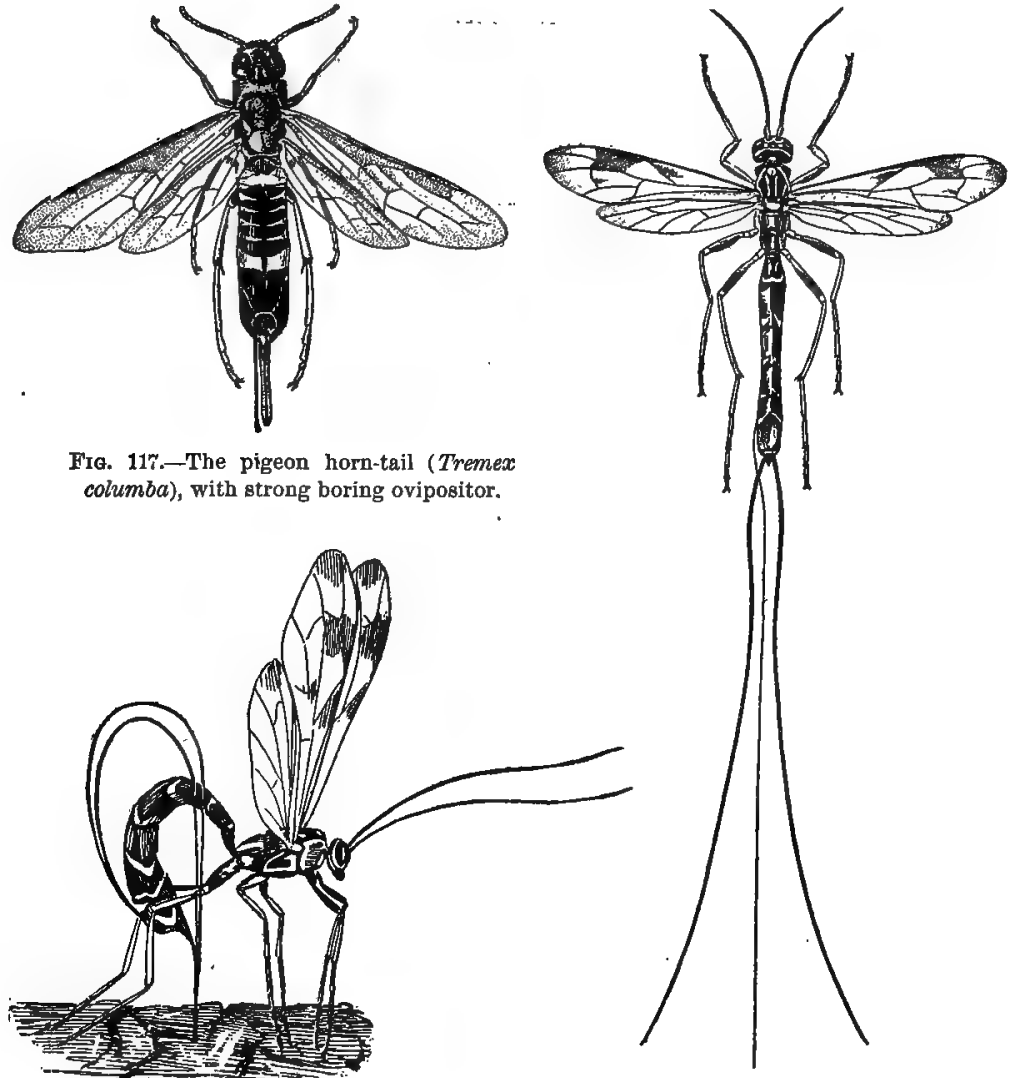

Fra. 118.-Thalessa lunator boring,-After COMSTOCK.

118), she makes a derrick out of her body and proceeds with

Fis. 119.-The large ichneumon fy Thalessa, with long flexible ovipositor. The various parts of this ovipositor are spread apart in the figure; naturally they lie together to form a single piercing organ. great skill and precision to drill a hole into the tree. When the Tremex burrow is reached she deposits an egg in it. 
The larva that hatches from this egg creeps along this burrow until it reaches its victim, and then fastens itself to the horn-tail larva, which it destroys by sucking its blood.

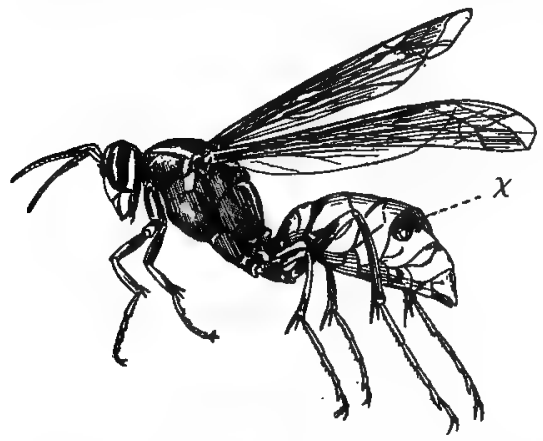

Fre. 120.-Wasp (Polistes), with female Stylops parasite $(x)$ in body.

The larva of Thales$s a$, when full grown, changes to a pupa within the burrow of its host, and the adult gnaws a hole out through the bark if it does not find the hole already made by the Tremex."

The beetles of the family Stylopidæ present an interesting case of parasitism. The adult males are winged, but the adult females are wingless and grub-like. The larval stylopid attaches itself to a wasp or bee, and bores into its abdomen. It pupates within the abdomen of the wasp or bee, and lies there with its head projecting slightly from a suture between two of the body rings of its host (Fig. 120). The adult finally issues and leaves the host's body.

Almost all of the mites and ticks, which are more nearly allied to the spiders than to the true insects, live parasitically. Most of them live as external parasites, sucking the blood of their host, but some live underneath the skin like the itch-mites

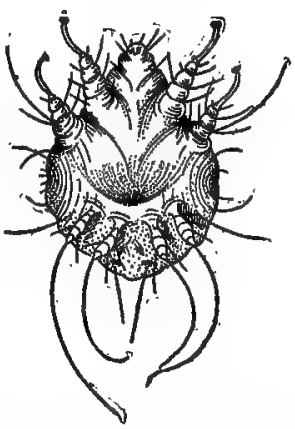

Fig. 121,-The itch-mite (Sarcoptes scabei). (Fig. 121), which cause, in man, the disease known as the itch. 
101. Parasitic vertebrates.-Among the vertebrate animals there are not many examples of true parasitism. The hag-fisbes or borers (Myxine, Heptatrema, Polistotrema) are long and cylindrical, eel-like creatures, very slimy and very low in structure. The mouth is without jaws, but forms a sucking disk, by which the hag-fish attaches itself to the body of some other fish. By means of the rasping teeth on its tongue, it makes a round hole through the skin, usually at the throat. It then devours all the muscular substance of the fish, leaving the viscera untouched. When the fish finally dies it is a mere hulk of skin, scales, bones, and viscera, nearly all the muscle being gone. Then the hagfish slips out and attacks another individual.

The lamprey, another low fish, in similar fashion feeds leech-like on the blood of other fishes, which it obtains by lacerating the flesh with its rasp-like teeth, remaining attached by the round sucking disk of its mouth.

Certain birds, as the cow-bird and the European cuckoo, have a parasitic habit, laying their eggs in the nests of other birds, leaving their young to be hatched and reared by their unwilling hosts. This is, however, not bodily parasitism, such as is seen among lower forms.

102. Degeneration through quiescence.-While parasitism is the principal cause of degeneration among animals, yet it is not the sole cause. It is evident that if for any other reason animals should become fixed, and live inactive or sedentary lives, they would degenerate. And there are not a few instances of degeneration due simply to a quiescent life, unaccompanied by parasitism. The Tunicata, or sea、 squirts (Fig. 122), are animals which have become simple through degeneration, due to the adoption of a sedentary life, the withdrawal from the crowd of animals and from the struggle which it necessitates. The young tunicate is a free-swimming, active, tadpole-like or fish-like creature, which possesses organs very like those of the adult of the simplest fishes or fish-like forms. That is, the sea-squirt 
begins life as a primitively simple vertebrate. It possesses in its larval stage a notochord, the delicate structure which precedes the formation of a backbone, extending along the

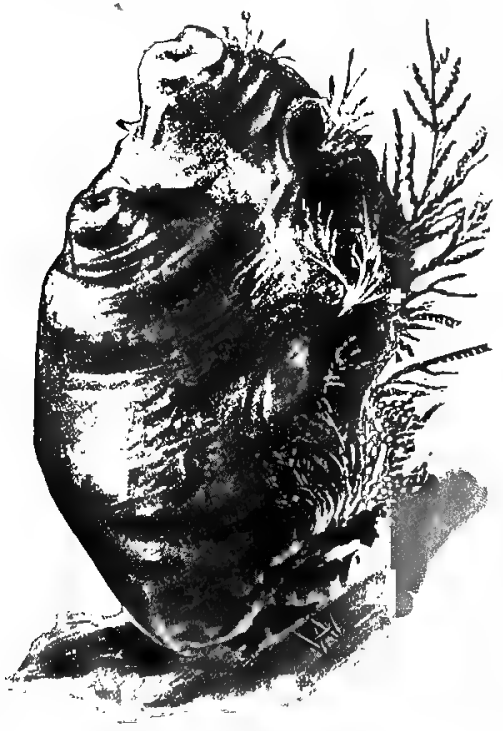

Fig. 122.-A sea-squirt, or tunicate.

upper part of the body, below the spinal cord. It is found in all young vertebrates, and is characteristic of the class. The other organs of the young tunicate are all of vertebral type. But the young sea-squirt passes a period of active and free life as a little fish, after which it settles down and attaches itself to a stone or shell or wooden pier by means of suckers, and remains for the rest of its life fixed. Instead of going on and developing into a fish-like creature, it loses its notochord, its special sense organs, and other organs; it loses its complexity and high organization, and becomes a "mere rooted bag with a double neck," a thoroughly degenerate animal.

A barnacle is another example of degeneration through quiescence. The barnacles are crustaceans related most nearly to the crabs and shrimps. The young barnacle just from the egg (Fig. 123, $f$ ) is a six-legged, free-swimming nauplius, very like a young prawn or crab, with single eye. In its next larval stage it has six pairs of swimming feet, two compound eyes, and two large antennæ or feclers, and still lives an independent, free-swimming life. When it makes its final change to the adult condition, it attaches 
itself to some stone or shell, or pile or ship's bottom, loses its compound eyes and feelers, develops a protecting shell, and gives up all power of locomotion. Its swimming feet become changed into grasping organs, and it loses most of its outward resemblances to the other members of its class (Fig. 123,e).

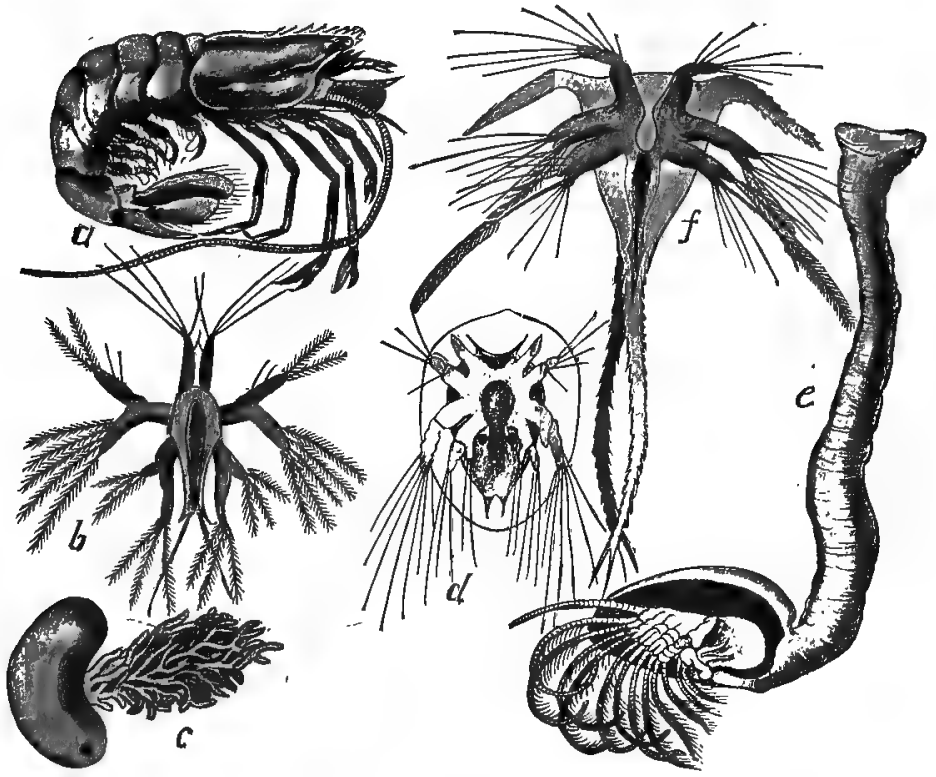

Fra. 123,-Three adult crustaceans and their larvæ. $u$, prawn (Peneus), active and free-living; $b$, larva of prawn; $c$, Sacculina, parasite ; $d$, larva of Sacculina ; $e$, barnacle (Lepas), with fixed quiescent life; $f$, larva of barnacle.-After HABCKBL.

Certain insects live sedentary or fixed lives. All the members of the family of scale insects (Coccidæ), in one sex at least, show degeneration, that has been caused by quiescence. One of these coccids, called the red orange scale (Fig. 124), is very abundant in Florida and California and in other orange-growing regions. The male is a beautiful, tiny, two-winged midge, but the female is a wingless, 
footless little sac without eyes or other organs of special sense, which lies motionless under a flat, thin, circular, reddish scale composed of wax and two or three cast skins of the insect itself. The insect has a long, slender, flexible, sucking beak, which is thrust into the leaf or stem or fruit of the orange on which the "scale bug" lives and through which the insect sucks the orange sap, which is its only

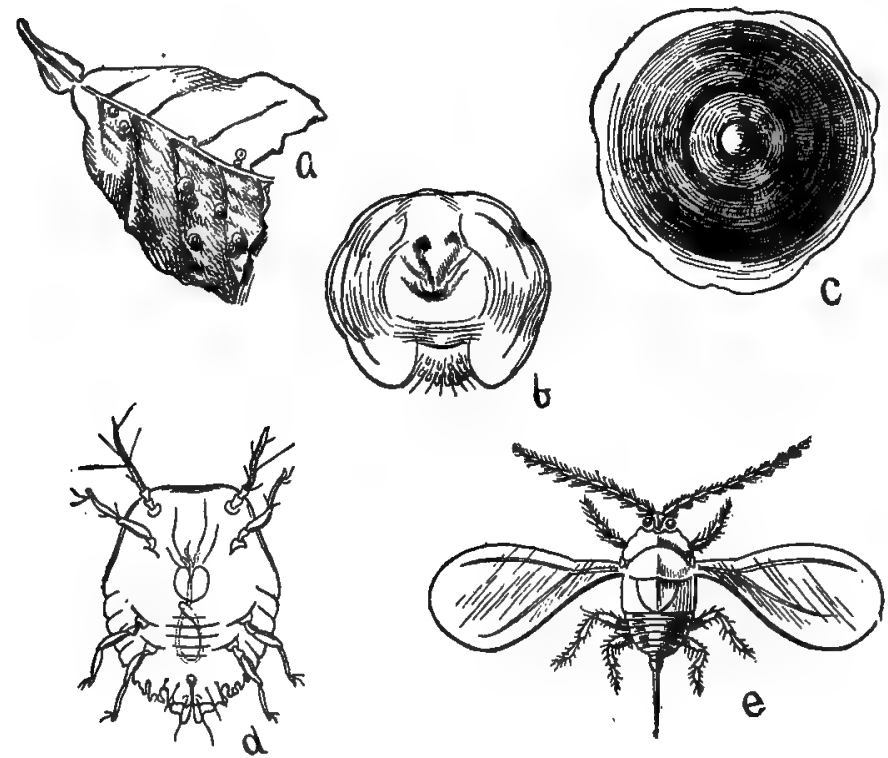

Fra. 124.-The red orange scale of California. a, bit of leaf with scales; $b$, adult female; $c$, wax scale under which adnlt female lives; $d$, larva; $e$, adult male.

food. It lays eggs under its body, and thus also under the protesting wax scale, and dies. From the eggs hatch active little larval scale-bugs with eyes and feelers and six legs. They crawl from under the wax scale and roam about over the orange tree. Finally, they settle down, thrusting their sucking beak into the plant tissues, and cast their skin. The females lose at this molt their legs and eyes and 
feelers. Each becomes a mere motionless sac capable only of sucking up sap and of laying eggs. The young males, however, lose their sucking beak and can no longer take food, but they gain a pair of wings and an additional pair of eyes. They fly about and fertilize the sac-like females, which then molt again and secrete the thin wax scale over them.

Throughout the animal kingdom loss of the need of movement is followed by the loss of the power to move, and of all structures related to it.

103. Degeneration through other sauses,--Loss of certain organs may occur through other causes than parasitism and a fixed life. Many insects live but a short time in their adult stage. May-flies live for but a few hours or, at most, a few days. They do not need to take food to sustain life for so short a time, and so their mouth parts have become rudimentary and functionless or are entirely lost. This is true of some moths and numerous other specially shortlived insects. Among the social insects the workers of the termites and of the true ants are wingless, although they are born of winged parents, and are descendants of winged ancestors. The modification of structure dependent apon the division of labor among the individuals of the community has taken the form, in the case of the workers, of a degeneration in the loss of the wings. Insects that live in caves are mostly blind; they have lost the eyes, whose function could not be exercised in the darkness of the cave. Certain island-inhabiting insects have lost their wings, flight being attended with too much danger. The strong sea-breezes may at any time carry a flying insect off the small island to sea. Only those which do not fly much survive, and by natural selection wingless breeds or species are produced. Finally, we may mention the great modifications of structure, often resulting in the loss of certain organs, which take place to produce protective resemblances (see Chapter XII). In such cases the body may be modified in 
color and shape so as to resemble some part of the environment, and thus the animal may be unperceived by its enemies. Many insects have lost their wings through this cause.

104. Immediate causes of degeneration.-When we say that a parasitic or quiescent mode of life leads to or causes degeneration, we have explained the stimulus or the ultimate cause of degenerative changes, but we have not shown just how parasitism or quiescence actually produces these changes. Degeneration or the atrophy and disappearance of organs or parts of a body is often said to be due to disuse. That is, the disuse of a part is believed by many naturalists to be the sufficient cause for its gradual Iwindling and final loss. That disuse can so affect parts of a body during the lifetime of an individual is true. A muscle unused becomes soft and flabby and small. Whether the effects of such disuse can be inherited, however, is open to serious doubt. Such inheritance must be assumed if disuse is to account for the gradual growing less and final disappearance of an organ in the course of many generations. Some naturalists believe that the results of such disuse can be inherited, but as yet such belief rests on no certain knowledge. If characters assumed during the lifetime of the individual are subject to inheritance, disuse alone may explain degeneration. If not, some other immediate cause, or some other cause along with disuse, must be found. Such a cause must be sought for in the action of natural selection, preserving the advantages of simplicity of structure where action is not required.

105. Advantages and disadvantages of parasitism and degeneration.-We are accustomed, perhaps, to think of degeneration as necessarily implying a disadvantage in life. A degenerate animal is considered to be not the equal of a nondegenerate animal, and this would be true if both kinds of animals had to face the same conditions of life. The blind, footless, simple, degenerate animal could not cope with the 
active, keen-sighted, highly organized non-degenerate in free competition. But free competition is exactly what the degenerate animal has nothing to do with. Certainly the Sacculina lives successfully ; it is well adapted for its own peculiar kind of life. For the life of a scale insect, no better type of structure could be derised. A parasite enjoys certain obvious advantages in life, and even extreme degeneration is no drawback, but rather favors it in the advantageousness of its sheltered and easy life. As long as the host is successful in eluding its enemies and avoiding accident and injury, the parasite is safe. It needs to exercise no activity or vigilance of its own; its life is easy as long as its host lives. But the disadvantages of parasitism and degeneration are apparent also. The fate of the parasite is usually bound up with the fate of the host. When the enemy of the host crab prevails, the Sacculina goes down without a chance to struggle in its own defense. But far more important than the disadvantage in such particular or individual cases is the disadvantage of the fact that the parasite can not adapt itself in any considerable degree to new conditions. It has become so specialized, so greatly modified and changed to adapt itself to the one set of conditions under which it now lives; it has gone so far in its giving up of organs and body parts, that if present conditions should change and new ones come to exist, the parasite could not adapt itself to them. The independent, active animal with all its organs and all its functions intact, holds itself, one may say, ready and able to adapt itself to any new conditions of life which may gradually come into existence. The parasite has risked everything for the sake of a sure and easy life under the presently existing conditions. Change of conditions means its extinction.

106. Human degeneration.-It is not proposed in these pages to discuss the application of the laws of animal life to man. But each and every one extends upward, and can 
be traced in the relation of men and society. Thus, among men as among animals, self-dependence favors complexity of power. Dependence, parasitism, quiescence favor degeneration. . Degeneration means loss of complexity, the narrowing of the range of powers and capabilities. It is not necessarily a phase of disease or the precursor of death. But as intellectual and moral excellence are matters associated with high development in man, dependence is unfavorable to them.

Degeneration has been called animal pauperísm. Pauperism in all its forms, whether due to idleness, pampering, or misery, is human degeneration. It has been shown that a large part of the criminality and pauperism among men is hereditary, due to the survival of the tendency toward living at the expense of others. The tendency to live without self-activity passes from generation to generation. Beggary is more profitable than unskilled and inefficient labor, and our ways of careless charity tend to propagate the beggar. That form of charity which does not render its recipient self-helpful is an incentive toward degeneration. Withdrawal from the competition of life, withdrawal from self-helpful activity, aided by the voluntary or involuntary assistance of others-these factors bring about dcgeneration. The same results follow in all ages and with all races, with the lower animals as with men. 


\section{CHAPTER XII}

\section{PROTECTIVE RESEMBLANCES, AND MIMICRY}

10\%. Protective resemblance defined.-If a grasshopper be startled from the ground, you may watch it and determine exactly where it alights after its leap or flight, and yet, on going to the spot, be wholly unable to find it. The colors and marking of the insect so harmonize with its surroundings of soil and vegetation that it is nearly indistinguishable as long as it remains at rest. And if you were intent on capturing grasshoppers for fish-bait, this resemblance in appearance to their surroundings would be very annoying to you, while it would be a great advantage to the grasshoppers, protecting some of them from capture and death. This is protective resemblance. Mere casual observation reveals to us that such instances of protective resemblance are very common among animals. A rabbit or grouse crouching close to the ground and remaining motionless is almost indistinguishable. Green caterpillars lying outstretched along green grass-blades or on green leaves may be touched before being recognized by sight. In arctic regions of perpetual snow the polar bears, the snowy arctic foxes, and the hares are all pure white instead of brown and red and gray like their cousins of temperate and warm regions. Animals of the desert are almost without exception obscurely mottled with gray and sand color, so as to harmonize with their surroundings.

In the struggle for existence anything that may give an animal an advantage, however slight, may be sufficient to turn the scale in favor of the organism possessing the 
advantage. Such an advantage may be swiftness of movement, or unusual strength or capacity to withstand unfavorable meteorological conditions, or the possession of such color and markings or peculiar shape as tend to conceal the animal from its enemies or from its prey. Resemblances may serve the purpose of aggression as well as protection. In the case of the polar bears and other predaceous animals that show color likenesses to their surroundings, the resemblance can better be called aggressive than protective. The concealment afforded by the resemblance allows them to steal unperceived on their prey. This, of course, is an advantage to them as truly as escape from enemies would be.

We have already seen that by the action of natural selection and heredity those variations or conditions that give animals advantages in the struggle for life are preserved and emphasized. And so it has come about that advantageous protective resemblances are very widespread among animals, and assume in many cases extraordinarily striking and interesting forms. In fact, the explanation of much of the coloring and patterning of animals depends on this principle of protective resemblance.

Before considering further the general conditions of protective resemblances, it will be advisable to refer to specific examples classified roughly into groups or special kinds of adrantageous colorings and markings.

108. General protective or aggressive resemblance.-As examples of general protective resemblance-that is, a general color effect harmonizing with the usual surroundings and tending to hide or render indistinguishable the animal - may be mentioned the hue of the green parrots of the evergreen tropical forests; of the green tree-frogs and treesnakes which live habitually in the green foliage; of the mottled gray and tawny lizards, birds, and small mammals of the deserts; and of the white hares and foxes and snowy owls and ptarmigans of the snow-covered arctic regions. Of the same nature is the slaty blue of the 


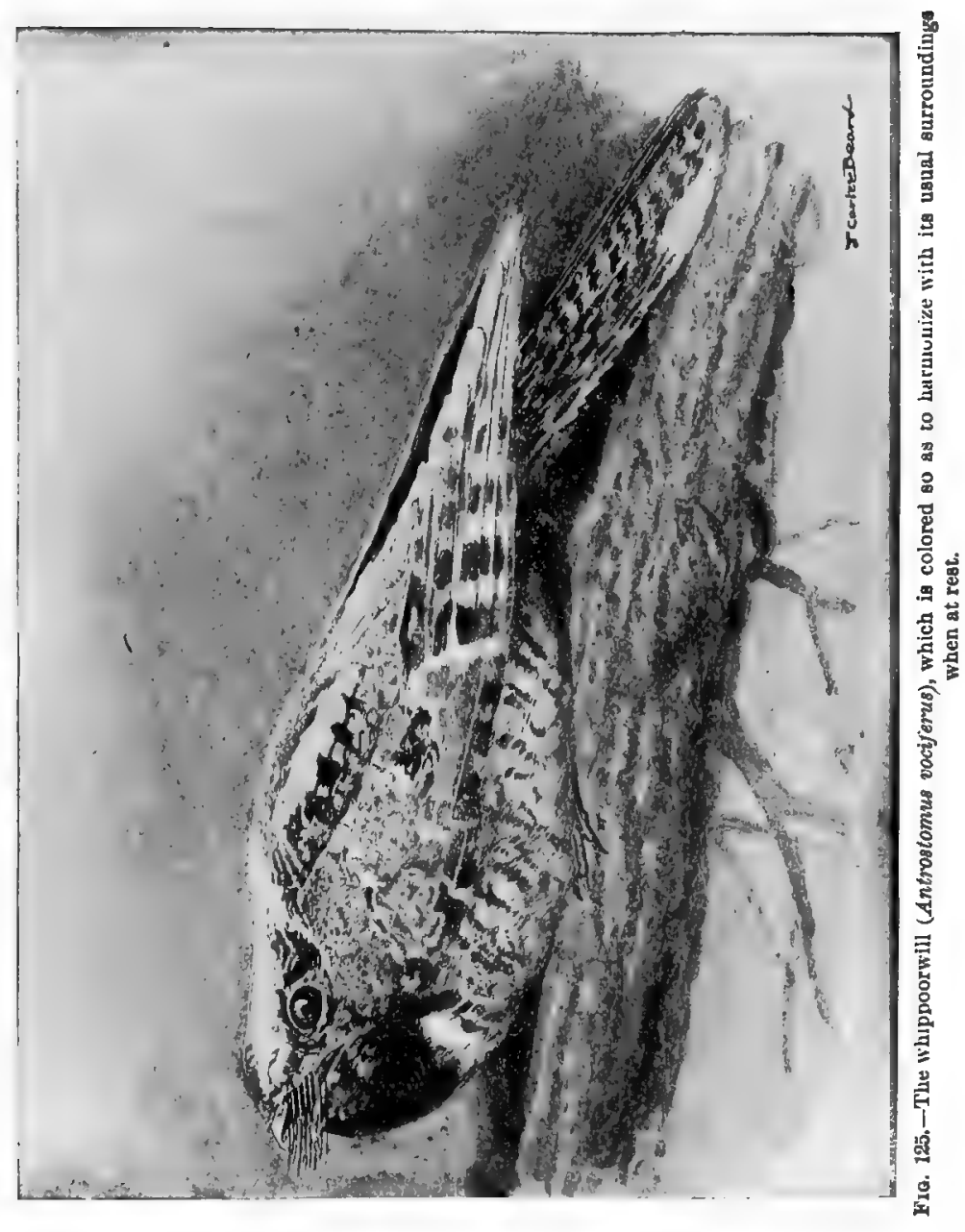


gulls and terns, colored like the sea. In the brooks most fishes are dark olive or greenish above and white below. To the birds and other enemies which look down on them from above they are colored like the bottom. To their fish enemies which look up from below, their color is like the white light above them, and their forms are not clearly seen. The fishes of the deep sea in perpetual darkness are

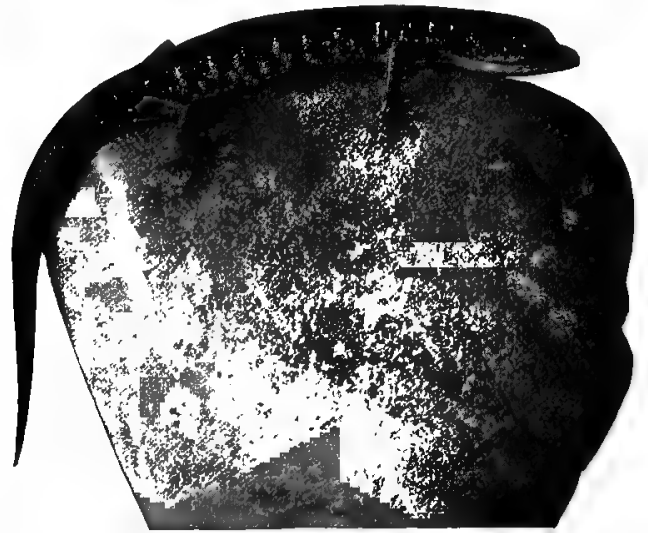

Fra. 126.-Alligator lizard (Gemhonotus scincicauda) on granite rock. Photograph by J, O. SNYDER, Stanford University, California.

inky violet in color below as well as above. Those that live among sea-weeds are red, grass-green, or olive, like the plants they frequent. General protective resemblance is very widespread among animals, and is not easily appreciated when the animal is seen in museums or zoölogical gardens-that is, away from its natural or normal environment. A modification of general color resemblance found in many animals may be called variable protective resemblance. Certain hares and other animals that live in northern latitudes are wholly white during the winter when the snow covers everything, but in summer, when much of the snow melts, revealing the brown and gray rocks and 
withered leaves, these creatures change color, putting on a grayish and brownish coat of hair. The ptarmigan of the Rocky Mountains (one of the grouse), which lives on the snow and rocks of the high peaks, is almost wholly white in winter, but in summer when most of the snow is melted its plumage is chiefly brown. On the campus at Stanford University there is a little pond whose shores are covered in some places with bits of bluish rock, in other places with bits of reddish rock, and in still other places with sand. A small insect called the toad-bug (Galgulus oculatus) lives abundantly on the banks of this pond. Specimens collected from the blue rocks are bluish in color, those from the red rocks are reddish, and those from the sand are sand-colored. Such changes of color to suit the changing surroundings can be quickly made in the case of some animals. The chameleons of the tropics, whose skin changes color momentarily from green to brown, blackish or golden, is an excellent example of this highly specialized condition. The same change is shown by a small lizard of our Southern States ( A nolius), which from its habit is called the Florida chameleon. There is a little fish (Otigocotlus snyderi) which is common in the tide pools of the bay of Monterey, in California, whose color changes quickly to harmonize with the different colors of the rocks it happens to rest abore. Some of the treefrogs show this variable coloring. $\Lambda$ very striking instance of variable protective

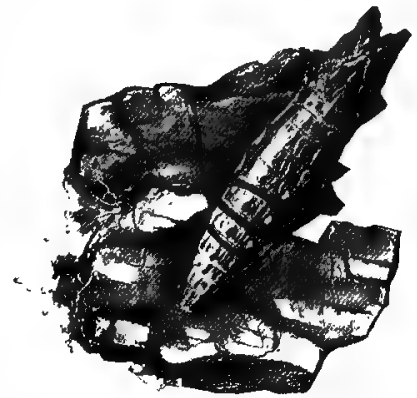

Fig. 127.-Chrysalid of swallow-tail butterfly (Papilio), harmonizing with the bark on which it rests. resemblance is shown by the chrysalids of certain butterflies. An eminent English naturalist collected many caterpillars of a certain species of 
butterfly, and put them, just as they were about to change into pupæ or chrysalids, into various boxes, lined with paper of different colors. The color of the chrysalid was found

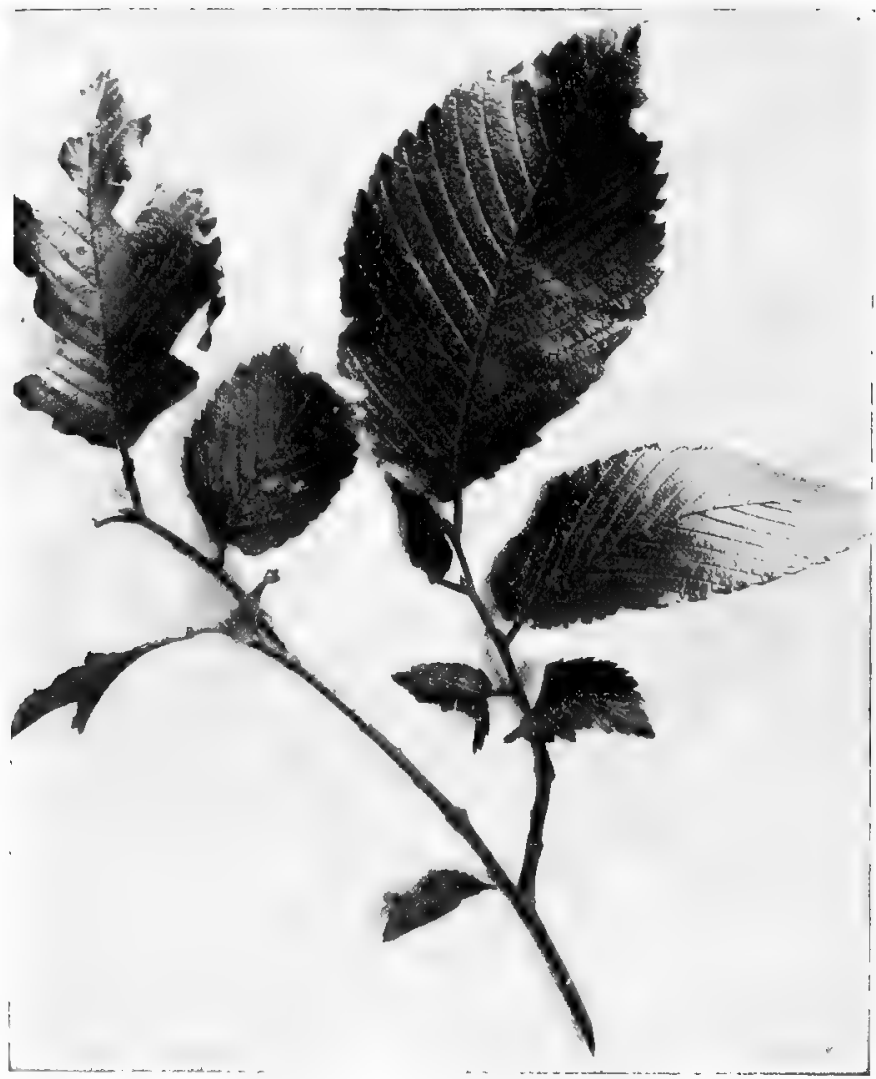

Fia. 128.-Chrysalia of butterfiy (lower left-hand projection from stem), showing proteetive resemblance. Photograph from Nature.

to harmonize very plainly with the color of the lining of the box in which the chrysalid hung. It is a familiar fact to entomologists that most butterfly chrysalids resemble in 
color and general external appearance the surface of the object on which they rest (Figs. $12 \%$ and 128).

109. Special protective resemblance.-Far more striking are those cases of protective resemblance in which the animal resembles in color and shape, sometimes in extraordinary detail, some particular object or part of its usual environment. Certain parts of the Atlantic Ocean are covered with great patches of sca-weed called the gulf-weed (Sargassum), and many kinds of animals-fishes and other creatures-live upon and among the algæ. No one can fail to note the extraordinary color resemblances which exist between those animals and the weed itself. The gulf-weed. is of an olive-yellow color, and the crabs and shrimps, a certain flat-worm, a certain mollusk, and a little fish, all of which live among the Sargassum, are exactly of the same shade of yellow as the weed, and have small white markings on their bodies which are characteristic also of the Sargassum. The mouse-fish or Sargassum fish and the little seahorses, often attached to the gulf-weed, show the same traits of coloration (Fig. 129). In the black rocks about Tabiti is found the black nokee or lava-fish (Emmydrichthys vulcanus) (Fig. 66), which corresponds perfectly in color and form to a piece of lava. This fish is also noteworthy for having envenomed spines in the fin on its back. The slender grass-green caterpillars of many moths and butterflies resemble very closely the thin grass-blades among which they live. The larræ of the geometrid moths, called inch-worms or span-worms, are twig-like in appearance, and have the habit, when disturbed, of standing out stiffly from the twig or branch upon which they rest, so as to rescmble in position as well as in color and markings a short or a broken twig. One of the most striking resemblances of this sort is shown by the large geometria larva illustrated in Fig. 130, which was found near Ithaca, New York. "The body of this caterpillar has a few small, irregular spots or humps, resembling very exactly the scars left by fallen. 


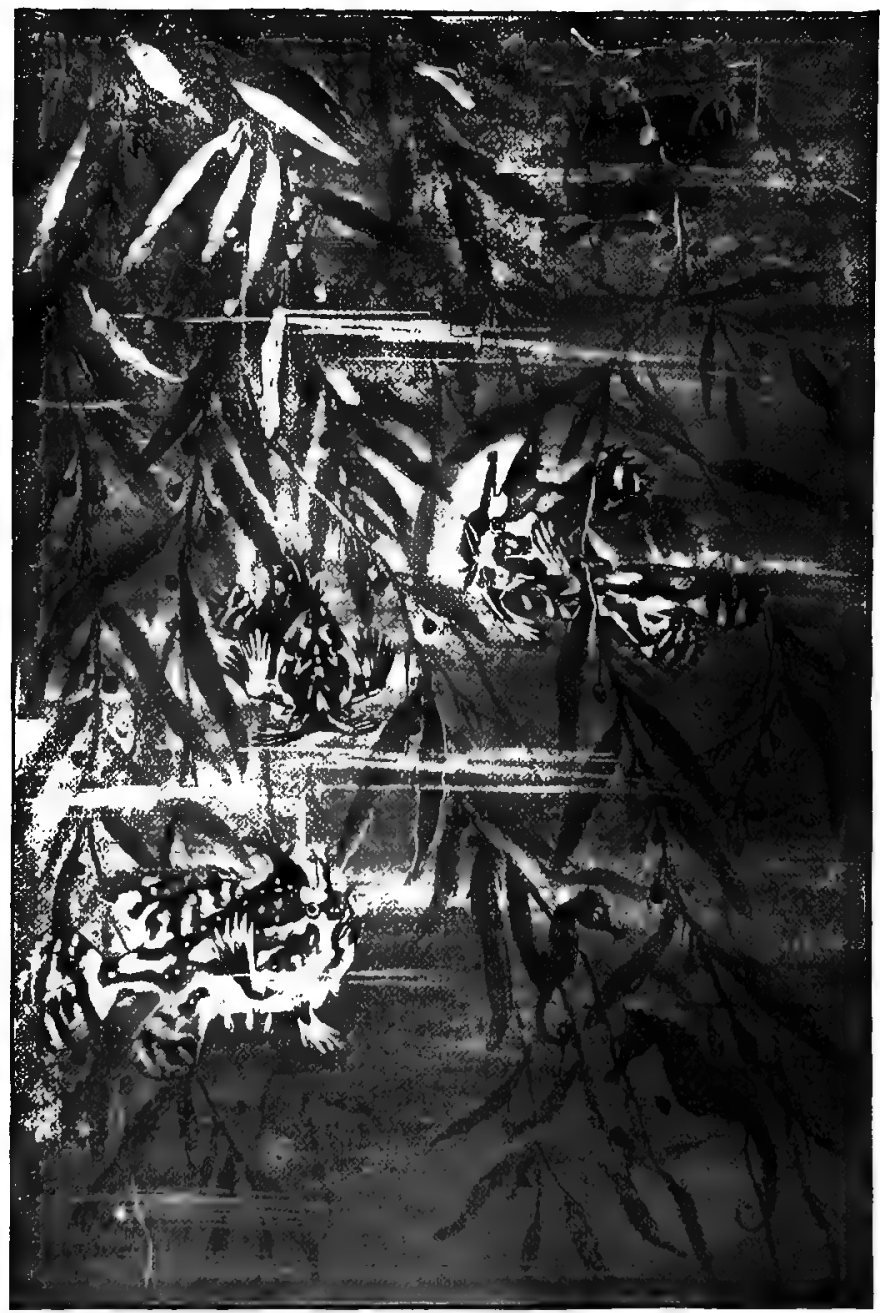

Fro. 129. -The mouse-fish (Pterophryne histrio) in the Sargassum or gulf-weed. 'The fishes are marked and colored so an to b" nesrly indistinguighable from the magate of the gulf-weed. In the lower right-hanul corner of flgure are two sea-borges, alsu shaped and marked so ar to be concenled. 


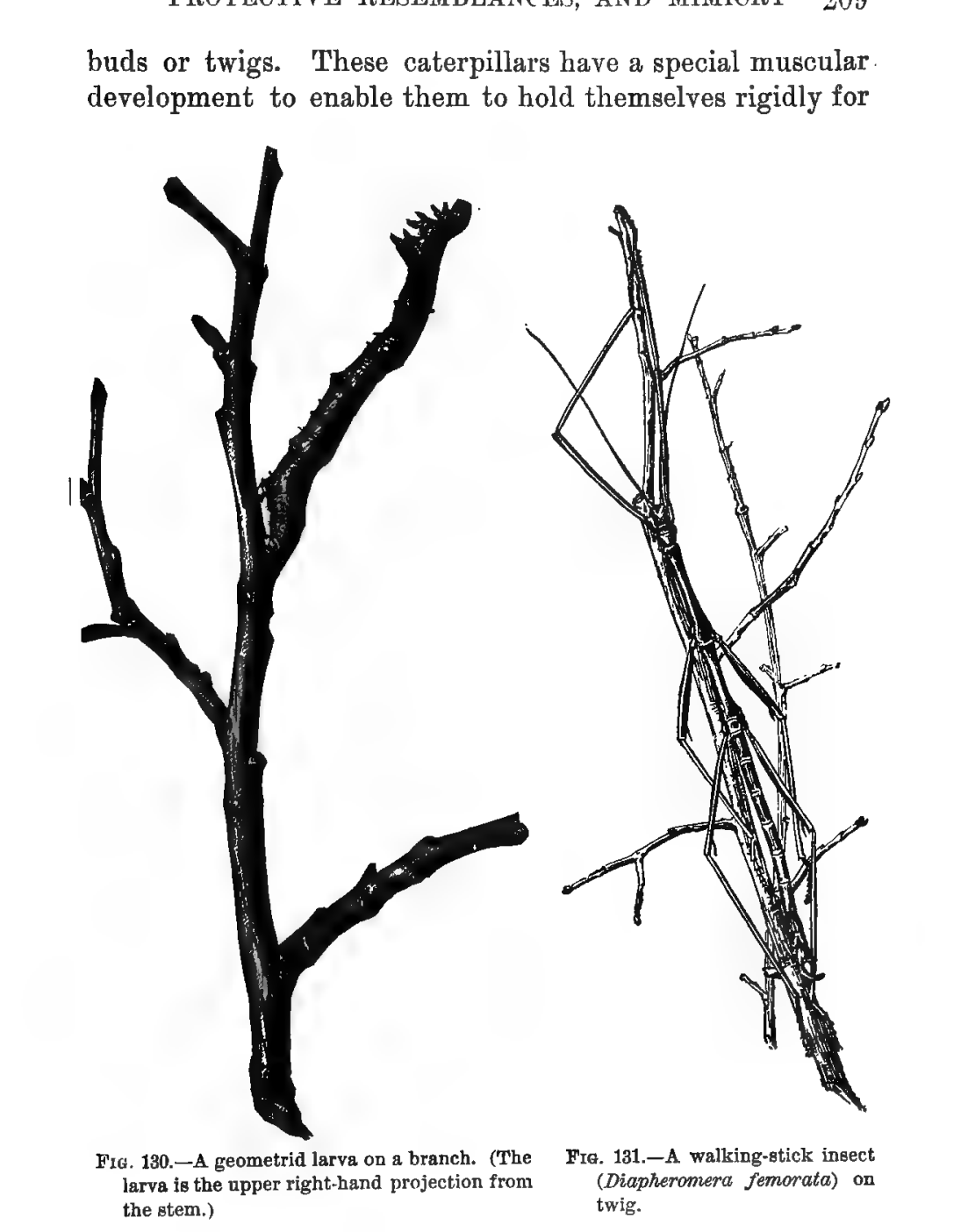


ous larvæ, the presence of which would tend to destroy the illusion so successfully carried out by them. The common walking-stick (Diapheromera) (Fig. 131), with its wingless, greatly elongate, dull-colored body, is an excellent example of special protective resemblance. It is quite indistinguishable, when at rest, from the twigs to which it is clinging. Another member of the family of insects to which the walking-stick belongs is the famous green-leaf insect (Phyllium)

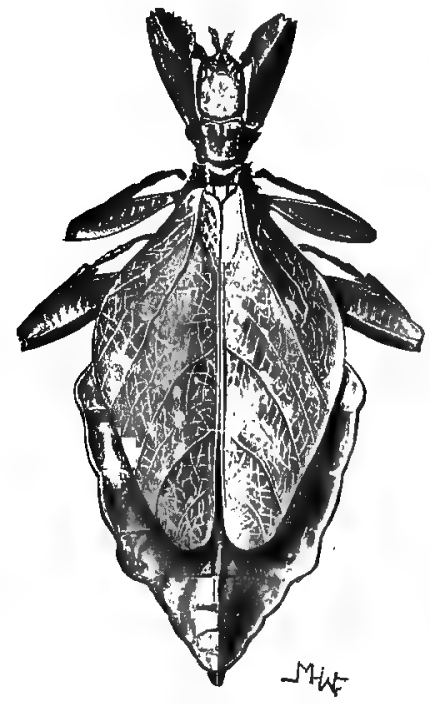

F19. 132.-The green-lea? insect (Plyllium).

(Fig. 132). It is found in South America and is of a bright green color, with broad leaf-like wings and body, with markings which imitate the leaf veins, and small irregular yellowish spots which mimic decaying or stained or fungus-covered spots in the leaf.

There are many butterflies that resemble dead leaves. All our common meadow browns (Grapta), brown and reddish butterflies with ragged-edged wings, that appear in the autumn and flutter aimlessly about $\mathrm{ex}$ actly like the falling leaves, show this resemblance. But most remarkable of all is a large butterfly (Kallima) (Fig. 133) of the East Indian region. The upper sides of the wings are dark, with purplish and orange markings, not at all resembling a dead leaf. But the butterflies when at rest hold their wings together over the back, so that only the under sides of the wings are exposed. The under sides of Kallima's wings are exactly the color of a dead and dried leaf, and 
the wings are so held that all combine to mimic with extraordinary fidelity a dead leaf still attached to the twig by a short pedicle or leaf-stalk imitated by a short tail on the

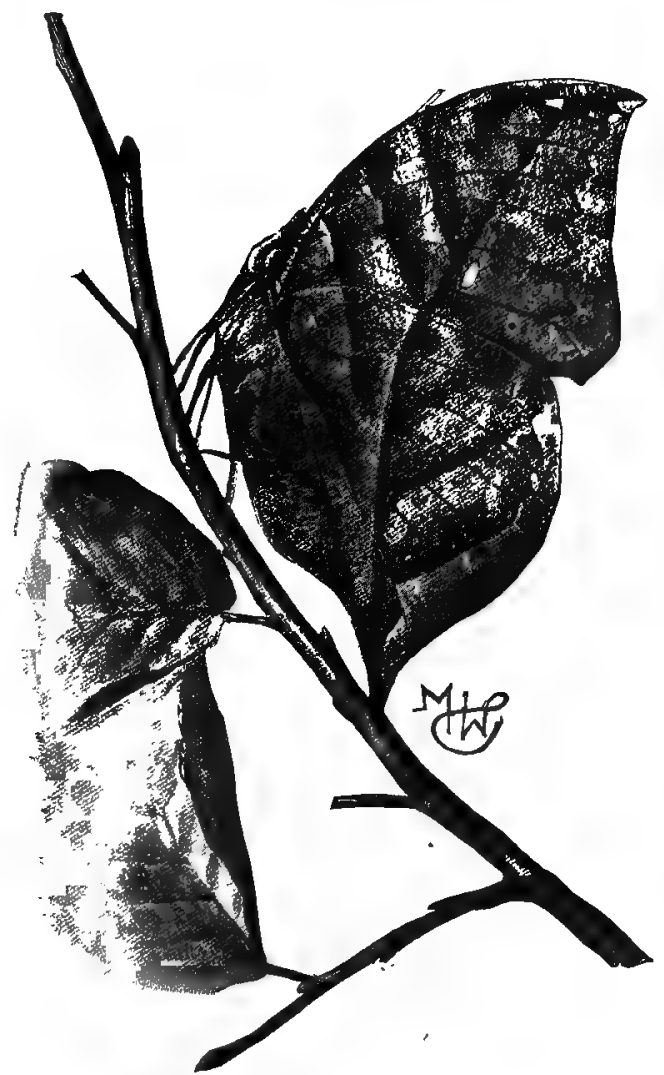

Fra. 133.-Kallima, the "dead-leaf butterfly."

hind wings, and showing midrib, oblique veins, and, most remarkable of all, two apparent holes, like those made in leaves by insects, but in the butterfly imitated by two small circular spots free from scales and hence clear and trans- 
parent. With the head and feelers concealed beneath the wings, it makes the resemblance wonderfully exact.

There are numerous instances of special protective resemblance among spiders. Many spiders (Fig. 134) that
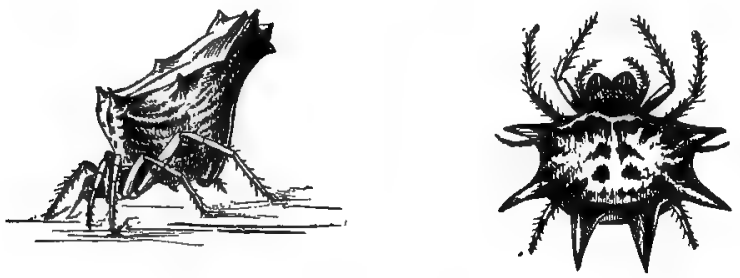

Fra. 134.-Spiders showing unusual shnpes and patterns, for purposes of aggressive resemblance.

live habitually on tree trunks resemble bits of bark or small, irregular masses of lichen. A whole family of spiders, which live in flower-cups lying in wait for insects, are white and pink and party-colored, resembling the markings of the special flowers frequented by them. This is, of course, a

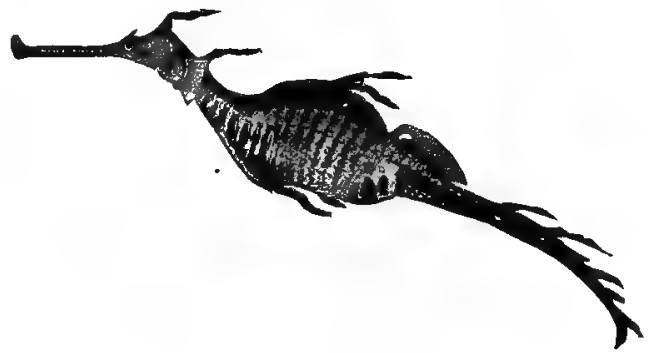

Fı.. 135.-A pipe-fish (Plyllopteryy resembling se:l-wred, in which it live's.

special resemblance not so much for protection as for aggression; the insects coming to visit the flowers are unable to distinguish the spiders and fall an easy prey to them.

110. Warning colors and terrifying appearances,-In the cases of udvantageous coloring and patterning so far dis- 
cussed the advantage to the animal lies in the resemblance. between the animals and their surroundings, in the inconspicuousness and concealment afforded by the coloration. But there is another interesting phase of advantageous coloration in which the advantage derived is in rendering the animals as conspicuous and as readily recognizable as possible. While many animals are very inconspicuously colored, or are manifestly colored so as to resemble their surroundings, generally or specifically, many other animals are very brightly and conspicuously colored and patterned. If we are struck by the numerous cases of imitative coloring among insects, we must be no less impressed by the many cases of bizarre and conspicuous coloration among them.

Many animals, as we well know, possess special and effective weapons of defense, as the poison-fangs of the venomous snakes and the stings of bees and wasps. Other animals, and with these cases most of us are not so well acquainted, possess a means of defense, or rather safety, in being inedible-that is, in possessing some acrid or illtasting substance in the body which renders them unpalatable to predaceous animals. Many caterpillars have been found, by observation in Naturo and by experiment, to be distasteful to insectivorous birds. Now, it is obvious that it would be a great advantage to these caterpillars if they could be readily recognized by birds, for a severe stroke by a bird's bill is about as fatal to a caterpillar as being wholly eaten. Its soft, distended body suffers mortal hurt if cut or bitten by the bird's beak. This advantage of being readily recognizable is possessed by many if not all illtasting caterpillars by being brilliantly and conspicuously colored and marked. Such colors and markings are called warning colors. They are intended to inform birds of the fact that the caterpillar displaying them is an ill-tasting insect, a caterpillar to be let alone. The conspicuously black-and-yellow banded larva (Fig. 43, b) of the common 
Monarch butterfly is a good example of the possession of warning colors by distasteful caterpillars.

These warning colors are possessed not only by the illtasting caterpillars, but by many animals which have special means of defense. The wasps and bees, provided with stings-dangerous animals to trouble-are almost all conspicuously marked with yellow and black. The lady-bird beetles (Fig. 136), composing a whole family of small beetles
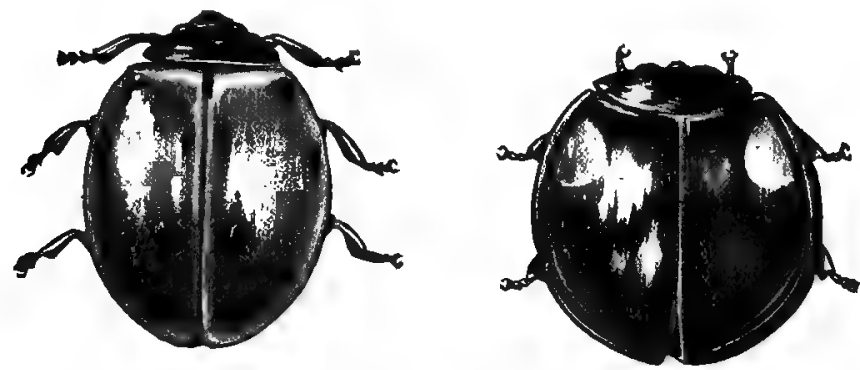

Fra. 136.-Two lady-bird beetles, conspicuously colored and marked.

which are all ill-tasting, are brightly and conspicuously colored and spotted. The Gila monster (Heloderma), the only poisonous lizard, differs from most other lizards in being strikingly patterned with black and brown. Some of the venomous snakes are conspicuously colored, as the coral snakes (Elaps) or coralillos of the tropics. The naturalist Belt, whose observations in Nicaragua have added much to our knowledge of tropical animals, describes as follows an interesting example of warning colors in a species of frog: "In the woods around Santo Domingo (Nicaragua) there are many frogs. Some are green or brown and imitate green or dead leaves, and live among foliage. Others are dull earth-colored, and hide in holes or under logs. All these come out only at night to feed, and they are all preyed upon by snakes and birds. In contrast with these obscurely colored specios, another little frog hops about in 
the daytime, dressed in a bright livery of red and blue. IIe can not be mistaken for any other, and his flaming breast and blue stockings show that he does not court conccalment. He is very abundant in the damp woods, and I was convinced he was uneatable so soon as I made his acquaintance and saw the happy sense of security with which he hopped about. I took a few specimens home with me, and tried my fowls and ducks with them, but none would touch them. At last, by throwing down pieces of meat, for which there was a great competition among them, I managed to entice a young duck into snatching up one of the little frogs. Instcad of swallowing it, however, it instantly threw it out of its mouth, and wont about jerking its head, as if trying to throw off some unpleasant taste."

Certain animals which are without special means of defense and are not at all formidable or ciwngerous are yet so marked or shaped and so behave as to present a threatening or terrifying appearance. The large green caterpillars (Fig. 13\%) of the Sphinx moths-the tomato-worm is a familiar one of these larvæ-have a formidable-looking,

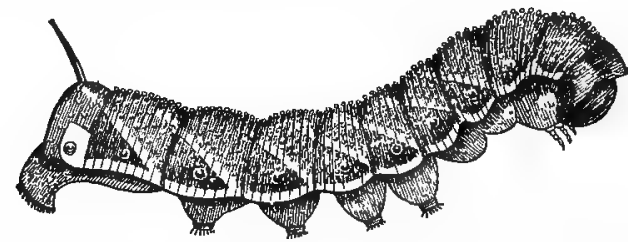

FIG. 137.-A "tomato-worm" lurva of the Sphinx moth, Phlegethontius carolina, showing terrifying appearance.

sharp horn on the back of the next to last body ring. When disturbed they lift the hinder part of the body, bearing the horn, and move it about threateningly. As a matter of fact, the horn is not at all a weapon of defense, but is quite harmless. Numcrous insects when disturbed lift the hind part of the body, and by making threatening mo- 
tions lead encmies to believe that they possess a sting. The striking eye-spots of many insects are believed by some entomologists to be of the nature of terrifying appearances. The larva (Fig. 138) of the Puss moth (C'erura) has been often referred to as a striking example of terrifying appearances. When one of these larvæ is disturbed, "it retracts

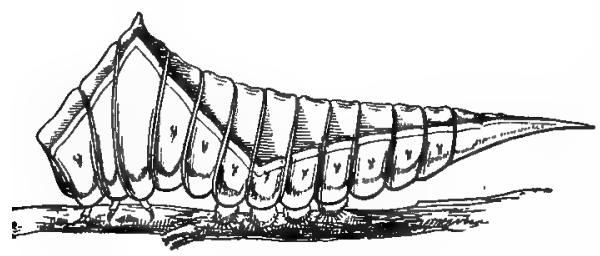

its head into the first body ring inflating the margin, which is of a bright red color. There are two intensely black spots

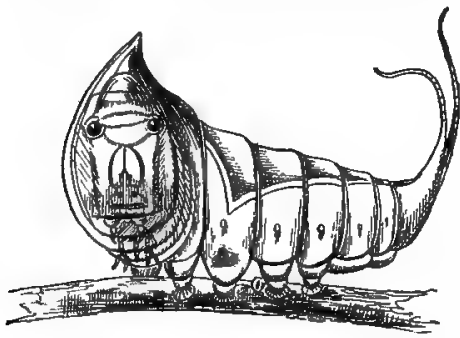

Fig. 138.-Larva of the Pnss moth (Cerura).

Upper figure shows the lurva as it appears when undisturbed; lower figure, when disturbed.-After Poultow.

on this margin in the appropriate position for eyes, and the whole appearance is that of a large flat face extending to the outer edge of the red margin. The effect is an intensely exaggerated caricature of a vertebrate face, which is probably alarming to the vertebrate enemies of the caterpillar. . . The effect is also greatly strengthened by two pink whips which are swiftly protruded from the prongs of the fork in which the body terminates. . . The end of the body is at the same time curved forward over the back, so that the pink filaments are brandished above the head."

111. Alluring coloration.-A few animals show what are called alluring colors-that is, they display a color pattern so arranged as to resemble or mimic a flower or other lure, and thus to entice to them other animals, their natural prey. This is a special kind of aggressive resemblance. A species 
of predatory insect called a "praying-horse" (allied to the genus Mantis), found in India, has the shape and color of an orchid. Small insects are attracted and fall a prey to it. Certain Brazilian fly-catching birds have a brilliantly colored crest which can be displayed in the shape of a flower-cup. The insects attracted by the apparent flower furnish the flycatcher with food. An Asiatic lizard is wholly colored like the sand upon which it lives except for a peculiar red fold of skin at each angle of the mouth. This fold is arranged in flower-like shape, "exactly resembling a little red flower which grows in the sand." Insects attracted by these flowers find out their mistake too late. In the tribe of fishes called the "anglers" or fishing frogs the front rays of the dorsal fin are prolonged in shape of long, slender filaments, the foremost and longest of which has a flattened and divided extremity like the bait on a hook. The fish conceals itself in the mud or in the cavities of a coral reef and waves the filaments back and forth. Small fish are attracted by the lure, mistaking it for worms writhing about in the water or among the weeds. As they approach they are ingulfed in the mouth of the angler, which in some of the species is of enormous size. One of these species is known to fishermen as the "all-mouth." These fishes (Lophius piscatorius), which live in the mud, are colored like mud or clay. Other forms of anglers, living among coral reefs, are brown and red (Antennarius), their coloration imitating in minutest detail the markings and outgrowths on the reef itself, the lure itself imitating a worm of the reef. In a certain group of deep-sea anglers, the seadevils (Ceratiida), certain species show a still further specialization of the curious fishing-rod. In one species ( $\mathrm{Co}$ rynolophus reinhardti) (Fig. 54), living off the coast of Greenland at a depth of upward of a mile, the fishing-rod or first dorsal spine has a luminous bulb at its tip around which are fleshy, worm-like streamers. At the abyssal depths of a mile, more or less, frequented by these sea- 
devils there is no light, the inky darkness being absolute. This shining lure is therefore a most effective means of securing food.

112. Mimicry.-Although the word mimicry could often have been used aptly in the foregoing account of protective resemblances, it has been reserved for use in connection with a certain specific group of cases. It has been reserved to be applied exclusively to those rather numerous instances where an otherwise defenseless animal, one without poisonfangs or sting, and without an ill-tasting substance in its body, mimics some other specially defended or inedible animal sufficiently to be mistaken for it and so to escape attack. Such cases of protective resemblance are called true mimicry, and they are especially to be observed among insects.

In Fig. 139 are pictured three familiar American butterflies. One of these, the Monarch butterfly (Anosia plexip$p u s$ ), is perhaps the most abundant and widespread butterfly of our country. It is a fact well known to entomologists that the Monarch is distasteful to birds and is let alone by them. It is a conspicuous butterfly, being large and chiefly of a red-brown color. The Viceroy butterfly (Basilarchia archippus), also red-brown and much like the Monarch, is not, as its appearance would seem to indicate, a very near relative of the Monarch, belonging to the same genus, but on the contrary it belongs to the same genus with the third butterfly figured, the black and white Basilarchia. All the butterflies of the genus Basitarchia are black and white except this species, the Viceroy, and one other. The Viceroy is not distasteful to birds; it is edible, but it mimics the inedible Monarch so closely that the deception is not detected by the birds, and so it is not molested.

In the tropics there have been discovered numerous similar instances of mimicry by edible butterflies of inedible kinds. The members of two great families of butterflies (Danaida and Heliconidx) are distasteful to birds, and are 


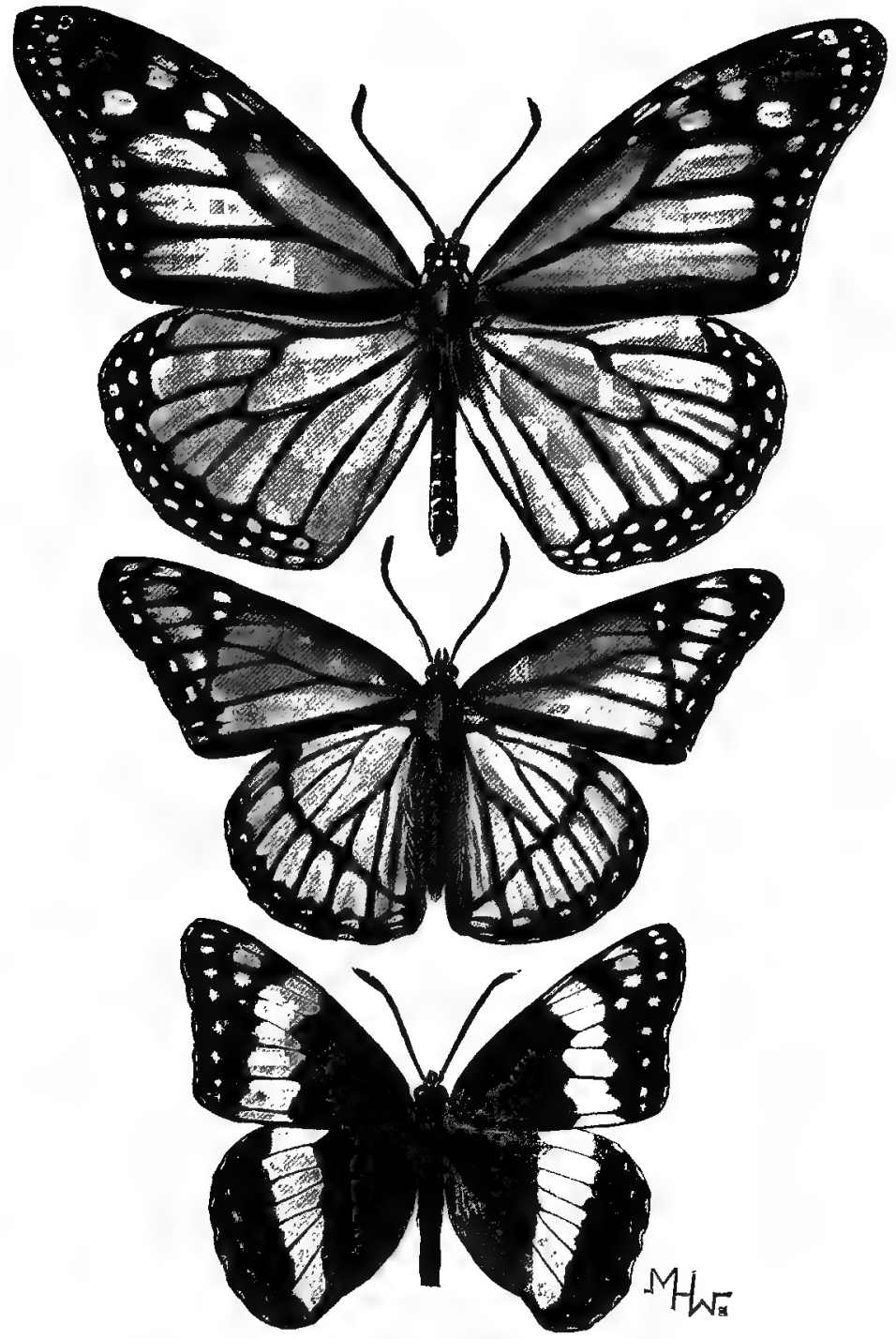

Fre. 139,-The mimicking of the inedible Monarch butterfly by 'the edible Viceroy. Upper figure is the Monarch (Anosia plexippus); middle figure is the Viceroy (Basilarchia archippros); lowest figure is another member of the same genus (Basilarchia), to show the upsual color pattern of the species of the genus. 
mimicked by members of the other butterfly families (espe. cially the Pieridæ), to which family our common white cabbage-butterfly belongs, and by the swallow-tails (Papilionidæ).

The bees and wasps are protected by their stings. They are usually conspicnous, being banded with yellow and black. They are mimickerl by numerous other insects, especially moths and flies, two defenseless kinds of insects. This mimicking of bees and wasps by flies is very common, and can be observed readily at any flowering shrub. The flowerflies (Syrphidæ), which, with the bees, visit flowers, can be distinguished from the bees only by sharp observing. When these bees and flies can be caught and examined in hand, it will be found that the flies have but two wings while the bees have four.

A remarkable and interesting case of mimicry among insects of different orders is that of certain South American tree-hoppers (of the family Membracidæ, of the order Hemiptera), which mimic the famous leaf-cutting ant (Sauba) of the Amazons (Fig. 140). These ants have the curious habit of cutting off, with their sharp jaws, bits of

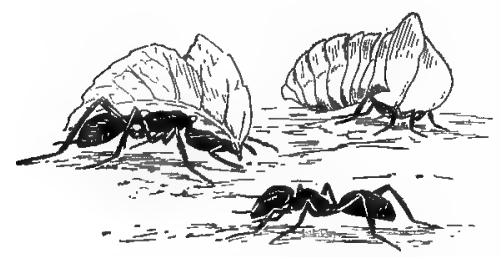

liti. 140.-Tree-hopper (Membracidæ), which mimics the leaf-cutting ant (Sauba) of Brazil. (Upper right-hand insect is the treehopper.) green leaves and carrying them to their nests. In carrying the bits of leaves the ants hold them vertically above their heads. The leaf-hoppers mimic the ants and their burdens with remarkable exactitude by having the back of the body elevated in the form of a thin, jagged-edged ridge no thicker than a leaf. This part of the body is green like the ledves, while the under part of the body and the legs are brown like the ants.

Some examples of mimicry among other animals than 
insects are known, but not many. The conspicuously marked venomous coral-snake or coralillos (Elaps) is mimicked by certain non-venomous snakes called king-snakes (Lampropeltis, Osceola). The pattern of red and black bands surrounding the cylindrical body is perfectly imitated. But whether this is true mimicry brought about for purposes of protection may be doubted. Instances :tmong birds have been described, and a single case has been recorded in the class of mammals. But it is among the insects that the best attested instances occur. The simple fact of the close resemblance of two widely related animals can not be taken to prove the existence of mimicry. Two animals may both come to resemble some particular part in their common environment and thus to resemble closely each other. Here we have simply two instances of special protective resemblance, and not an instance of mimicry. The student of zoölogy will do well to watch sharply for examples of protective resemblance or mimicry, for but few of the instances that undoubtedly exist are as yet known.

\section{Protective resemblances and mimicry most common} among insects.--The large majority of the preceding examples have been taken from among the insects. This is explained by the fact that the phenomena of protective resemblances and mimicry have been studied especially among insects; the theory of mimicry was worked out chiefly from the observation and study of the colors and markings of insects and of the economy of insect life. Why protective resemblances and mimicry among insects have been chiefly studied is because these conditions are specially common among insects. The great class Insecta includes more than two thirds of all the known living species of animals. The struggle for existence among the insects is especially severe and bitter. All kinds of "shifts for a living" are pushed to extremes; and as insect colors and patterns are especially varied and conspicuous, it is 
only to be expected that this useful modification of colors and patterns, that results in the striking phenomena of special protective resemblances and mimicry, should be specially widespread and pronounced among insects. Moreover, they are mostly deficient in other means of defense, and seem to be the favorite food for many different kinds of animals. Protective resemblance is their best and most widely adopted means of preserving life.

114. No volition in mimicry. - The use of the word mimicry has been criticised because it suggests the exercise of volition or intent on the part of the mimicking animal. The student should not entertain this conception of mimicry. In the use of "mimicry" in connection with the phenomena just described, the biologist ascribes to it a technical meaning, which excludes any suggestion of volition or intent on the part of the mimic. Just how such extraordinary and perfect cases of mimicry as shown by Phyllium and Kallima have come to exist is a problem whose solution is not agreed on by naturalists, but none of them makes volition - the will or intent of the animal-any part of his proposed solution. Each case of mimicry is the result of a slow and gradual change, through a long series of ancestors. The mimicry may indeed include the adoption of certain habits of action which strengthen and make more pronounced the deception of shape and color. But these habits, too, are the result of a long development, and are instinctive or reflex-that is, performed without the exercise of volition or reason.

115. Color; its utility and beauty.-The causes of color, and the uses of color in animals and in plants are subjects to which naturalists have paid and are paying much attention. The subject of "protective resemblances and mimicry" is only one, though one of the most interesting, branches or subordinate subjects of the general theory of the uses of color. Other uses are obvious. Bright colors and markings may serve for the attraction of mates; thus 
are explained by some naturalists the brilliant plumage of the male birds, as in the case of the bird-of-paradise and the pheasants. Or they may serve for recognition characters, enabling the individuals of a band of animals readily to recognize their companions ; the conspicuous whiteness of the short tail of the antelopes and cotton-tail rabbits, the black tail of the black-tail deer, and the white tailfeathers of the meadow-lark, are explained by many naturalists on this ground. Recognition marks of this type are especially numerous among the birds, hardly a species being without one or more of them, if their meaning is correctly interpreted. The white color of arctic animals may be useful not alone in rendering them inconspicuous, but may serve also a direct physiological function in preventing the loss of heat from the body by radiation. And the dark colors of animals may be of value to them in absorbing heat rays and thus helping them to keep warm. But "by far the most widespread use of color is to assist an animal in escaping from its enemies or in capturing its prey."

The colors of an animal may indeed not be useful to it at all. Many color patterns exist on present-day birds simply because, preserved by heredity, they are handed down by their ancestors, to whom, under different conditions of life, they may have been of direct use. For the most part, however, we can look on the varied colors and the striking patterns exhibited by animals as being in some way or another of real use and value. We can enjoy the exquisite coloration of the wings of a butterfly none the less, however, because we know that these beautiful colors and their arrangement tend to preserve the life of the dainty creature, and have been produced by the operation of fixed laws of Nature working through the ages. 


\section{CHAPTER XIII}

\section{THF SPECIAL SENSES}

116. Importance of the special senses.-The means by which animals become acquainted with the outer world are the special senses, such as feeling, tasting, smelling, hearing, and seeing. The behavior of animals with regard to their surroundings, with regard to all the world outside of their own body, deponds upon what they learn of this outer world through the exercise of these special senses. Habits are formed on the basis of experience or knowledge of the outer world gained by the special senses, and the development of the power to reason or to have sense depends on their pre-existence.

11\%. Difficulty of the study of the special senses.-We are accustomed to think of the organs of the special senses as extremely complex parts of the body, and this is cortainly true in the case of the higher animals. In our own body the cars and eyes are organs of most specialized and highly developed condition. But we must not overlook the fact that the animal kingdom is composed of creatures of widely varying degrees of organization, and that in any consideration of matters common to all animals those animals of simplest and most lowly organization must be studied as well as those of high development. The study of the special senses presents two phases, namely, the study of the structure of the organs of special sense, and the study of the physiology of specia! sense-that is, the functions of these organs. It will be recognized that in the study of how other animals feel and taste and smell and hear and 
see, we shall have to base all our study on our own experience. We know of hearing and seeing only by what we know of our own hearing and seeing; but by examination of the structure of the hearing and seeing organs of certain other animals, and by observation and experiments, zoölogists are convinced that some animals hear sounds that we ean not hear, and some see colors that we can not see.

While that phase of the study of the special senses which concerns their structure may be quite successfully undertaken, the physiological phase of the study of the actual tasting and seeing and hearing of the lower animals is a matter of much difficulty. The condition and character of the special senses vary notably among different animals. There may even exist other special senses than the ones we possess. Some zoölogists believe that certain marine animals possess a "density or pressure sense"that is, a sense which enables them to tell approximately how deep in the water they may be at any time. To certain animals is ascribed a "temperature sense," and some zoölogists believe that what we call the homing in. stinct of animals as shown by the homing pigeons and honey-bees and other animals, depends on their possession of a special sense which man does not possess. Recent experiments, however, seem to show that the homing of pigeons depends on their keen sight. In numerous animals there exist, besides the organs of the five special senses which we possess, organs whose structure compels us to believe them to be organs of special sense, but whose function is wholly unknown to us. Thus in the study of the special senses we are made to see plainly that we can not rely simply on our knowledge of our own body structure for an understanding of the structure and functions of other animals.

118. Special senses of the simplest animals.-In the $A$ moeba (see Chapter I), that type of the simplest animals, with 
onc-celled body, without organs, and yet with its capacity for performing the necessary life processes, there are no special senses except one (perhaps two). The $A$ moba can feel. It possesses the tactile sense. And there are no special sense organs except one, which is the whole of the outer surface of the body. If the $A$ moba be touched with a fine point it feels the touch, for the soft viscous protoplasm of its body flows slowly away from the foreign object. The sense of feeling or touch, the tactile sense, is the simplest or most primitive of the special senses, and the simplest, most primitive organ of special sense is the outer surface or skin of the body. Among those simple animals that possess the simplest organs of hearing and perceiving light, we shall find these organs to be simply specialized parts of the skin or outer cell layer of the body, and it is a fact that all the special sense organs of all animals are derived or developed from the outer cell layer, ectoblast, of the embryo. This is true also of the whole nervous system, the brain and spinal cord of the vertebrates, and the ganglia and nerve commissures of the invertebrates. And while in the higher animals the nervous system lies underneath the surface of the body, in many of the lower, many-celled animals all the ganglia and nerves, all of the nervous system, lie on the outer surface of the body, being simply a specialized part of the skin.

119. The sense of touch.-In some of the lower, manycelled animals, as among the polyps, there are on the skin certain sense cells, either isolated or in small groups, which seem to be stimulated not alone by the touching of foreign substances, but also by warmth and light. They are not limited to a single special sense. They are the primitive or generalized organs of special sense, and can develop into specialized organs for any one of the special senses.

The simplest and most widespread of these special senses with, as a whole, the simplest organs, is the tactile 
sense, or the sense of touch. The special organs of this sense are usually simple hairs or papillæ connecting with a nerve. These tactile hairs or papillæ may be distributed pretty evenly over most of the body, or may be mainly concentrated upon certain parts in crowded groups. Many of the lower animals have projecting parts, like the feeling tentacles of many marine invertebrates, or the antennæ (feelers) of crabs and insects; which are the special seat of the tactile organs. Among the vertebrates the tactile organs are either like those of the invertebrates, or are little sac-like bodies of connective tissue in which the end of a nerve is curiously folded and convoluted (Fig. 141). These little touch corpuscles simply lie in the cell layer of the skin, covered over thinly by the cuticle. Sometimes they are simply free, branched nerve-endings in the skin. These tactile corpuscles or free nerve-endings are especially abundant in those parts of the body which can be best used for feeling. 'In man the finger-tips are thus especially supplied; in certain tailed monkeys the tip of the tail, and in hogs the end of the snout. The difference in abundance of these tactile corpuscles of the skin can be readily shown by experiment. With a pair of compasses, whose points have been slightly blunted, touch the skin of the forearm of a

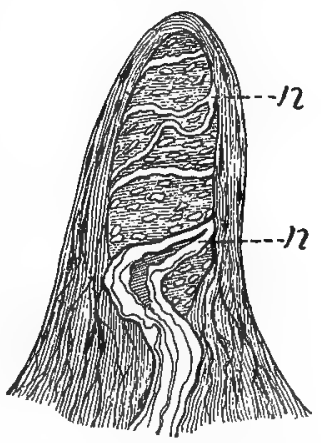

Fra. 141.-Tactile papilla of skin of man. $n$, nerve. After KOELLIKER. person who has his eyes shut, with the points about three inches apart and in the direction of the length of the arm. The person touched will feel the points as two. Repeat the touching several times, gradually lessening the distance between the points. When the points are not more than an inch to an inch and a half apart, the person touched will feel but a single touch-that is, the touching 
of both points will give the sensation of but a single contact. Repeat the experiment on the tip of the forefinger, and both points will be felt until the points are only about one tenth of an inch apart.

120. The sense of taste.-The sense of taste enables us to test in some degree the chemical constitution of substances which are taken into the mouth as food. We discriminate by the taste organs between good food and bad, well-tasting and ill-tasting. These organs are, with us and the other airbreathing animals, located in the mouth or on the mouth parts. They must be located so as to come into contact with the food, and it is also necessary that the food substance to be tasted be made liquid. This is accomplished by the fluids poured into the mouth from the salivary glands. With the lower aquatic animals it is not improbable that taste organs are situated on other parts of the body besides the mouth, and that taste is used not only to test food substances, but also to test the chemical character of the fluid medium in which they live.

The taste organs are much like the tactile organs, exrept that the special taste cell is exposed, so that small particles of the substance to be tasted can come into actual contact with it. The nerve-ending is usually in a small rased papilla or depressed pit. In the simplest animals there is no special organ of taste, and yet $A m \infty b a$ and other Protozoa show that they appreciate the chemical constitution of the liquid in which they lie. They taste-that is, test the chemical constitution of the substances-by means of their undifferentiated body surface. The taste organs are not always to be told from the organs of smell. Where an animal has a certain special seat of smell, like the nose of the higher animals, then the special sense organs of the mouth can be fairly assumed to be taste organs; but where the seat of both smell and taste is in the mouth or mouth parts, it is often impossible to distinguish between the two kinds of organs. 
In mammals taste organs are situated on certain parts of the tongue, and have the form of rather large, low, broad papillæ, each bearing many small taste-buds (Fig. 142). In fishes similar papillæ and buds have been found in various places on the surface of the body, from which it is believed that the sense of taste in fishes is not limited to the mouth. In insects the taste-papillæ and taste - pits are grouped in certain places on the mouth parts, being especially abundant on

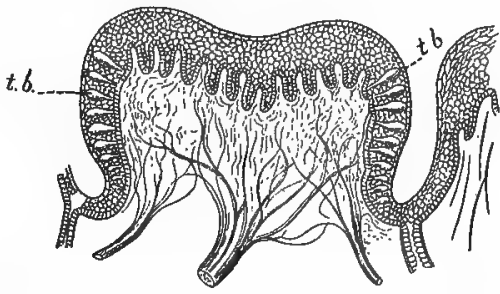

FIa. 142.-Vertical aection of large papilla on tongue of a calf ; $t . b$, taste-buds. - After LovÉN.

the tips of small, segmented, feeler-like processes called palpi, which project from the under lip and from the socalled maxillæ.

121. The sense of smell.-Smelling and tasting are closely allied, the one testing substances dissolved, the other testing substances vaporized. The organs of the sense of smell are, like those of taste, simple nerve-endings in papillæ or pits. The substance to be smelled must, however, be in a very finely divided form; it must come to the organs of smell as a gas or vapor, and not, as to the organs of taste, in liquid condition. The organs of smell are situated usually on the head, but as the sense of smell is used not alone for the testing of food, but for many other purposes, the organs of smell are not, like those of taste, situated principally in or near the mouth. Smell is a special sense of much wider range of use than taste. By smell animals can discover food, aroid enemies, and find their mates. They can test the air they breathe as well as the food they eat. In the matter of the testing of food the senses of both taste and smell are constantly used, and are indeed intimately associated. 
The sense of smell varies a great deal in its degreo of development in various animals. With the strictly aquatic animals-and these include most of the lower invertebrates, as the polyps, the star-fishes, sea-urchins, and most of the worms and mollusks-the sense of smell is probably but little developed. There is little opportunity for a gas or vapor to come to these animals, and only as a gas or vapor can a substance be smelled. With these animals the sense of taste must take the place of the olfactory sense. But among the insects, mostly terrestrial animals, there is an extraordinary development of the sense of smell. It is indeed probably their principal special sense. Insects must depend on smell far more than on sight or hearing for

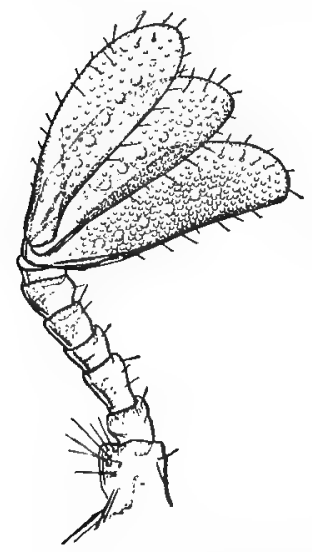

FIG. 143,-Antenna of a leafeating beetle, showing smelling-pits on the expanded terminal gegments. the discovery of food, for becoming aware of the presence of their enemies and of the proximity of their mates and companions. The organs of smell of insects are situated principally on the antennæ or feelers, a single pair of which is borne on the head of every insect (Fig. 143). That many insects have an extraordinarily keen sense of smell has been shown by numerous experiments, and is constantly proved by well-known habits. If a small bit of decaying flesh be inclosed in a box so that it is wholly concealed, it will nevertheless soon be found by the flies and carrion beetles that either feed on carrion or must always lay their eggs in decaying matter so that their carrion-eating larvæ may be provided with food. It is believed that ants find their way back to their nests by the sense of smell, and that they can recognize by scent among hundreds of individuals taken from various communities the members of their 
own community. In the insectary at Cornell University, a few years ago, a few females of the beautiful promethea moth (Callosamia promethea) were inclosed in a box, which was kept inside the insectary building. No males had been seen about the insectary nor in its immediate vicinity, although they had been sought for by collectors. A few hours after the beginning of the captivity of the female moths there were forty male prometheas fluttering about over the glass roof of the insectary. They could not

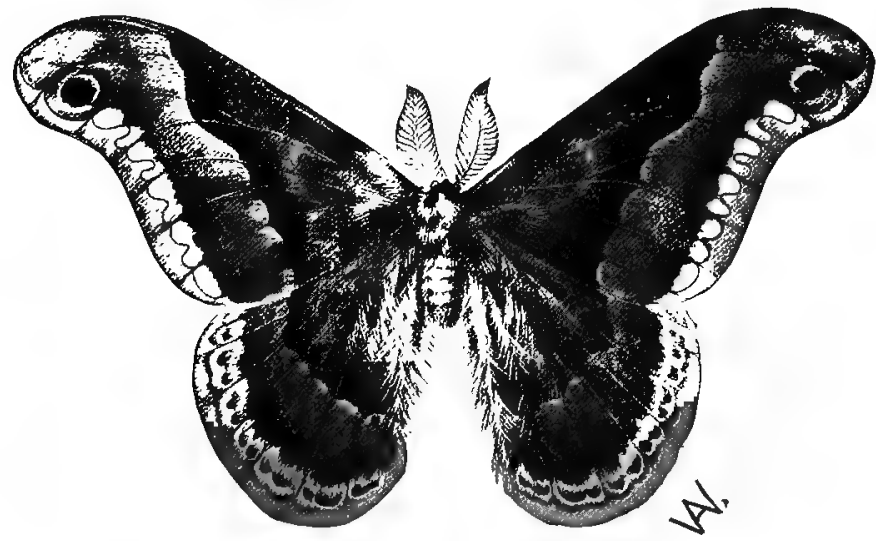

FIG. 144.-Promethea moth, male, showing specialized antennæ.

see the females, and yet had discovered their presence in the building. The discovery was undoubtedly made by the sense of smell. These moths have very elaborately developed antennæ (Fig. 144), finely branched or feathered, affording opportunity for the existence of very many smelling-pits.

The keenness of scent of hounds and bird dogs is familiar to all, although ever a fresh source of astonishment as we watch these animals when hunting. We recently watched a retriever dog select unerringly, by the sense of smell, any particular duck out of a pile of a hundred. In 
the rase of man the sense of smell is not nearly so well developed as among many of the other vertebrates. This inferiority is largely due to degeneration through lessened need; for in Indians and primitive races the sense of smell is keener and better developed than in civilized races. Where man has to make his living by hunting, and has to avoid his enemies of jungle and plain, his special senses are better developed than where the necessity of protection and advantage by means of such keenness of scent and hearing is done away with by the arts of civilization.

122. The sense of hearing,-Hearing is the perception of certain vibrations of bodies. These vibrations give rise to waves-sound waves as they are called-which proceed from the vibrating body in all directions, and which, conling to an animal, stimulate the special auditory or hearing organs, that transmit this stimulation along the auditory nerve to the brain, where it is translated as sound. These sound waves come to animals usually through the air, or, in the case of aquatic animals, through water, or through both air and water.

The organs of hearing are of very complex structure in the case of man and the higher vertebrates. Our ears, which are adapted for perceiving or being stimulated by vibrations ranging from 16 to 40,000 a second-that is, for hearing all those sounds produced by vibrations of a rapidity not less than 16 to a second nor greater than 40,000 to a second-are of such complexity of structure that many pages would be required for their description. But among the lower or less highly organized animals the ears, or auditory organs, are much simpler.

In most animals the auditory organs show the common characteristic of being wholly composed of, or having as an essential part, a small sac filled with liquid in which one or more tiny spherical liard bodies called otoliths are held. This auditory sac is formed of or lined internally by 
auditory cells, specialized nerve cells, which often bear delicate vibratile hairs (Fig. 145). Auditory organs of this general character are known among the polyps, the worms, the crustaceans, and the mollusks. In the common crayfish the "ears" are situated in the basal segment of the inner antennæ or feelers (Fig. 146). They consist each of a small sac filled with liquid in which are suspended several grains of sand or other hard bodies. The inner

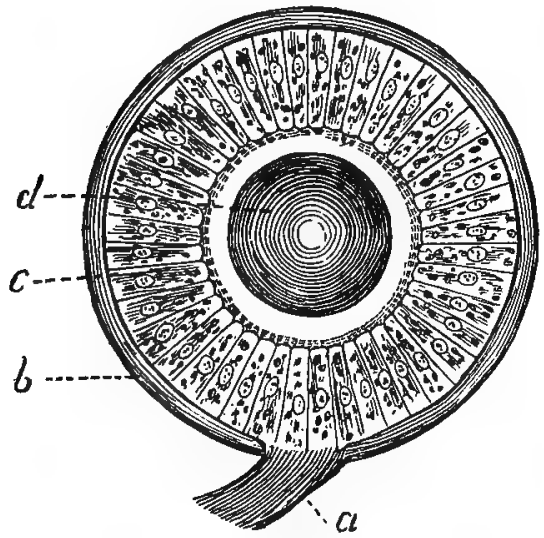

Fia. 145.-Auditory organ of a molluek. $\alpha$, auditory nerve; $b$, outer wall of connective tissue; $c$, cells with auditory hairs; $d$, otolith.-After LEYDIG.

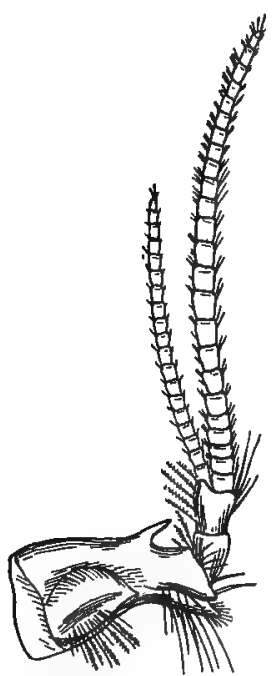

Fra. 146. - Antenna of cray - fish, with auditory sac at buse.After HUXLEY.

surface of the sac is lined with fine auditory hairs. The sound waves coming through the air or water outside strike against this sac, which lies in a hollow on the upper or outer side of the antennæ. The sound waves are taken up by the contents of the sac and stimulate the fine hairs, which in turn give this stimulus to the nerves which run from them to the principal auditory nerve and thus to the brain of the cray-fish. Among the insects other kinds of auditory organs exist. The common locust or grasshopper 
has on the upper surface of the first abdominal segment a pair of tympana or ear-drums (Fig. 147), composed simply of the thinned, tightly stretched chitinous

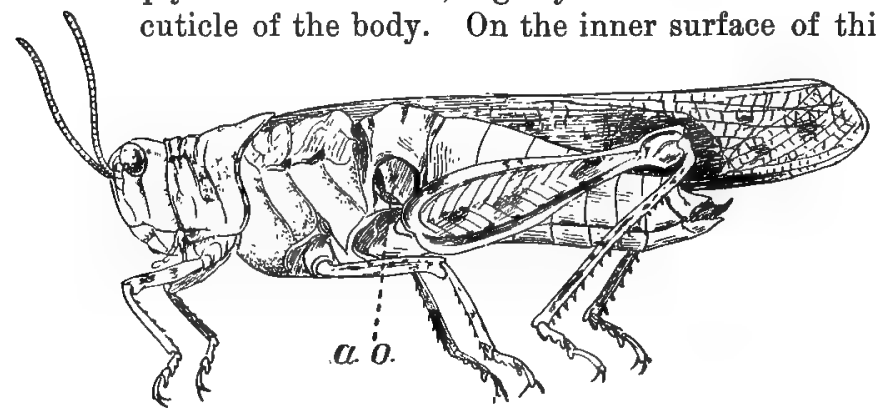

Fig. 147.-Grasshopper, showing anditory organ (a.o.) in first segment of abdomen. (Wings of one side removed,)

ear-drum there are a tiny auditory sac, a fine nerve leading from it to a small auditory ganglion lying near the tympanum, and a large nerve leading from this ganglion to one of the larger ganglia situated on the floor of the

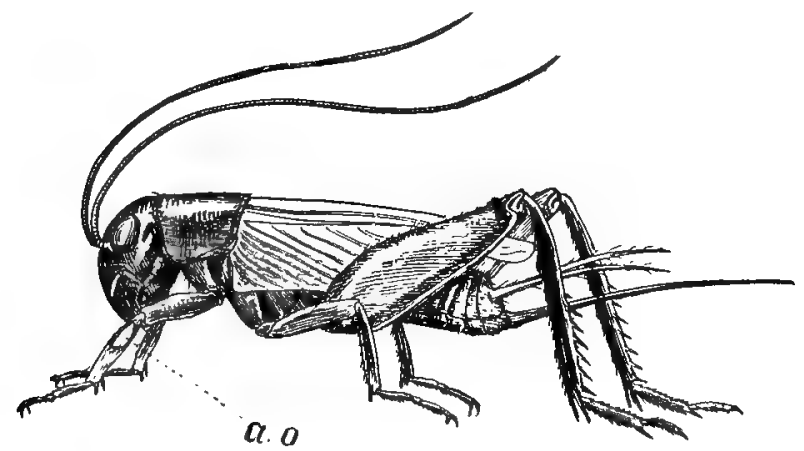

Fra. 148.-A cricket, showing anditory organ (a. o.) in fore-leg.

thorax. In the crickets and katydids, insects related to the locusts, the auditory organs or eurs are situated in the fore-legs (Fig. 148).

Certain other insects, as the mosquitoes and other midges 
or gnats, undoubtedly hear by means of numerous delicate hairs borne on the antennæ. The male mosquitoes (Fig. 149) have many hundreds of these long, fine antennal hairs, and on the sounding of a tuning-fork these hairs have been observed to vibrate strongly. In the base of each antenna there is a most elaborate organ, composed of fine chitinous rods, and accompanying nerves and nerve cells whose function it is to take up and transmit through the auditory nerve to the brain the stimuli received from the external auditory hairs.

123. Sound-making: - The sense of hearing enables animals not only to hear the warning natural sounds of storms and falling trees and plunging avalanches, but the sounds made by each other. Sound-making among animals serves to aid in frightening away enemies or in warning companions of their approach,

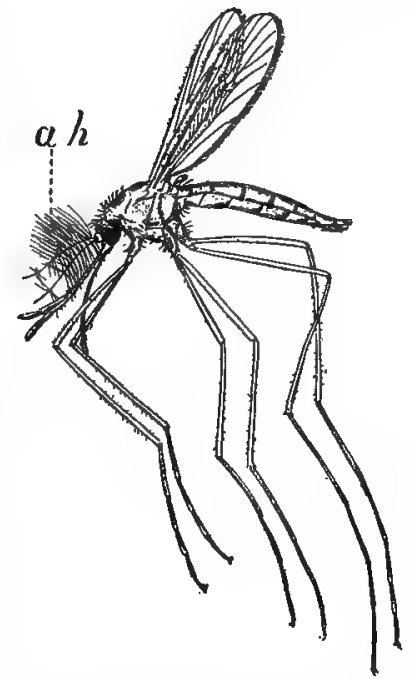

FIG. 149.-A male mosquito, showing auditory hairs $(a, h$.) on the antennæ. for recognition among mates and members of a band or species, for the attracting and wooing of mates, and for the interchange of information. With the cries and roars of mammals, the songs of birds, and the shrilling and calling of insects all of us are familiar. These are all sounds that can be heard by the human ear. But that there are many sounds made by animals that we can not hear-that is, that are of too high a pitch for our hearing organs to be stimulated by-is believed by naturalists. Especially is this almost certainly true in the case of the insects, The peculiar sound-producing organs of 
many sound-making insects are known; but certain other insects, which make no sound that we can hear, nevertheless possess similar sound-making organs.

Sound is produced by mammals and birds by the striking of the air which goes to and comes from the lungs against certain vibratory cords or flaps in the air-tubes. Sounds made by this vibration are re-enforced and made louder by arrangements of the air-tubes and mouth for resonance, and the character or quality of the sound is modified at will to a greater or less degree by the lips and teeth and other mouth structures. Sounds so made are said to be produced by a voice, or animals making sounds in this way are said to possess a voice. Animals possessing a voice have far more range and variety in their soundmaking than most of the animals which produce sounds in other ways. The marvelous variety and the great strength of the singing of birds and of the cries and roars of mammals are unequaled by the sounds of any other animals.

But many animals without a voice-that is, which do not make sounds from the air-tubes-make sounds, and some of them, as certain insects, show much variety and range in their singing. The sounds of insects are made by the rapid vibrations of the wings, as the humming or buzzing of bees and flies, by the passage of air out or into the body through the many breathing pores or spiracles (a kind of voice), by the vibration of a stretched membrane or tympanum, as the loud shrilling of the cicada, and most commonly by stridulation-that is, by rubbing together two roughened parts of the body. The male crickets and the male katydids rub together the bases of their wing covers to produce their shrill singing. The locusts or grasshoppers make sounds when at rest by rubbing the roughened inside of their great leaping legs against the upper surface of their wing covers, and when in flight by striking the two wings of each side together. Numerous other insects make souncls by stridulation, but many of 
these sounds are so feeble or so high in pitch that they are rarely heard by us. Certain butterflies make an odd clicking sound, as do some of the water-beetles. In Japan, where small things which are beautiful are prized not less than large ones, singing insects are kept in cages and highly valued, so that their capture becomes a lucrative industry, just as it is with song birds in Europe and America. Among the many species of Japanese singing insects is a night cricket, known as the bridle-bit insect, because its note resembles the jingling of a bridle-bit.

124. The sense of sight. - Not all animals have eyes. The moles which live underground, insects, and other animals that live in caves, and the deep-sea fishes which live in waters so deep that the light of the sun never comes to them, have no eyes at all, or have eyes of so rudimentary a character that they can no longer be used for seeing. But all these eyeless animals have no eyes because they live under conditions where eyes are useless. They have lost their eyes by degeneration. There are, however, many animals that have no eyes, nor have they or their ancestors ever had eyes. These are the simplest, most lowly organized animals. Many, perhaps all eyeless animals are, however, capable of distinguishing light from darkness. They are sensitive to light. An investigator placed several individuals of the common, tiny fresh-water polyp (Hydra) in a glass cylinder the walls of which were painted black. He left a small part of the cylinder unpainted, and in this part of the cylinder where the light penetrated the Hydras all gathered. The eyeless maggots or larvæ of flies, when placed in the light will wriggle and squirm away into dark crevices. They are conscious of light when exposed to it, and endeavor to shun it. Most plants turn their leaves toward the light; the sunflowers turn on their stems to face the sun. Light seems to stimulate organisms whether they have eyes or not, and the organisms either try to get into the light or to avoid it. But this is not seeing. 
The simplest eyes, if we may call them eyes, are not capable of forming an image or picture of external objects. They only make the animal better capable of distinguishing between light and darkness or shadow. Many lowly organized animals, as some polyps, and worms, have certain cells of the skin specially provided with pigment. These cells grouped together form what is called a pigment fleck, which can, because of the presence of the pigment, absorb more light than the skin cells, and are more sensitive to the light. By such pigment-flecks, or eye-spots, the animal can detect, by their shadows, the passing near them of moving bodies, and thus be in some measure informed of the approach of enemies or of prey. Some of these eye-flecks are provided, not simply with pigment, but with a simple sort of lens that serves to concentrate rays of light and

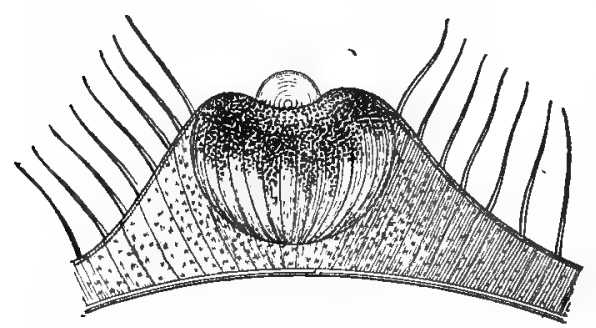

Fig. 150.-The simple eye of a jelly-fish (Lizzia koellikeri),-After O. and R. Hertwia. make this simplest sort of eye even more sensitive to changes in the intensity of light (Fig. 150).

Most of the many-celled animals possess eyes by means of which a picture of external objects more or less nearly complete and perfect can be formed. There is great variety in the finer structure of these picture-forming eyes, but each consists essentially of an inner delicate or sensitive nervous surface called the retina, which is stimulated by light, and is connected with the brain by a large optic nerve, and of a transparent lightrefracting lens lying ontside of the retina and exposed to the light. These are the constant essential parts of an image-forming and image-perceiving eye. In most 'yes there are other accessory parts which may make the whole 
eye an organ of excessively complicated structurc and of remarkably perfect seeing capacity. Our own eyes are orgains of extreme structural complexity and of high development, although some of the other vertebrates have undoubtedly a keener and more nearly perfected sight.

The crustaceans and insects have eyes of a peculiar character called compound eyes. In addition most insects have smaller simple eyes. Each of the compound eyes is composed of many (from a few, as in certain ants, to as many as twenty-five thousand, as in certain beetles) eye elements, each eye element seeing independently of the other eye elements and seeing only a very small part of any object in front of the whole eye. All these small parts of the external object seen by the many distinct eye elements are combined so as to form an image in mosaic-that is, made up of separate small parts-of the external object.

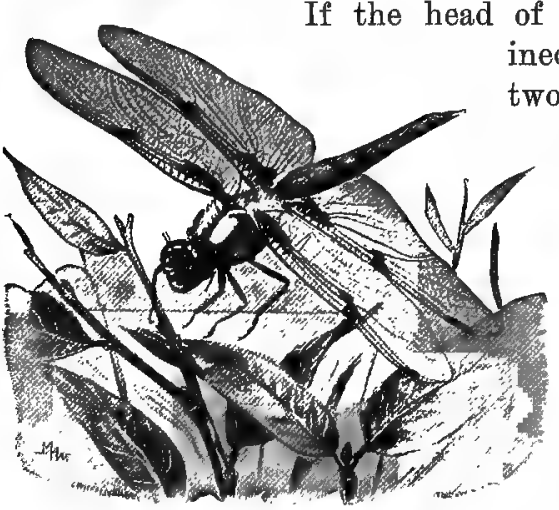

FId. 151,-A dragon-fly, showing the large componnt eyes on the head.

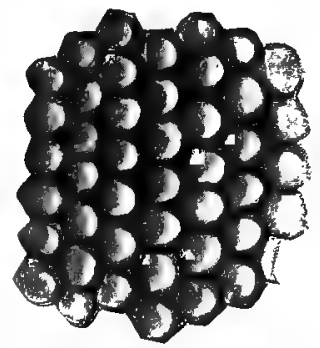

Fra. 152,-Some of the facets of the compound eye of a dragon-fly.

whole head is made up of the two large compound eyes (Fig. 151), and with a lens it may be seen that the outer surface of each of these eyes is composed of many small spaces or facets (Fig. 152) which are the outer lenses of the many eye elements composing the whole eye. 


\section{CHAPTER XIV \\ INSTINC'T AND REASON}

125. Irritability.-All animals of whatever degree of organization show in life the quality of irritability or response to external stimulus. Contact with external things produces some effect on each of them, and this effect is something more than the mere mechanical effect on the matter of which the animal is composed. In the onecelled animals the functions of response to external stimulus are not localized. They are the property of any part of the protoplasm of the body. Just as breathing or digestion is a function of the whole cell, so are sensation and response in action. In the higher or many-celled animals each of these functions is specialized and localized. A certain set of cells is set apart for each function, and each organ or series of cells is released from all functions save its own.

126. Nerve cells and fibers.-In the development of the individual animal certain cells from the primitive external layer or ectoblast of the embryo are set apart to preside over the relations of the creature to its environment. These cells are highly specialized, and while some of them are highly sensitive, others are adapted for carrying or transmitting the stimuli receired by the sensitive cells, and still others have the function of receiving sense-impressions and of translating them into impulses of motion. The nerve cells are receivers of impressions. These are gathered together in nerve masses or ganglia, the largest of these being known as the brain, the ganglia in general being known as nerve centers. The nerves are of two classes. 
The one class, called sensory nerves, extends from the skin or other organ of sensation to the nerve center. The nerves of the other class, motor nerves, carry impulses to motion.

12\%. The brain or sensorium,-The brain or other nerve center sits in darkness surrounded by a bony protecting box. To this main nerve center, or sensorium, come the nerves from all parts of the body that have sensation, the external skin as well as the special organs of sight, hearing, taste, smell. With these come nerves bearing sensations of pain, temperature, muscular effort-all kinds of sensation which the brain can receive. These nerves are the sole sources of knowledge to any animal organism. Whatever idea its brain may contain must be built up through these nerve impressions. The aggregate of these impressions constitute the world as the organism knows it. All sensation is related to action. If an organism is not to act, it can not feel, and the intensity of its feeling is related to its power to act.

128. Reflex action-These impressions brought to the brain by the sensory nerves represent in some degree the facts in the animal's environment. They teach something as to its food or its safety. The power of locomotion is characteristic of animals. If they move, their actions must depend on the indications carried to the nerve center from the outside; if they feed on living organisms, they must seek their food; if, as in many cases, other living organisms prey on them, they must bestir themselves to escape. The impulse of hunger on the one hand and of fear on the other are elemental. The sensorium receives an impression that food exists in a certain direction. At once an impulsc to motion is sent out from it to the muscles necessary to move the body in that direction. In the higher animals these movements are more rapid and more exact. This is because organs of sense, muscles, nerve fibers, and nerve cells are all alike highly specialized. In the star-fish the sensation is slow, the muscular response sluggish, but the 
method remains the same. This is simple reflex action, an impulse from the environment carried to the brain and then unconsciously reflected back as motion. The impulse of fear is of the same nature. Strike at a dog with a whip, and he will instinctively shrink away, perhaps with a cry. Perhaps he will leap at you, and you unconsciously will try to escape from him. Reflex action is in general unconscious, but with animals as with man it shades by degrees into conscious action, and into volition or action "done on purpose."

129. Instinct.-Different one-celled animals show differences in method or degree of response to external influences. The feelers of the $A m o b a$ will avoid contact with the feelers or pseudopodia of another $A m c b a$, while it does not shrink from contact with itself or with an organism of unlike kind on which it may feed. Most Protozoa will discard grains of sand, crystals of acid, or other indigestible object. Such peculiarities of different forms of life constitute the basis of instinct.

Instinct is automatic obedience to the demands of external conditions. As these conditions vary with each kind of animal, so must the demands vary, and from this arises the great variety actually seen in the instincts of different animals. As the demands of life become complex, so may the instincts become so. The greater the stress of environment, the more perfect the automatism, for impulses to safe action are necessarily adequate to the duty they have to perform. If the instinct were inadequate, the species would have become extinct. The fact that its individuals persist shows that they are provided with the instincts necessary to that end. Instinct differs from other allied forms of response to external condition in being hereditary, continuous from generation to generation. This sufficiently distinguishes it from reason, but the line between instinct and reason and other forms of reflex action can not be sharply draws. 
It is not necessary to consider here the question of the origin of instincts. Some writers regard them as "inherited habits," while others, with apparent justice, doubt if mere habits or voluntary actions repeated till they become a "second nature" ever leave a trace upon heredity. Such investigators regard instinct as the natural survival of those methods of automatic response which were most useful to the life of the animal, the individuals having less effective methods of reflex action having perished, leaving no posterity.

An example in point would be the homing instinct of the fur-seal. When the arctic winter descends on its home in the Pribilof Islands in Bering Sea, these animals take to the open ocean, many of them swimming southward as far as the Santa Barbara Islands in California, more than three thousand miles from home. While on the long swim they never go on shore, but in the spring they return to the northward, finding the little islands hidden in the arctic fogs, often landing on the very spot from which they were driven by the ice six months before, and their arrival timed from year to year almost to the same day. The perfection of this homing instinct is vital to their life. If defective in any individual, he would be lost to the herd and would leave no descendants. Those who return become the parents of the herd. As to the others the rough sea tells no tales. We know that, of those that set forth, a large percentage never comes back. To those that return the homing instinct has proved adequate. This must be so so long as the race exists. The failure of instinct would mean the extinction of the species.

130. Classification of instincts.-The instincts of animals may be roughly classified as to their relation to the individual into egoistic and altruistic instincts.

Egoistic instinets are those which concern chiefly the individual animal itself. To this class belong the instincts of feeding, those of self-defense and of strife, the instincts 
of play, the climatic instincts, and environmental instincts, those which direct the animal's mode of life.

Altruistic instincts are those which relate to parenthood and those which are concerned with the mass of individuals of the same species. The latter may be called the social instincts. In the former class, the instincts of parenthood, may be included the instincts of courtship, reproduction, home-making, nest-building, and care for the young.

131. Feeding.-The instincts of feeding are primitively simple, growing complex through complex conditions. The protozoan absorbs smaller creatures which contain nutriment. The sea-anemone closes its tentacles over its prey. The barnacle waves its feelers to bring edible creatures within its mouth. The fish seizes its prey by direct motion. The higher vertebrates in general do the same, but the conditions of life modify this simple action to a very great degree.

In general, animals decide by reflex actions what is suitable food, and by the same processes they reject poisons or unsuitable substances. The dog rejects an apple, while the horse rejects a piece of meat. Either will turn away from an offered stone. Almost all animals reject poisons instantly. Those who fail in this regard in a state of nature die and leave no descendants. The wild vetches or "loco-weeds" of the arid regions affect the nerve centers of animals and cause dizziness or death. The native ponies reject these instinctively. This may be because all ponies which have not this reflex dislike have been destroyed. The imported horse has no such instinct and is poisoned. Very few animals will eat any poisonous object with which their instincts are familiar, unless it be concealed from smell and taste.

In some cases, very elaborate instincts arise in connection with feeding habits. With the California woodpeckers (Melanerpes formicivorus bairdii) a large number of them 
together select a live-oak tree for their operations. They first bore its bark full of holes, each large enough to hold an acorn. Then into each hole an acorn is thrust (Figs. 61 and 62). Only one tree in several square miles may be selected, and when their work is finished all those interested go about their business elsewhere. At irregular intervals a dozen or so come back with much clamorous discussion to look at the tree. When the right time comes, they all return, open the acorns one by one, devouring apparently the substance of the nut, and probably also the grubs of beetles which have developed within. When the nuts are ripe, again they return to the same tree and the same process is repeated. In the tree figured this has been noticed each year since 1891 .

132. Self-defense.-The instinct of self-defense is even more varied in its manifestations. It may show itself either in the impulse to make war on an intruder or in the desire to flee from its enemies. Among the flesh-eating mammals and birds fierceness of demeanor serves both for the securing of food and for protection against enemies. The stealthy movements of the lion, the skulking habits of the wolf, the sly selfishness of the fox, the blundering goodnatured power of the bear, the greediness of the hyena, are all proverbial, and similar traits in the eagle, owl, hawk, and vulture are scarcely less matters of common observation.

Herbivorous animals, as a rule, make little direct resistance to their enemies, depending rather on swiftness of foot, or in some cases on simple insignificance. To the lattor cause the abundance of mice and mouse-like rodents may be attributed, for all are the prey of carnivorous beasts and birds, and even snakes.

Even young animals of any species show great fear of their hereditary enemies. The nestlings in a nest of the American bittern when one week old showed no fear of man, but when two wecks old this fear was very manifest 
(Figs. 153 and 154). Young mocking-birds will go into spasms at the sight of an owl or a cat, while they pay little attention to a dog or a hen. Monkeys that have never seen a snake show almost hysterical fear at first sight of one, and the same kind of feeling is common to most men. A monkey was allowed to open a paper bag which

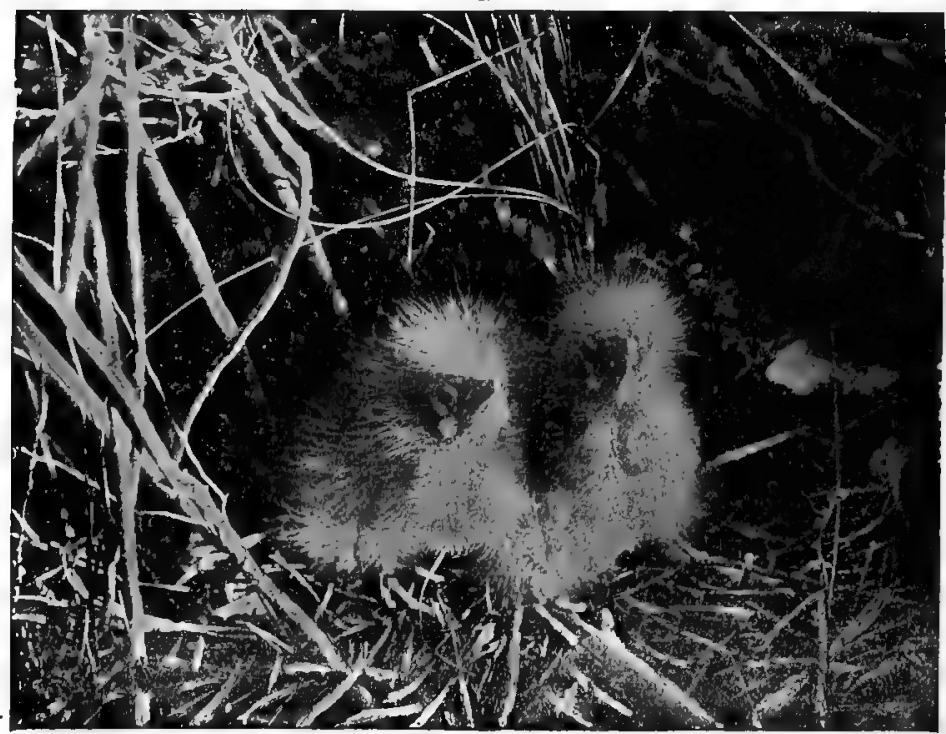

III. 153.-Nestlinge of the American bitterm. Two of $n$ hrond of four birds one week old, at which age they showed no fear of Inas. J'holograph by E. II. TABOR, Meridian, N. Y., May 31, 1898. (Permission of Mucmulian Company, publishers of Bird-Lore.)

contained a live snake. He was staggered by the sight, but after a while went back and looked in again, to repeat the experience. Each wild animal has its special instinct of resistance or method of keeping off its enemies. The stamping of a sheep, the kicking of a horse, the running in a circle of a hare, and the skulking in a circle of some foxes, are examples of this sort of instinct. 
133. Play.-The play instinct is developed in numerous animals. To this class belong the wrestlings and mimic fights of young dogs, bear cubs, seal pups, and young beasts generally. Cats and kittens play with mice. Squir-

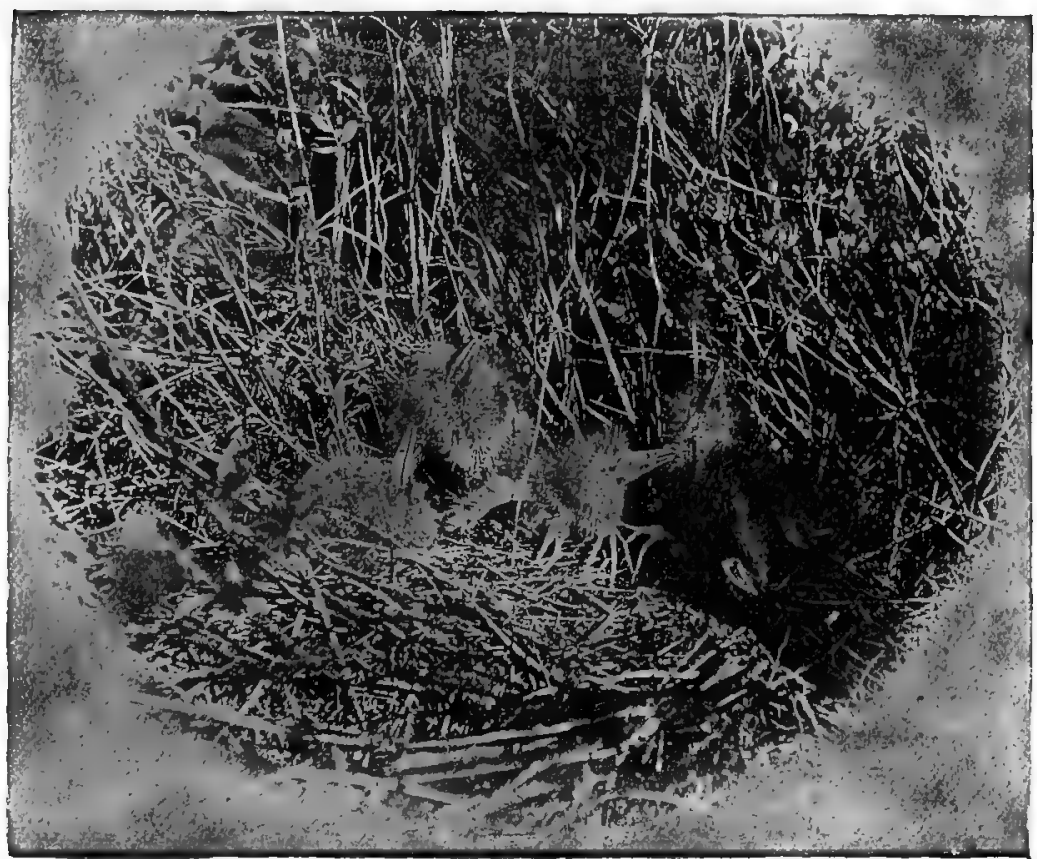

III. 154,-Nestlings of the American bittern. The four members of the brood of whicll two are shown in Fig. 153, two weeks old, when they showed marked fear of mun. Photograph by F. M. Chapman, Meridian, N. Y., June 8, 1898. (Permission of Macmillan Company, publishers of Bird-Lore.)

rels play in the trees. Perhaps it is the play impulse which leads the shrike or butcher-bird to impale small birds and beetles on the thorns about its nest, a ghastly kind of ornament that seems to confer satisfaction on the bird itself. The talking of parrots and their imitations of the sounds they hear seem to be of the nature of play. The greater 
their superfluous energy the more they will talk. Much of the singing of birds, and the crying, calling, and howling of other animals, are mere play, although singing primarily belongs to the period of reproduction, and other calls and cries result from social instincts or from the instinct to care for the young.

134. Climate-Climatic instincts are those which arise from the change of seasons. When the winter comes the fur-seal takes its long swim to the southward; the wild geese range themselves in wedge-shaped iocks and fly high and far, calling loudly as they go; the bobolinks straggle away one at a time, flying mostly in the night, and most of the smaller birds in cold countries move away toward the tropics. All these movements spring from the migratory instinct. Another climatic instinct leads the bear to hide in a cave or hollow tree, where he sleeps or hibernates till spring. In some cases the climatic instinct merges in the homing instinct and the instinct of reproduction. When the birds move north in the spring they sing, mate, and build their nests. The fur-seal goes home to rear its young. The bear exchanges its bed for its lair, and its first business after waking is to make ready to rear its young.

135. Environment.-Environmental instincts concern the creature's mode of life. Such are the burrowing instincts of certain rodents, the woodchucks, gophers, and the like. To enumerate the chief phases of such instincts would be difficult, for as all animals are related to their environment, this relation must show itself in characteristic instincts.

136. Courtship.-The instincts of courtship relate chiefly to the male, the female being more or less passive. Among many fishes the male struts before the female, spreading his fins, intensifying his pigmented colors through muscular tension, and in such fashion as he can makes himself the preferred of the female. In the little brooks in spring male minnows can be found with warts on the nose or head, 
with crimson pigment on the fins, or blue pigment on the back, or jet-black pigment all over the head, or with varied combinations of all these. Their instinct is to display all these to the best advantage, even though the conspicuous hues lead to their own destruction. Against this contingency Nature provides a superfluity of males.

Among the birds the male in spring is in very many species provided with an ornamental plumage which he sheds when the breeding season is over. The scarlet, crimson, orange, blue, black, and lustrous colors of birds are commonly seen only on the males in the breeding season, the young. males and all males in the fall having the plain brown gray or streaky colors of the fumale. Among the singing birds it is chiefly the male that sings, and his voice and the instinct to use it are commonly lost when the young are hatched in the nest.

Among polygamous mammals the male is usually much larger than the female, and his courtship is often a struggle with other males for the possession of the female. Among the deer the male, armed with great horns, fight to the death for the possession of the female or for the mastery of the herd. The fur-seal has on an average a family of about thirty-two females (Fig. " 11), and for the control of his harem others are ready at all times to dispute the possession. But with monogamous animals like the true or hair seal or the fox, where a male mates. with a single female, there is no such discrepancy in size and strength, and the warlike force of the male is spent on outside enemies, not on his own species.

13\%. Reproduction.-The movements of many migratory animals are mainly controlled by the impulse to reproduce. Some pelagic fishes, especially flying-fishes and fishes allied to the mackerel, swim long distances to a region favorable for a. deposition of spawn. Some species are known only in the waters they make their breeding homes, the individuals being scattered through the wide seas at 
other times. Many fresh-water fishes, as trout, suckers, etc., forsake the large streams in the spring, ascending the small brooks where they can rear their young in greater safety. Still others, known as anadromous fishes, feed and mature in the sea, but ascend the rivers as the impulse of reproduction grows strong. Among such species are the salmon, shad, alewife, sturgeon, and striped bass in American waters. The most notewortly case of the anadromous instinct is found in the king salmon or quinnat of the Pacific coast. This great fish spawns in November. In the Columbia River it begins running in March and April, spending the whole summer in the ascent of the river without feeding. By autumn the individuals are greatly changed in appearance, discolored, worn, and distorted. On reaching the spawning beds, some of them a thousand miles from the sea, the female deposits her eggs in the gravel of some shallow brook. After they are fertilized both male and female drift tail foremost and helpless down the stream, none of them ever surviving to reach the sea. The same habits are found in other species of salmon of the Pacific, but in most cases the individuals of other species do not start so early or run so far. A few species of fishes, as the eel, reverse this order, feeding in the rivers and brackish creeks, dropping down to the sea to spawn.

The migration of birds has relation to reproduction as well as to changes of weather. As soon as they reach their summer homes, courtship, mating, nest-building, and the care of the young occupy the attention of every species.

138. Care of the young.--In the animal kingdom one of the great factors in development has been the care of the young. This feature is a prominent one in the specialization of birds and mammals. When the young are cared for the percentage of loss in the struggle for life is greatly reduced, the number of births necessary to the maintenance of the species is much less, and the opportunities for specialization in other relations of life are much greater. 
In these regards, the nest-building and home-making animals have the advantage over those that have not these instincts. The animals that mate for life have the advantage over polygamous animals, and those whose social or mating habits give rise to a division of labor over those with instincts less highly specialized.

The interesting instincts and habits connected with nest or home building and the care of the young are discussed in the next chapter.

139. Variability of instincts.-When we study instincts of animals with care and in detail, we find that their regularity is much less than has been supposed. There is as much variation in regard to instinct among individuals as there is with regard to other characters of the species. Some power of choice is found in almost every operation of instinct. Even the most machine-like instinct shows some degree of adaptability to new conditions. On the other hand, in no animal does reason show entire freedom from automatism or reflex action. "The fundamental identity of instinct with intelligence," says an able investigator, "is shown in their dependence upon the same structural mechanism (the brain and nerves) and in their responsive adaptability."

140. Reason.-Reason or intellect, as distinguished from instinct, is the choice, more or less conscious, among responses to external impressions. Its basis, like that of instinct, is in reflex action. Its operations, often repeated, become similarly reflex by repetition, and are known as habit. A habit is a voluntary action repeated until it becomes reflex. It is essentially like instinct in all its manifestations. The only evident difference is in its origin. Instinct is inherited. Habit is the reaction produced within the individual by its own repeated actions. In the varied relations of life the pure reflex action becomes inadequate. The sensorium is offered a choice of responses. To choose one and to reject the others is the function of intel- 
lect or reason. While its excessive development in man obscures its close relation to instinct, both shade off by degrees into reflex action. Indeed, no sharp line can be drawn between unconscious and subconscious choice of reaction and ordinary intellectual processes.

Most animals have little self-consciousness, and their reasoning powers at best are of a low order; but in kind, at least, the powers are not different from reason in man. $\Lambda$ horse reaches over the fence to be company to another. This is instinct. When it lets down the bars with its teeth, that is reason. When a dog finds its way home at night by the sense of smell, this may be instinct; when he drags a stranger to his wounded master, that is reason. When a jack-rabbit leaps over the brush to escape a dog, or runs in a circle before a coyote, or when it lies flat in the grass as a round ball of gray indistinguishable from grass, this is instinct. But the same animal is capable of reason-that is, of a distinct choice among lines of action. Not long ago a rabbit came bounding across the university campus at Palo Alto. As it passed a corner it suddenly faced two hunting dogs running side by side toward it. It had the choice of turning back, its first instinct, but a dangerous one; of leaping over the dogs, or of lying flat on the ground. It chose none of these, and its choice was instantaneous. It ceased leaping, ran low, and went between the dogs just as they were in the act of seizing it, and the surprise of the dogs, as they stopped and tried to hurry around, was the same feeling that a man would have in like circumstances.

On the open plains of Merced County, California, the jack-rabbit is the prey of the bald eagle. Not long since a rabbit pursued by an eagle was seen to run among the cattle. Leaping from cow to cow, he used these animals as a shelter from the savage bird. When the pursuit was closer, the rabbit broke cover for a barbed wire fence. When the eagle swooped down on it, the rabbit moved $u$ few inches to the right, and the eagle could not reach him 
through the fence. When the eagle came down on the other side, he moved across to the first. And this was continued until the eagle gave up the chase. It is instinct that leads the eagle to swoop on the rabbit. It is instinct again for the rabbit to run away. But to run along the line of a barbed wire fence demands some degree of reason. If the need to repeat it arose often in the lifetime of a single rabbit it would become a habit.

The difference between intellect and instinct in lower animals may be illustrated by the conduct of certain monkeys brought into relation with new experiences. At one time we had two adult monkeys, "Bob" and "Jocko," belonging to the genus Macacus. Neither of these possessed the egg-eating instinct. At the same time we had a baby monkey, "Mono," of the genus Cercopithecus. Mono had never seen an egg, but his inherited impulses bore a direct relation to feeding on eggs, just as the heredity of Macacus taught the others how to crack nuts or to peel fruit.

To each of these monkeys we gave an egg, the first that any of them had ever secn. The baby monkey, Mono, being of an egg-eating race, devoured his egg by the operation of instinct or inherited habit. On being given the egg for the first time, he cracked it against his upper teeth, making a hole in it, and sucked out all the substance. Then holding the egg-shell up to the light and seeing that there was no longer anything in it, he threw it away. All this he did mechanically, automatically, and it was just as well done with the first egg he ever saw as with any other he ate. All eggs since offered him he has treated in the same way.

The monkey Bob took the egg for some kind of nut. He broke it against his upper teeth and tried to pull off the shell, when the inside ran out and fell on the ground. He looked at it for a moment in bewilderment, took both hands and scooped up the yolk and the sand with which it was mixed and swallowed the whole. Then he stuffed the 
shell itself into his mouth. This act was not instinctive. It was the work of pure reason. Evidently his race was not familiar with the use of eggs and had acquired no instincts regarding them. He would do it better next time. Reason is an inefficient agent at first, a weak tool; but when it is trained it becomes an agent more valuable and more powerful than any instinct.

The monkey Jocko tried to eat the egg offered him in much the same way that Bob did, but, not liking the taste, he threw it away.

The confusion of highly perfected instinct with intellect is very common in popular discussions. Instinct grows weak and less accurate in its automatic obedience as the intellect becomes available in its place. Both intellect and instinct are outgrowths from the simple reflex response to external conditions. But instinct insures a single definite response to the corresponding stimulus. The intellect has a choice of responses. In its lower stages it is vacillating and ineffective; but as its development goes on it becomes alert and adequate to the varied conditions of life. It grows with the need for improvement. It will therefore become impossible for the complexity of life to outgrow the adequacy of man to adapt himself to its conditions.

Many animals currently believed to be of high intelligence are not so. The fur-seal, for example, finds it way back from the long swim of two or three thousand miles through a foggy and stormy sea, and is never too late or too early in arrival. The female fur-seal goes two hundred miles to her feeding grounds in summer, leaving the pup on the shore. After a week or two she returns to find him within a few rods of the rocks where she had left him. Both mother and young know each other by call and by odor, and neither is ever mistaken, though ten thousand other pups and other mothers occupy the same rookery. But this is not intelligence. It is simply instinct, becuuse it has no element of choice in it. Whatever its ancestors 
were forced to do the fur-seal docs to perfection. Its instincts are perfect as clockwork, and the necessities of migration must keep them so. But if brought into new conditions it is dazed and stupid. It can not choose when different lines of action are presented.

The Bering Sea Commission once made an experiment on the possibility of separating the young male fur-seals, or "killables," from the old ones in the same band. The method was to drive them through a wooden chute or runway with two valve-like doors at the end. These animals can be driven like sheep, but to sort them in the way proposed proved impossible. The most experienced males would beat their noses against a closed door, if they had seen a seal before them pass through it. That this door had been shut and another opened beside it passed their comprehension. They could not choose the new direction. In like manner a male fur-seal will watch the killing and skinning of his mates with perfect composure. He will sniff at their blood with languid curiosity; so long as it is not his own it does not matter. That his own blood may flow out on the ground in a minute or two he can not foresee.

Reason arises from the necessity ior a choice among actions. It may arise as a clash among instincts which forces on the animal the necessity of choosing. A doe, for example, in a rich pasture has the instinct to feed. It hears the hounds and has the instinct to flee. Its fawn may be with her and it is her instinct to remain and protect it. This may be done in one of several ways. In proportion as the mother chooses wisely will be the fawn's chance of survival. Thus under difficult conditions, reason or choice among actions rises to the aid of the lower animals as well as man.

141. Mind.-The word mind is popularly used in two different senses. In the biological sense the mind is the collective name for the functions of the sensorium in men and animals. It is the sum totai of all psychic changes, 
actions and reactions. Under the head of psychic functions are included all operations of the nervons system as well as all functions of like nature which may exist in organisms without specialized nerve fibers or nerve cells. As thus defined mind would include all phenomena of irritability, and even plants have the rudiments of it. The operations of the mind in this sense need not be conscious. With the lower animals almost all of them are automatic and unconscious. With man most of them must be so. All functions of the sensorium, irritability, reflex action, instinct, reason, volition, are alike in essential nature though differing greatly in their degree of specialization.

In another sense the term mind is applied only to conscious reasoning or conscious volition. In this sense it is mainly an attribute of man, the lower animals showing it in but slight degree. The discussion as to whether lower animals have minds turns on the definition of mind, and our answer to it depends on the definition we adopt.

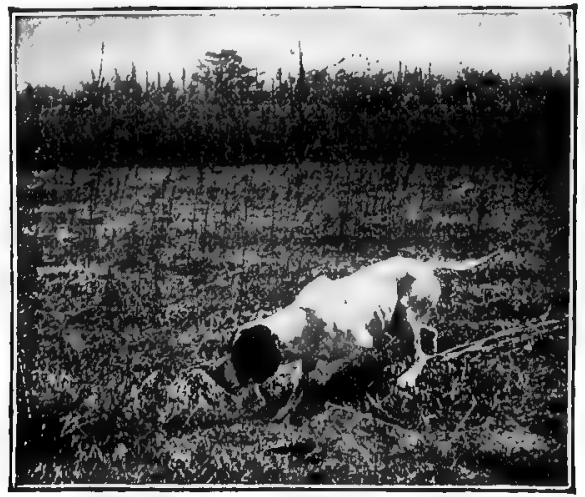

Fre. 165.-A "pointer" dog in the act of " pointing," a speciallzed instinct. (Permission of G. O. Shields, publiaher of Recreation.) 


\section{CHAPTER XV}

\section{HOMES AND DOMESTIC HABITS}

142. Importance of care of the young.-The nest-building and domestic habits of animals are adaptations, but adaptations of behavior or habit rather than of structure, and are based on instinct, intelligence, and reason. These instincts and habits are among the most important shown by animals, because on them depends largely the continuance of the species. Of primary importance in the perpetuation of the species is the possession by animals of adaptations of structure and behavior, which help the individual live long enough to attain full development and to leave offspring. But in the case of many animals a successful start in life on the part of the offspring depends on the existence in the parents of certain domestic habits concerned with the care and protection of their young. The young of many animals depend absolutely, for a part of their lifetime, on this parental care. In these cases it is quite as necessary for the continued existence of the species that the habits that afford this care be successful as that the parent should come successfully to mature development and to the production of offspring.

143. Care of the young, and communal life.-The nestbuilding or home-making habits and the continued personal care of the young for a part of their lifetime are most highly developed and widespread among the birds, mammals, and insects; and it is both among the insects and the higher vertehrates that we find most developed those social and communal halits discussed in Chapter TX. The principal activities of an animal community have to do 
with the protection and sustenance of the young, and the care of the young is undoubtedly a chief factor in the development of communal life.

144. The invertebrates (except spiders and insects).Among the lower invertebrates parental aid to the young is confined almost exclusively to exhibitions of pure instinct. And this is true of many of the higher animals also. Eggs are deposited in sheltered places, and in such places and under such circumstances that the young on hatching will find themselves close to a supply of their natural food. The depositing of eggs in water by parents with terrestrial habits whose young are aquatic, is an example. The toad, which lives on land, feeding on insects, has young which live in water and feed on minute aquatic plants (algæ). The dragon fly, that hawks over the pond or brook with glistening wings, has young that crawl in the slime and mud at the bottom of the pool. With most animals, after laying eggs, the parents show no further solicitude toward their offspring. The eggs are left to the vicissitudes of fortune, and the parents know nothing of their fate. In many cases the parent dies before the young are hatched. The mammals and birds are the only two great groups excepted, although there are numerous specific exceptions scattered among the lower invertebrates, fishes, batrachians, and higher invertebrates, notably the insects.

There are no instances of care of the young after hatching among the sponges, polyps, worms, or star-fishes and sea-urchins, and but few among the crustaceans and mollusks. But there are in some of these groups a few cases of nest or home building in a crude and simple way. Certain sea-urchins (Fig. 156) and worms and mollusks bore into stones, and remain in the shelter afforded by the cavity. A shell-fish (Lima hiams) cements together bits of coralline, shells, and sand to form a crude nest or hidingplace. The cray-fish digs a cylindrical burrow in the ground in which it can hide. 
145. Spiders.-Most spiders spin silken cocoons or sacs in which to deposit their eggs. Some spiders carry this egg-filled cocoon about with them for the sake of protecting the eggs. After hatching, the spiderlings remain in the cocoon a short time, feeding on each other! Thus only the

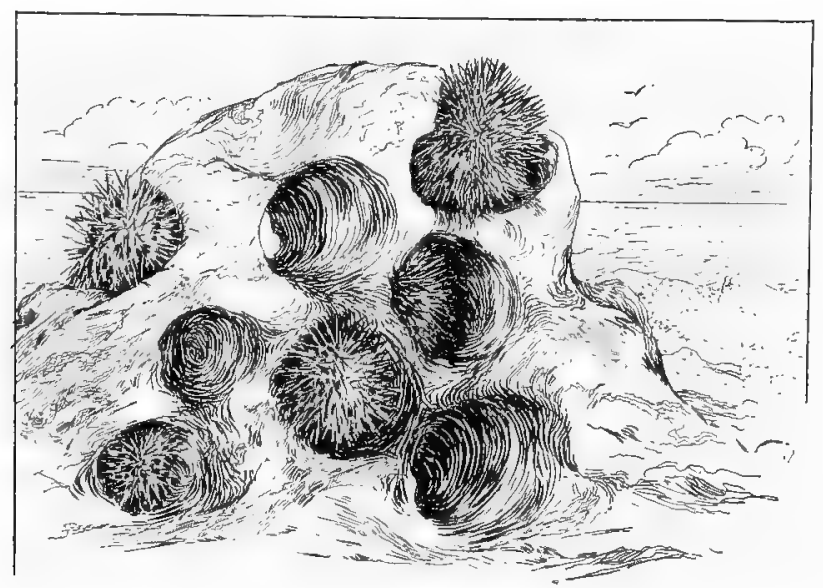

Fro. 150.-Sea-urchins living in holes bored into rocks of the seashore below hightide line.

strongest survive and issue from the cocoon to earn their living in the outer world. With certain species of spiders the young after hatching leave the cocoon and gather on the back of the mother and are carried about by her for some time. In connection with their webs or snares many spiders have silken tunnels or tubes in which to lie hidden, a sort of sheltering nest. Those spiders that live on the ground make for themselves cylindrical burrows or holes in the ground, usually lined with silk, in which they hide when not hunting for food. Especially interesting among the many kinds of these spider nests are the burrows of the various trap-door spiders. These spiders are common in California and some other far Western States. The bur. 
row (Fig. 15\%) or cylindrical hole is closed above by a silken, thick, hinged lid or door, a little larger in diameter than the hole and neatly beveled on the edge, so as to fit tightly into and perfectly cover the hole when closed. The upper surface of the door is covered with soil, bits of leaves, and wood, so as to resemble very exactly the ground surface about it. We have found these trap-door nests in California in moss-covered ground, and here the lids of the nests were always covered with green, growing moss.

An English naturalist who studied the habits of these trap-door spiders found that if he removed the soil and bits of bark and twigs, or the moss, from the upper surface of the lid the spider always re-covered it. It is, of course, plain that by means of this covering the nest is perfectly concealed, the surface of the closed door not being different from the surrounding ground surface. This naturalist finally removed the moss not only from the surface of a trap-door, but also from all the ground in a circle of a few feet about the nest. The next day he found that the spider had brought moss from outside the cleared space and covered the trap-door with it, thus making it very conspicuous in the cleared ground space. The spider's instinct was not capable of that quick modification to allow it to do what a reasoning animal would have done-namely, covered the trap-door only with soil to make it resemble the cleared ground about it.

Another interesting nest-making spider is the turretspider, that builds up a little tower (Fig. 158) of sticks and soil and moss above its burrow. The sticks of which this burrow are built are an inch or two in length, and are arranged in such manner as make the turret five-sided. The sticks are fastened together with silk, and the turret is made two or three inches high. This turret-building spider is one of those that carry about their egg-cocoon with them. A female of this spider in captivity was observed to pay much attention to caring for this cocoon. 


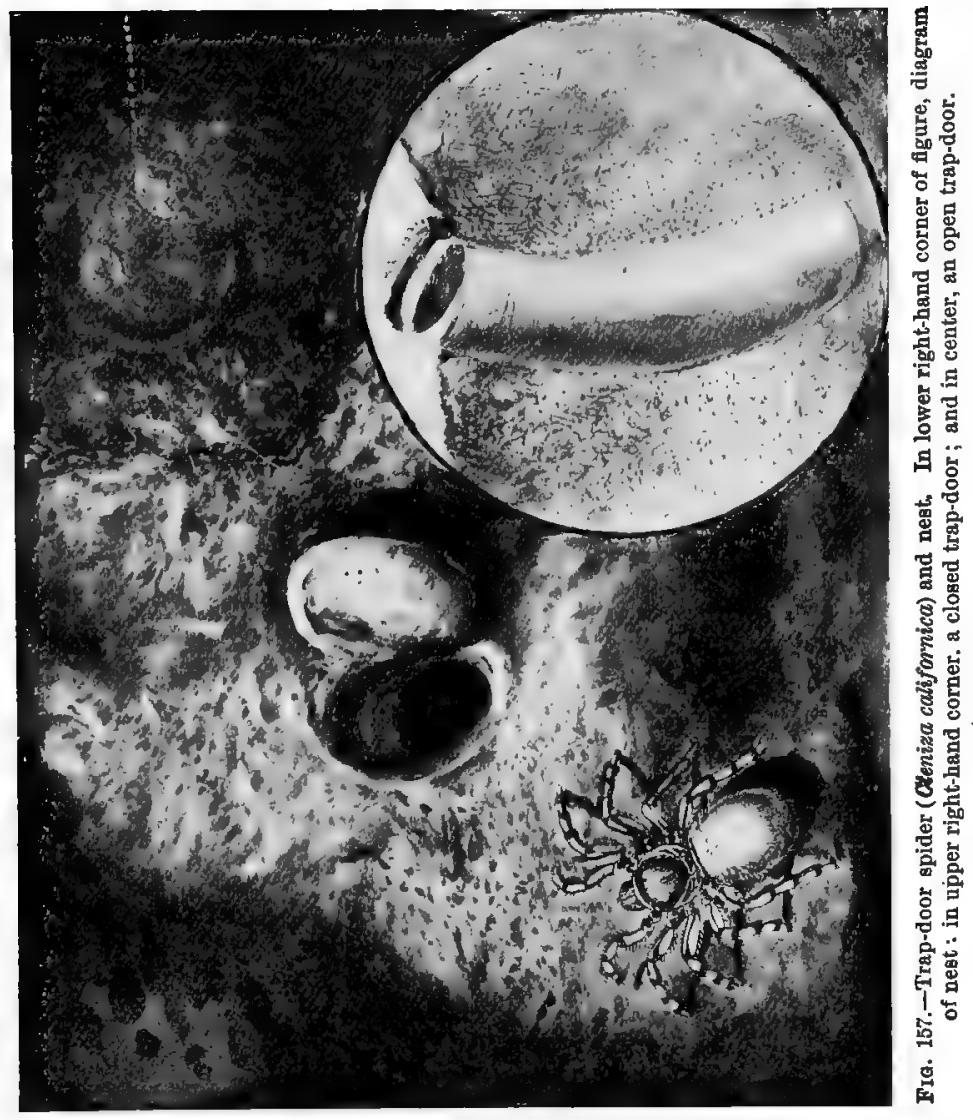


"If the weather was cold or damp, she retired to her tunnel; but if the jar in which she lived was set where the sun

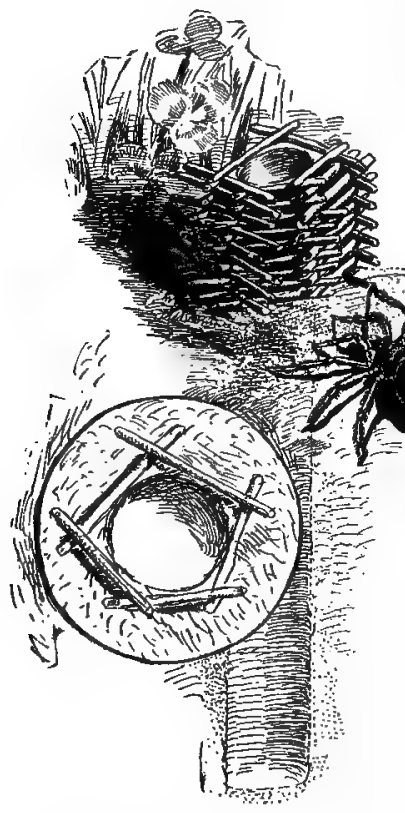

Fia. 158,-Nest of the turretspider. could shine upon it, she soon reappeared and allowed the cocoon to bask in the sunlight. If the jar was placed near a stove that had a fire in it, the cocoon was put on the side next the source of warmth; if the jar was turned around, she lost no time in moving the cocoon to the warmer side. Two months after the eggs were laid the young spiders made their appearance and immediately perched upon their mother, many on her back, some on her head, and even on her legs. She carried them about with her and fed them, and until they were older they never left their mother for a moment."

146. Insects.-So much space has already been devoted to an account of the elaborate nest-making and domestic habits of the bees, ants, and termites (see Chapter IX), that we need in this place merely refer to that account. It is among these social insects that the most interesting and highly specialized habits connected with the care of the young and the building of homes are found.

Many insects make for themselves simple burrows or nests in the ground or in wood. The young or larvæ of certain moths burrow about in the soft inside tissue of seaves, and the whole life of the moth except its short adult stage is passed inside the leaf. These larvæ are called leaf- 
miners. The larvæ of some moths and of many hymenopterous insects live in galls on live plants. These galls are simply abnormal growths of plant tissue, and are caused by the irritating effect on the tissue of the larvæ which hatch from eggs that have been thrust into the soft plant substance by the female insects. In the familiar galls on the golden-rod live the larvæ of a small moth, and in the various kinds of oak galls live the young of the numerous species of Cynipida, the hymenopterous gall insects. The tiny larvæ of some of the midges live in small galls on various plants. To this last group of gall-making insects belongs the dreaded Hessian $\mathrm{fly}$, the most destructive insect pest of wheat.

Among the bees and wasps only a few species, comparatively, are communal or live in communities. But nearly all the wasps and bees, whether social or solitary in habit, build nests for their young and provide the young with food, either by storing it in the nest or by hunting for it and bringing it to the nest as long as the young are in the larval condition. The "mud-daubers" or thread-waisted wasps make nests of mud attached to the lower surface of flat stones, to the ceiling of buildings, or in other out-ofthe-way and safe places. These nests usually have the form of several tubes an inch or so long placed side by side. In each of the tubes or cells an egg is laid, and with it a spider which has been stung so as to be paralyzed but not killed. When the young wasp hatches from the egg as a grub or larva, it feeds on the unfortunate spider. Others of the solitary wasps make nests in the ground or in wood, and all of them provision their nests with some particular kind of insect or spider. Some use only caterpillars, some plant-lice, and some grasshoppers. Similarly the solitary bees make nests in the ground as do the mining-bees, or in wood as do the carpenter-bees, or by cutting and fastening together leaves, as do the leaf-cutting bees. The bees provision their nests, not with paralyzed 
insects, but with masses of pollen or pollen mixed with nectar.

14\%. The vertebrates.-It is among the vertebrates, especially in the higher groups, the birds and mammals, that we find the care of the young most perfectly undertaken and most widespread.

Among the fishes, the lowest of the vertebrates, most species content themselves with the laying of many eggs in a situation best suited for their safe hatching. But some species show interesting domestic habits. The female catfish swims about with her brood, much as a hen moves about with her chickens. Some of the larger ocean catfish of the tropics receive the eggs or the young within the mouth for safety in time of danger. Certain sunfishes care for their young, keeping them together in still places in the brook. They also make some traces of a nest, which the male defends. The male salmon scoops out gravel to make a shallow nest, in which the female deposits her eggs. The male then covers the eggs. The males of the species of pipe-fish and sea-horses receive the eggs of the female into a groove or sac between the folds of skin on the lower part of the tail. Here they are kept until the little fishes are large enough to swim about for themselves. The brave little sticklebacks build tiny nests about an inch and a half or two inches in diameter, with a small opening at the top. The eggs are laid in this nest, and the young fish remain in it some time after hatching. The male parent jealously guards the nest, and fights bravely with would-be intruders.

The batrachians and reptiles rarely show any care for their young. The eggs of most batrachians are laid in the water and left by the female. The males of the Surinam toad receive the eggs in pits of the spongy skin of the back, where they remain until the young hatch. The eggs of snakes are laid under logs or buried in the sand, and no further attention is given them by the parents.

Among the birds, on the other hand, nest-building and 
care of the young are the rule, and a high degreo of development in these habits is reached. All of us are familiar with many different kinds of nests, from the few twigs loosely put together by the mourning-dove to the firm, closely knit, wool or feather lined nest of the hummingbird (Fig. 159), and the basket-like hanging nest of the

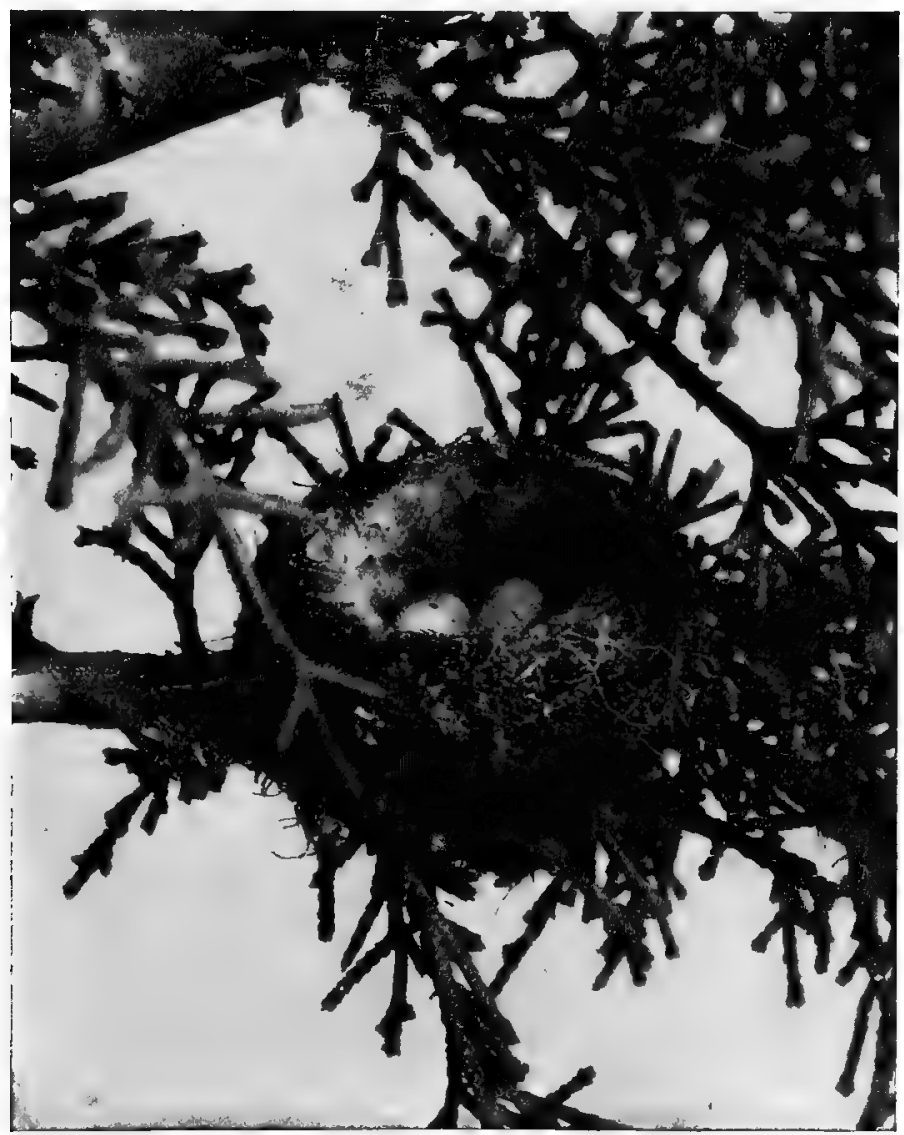

Fra. 159.-Nest and eggs of the Rufns humming-bird (Trochilus mufus). Photograph by J. O. SNYDER, Stanf ord University, California. 
oriole (Fig. 161). Not all birds make nests. On the rocky islets of the northern oceans, where thousands of puffins and auks and other maritime birds gather to breed, the eggs are laid on the bare rock. At the other extreme is the tailor bird of India, which sews together leaves by means of fibrous strips plucked from a growing plant to

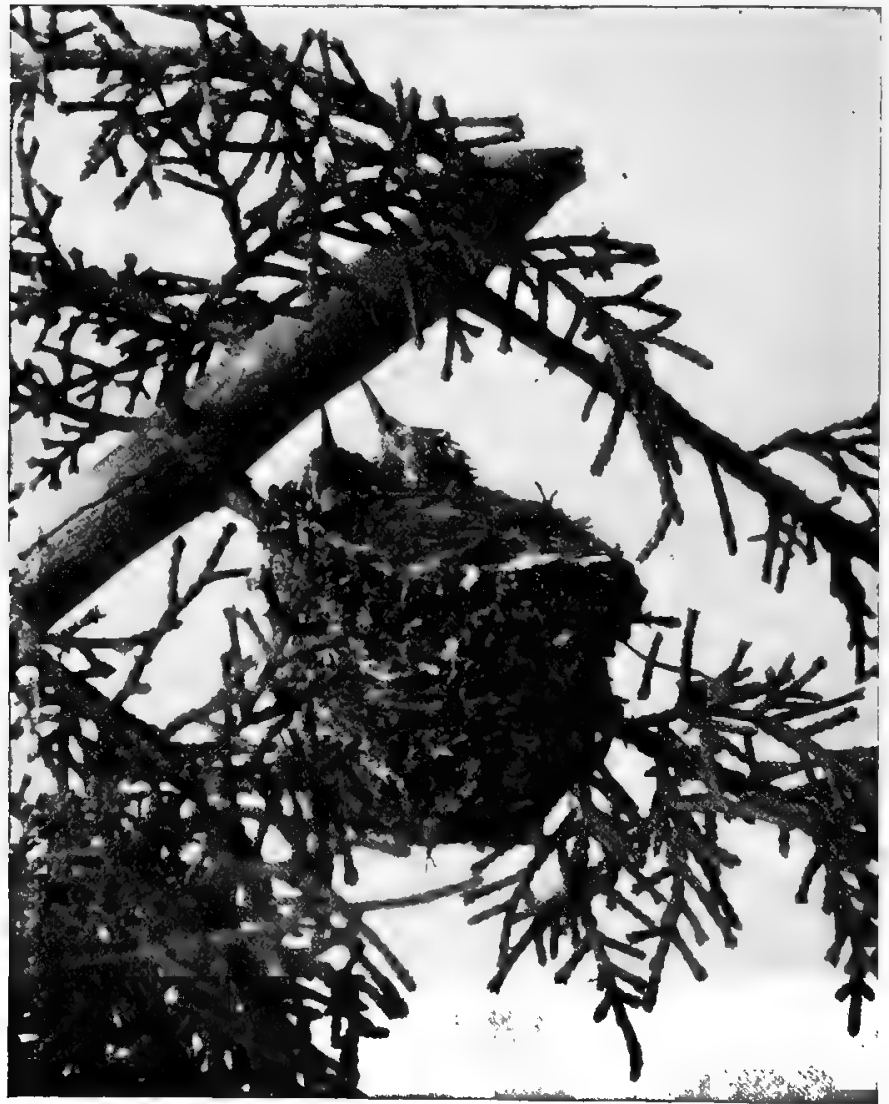

Fig. 160.-Nest and young of the Rupus humming-bird ('Thochllus rufus). Photograph by J. O. SNYDER, Stanford University, Gallfornia. 


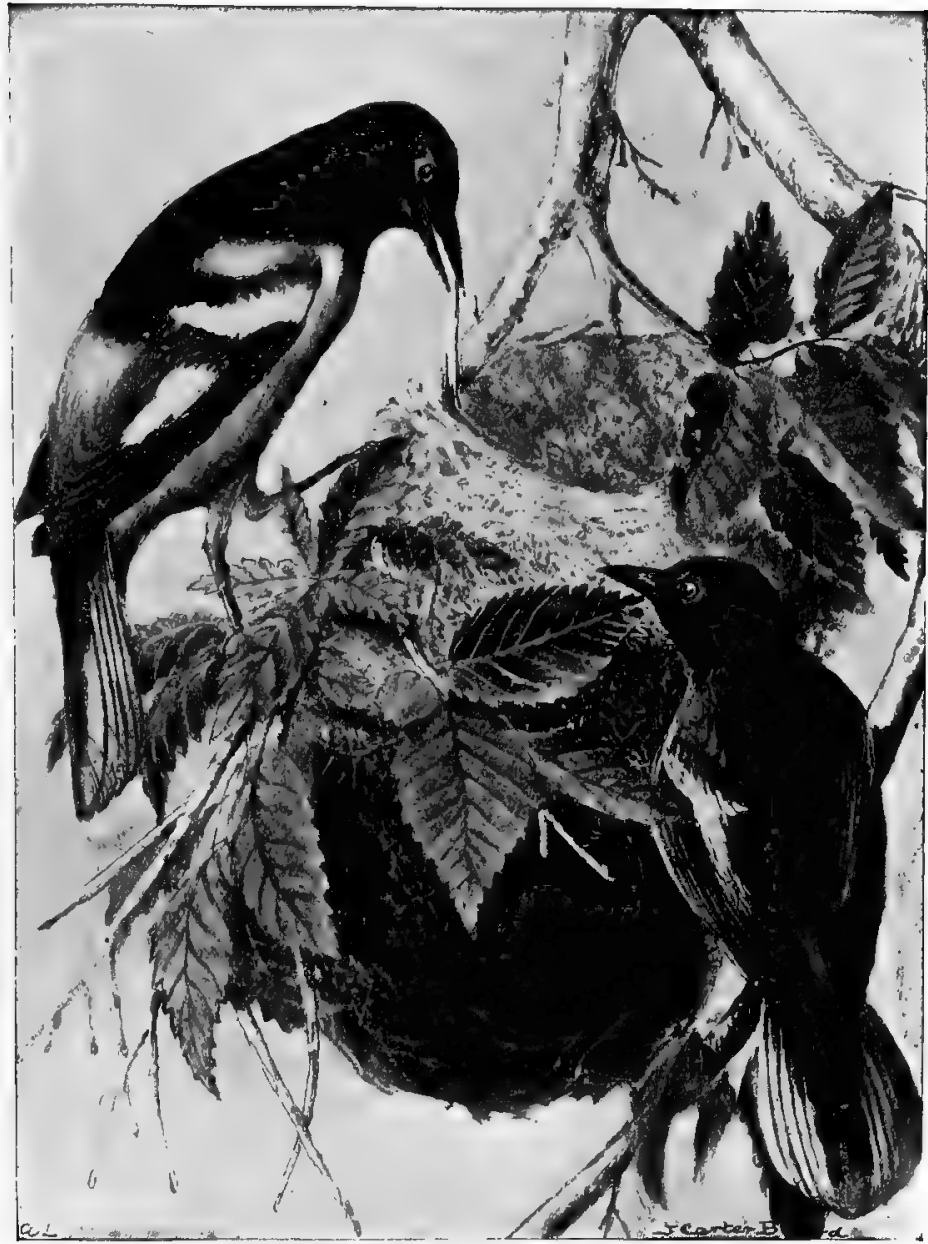

Fig. 161.-Baltimore orioles and nest; the male in upper left-hand corner of figure.

form a long, bag-like nest (Fig. 162). In the degree of care given the nestlings there is also much difference. The robin brings food to the helpless young for many days, and 
finally teaches it to fly and to hunt for food for itself. Young chickens are not so helpless as the nestling robins, but are able to run about, and care of the hen mother to

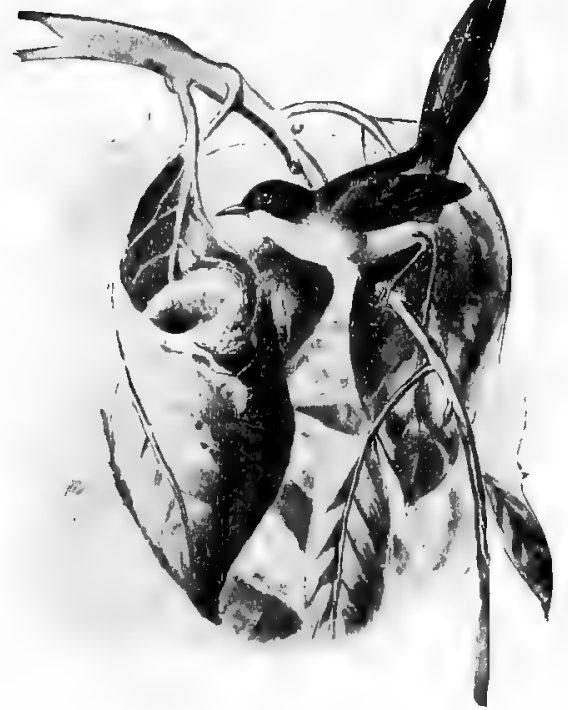

FiG. 162,-Tailor-bird (Omithotomus sutorius) and nest.

under the guiding pick up food for themselves.

Among the mammals the young arc always given some degree of care. Excepting in the case of the duck-bills, the lowest of the mammals, the young are born alive-that is, are not hatched from eggs laid outside the body - and are nourished after birth for a shorter or longer time with milk drawn from the body of the mother. Before birth the young undergoes a longer or shorter period of development and growth in the body of the mother, being nourished by the blood of the mother. The nests or homes of mammals present varying degrees of elaborateness, from a simple cave-like hole in the rocks or ground to the elaborately constructed villages of the beavers with their dams and conical several-storied houses (Fig. 163). The wood-rat piles together sticks and twigs in what seems, from the outside, a most haphazard fashion, but which results in the construction of a convenient and ingenious nest. The moles and pocket-gophers (Fig. 165) build underground nests composed of chambers and cal- 


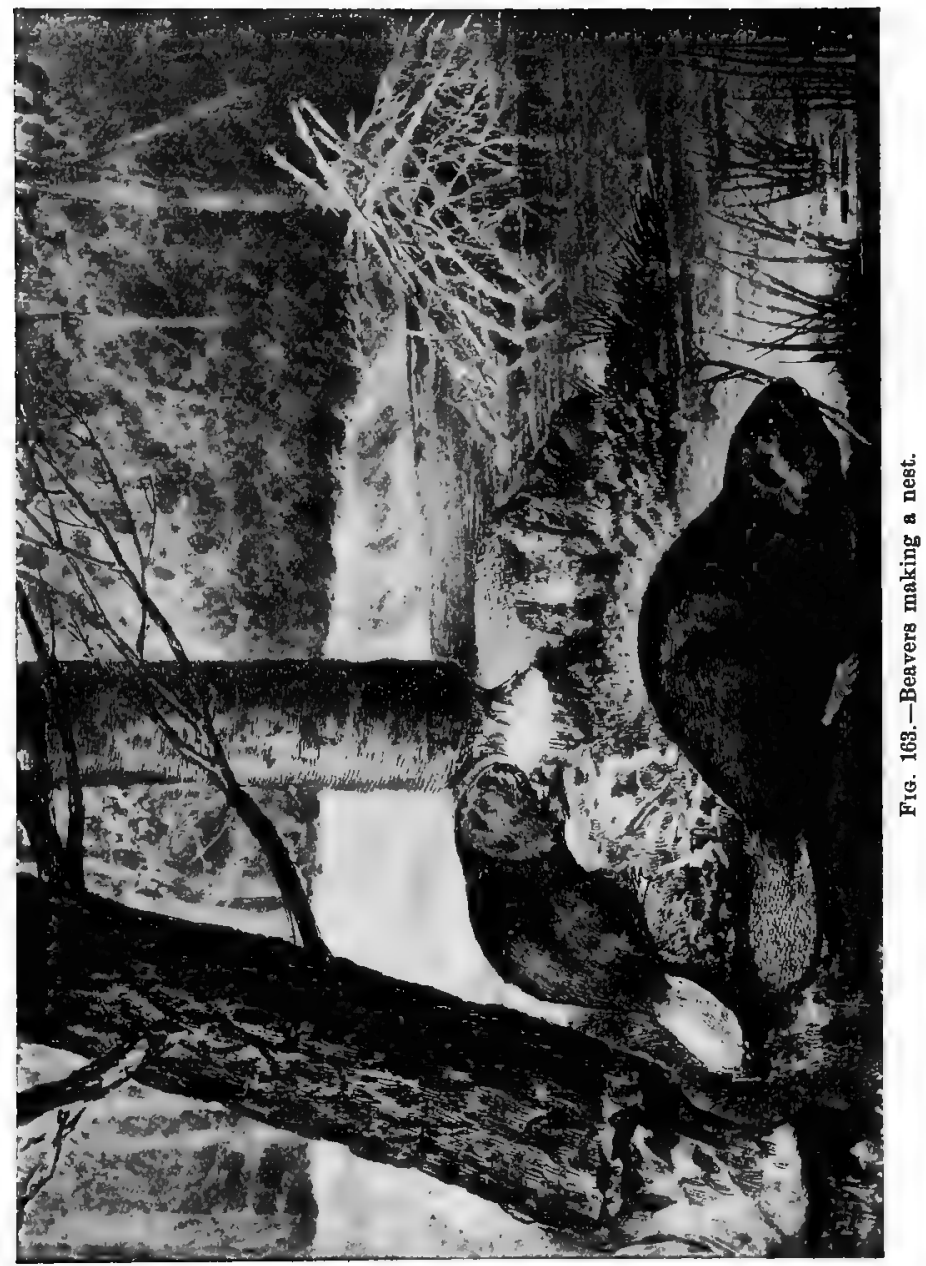




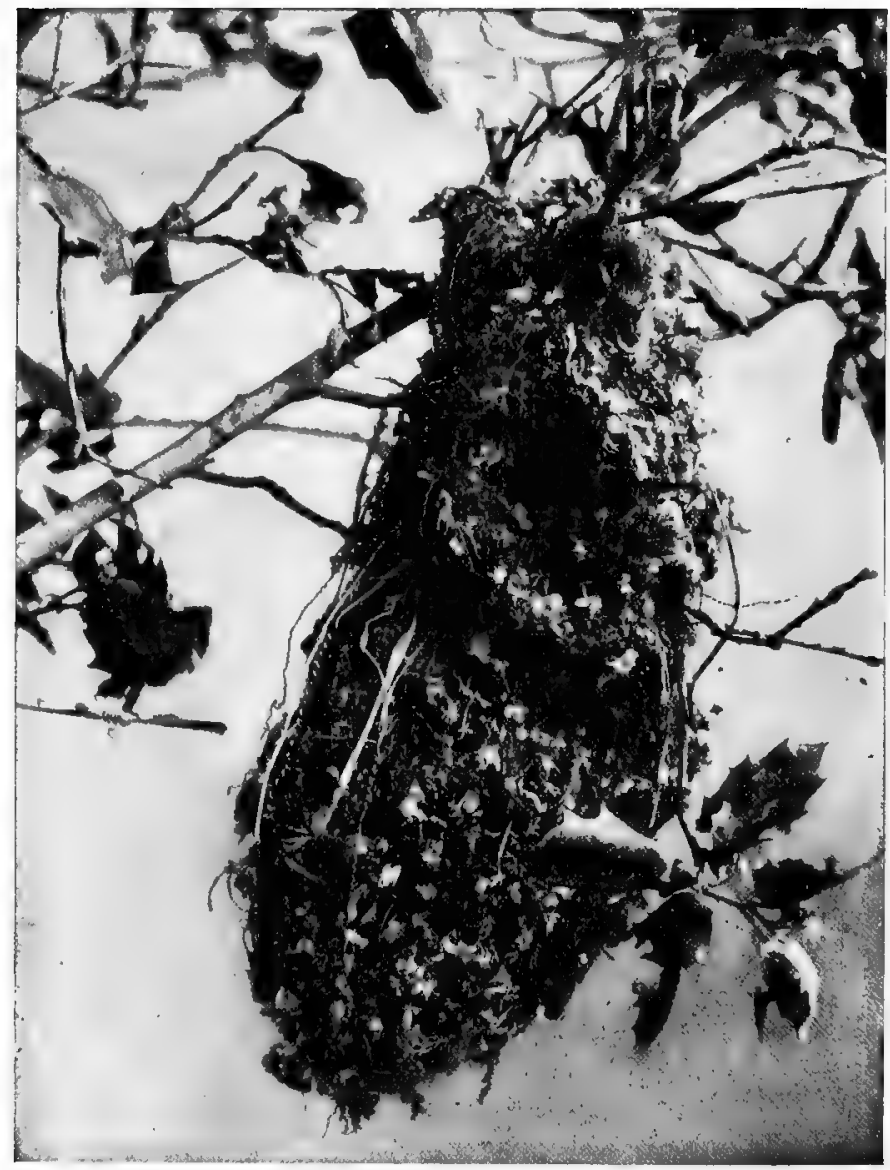

FIG. 164.-Nest of the Californian bush-tit (Psaltripames minimus). Photograph by G. O. SNYDER, Stanford University, California.

leries. The prairie-dogs make burrows in groups, forming large villages.

The devotion to their young displayed by birds and mammals is familiar to us. The parents will often risk or 
suffer the loss of their 'own lives in protecting their off spring from enemies. Many mother birds have the instinct to flutter about a discovered nest crying and apparently broken-winged, thus leading the predatory fox or weasel to

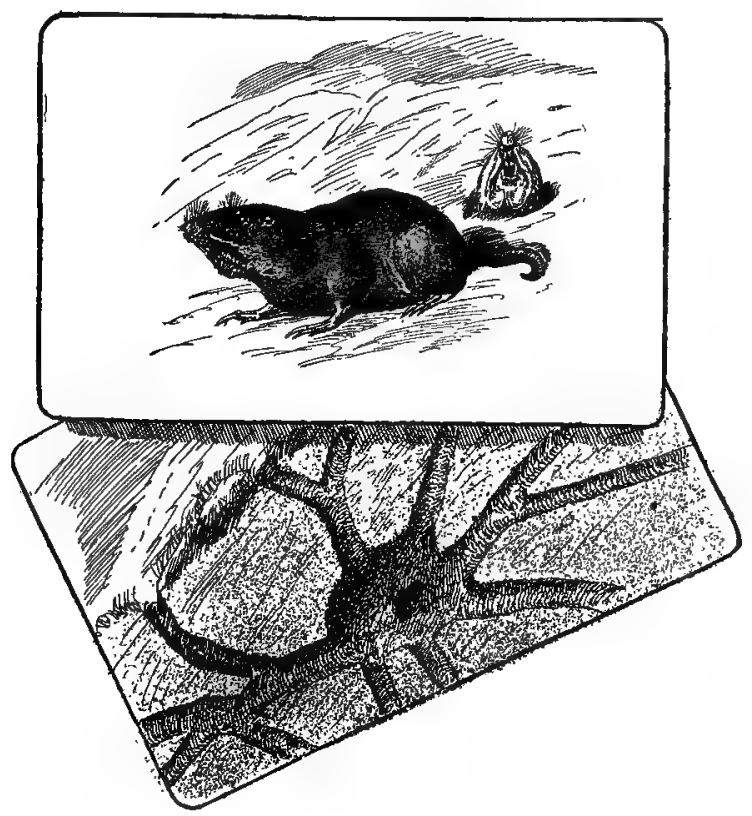

Fic. 165.-Nest and run-way of the pocket-gopher.

fix his attention on the mother and to leave the nest unharmed. This development of parental care and protection of the young reaches its highest degree in the case of the human species. The existence of the family, which is the unit of human society, rests on this high development of care for the young. 


\section{CHAPTER XVI}

\section{GECIGRAPHICAL DISTRIBUTION OF ANIMALS}

148. Geographical distribution.-Under the head of distribution we consider the facts of the diffusion of organisms over the surface of the earth, and the laws by which this diffusion is governed.

The geographical distribution of animals is often known as zoögeography. In physical geography we may prepare maps of the earth which shall bring into prominence the physical features of its surface. Such maps would show here a sea, here a plateau, here a range of mountains, there a desert, a prairie, a peninsula, or an island. In political geography the maps show the physical features of the earth, as related to the states or powers which claim the allegiance of the people. In zoögeography the realms of the earth are considered in relation to the types or species of animals which inhabit them. Thus a series of maps of the United States could be drawn which would show the gradual disappearance of the buffalo before the attacks of man. Another might be drawn which would show the present or past distribution of the polar bear, black bear, and grizzly. Still another might show the original range of the wild hares or rabbits of the United States, the white rabbit of the Northeast, the cotton-tail of the East and South, the jack-rabbit of the plains, the snowshoe rabbit of the Columbia River, the tall jack-rabbit of California, the black rabbits of the islands of Lower Califonia, and the marsh-hare of the South and the water-hare of the canebrakes, and that of all their relatives. Such a 272 


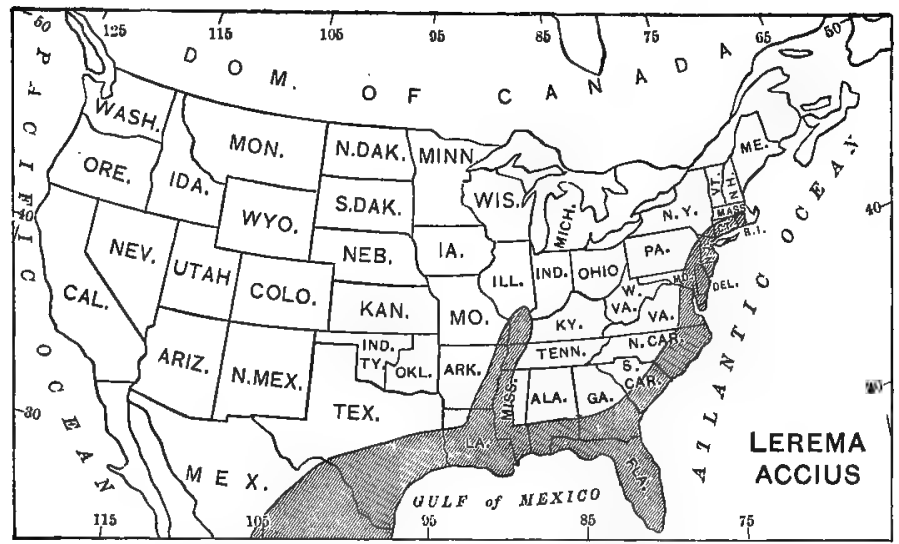

FiG. 166.-Map showing the distribution of the clouded Skipper butterfy (Lerema accius) In the Uniterl states. 'l'he burterfly is found in that part of the coutry shaded in the map, a warm and moist region.-After Scunves.

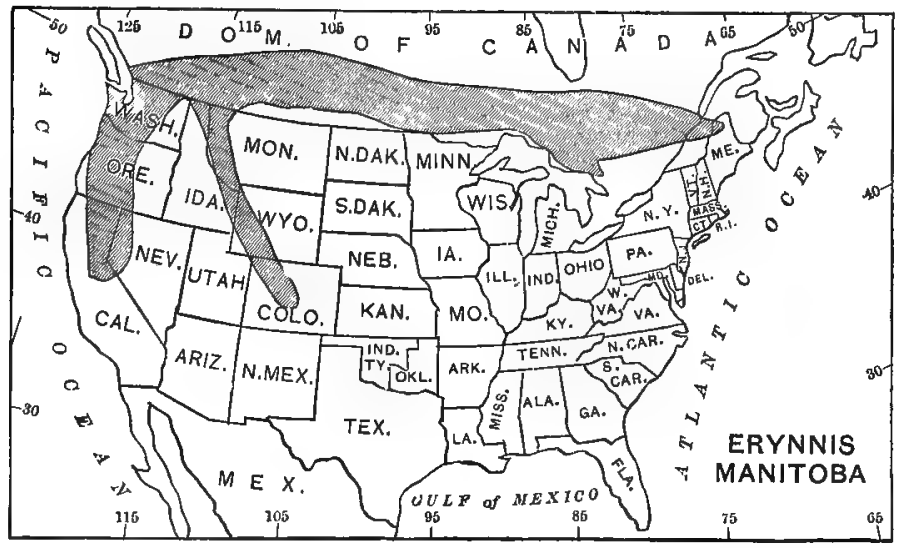

FIs. 167.-Map showing the distribution of the Canadian Skipper butterfly (Erynnis manifolm in the United Statco. The butterfiy is found in that part of the cosntry mladed in the map. This butterfly is subarctic and subalpine in distribution, beine fonnel nnly far north or on high mountains, the two nonthern projecting parts of its range being in the Rooky Mountains and in the Sierra Nevada Mountains.-After ScudDER, 
map is very instructive, and it at once raises a series of questions as to the reasons for each of the facts in geographical distribution, for it is the duty of science to suppose that none of these facts is arbitrary or meaningless. Fach fact has some good cause behind it.

149. Laws of distribution.-The laws governing the distribution of animals are reducible to three very simple propositions. Every species of animal is found in every part of the earth having conditions suitable for its maintenance, unless-.

(a) Its individuals have been unable to reach this region, through barriers of some sort; or-

(b) Having reached it, the species is unable to maintain itself, through lack of capacity for adaptation, through severity of competition with other forms, or through destructive conditions of environment; or-

(c) Having entered and maintained itself, it has become so altered in the process of adaptation as to become a species distinct from the original type.

150. Species debarred by barriers.-As examples of the first class we may take the absence of kingbirds or meadowlarks or coyotes in Europe, the absence of the lion and tiger in South America, the absence of the civet-cat in New York, and that of the bobolink or the Chinese flying-fox in California. In each of these cases there is no evident reason why the species in question should not maintain itself if once introduced. The fact that it does not exist is, in general, an evidence that it has never passed the barriers which separate the region in question from its original home.

Local illustrations of the same kind may be found in most mountainous regions. In the Yosemite Valley in California, for example, the trout ascend the Merced River to the base of a vertical fall. They can not rise above this, and so the streams and lakes above this fall are destitute of fish. 


\section{Species debarred by inability to maintain their ground.} - Examples of the second class are seen in animals which man has introduced from one country to another. The nightingale, the starling, and the skylark of Europe have been repeatedly set free in the United States. But none of these colonies has long endured, perhaps from lack of adaptation to the climate, more likely from severity of competition with other birds. In other cases the introduced species has been better fitted for the conditions of life than the native forms themselves, and so has graduallv crowded out the latter. Both these cases are illustrated among the rats. The black rat, first introduced into America from Europe about 1544, helped crowd out the native rats, while the brown rat, brought in still later, about $17 \% 5$, in turn practically exterminated the black rat, its fitness for the conditions of life here being still greater than that of the other European species.

Certain animals have followed man from land to land, having been introduced by him against his will and to the detriment of his domestic animals or crops. To many of these the term vermin has been applied. Among the ver, min or "animal weeds" are certain of the rodents (rats, mice, rabbits, etc.), the mongoose of India, the English sparrow, and many kinds of noxious insects. Of all the vermin of this class few have caused such widespread destruction of property as the common European rabbit introduced into Australia. The annual loss through its presence is estimated at $\$ 3,500,000$.

It often happens that man himself so changes the environment of a species that it can no longer maintain itself. Checking the increase of a species, either by actually killing off.its members or by adverse change in its surroundings, is to begin the process of its destruction. Circumstances become unfavorable to the growth or reproduction of an animal. Its numbers are reduced, fewer are born each year, and fewer reach maturity, it grows rare, 
is gone, and the final step of extinction may often pass unnoticed.

But a few years ago the air in the Ohio Valley was dark in the season of migration with the hordes of passenger pigeons. The advance of a tree-destroying, pigeon-shooting civilization has gone steadily on, and now the bird which once crowded our Western forests is in the same region an ornithological curiosity. The extinction of the American bison or "buffalo," and the growing rarity of the grizzly bear, the wolf, and of large carnivora gencrally, furnishes cases in point. When Bering and Steller landed on the Commander Islands in $1^{17} 41$, the sea-cow, a large herbivorous creature of the shores, was abundant there. In about fifty years the species, being used for food by fishermen, entirely disappeared. In most cases, however, a species that crosses its limiting barriers, but is unable to maintain itself, leaves no record of the occurrence. We know, as a matter of fact, that stray individuals are very often found outside the usual limit of a species. A tropical bird may be found in New Jersey, a tropical fish on Cape Cod, or a bird from Europe on the shores of Maine. Of course, hundreds of other cases of this sort must escape notice; but, for one reason or another, the great majority of these waifs are unable to gain a new foothold. For this reason, outside of the disturbances created by man, the geographical distribution of species changes but little from century to century; and yet, when we study the facts more closely, evidences of change appear everywhere.

152. Species altered by adaptation to new conditions.Of the third class or species altered in a new environment examples are numerous, but in most cases the causes involved can only be inferred from their effects. One class of illustrations may be taken from island faunæ. An island is set off from the mainland by barriers which species of land animals can very rarely cross. On an island a few waifs of wave and storm may maintain themselves, increasing in 


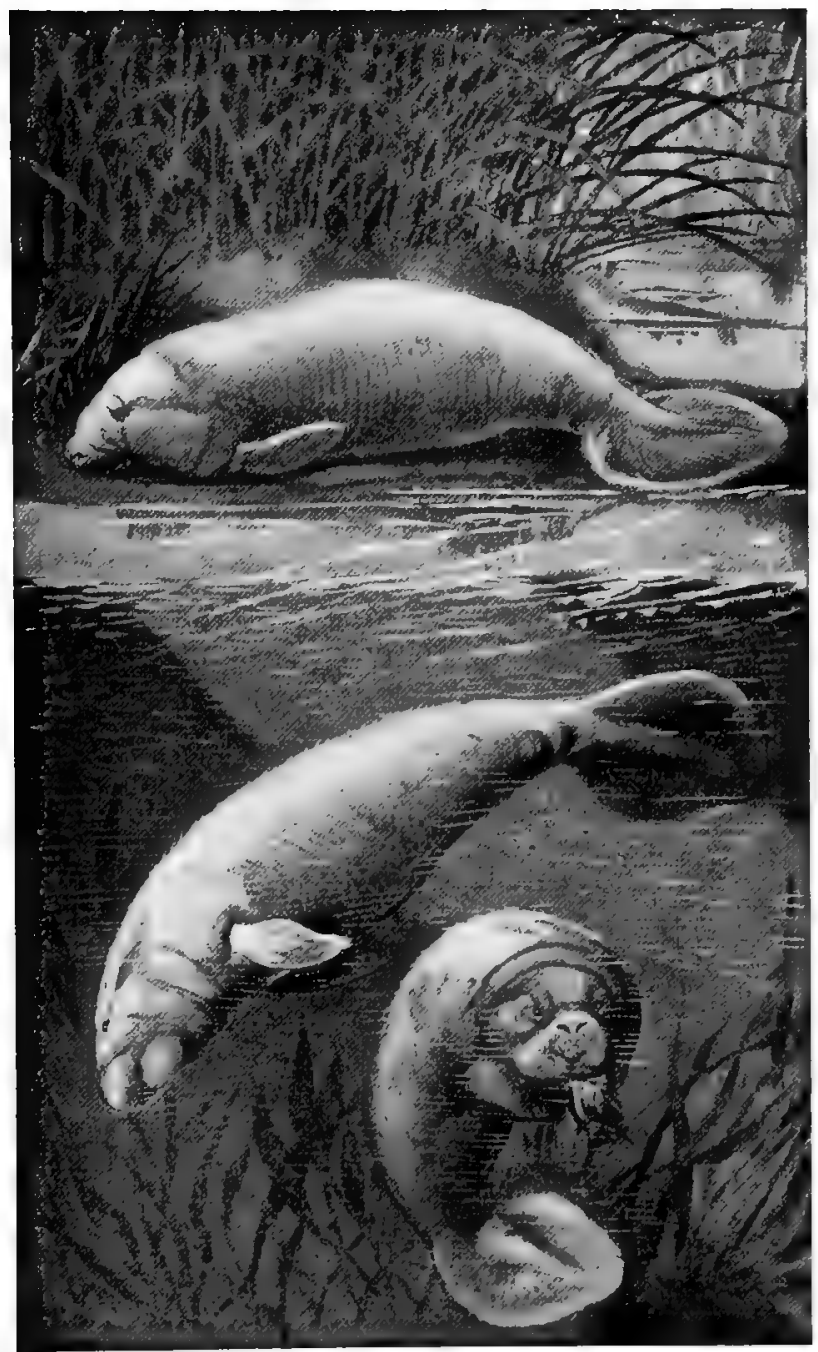

Fre. 168-The manatee, or sea-cow (Trichechus latirostris). A living species of sear cow related to the now extinct Steller's sea-cow. 


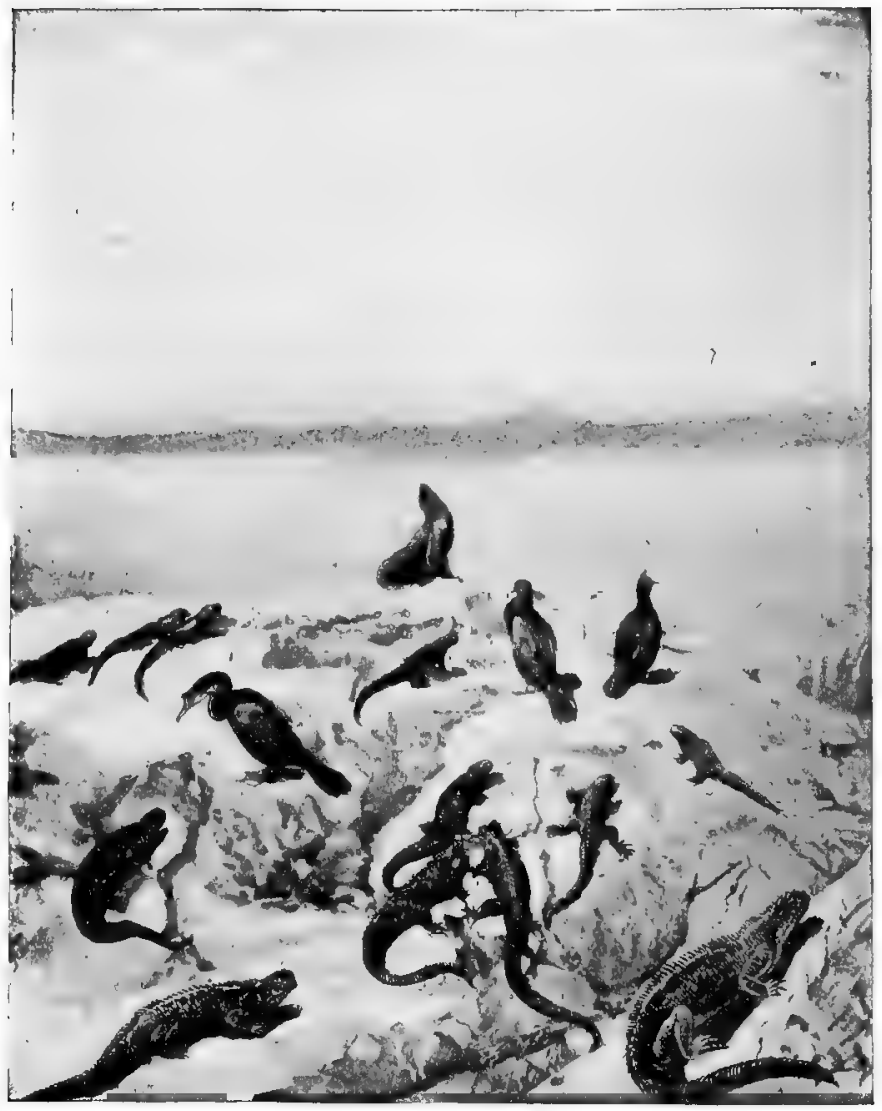

Fra, 169.-On the shore of Narborough Island, one of the Galapagos Islands, Pacific Ocean, showing yecaliar species of sea-lions, lizards, and cormorants. Drawn from a photograph made by Mesers. SNODGRAss and HrLLER.

numbers so as to occupy the territory; but in so doing only those will survive that can fit themselves to the new conditions. Through this process a new species will be formed, like the parent species in general structure, but having gained new traits adjusted to the new environment. 
The Galapagos Islands are a cluster of volcanic rocks lying in the open sea about six hundred miles to the west of Ecuador. On these islands is a peculiar land fauna, derived from South American stock, but mostly different in species. Darwin noted there "twenty-six land birds; of these, twenty-one, or perhaps twenty-three, are ranked as distinct species. Yet the close affinity of most of these birds to American species is manifest in every character, in their habits, gestures, and tones of voice."

Among land animals similar migrations may occur, giving rise, through the adaptation to new conditions, to new species. The separation of species of animals isolated in river basins or lakes often permits the acquisition of new characters, which is the formation of distinct species in similar fashion. On the west side of Mount Whitney, the highest mountain in the Sierra Nevada of California, there is a little stream called Volcano Creek. In this brook is a distinct species or form of trout, locally called golden trout. It is unusually small, very brilliantly colored, its fins being bright golden, and its tiny scales scarcely overlap each other along its sides. This stream flows over a high waterfall (Agua Bonita) into the Kern River. The Kern River is full of trout, of a kind (Salmo gilberti) to which the golden trout is most closely allied. There can not be much doubt that the latter is descended from the former. With this assumption, it is easy to suppose that once the waterfall did not exist, or that through some agency we can not now identify certain fishes had been carried over it. Once above it, they can not now return, nor can they mix with the common stock of the river. Those best adapted to the little stream have survived. The process of adaptation has gone on till at last a distinct species (or sub-species*) is formed. In recent times the

* In descriptive works the name species is applied to a form when the process of adaptation seems complete. When it is incomplete, or 


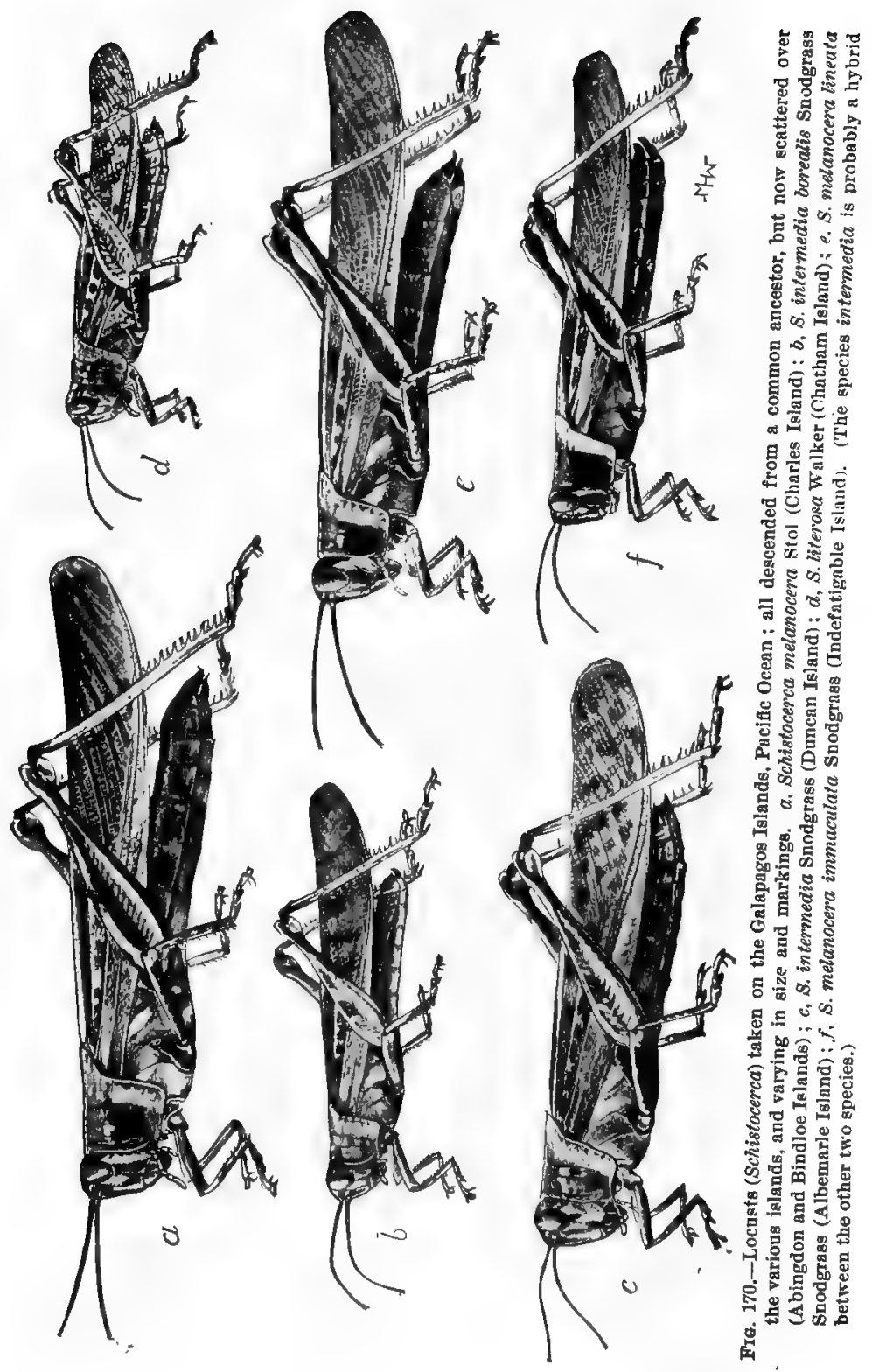



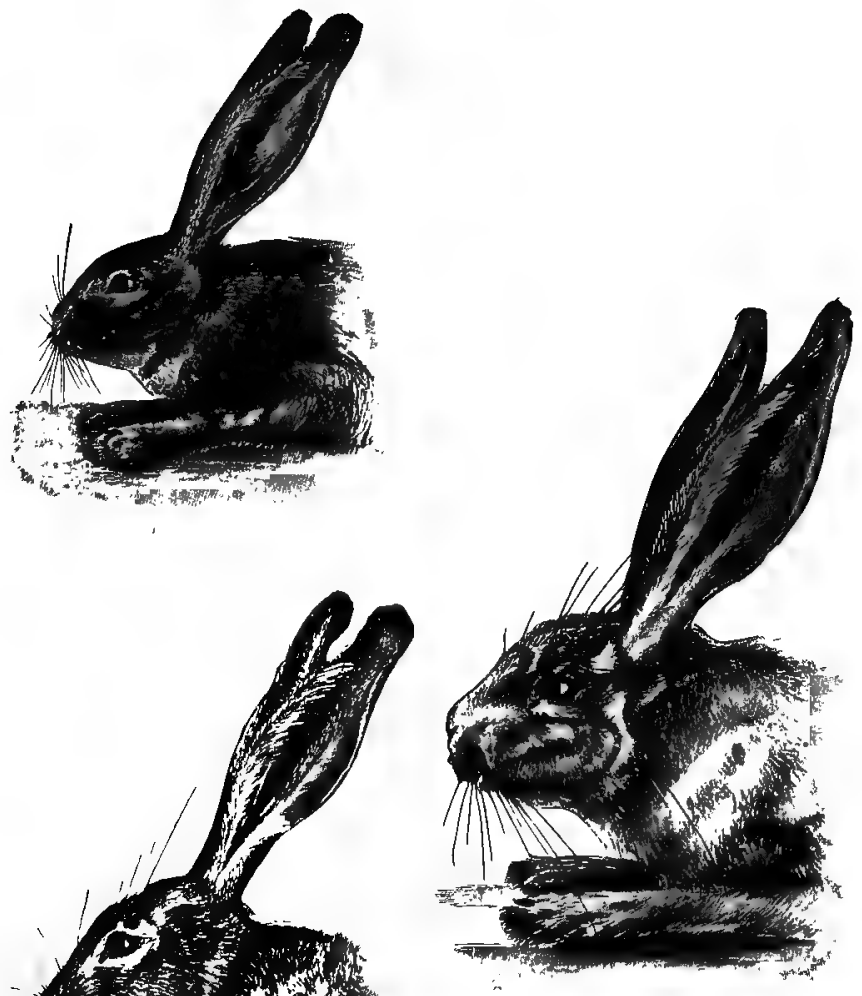

Fig. 171.-Three species of jack-rabbits, differing in size, color, and markings, but believed to be derived from n common stock. The differences have arisen through ieolation and adaptation. The upper figure shows the head and fore lega of the black jack-rqbbit (Lepus insularis), of Espiritu Santo Island, Gulf of California ; the lower right-hand figure, the Arizona jack-rabbit (Lepus alleni), specimen from Fort Lowell, Arizona ; and the lower left-hand figure is the San Pedro Martir jack-rabbit (Lupus martirensis), Prom San Pedro Martir, Baja California. 
hand of man has carried the golden trout to other little mountain torrents, where it thrives as well as in the one where its peculiarities were first acquired.

Other cases of this nature are found among the blind fishes of the caves in different parts of the world (Fig. 172).

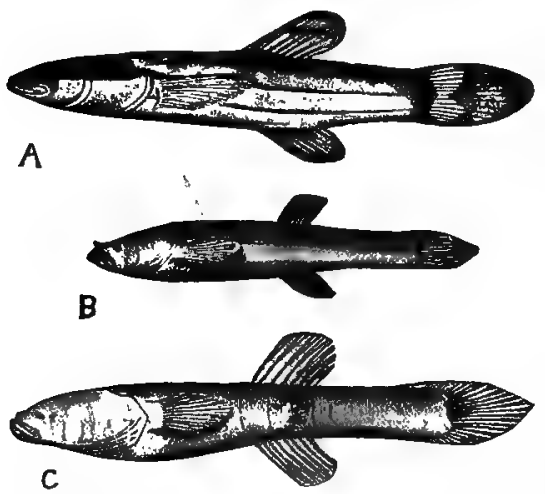

Fra. 172,-Fishes showing stages in the loss of eyes and color. A, Dismal Swamp fish (Chologaster avitus), ancestor of the blind fish; B, Agassiz'B cave flish (Chologaster agassizi); $\mathbf{C}$, cave blind fish (Typhlichthys subterraneus).

In general, caves are formed by the erosion or wearing of underground rivers. These streams are usually clear and cold, and when they issue to the surface those fishes that like cold and shaded waters are likely to enter them. But to have eyes in absolute darkness, in which no use can be made of them, is a disadvantage in the struggle for life. Hence the eyed species die or withdraw, while those in which the eye grows less from generation to generation, until its function is finally lost, are the ones which survive. By such processes the blind fishes in the limestone caves of Kentucky, Indiana, Tennessee, and Missouri have been formed.

rather when specimens showing intergradation of characters are known, the word sub-species is used. The word variety has much the same meaning when used for a subdivision of a species, but it is a term defined with less exactness. Thus the common fox (Vulpes pennsylvamicus) is a distinct species, being separate from the arctic fox or the gray fox or the fox of Europe. The cross fox (Vulpes pennsylvanicus decussatus) is called a sub-speoies, as is the silver fox (Vulpes pennsylvanicus argentatus), because these intergrade perfectly with the common red for. 
To processes of this kind, on a larger or smaller scale, the variety in the animal life of the globe is very largely due. Isolation and adaptation give the clew to the formation of a very large proportion of the "new species" in any group.

153. Effect of barriers.-It will be thus seen that geographical distribution is primarily dependent on barriers or checks to the movement of animals. The obstacles met in the spread of animals determine the limits of the species. Each species broadens its range as far as it can. It attempts unwittingly, through natural processes of increase, to overcome the obstacles of ocean or river, of mountain or plain, of woodland or prairie or desert, of cold or heat, of lack of food or abundance of enemies-whatever the barriers may be. Were it not for these barriers, each type or species would become cosmopolitan or universal. Man is pre-eminently a barrier-crossing animal. Hence he is found in all regions where human life is possible. The different races of men, howerer, find checks and barriers entirely similar in nature to those experienced by the lower animals, and the race peculiaritios are wholly similar to characters acquired by new species undcr adaptation to changed conditions. The degree of hindrance offered by any barrier differs with the nature of the species trying to surmount it. That which constitutes an impassable obstacle to one form may be a great aid to another. The river which blocks the monkey or the cat is the highway of the fish or the turtle. The waterfall which limits the ascent of the fish is the chosen home of the ouzel. The mountain barrier which the bobolink or the prairie-dog does not cross may be the center of distribution of the chief hare or the arctic bluebird.

154. Relation of species to habitat.-The habitat of a species of animal is the region in which it is found in a state of Nature. It is currently believed that the habitat of any creature is the region for which it is best adapted. 
But the reverse of this is often true. There are many cases in which a species introduced in a new territory, through the voluntary or involuntary influence of man, has shown a marvelous adaptation and power of persistence. The rapid spread of rabbits and pigs as wild animals in Australia, of horses and cattle in South America, and of the English sparrow in North America, of bumble-bees and houseflies in New Zealand, are illustrations of this. Not one of these animals has maintained itself in the wild state in its native land as successfully as in these new countries to which it has been introduced. The work of introduction of useful animals illustrates the same fact. The shad, striped bass, and cat-fish from the Potomac River, introduced into the Sacramento River and its tributaries by the United States Fish Commission, are examples in point. These valued food-fishes are nowhere more at home than in the new waters where no species of their types had ever existed before. The carp, originally brought to Europe from China, and thence to the United States as a foodfish, becomes in California a nuisance, which can not be eradicated, destroying the eggs and the foodstuff of far better fish.

In all mountain regions waterfalls are likely to occur, and these serve as barriers, preventing the ascent of trout and other fishes. On this account in the mountains of California, Colorado, Wyoming, and other States, hundreds of Jakes and streams suitable for tront are found in which no fishes ever exist. In the Yellowstone Park this fact is especially noticeable. This region is a high volcanic plateau, formed by the filling of an ancient granite basin with a vast deposit of lava. The streams of the park are very cold and clear, in every way favorable for the growth of trout; yet, with the exception of a single stream, the Yellowstone River, none of the streams was found to contain any fish in that part of it lying on the plateau. Below the platean all of them are well stocked. The reason for this is ap- 


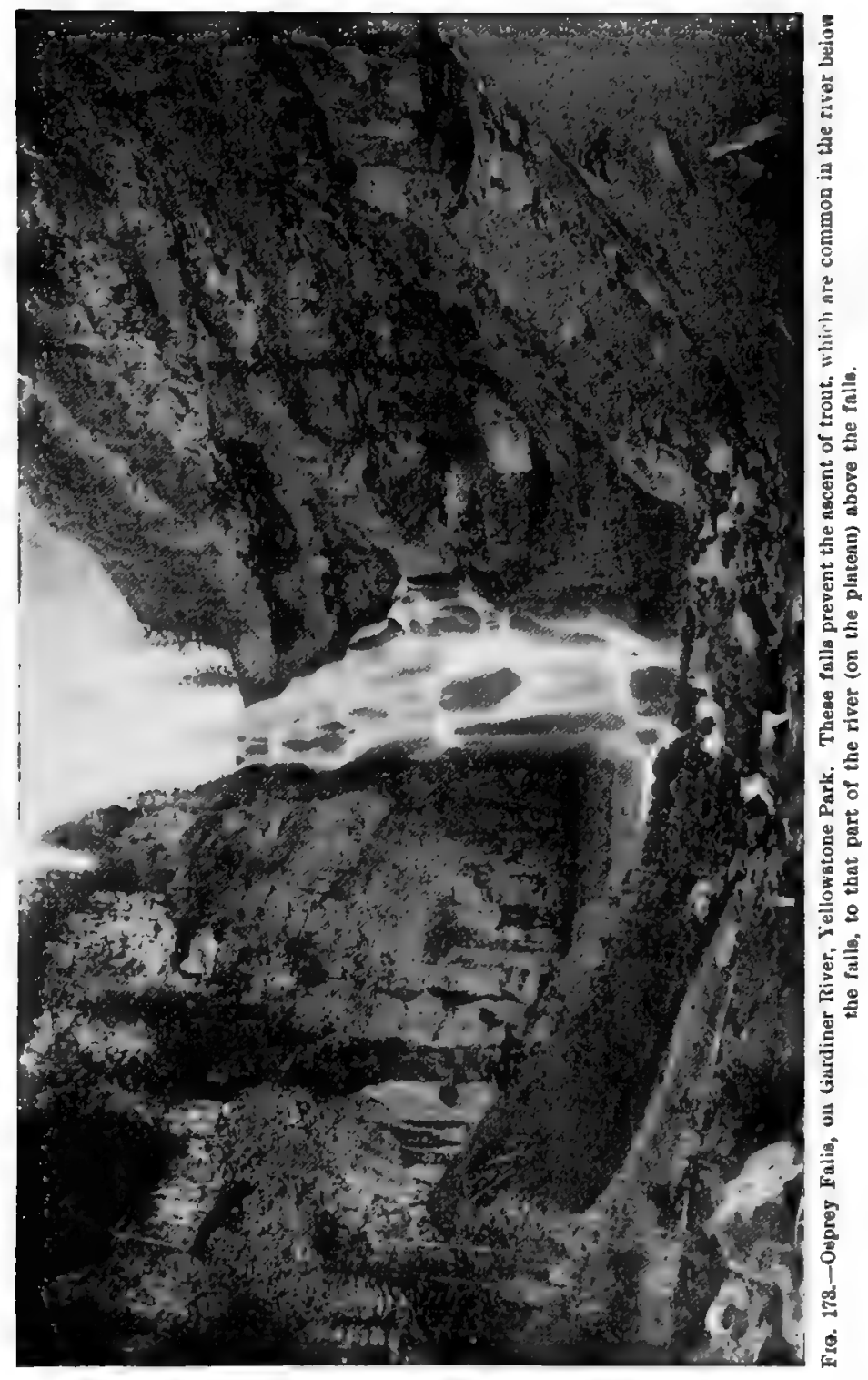


parent in the fact that the platean is fringed with cataracts which fishes can not ascend. Each stream has a cañon or deep gorge with a waterfall at its head, near the point where it leaves the hard bed of black lava for the rock below (Fig. 173). So for an area of fifteen hundred square miles within the Yellowstone National Park the streams were without trout because their natural inhabitants had never been able to reach them. When this state of things was discovered it was easy to apply the remedy. Trout of different species were carried above the cascades, and these have multiplied with great rapidity.

The exception noted above, that of the Yollowstone River itself, evidently needs explanation. An abundance of trout is found in this river both above and below the great falls, and no other fish occurs with it. This anomaly of distribution is readily explained by a study of the tributaries at the head waters of the river. When we ascend above Yellowstone Lake to the continental divide, we find on its very summit that only about an eighth of a mile of wet meadow and marsh, known as Two Ocean Pass (Fig. 174), separates the drainage of the Yellowstone from that of the Columbia. A stream known as Atlantic Creek flows into the Yellowstone, while the waters of Pacific Creek on the other side find their way into the Snake River. These two creeks are connected by waterways in the wet meadow, and trout may pass from one to the other without check. Thus from the Snake River the Yellowstone received its tront, and from the Yellowstone they have spread to the streams tributary to the upper Missouri.

This case is a type of the anomalies in distribution of which the student of zoögeography will find many. But each effect depends upon some cause, and a thorough stady of the surroundings or history of a species will show what this cause may be. In numerous cases in which fishes have been found above an insurmountable cascade, the cause is seen in a marsh flooded at high water, connecting one 


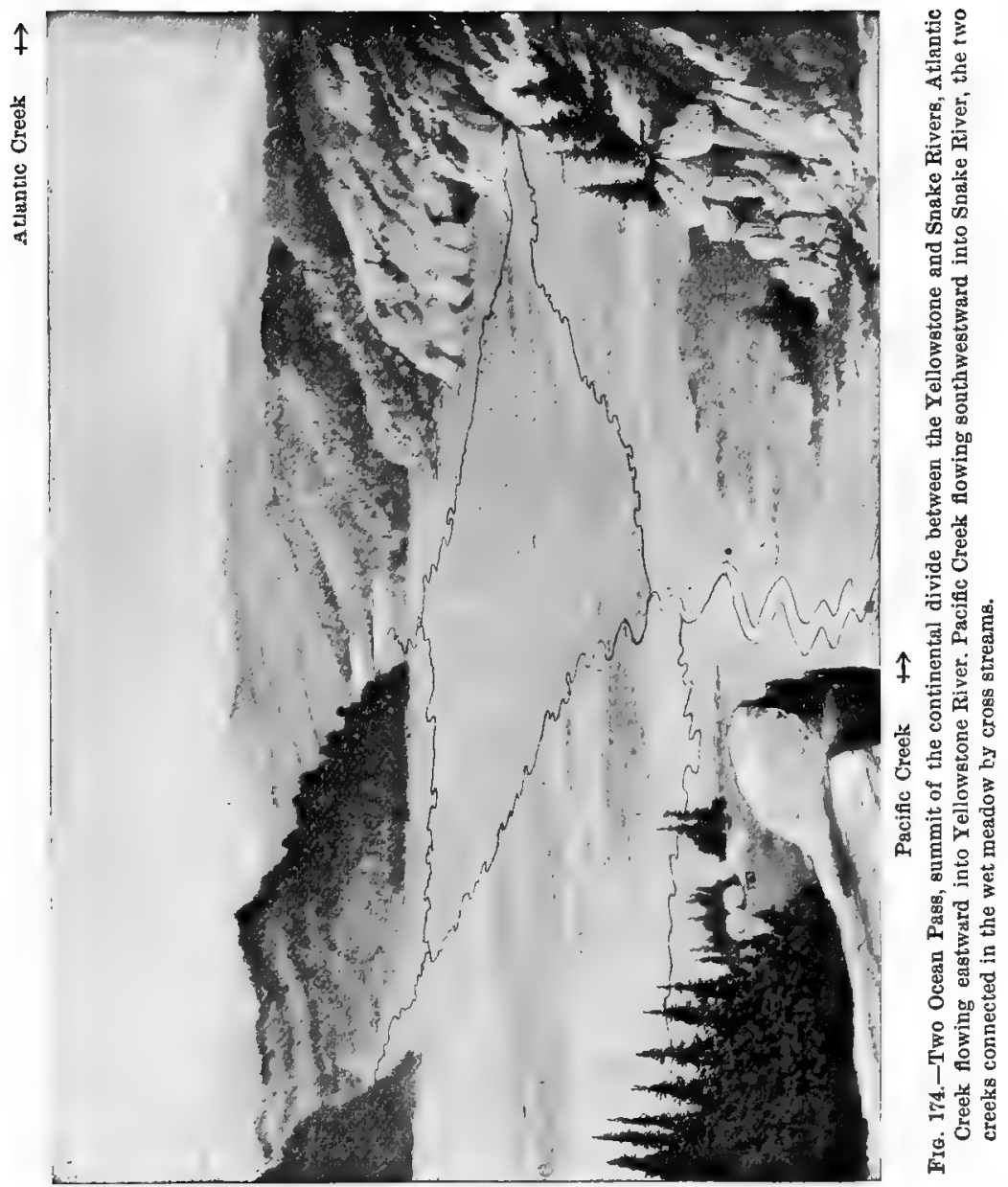


drainage basin with another. An example of this is found in Lava Creek in Yellowstone Park. Above Undine and Wraith Falls, both insurmountable, are found an abundance of trout. A marsh dry in summer connects Lava Creek with Black Tail Deer Creek, a tributary of the Yellowstone and without waterfall. From the Yellowstone through this creek and marsh the tront find their way into Lava Creck. In California numerous anomalies have been noted, as the occurrence of Tahoe trout in Feather River and in the Blue Lakes of Amador, which arc on the other side of the main crest of the Sierra Nevada from Lake Tahoe, and the occurrence of the Whitney golden trout in Lone Pine, Creek, another similar instance. In each case naturalists have found the man who actually carried the species across the divide. If this matter had. been investigated a generation later, these cases would have been unexplainable anomalies in geographical distribution. Real causes are almost always simple when they are once known.

The ways in which species may cross barriers in a state of Nature are as varied as the creatures themselves, and far more varied than the actual barriers. By the long-continued process of adjustment to conditions with the incessant destruction of the unadapted, the various organisms have become so well fitted to their surroundings that the casual observer may well suppose that each inhabits the region best fitted for it. Men have even thought that the conditions of life have been fitted to the creatures themselves, so perfect is this relation.

155. Character of barriers to distribution.-Taking the animal kingdom as a whole, the two great barriers modifying distribution are the presence of the sea and changes in temperature. It is only in rare cases that any land animals can cross either of the great oceans, and these rare cases relate chiefly to the arctic regions. For this reason the land faunæ of Africa, South America, and Australir 
have developed almost independently of one another. To the fresh-water fishes the sea forms equally a barrier, and
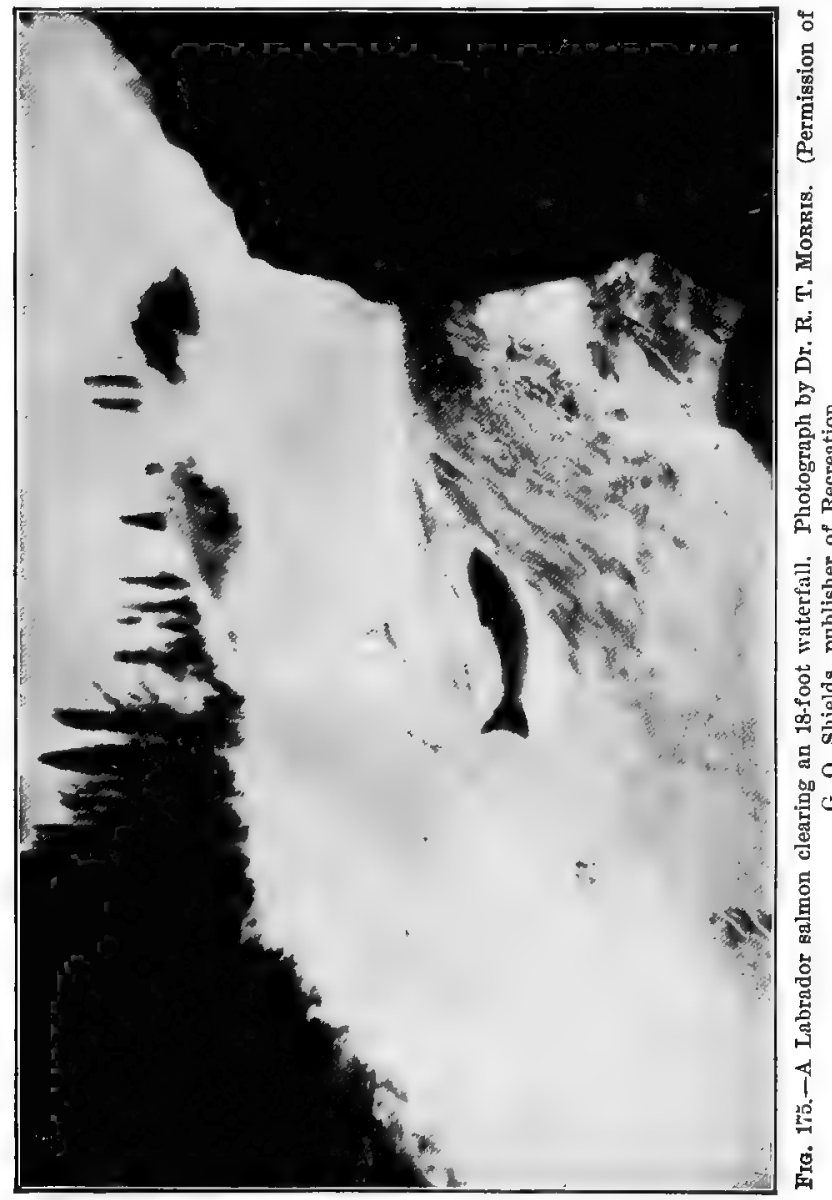

even the shore-fishes very rarely pass across great depths. Relatively few of the shore-fishes of Cuba, for example, ever cross the deep Florida Straits, and none of those of Cali- 
fornia ever reach Honolulu, nor are Hawaiian shore-fishes ever seen on the coast of California. For these reasons natural boundaries of the great realms of distribution are found in the sea.

The other great check to distribution is found in heat and cold. Most of the tropical animals can not endure frost. The arctic animals, however fierce or active, are enfeebled by heat. The timber line, north of which and above which frost occurs the year round, therefore serves

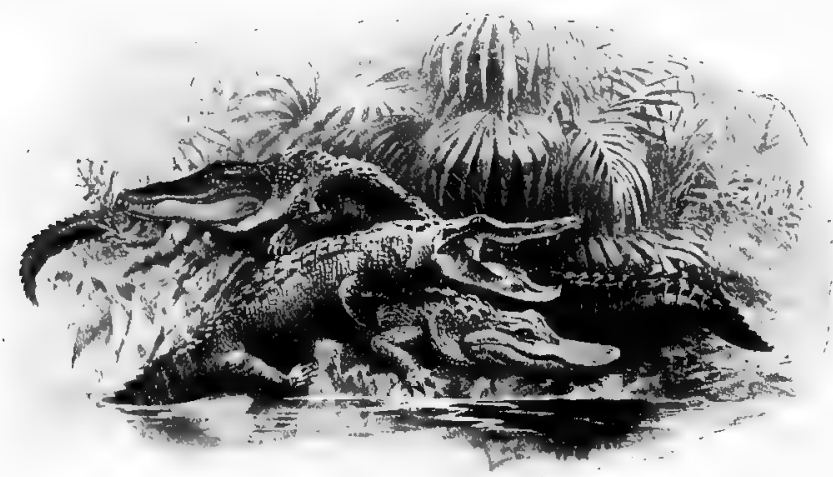

FIG, 176.-Alligators; animals found only in the warm waters of tropical and subtropical regions.

as a boundary of limitation. Another equally marked is the frost line. Even the fishes of the tropics are extremely sensitive to slight cold. Off Florida Keys the cutlassfish is sometimes seen stiff and benumbed on the water, where the temperature is scarcely below $60^{\circ}$ Fahr. A "norther" on the Gulf of Mexico will sometimes bring fishes which live in considerable depths to the surface, through chilling the water. These barriers are rarely crossed by localized species, but many forms, especially birds, keep within a relatively uniform temperature through migration. The summers are spent in the north or in the mountains, the winters in districts that are warmer. 
The climate, as distinct from the temperature, also greatly influences many species. In the Eastern United States and in the extreme Northwest, as in Europe and much of Asia, the atmosphere is humid all the year long. Rains occur at intervals in the summer, and rain or snow in the winter. The green season is from spring to fall, and the resting of plants is in the winter. To this condition the native animals adapt themselves, and this would seem to be the natural order of things.

But as we pass the Western plains of Nebraska, Kansas, and Texas this condition is materially changed. For part of the year rainfall is practically unknown. The air becomes dry, and under the cloudless sky the greater part of the vegetation ripens its seed and perishes. This is the arid climate. When the rainfall is very scant the region is never covered with verdure, and is known as desert. Such great desert tracts are found in parts of Wyoming, Utah, Nevada, Idaho, Colorado, Arizona, New Mexico, California, as well as in the northern parts of Mexico. In some cases the deserts are exposed to great heat, forming an ultra-torrid region, as in Death Valley in California and in certain parts of Arizona.

But the arid region is not as a whole desolate. In many parts rain falls more or less heavily for part of the year, bringing a rank growth of annual grasses and of verdure in general. In California this rainfall is in the winter, the coldest part of the year, and the country is green from November or October to June or May. In Mexico and northward to Colorado the chief rainfall is in midsummer, the warmest part of the year, and the summer is the time of verdure.

To all these conditions the plant life must adapt itself and with this the animal life. But the species that have become fitted to the arid habitat have undergone some change in the process and may have become different species. It is, then, not easy for them to recross the barrier 
of climate to compete with those forms already adapted. For this reason a marked change of climate like a marked change of temperature forms a natural barrier to distribution and serves to circumscribe a natural fauna.

Closely associated with climate is the nature of forest growth, the growth of grass, and in general the development of conditions which serve for food or shelter to animals. These conditions depend in part on soil, partly on climate and topography, and partly on the acts of man. The forest and forest soils, acting like a great sponge, retain the waters of the rainy season, and thus regulate the size of the streams. The stream that changes least in volume is most favorable to the life of fishes, frogs, and water animals generally. The destruction of forests on the mountain sides acts adversely to the life of these creatures as well as to the interests of the farmer below whose lands the streams should water. When the forests are destroyed, the great host of wood creatures, the bears, squirrels, warblers, various birds, beasts, and insects of the woods can no longer maintain themselves, and grow rare and disappear. For reasons that are obvious the conditions that produce forest, prairie, canebrake, sage-desert, cactus-desert, and the like are potent in regulating the distribution of the species.

Still another set of conditions depends on the food supply. The planting of orchards tends to multiply greatly the number of individuals of those species which prey upon fruit. When food is abundant the severity of the struggle for life is relaxed and individuals increase in number. A species may be put to great stress by the disappearance of the animal or plant on which it has depended. Each change made by man among the wild animals or plants may have far-reaching effects upon others. The coyote or prairie-wolf destroys sheep in the ranges of the West. It is thinned out by means of the bounty upon its scalp. Then the jack-rabbit, on which it also feeds, greatly in- 
creases in abundance, injuring fruit trees and grain ficlds. It is then necessary to pay for its destruction also.

To destroy hawks or owls because they catch chickens may increase the numbers and destructiveness of field-mice on which they also prey. 'To shoot robins, linnets, and other birds that destroy small fruits is likely to increase greatly the insect pests on which these birds also feed. The inter-relations of species and species are so close that none should be exterminated by man unless its habits and relations have been subjected to careful scientific study. Still less should any new ones be introduced withont the fullest consideration of the possible results. For example, the mongoose, a weasel-like creature, was introduced from India into Jamaica to kill rats and mice. It killed also the lizards, and thus produced a plague of fleas, an insect which the lizards kept in check. The English sparrow, introduced that it might feed on insects inhabiting shade-trees, has become a nuisance, crowding out better birds and not accomplishing the purpose for which it was brought to the United States.

To most kinds of animals a mountain range must act as a barrier to distribution. In a region having high mountains a species will become in time split up into several, because the individuals in one valley will be isolated from those of another. The fauna of California furnishes many illustrations of this, as among its mountain chains are many deep valleys shut off from each other and having different peculiarities of temperature. For this reason two counties of California differ much more widely in their fauna than do two counties in Illinois. But Illinois as a whole has more different kinds of animals than California, because no barrier anywhere prevents their entrance. The State has, we may say, its doors wide open to immigrants from all quarters. The same is true of Iowa or of Kansas or Kentucky. Illinois has a richer fauna than Iowa, because its extension is north and south, and it therefore 
covers a wider range of climate. Kentucky has a richer fauna than Iowa because it includes a greater variety of conditions. New England was called by Professor Agassiz a "zoölogical island," because of the relatively small number of its native animals, especially of species inhabiting its rivers. The cause of this is found in its isolation, being shut off from the Middle States by mountain ranges, while it is bounded on two sides by the sea.

156. Barriers affecting fresh-water animals.-The animals inhabiting fresh-water streams are affected by differences in temperature and elevation much as land animals are. They tend to spread from stream to stream whenever they can find their way. An isolated stream is likely to have its peculiar fauna just as island life is likely to differ from that of the mainland. The same species wanders widely within the limits of a single river basin. If a kind of fish establishes itself anywhere in the Mississippi Valley, it may find its way to every stream in the whole basin. If it likes cold spring water, as the rainbow-darter does, we may look for it in any cold spring. If, like the long-eared sun-fish, it frequents deep pools in the brooks, we may look for it under roots of stumps and in every "swimming hole." If, like the channel-cat, it chooses the ripples of a river, we may fish for it wherever ripples are. The larger the whole river basin the more species find their way into it, and therefore the greater the number of species in any one of its streams.

Each species finds its habitat fitted to its life, and then in turn is forced to adapt itself to this habitat. Any other kind of habitat then appears as a barrier to its distribution. Thus to a fish of the ripples a stretch of still water becomes a barrier. A species adapted to sandy bottoms will seldom force its way through swift waters or among weeds or rocks. The effect of waterfalls as barriers is elsewhere noticed. In some streams the dam made by a colony of beavers has the same effect. Mill-dams and artificial 
waterfalls have checked the movements of many species, while others have been helped by artificial channels or canals. Streams that run muddy at times are not favorable for animal life. Still less favorable is the condition frequent in the arid region in which streams are full to the banks in the rainy season and shrunk to detached pools in the dry months.

The stream that has the greatest variety of animals in it would be one (1) connected with a large river, (2) in a warm climate, (3) with clear water and (4) little fluctuation from winter to summer, (5) with little change in the clearness of the water, (6) a gravelly bottom, (7) preferably of limestone, and (8) covered in its quiet reaches and its ripples with water-weeds. These conditions are best realized in tributaries of the Ohio, Cumberland, Tennessee, and Ozark Rivers among American streams, and it is in them that the greatest number of species of fresh-water animals (fishes, cray-fishes, mussels, etc.) has been recorded. These streams approach most nearly to the ideal homes for animals of the fresh waters. The streams of Wisconsin, Michigan, and the Columbia region have many advantages, but are too cold. Those of Mlinois, Iowa, northern Missouri, and Kansas are too sluggish, and sometimes run muddy. Those of Texas and California shrink too much in summer, and are too isolated. The streams of the Atlantic coast are less isolated, but none connect with a great basin, and those of New England run too cold for the great mass of the species. For similar reasons the fresh-water animal life of Europe is relatively scanty, that of the Danube and Volga being richest. The animal life of the fresh water of South America centers in the Amazon, and that of Africa in the Nile, the Niger, and the Congo. The great rivers of Siberia, like the Yukon in Alaska and the Mackenzie River in British America, have but few forms of fresh-water animals, though those kinds fitted for life in cold, clear water exist in great abundance. 
15\%. Modes of distribution. - The means and modes of migration and distribution are obvious in the case of animals that can fly or swim or make long journeys on foot. An island can be visited and become peopled by birds from the nearest mainland. Fishes and marine mammals can travel from ocean to ocean. But many animals have no means of crossing watery barriers. "Oceanic islands, that have been formed de novo in mid-ocean and are not detached portions of pre-existing continents, are almost invariably free from such animals as are incapable of traversing the sea. If sufficiently distant from any continent, oceanic islands are generally without mammals, reptiles, and amphibia, but have both birds and insects and certain other invertebrates which are transported to them by involuntary migration."

As suggested in the last sentence, migration may be passive or involuntary. For example, those minute animals that can become dried up and yet retain the power of renewing their active life under favorable conditions are sometimes carried in the dried mud adhering to the feet of birds, and may thus become widely distributed. Parasites are carried by their hosts in all their wanderings. Some animals, as rats and mice, are carried by ships and railway trains and thus widely distributed.

158. Fauna and faunal areas.-The term fauna is applied to the animals of any region considered collectively. Thus the fauna of Illinois comprises the entire list of animals found naturally in that State. It includes the aboriginal men, the black bear, the fox, and all its animal life down to the Amoba. The relation of the fauna of one region to that of another depends on the ease with which barriers may be crossed. Thus the fauna of Illinois differs little from that of Indiana or Iowa, because the State contains no barriers that animals may not readily pass. On the other hand, the fauna of C'alifornia or Colorado differs materially from that of adjoining regions, because a moun- 
tainous country is full of barriers which obstruct the diffusion of life. Distinctness is in direct proportion to isolation. What is true in this regard of the fauna of any region is likewise true of its individual species. The degree of resemblance among individuals is in strict proportion to the freedom of their movements. Variation within the limits of a species is again proportionate to the barriers which prevent equal and free diffusion.

159. Realms of animal life.-The various divisions or - realms into which the land surface of the earth may be divided on the basis of the character of animal life have their boundary in the obstacles offered to the spread of the average animal. In spite of great inequalities in this regard, we may yet roughly divide the land of the globe into seven principal realms or areas of distribution, each limited by barriers, of which the chief are the presence of the sea and the occurrence of frost. : There are the Arctic, North Temperate, South American, Indo-African, Lemurian, Patagonian, and Australian realms. Of these the Australian realm alone is sharply defined. Most of the others are surrounded by a broad fringe of debatable ground that forms a transition to some other zone.

The Arctic realm includes all the land area north of the isotherm of $32^{\circ}$. Its southern boundary corresponds closely with the northern limit of trees. The fauna of this region is very homogeneous. It is not rich in species, most of the common types of life of warmer regions being excluded. Among the large animals are the polar bear, the walrus, and certain species of "ice-riding" seals. There are a few species of fishes, mostly trout and sculpins, and a few insects. Some of these, as the mosquito, are excessively numerous in individuals. Reptiles are absent from this region and many of its birds migrate southward in the winter, finding in the arctic only their breeding homes. When we consider the distribution of insects and other small animals of wide diffusion we must add to the arctic realm all high moun- 


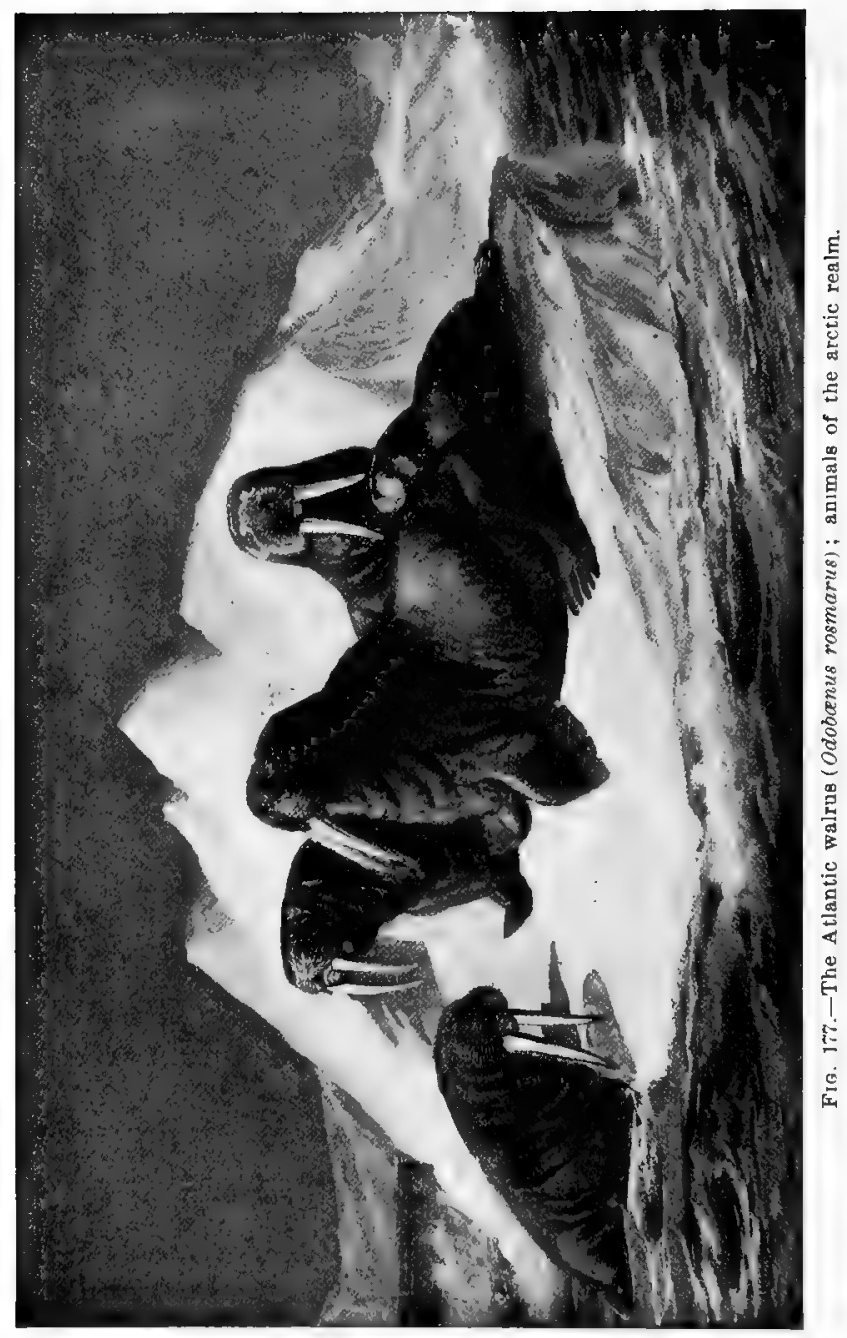


tains of other realms whose summits rise above the timber line. The characteristic large animals of the arctic, as the polar bear or the musk-ox or the reindeer, are not found there, because barriers shut them off. But the flora of the mountain top, even under the equator, may be characteristically arctic, and with the flowers of the north may be found the northern insects on whose presence the flower depends for its fertilization. So far as climate is concerned high altitude is equivalent to high latitude. On certain mountains the different zones of altitude and the corresponding zones of plant and insect life are very sharply defined (Fig. 178).

The North Temperate realm comprises all the land between the northern limit of trees and the southern limit of frost. It includes, therefore, nearly the whole of Europe, most of Asia, and most of North America. While there are large differences between the fauna of North America and that of Europe and Asia, these differences are of minor importance and are scarcely greater in any case than the difference between the fauna of California and that of our Atlantic coast. The close union of Alaska with Siberia gives the arctic region an almost continuous land area from Greenland to the westward around to Norway. To the south everywhere in the temperate zone realm the species increase in number and variety, and the differences between the fauna of North America and that of Europe are due in part to the northward extension into the one and the other of types originating in the tropics. Especially is this true of certain of the dominant types of singing birds. The group of wood-warblers, tanagers, American orioles, vireos, mocking-birds, with the fly-catchers and humming-birds so characteristic of our forests, are unrepresented in Europe. All of them are apparently immigrants from the neotropical realm where nearly all of them spend the winter. In the same way central Asia has many immigrants from the Indian realm to the southward. With all these variations there 


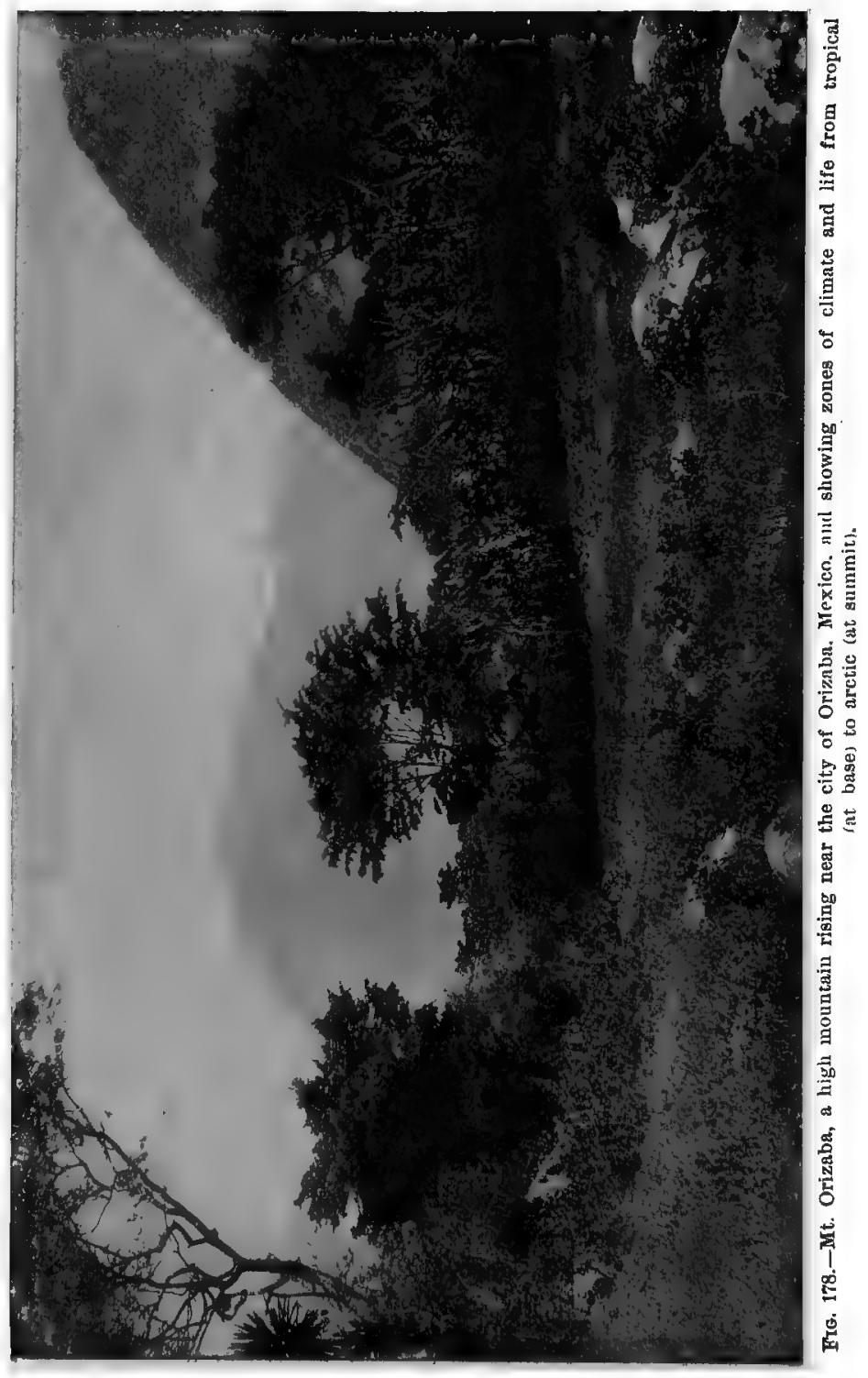


is an essential unity of life over this vast area, and the recognition of North America as a separate (nearctic) realm, which some writers have attempted, seems hardly practicable.

The Neotropical or South American realm includes South America, the West Indies, the hot coast lands of Mexico, and those parts of Florida and Texas where frost does not occur. Its boundaries through Mexico are not sharply defined, and there is much overlapping of the north temperate realm along its northern limit. Its birds especially range widely through the United States in the summer migrations, and a large part of them find in the North their breeding home. Southward, the broad barrier of the two oceaus keeps the South American fauna very distinct from that of Africa or Australia. The neotropical fauna is richest of all in species. The great forests of the Amazon are the dreams of the naturalists. Characteristic types among the larger animals are the snout or broad-nosed (platyrrhine) monkeys, which in many ways are very distinct from the monkeys and apes of the old World. In many of them the tip of the tail is highly specialized and is used as a hand. The Edentates (armadillos, ant-eaters, etc.) are characteristically South American, and there are many peculiar types of birds, reptiles, fishes, and insects.

The Indo-African realm corresponds to the neotropical realm in position. It includes the greater part of Africa, merging gradually northward into the north temperate realm through the transition districts which border the Mediterranean. It includes also Arabia, India, and the neighboring islands, all that part of Asia south of the limit of frost. In monkeys, carnivora, ungulates, and reptiles this region is wonderfully rich. In variety of birds, fishes, and insects the neotropical realm exceeds it. The monkeys of this district are all of the narrow-nosed (catarrhine) type, various forms being much more nearly related to man than is the case with the peculiar monkeys of South 
America. Some of these (anthropoid apes) have much in common with man, and a primitive man derived from these has been imagined by Haeckel and others. No creature of this character is yet known, but that it may have once existed is not impossible. To this region belong the elephant, the rhinoceros, and the hippopotamus, as well as the lion, tiger, leopard, giraffe, the wild asses, and horses of various species, besides a large number of ruminant animals not found in other parts of the world. It is, in fact, in its lower mammals and reptiles that its

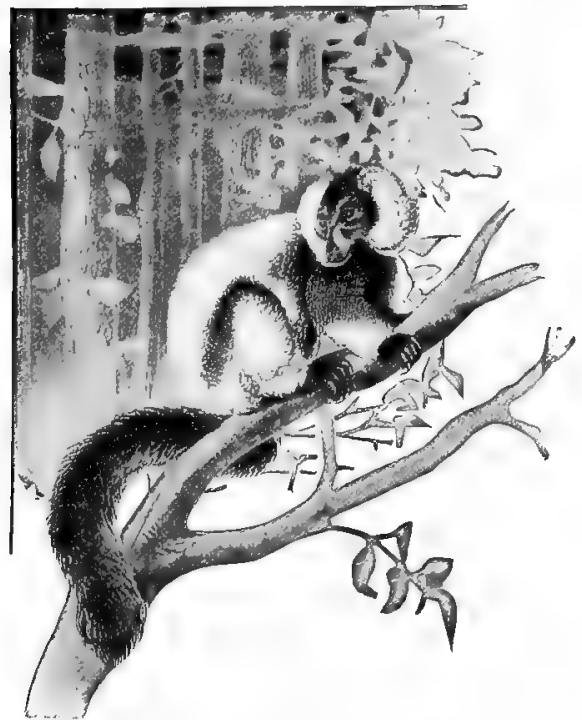

Fit. 179,-A lemur (Lemur varius). most striking distinctive characters are found. In its fish fauna it has very much in common with South America.

The Lemurian realm comprises Madagascar alone. It is an isolated division of the IndoAfrican realm, but the presence of many species of lemur and an unspecialized or primitive type of lemur is held to justify its recognition as a distinct realm. In most other groups of animals the fauna of Madagascar is essentially that of neighboring parts of Africa.

The Patagonian realm includes the south temperate zone of South America. It has much in common with the neotropical realm from which its fauna is mainly derived, 
but the presence of frost is a barrier which vast numbers of species can not cross. Beyond the Patagonian realm lies the Antarctic continent. The scanty fauna of this region is little known, and it probably differs from the Patagonian fauna chiefly in the absence of all but the ice-riding species.

The Australian realm comprises Australia and the neighboring islands. It is more isolated than any of the others, having been protected by the sea from the invasions of the characteristic animals of the Indo-African and temperate realms. It shows a singular persistence of low or primitive types of vertebrate life, as though in the process of evolution the region had been left a whole geological age behind the others. It is certain that if the closely competing fauna of Africa and India could have been able to invade Australia, the dominant mammals and birds of that region would not have been left as they are now-marsupials and parrots.

It is only when barriers have shut out competition that simple or unspecialized types abound. The larger the land area and the more varied its surface, the greater is the stress of competition and the more specialized are its characteristic forms. As part of this specialization is in the direction of hardiness and power to persist, the species from the large areas, as a whole, are least easy of extermination. The rapid multiplication of rabbits and foxes in Australia, when introduced by the hand of man, shows what might have taken place in this country had not impassable barriers of ocean shut them out.

160. Subordinate realms or provinces.-Each of these great realms may be indefinitely subdivided into provinces and sections, for there is no end to the possibility of analysis. No school district has exactly the same animals or plants as any other, as finally in ultimate analysis we find that no two animals or plants are exactly alike. Shut off one pair of animals from the others of its species, and its descendants will differ from the parent stock. This differ- 
ence increases with time and with distance so long as the separation is maintained. Hence new species and new fauna or aggregations of species are produced wherever free diffusion is checked by any kind of barrier.

161. Faunal areas of the sea.-In like manner, we may divide the oceans into faunal areas or zones, according to the distribution of its animals. For this purpose the fishes probably furnish the best indications, although results very similar are obtained when we consider the mollusks or the crustacea. The fresh-water fishes are not considered here, as in regard to their faunal areas they agree with the land animals of the same regions. Perhaps the most important basis for primary divisions is found in the separation from the localized shore-fishes of the cosmopolitan pelagic species, and the scarcely less widely distributed bassalian species or fishes of the deep sea.

The pelagic fishes are those which inhabit the open sea, swimming near the surface, and often in great schools. Such forms are mainly confined to the warmer waters. They are for the most part predatory fishes, strong swimmers, and many of the species are found in all warm seas. Most species have special homing waters, to which they repair in the spawning season. Often there will be special regions to which they never resort, either for breeding or for food. At other times a certain species will appear in numbers in regions where it has hitherto been unknown. For example, the frigate-mackerel (Auxis thazard), homing in the East Indies and the Mediterranean, appeared in great numbers in 1880 off the coast of New England. Typical pelagic fishes are the mackerel, tunny, dolphin, flyingfish, opah, and some species of shark. This group shades off by degrees into the ordinary shore-fish, some being partly pelagic, venturing out for short distances, and some are pelagic for part of the year only. To the free-swimming forms of classes of animals lower than fishes, found in the open ocean, the name Planleton is applied. 
The bassatian fauna, or deep-sea fauna, is composed of species inhabiting great depths (2,500 feet to 25,000 feet) in the sea. At a short distance below the surface the change in temperature from day to night is no ionger felt. At a still lower depth there is no difference between winter and summer, and still lower none between day and night. The bassalian fishes inhabit a region of great cold and inky darkness. Their bodies are subjected to great pressure, and the conditions of life are practically unvarying. There is therefore among them no migration, no seasonal change, no spawning season fixed by outside conditions, and no need of adaptation to varying environment. As a result, all are uniform indigo-black in color, and all show more or less degeneration in those characters associated with ordinary environment. Their bodies are elongate, from the lack of specialization in the vertebræ. The flesh, being held in place by the great

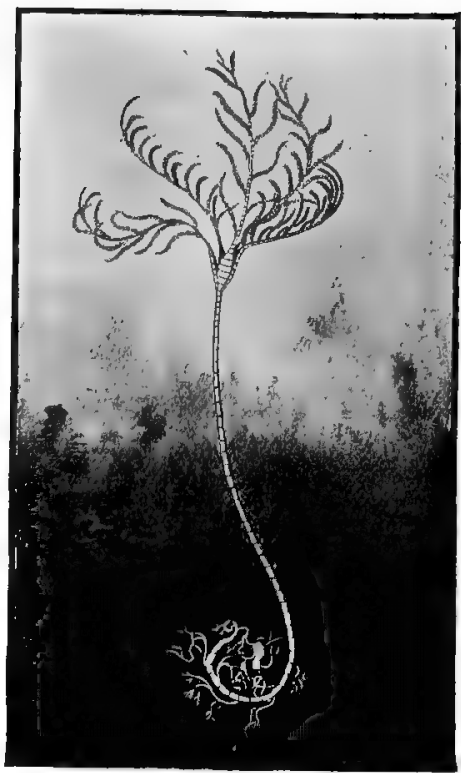

Fig. 180.-A crinoid (Rhizocrenua corviel sis). A deep-rea animal which lives, fixed plant like, at the bottom of the ocean, pressure of the water, is soft and fragile. The organs of touch are often highly developed. The eye is either excessively large, as if to catch the slightest ray of light, or else it is undeveloped, as if the fish had abandoned the effort to see. In many cases luminous spots or lanterns are developed by which the fish may see to guide his way in the 
sea, and in some forms these shining appendages are highly developed. In one form (Athoprora) a luminous body covers the end of the nose, like the head-light of an engine. In another (Ipnops) the two eyes themselves are flattened out, covering the whole top of the head, and are luminous in life. Many of these species have excessively large teeth, and some have been known to swallow animals actually larger than themselves. Those which have lantern-like spots have always large eyes.

The deep-sea fishes, however fantastic, have all near relatives among the shore forms. Most of them are degenerate representatives of well-known species-for example, of eels, cod, smelt, grenadiers, sculpin, and flounders. The deep-sea crustaceans and mollusks are similarly related to shore forms.

The third great subdivision of marine animals is the littoral or shore group, those living in water of moderate depth, never venturing far into the open sea either at the surface or in the depths. This group shades into both the preceding. The individuals of some of the species are excessively local, remaining their life long in tide pools or coral reefs or piles of rock. Others venture far from home, and might well be classed as pelagic. Still others ascend rivers either to spawn (anadromous, as the salmon, shad, and striped bass), or for purposes of feeding, as the robalo, corvina, and other shore-fishes of the tropics. Some live among rocks alone, some in sea-weed, some on sandy shores, some in the surf, and some only in sheltered lagoons. In all seas there are fishes and other marine animals, and each creature haunts the places for which it is fitted. 


\section{CLASSIFICATION OF ANIMALS *}

In this diagram of classification every animal referred to in this book, either by ite vernacular or its scientific name, is assigned to its proper class and branch. of the species mentioned by their scientific names, only the genus name is given in this list.

\section{KINGDOM ANIMALIA}

\section{BRANCH I. PROTOZOA}

\section{Class I. Rhizzoro'oda.}

$A m c^{\prime} b a$, Globigerīnæ, Rēdiolā'ria.

Chass II. Mycētozö'a.

Class III. Mastigðph'ora.

Volvocīn'ex, G'̄'nium, Păndorī'na, Eudorī'na, Vชt'vŏx.

Cuass IV. Spōrozōa.

Grĕgarī'na.

Class V. Infusō'ria.

Păramó'cium, Vorticèl'la.

\section{BRANCH II. PORĬF'ERA}

Class I. Porifera.

Sponges, Călcoly̆n'thus, Prophysê'ma, Spongŭl'la, Spon'gia, Clī'ona.

BRANCH III. CELLĚN'TERĀ'TA (sē-Ǐ̌n-te-rä'-ta)

\section{Class I. Hȳdrozō'a.}

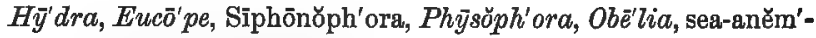
one, pǒl'yp, Phȳsā'lia, Părapăg'urus.

Class II. Soȳphozō'a (sī-fō-zō'-a).

Jelly-fish, $L z^{\prime} z i a$.

Class III. Actinozōa.

Cơr'als, Mètrü'dium.

Class IV. Ctø̆nŏph'ora (těn-ð̆ph'-o-ra).

* The arrangement of branches (or phyla) and classes here used is that adopted in Parker and Haswell's Text-Book of Zoölogy (1897). 
BRANCHI IV. PLĂTYHĔLMY̌N"THES

Class I. Turbellā'ria.

Plan̄̄'ria.

Class II. Trĕmatō'da.

Class III. Cěstō'da.

'l'ape-worm, Tae'nia, Lrg'ula, flat-worm.

Appendix to Platyhelminthes-Class Nemertín'ea.

BRANCH V. NËMATHËLMǏN"THES

Cluss I. Nĕmatō'da.

Sy̆n'gamus, round-worm, Tř̆chī'na, Böthriocĕph'alus, pup. worm, Uncinä'ria.

Class II. Acanthocĕph'ala.

Cluass III. Chæetŏg'natha (kē-tŏg'-na-tha).

BRANCH VI. TROCHELMIN'THES

Class I. Rotif' era.

Rotatō'ria.

Class II. Dinophř'lea.

Class III. Gastrot'richa.

BRANCH VII. MOLLUSCOI'DA

Crass I. Prlyzōa.

Cuass Il. Phōrǒ'nida.

Class III. Brăchióp'oda.

BRANCIF VIII. ECHINŌDL̆R'MATA

CI,ASs I. Asteroi'dea,

Starfish.

Class II. Ophiuroi'dea.

Class III. Echinoi' dea.

Sea-urchin.

Cuass IV. Hölothuroi' dea.

Sea-cucumber.

Cuass V. Crinoi'dea.

Crinoid, Rhäzōcrīnnus.

Class VI. Cy̆ytoi'dea.

Classs VII. Blăstoi'der. 


\section{BRANCH IX. ANNULĀ'TA}

Class I. Chæťrp'oda (kê-tǒp'-o-da).

Earth-worm.

A pPendix to The ChatTopoda-Class Mỹzostǒm'ida.

ClasS II. Gĕphyrēa (jĕf-e-rē'-z).

Class III. Archi-annělida.

Class IV. Hürudin'ea.

\section{BRANCH X. ARTHRŎP'ODA}

\section{Class I. Crustā'cea.}

Lobster, cray-fish, crab, barnacle, $L e^{\prime}$ pas, hermit-crab, Păg'urus, pea-crab, Prnnothë'res, Epizoăn'thus, fish-lice, whale-lice, Saccu$l_{\bar{n}}^{\prime} n a$, Lernoeóncera, prawn, Penē'us.

Appendix to Crustacea-Class Trilobi'ta.

Class II. Ŏnychð̌ph'ora.

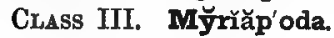

Cĕn'tipēd.

Crass IV. Insĕc'ta.

Water-beetle, water-bug, canker-worm moth, bee, white ant, cockroach, mosquito, weevil, grasshopper, caterpillar, butterfly, katydid, beetle, Dĭp'tera, Lĕpidŏp'tera, monarch butterfly, $A$ no' sia, Cu'lex, Melăn'oplus, May-fly, locust, cottony-cushion scale, Icë'rya, lady-bird, Vēdā'lia, praying-horse, Măn'tis, Sĕr'phus, Cécrōópia, gall insect, $A n^{\prime} d r i c u s$, mole-cricket, Grÿllotàl'pa, Hȳdrŏph'ilus, Prīónus, Camponō'tus, plant-lice, Ăph'idæ, Cǒc'cidæ, Āphis-lion, ant, Ec' iton, termite, bumble-bee, carpenter-bee, André'na, Halı̌c'tus, yellow-jacket, hornet, Vĕs' pa, wasp, $\breve{A} t ' t a$, bird-lice, Mallŏph'aga, flea, louse; Pedre'ulus, Lipeu'rus, Hÿmenzp'tera, ichneumon fly, Thalës'sa, horn-tail, Trë'mex, Polř'tes, Stȳlŏp'idæ, Stȳlops, red orange-scale, toad-bug, Găl'gulus, inch-worm, span-worm, geometrid, walking-stick, Diapherŏm'era, Phy̆l'lium, meadow brown, Grăp'ta, Kăl'lima, sphinx-moth, tomato-worm, Phlĕgethŏn'tius, puss-moth, Cerū'ra, viceroy butterfly, Bäsilar'chia, Danā'idæ, Helicŏn'idæ, Piĕr'idæ, Papùliŏn'idæ, Syr' phidæ, flower-flies, tree-hopper, Membrăc'idæ, Hemĭp'tera, $S a u^{\prime} b a$ (saw'-ba), carrionbeetle, Callosä'mia, promē'thea, cricket, cicā'da, dragon-fly, Cynìp'idæ, Hessian-fly, mud-dauber, Lerë'ma, Ery̆n'nis, skipper butterfly, Schistocèr'ca.

Cusss V. Arăch'nida.

Tardĭg'rada, bear-animalcule, scorpion, Lycŏs'idæ, tick, itchmite, Sarcŏp $p^{\prime} t e s$, spider, trap-door spider, turret-spider, Cten ̌̌' $z a$. 


\section{BRANCH XI. MǑLLŬS'CA}

\section{Class I. Pĕlecy̆p'oda.}

Clam, pond-mussel, $L^{-}{ }^{\prime} m a$.

Class II. Amphineu'ra.

Class III. Gastrop'oda.

Pond-snail, Lymnæ'us, whelk.

Appendix to the Gastropoda-Class Scaphrp'oda and Rhō'dope.

Class IV. Cĕphalöp'oda.

\section{BRANCH XII. CHORDĀ'TA}

\section{Sob-branch I. Adělochðr'da. Class Adelochorda.}

Sub-BRANCH II. Urochor'da. Class Urochorda.

Sea-squirts, Tunicā'ta.

Sub-Branch III. Vertebrā'ta. Division A. Acrā'nia Class Acrar

nia. Division B. Crāniā'ta.

\section{Class I. Ō̄olostrm'ata.}

Clisss II. Pìs'ces (pǐs'sēz).

Codfish, sculpin, skate, lady-fish, $\breve{A} l^{\prime} b u l a$, sword-fish, $X^{\prime} p h^{\prime} i a s$, flounder, Platöph'rys, Salanx, Cót'tus, blob, miller's-thumb, conger-eel, Rĕm'ora, Exocœ'tns, fifing-fish, Cypselu'rus (š̆p-se-lu rus), deep-sea angler, lantern-fish, Corynöl'ophus, Echtos'toma, Zithŏph'ora, nokee, scorpion-fish, Emmydrich'thys, mad-tom, Schilbeōdes, cat-fish, horned pout, toad-fish, sting-ray, globe-fish, porcupine-fish, torpedo, electric eel, electric cat-fish, star-gazer, electric ray, Uról'ophus, $D_{\bar{z}}^{\prime}$ odon, Narcī'ne,$R \bar{a}^{\prime} j a$, black-fish, mud-fish, trout, Săl'mo, chub, horned dace, Echeneididæ Amphiprion, $N \bar{o}^{\prime}$ meus, hag-fish, Myxī'ne, Heptatrē'ma, Polistotrë'ma, lamprey, Oligosŏt'tus, mouse-fish, lava-fish, Pterophrȳne, pipe-fish, Phyllop'teryx, anglers, Lo'phius, Antennā'rius, Ceratiide, minnow, mackerel, sucker, salmon, shad, alewife, sturgeon, striped bass, quĭn'nat, eel, sun-fish, stickle-back, carp, cutlass-fish, rainbow darter, channel-cat, $A u^{\prime} x i s$, tunny, dolphin. opah, shark, Asthopröra, $\breve{p}^{\prime}$ nops, cod, smelt, grenadier, rōb'alo, corvi'na, Chŏlogăs'ter, Ty̆phlžch'thy̆s, blind-fish.

ClaAss III. Amphíb'ia.

Toad, frog, salamander, tree-frog, $H \bar{y}^{\prime} l a$.

\section{Cuass IV. Reptülia.}

Tortoise, snake, horned toad, Phrīnōsō'ma, rattlesnake, lizards, An'olis, chameleon, Gila monster, Hèlodér'ma, Elaps, coralì'los, Lämpropél'tis, Osceóla, alligator. 
Cuass V. $\overline{\mathbf{A}}^{\prime}$ ves.

Bird-of-paradise, peacock, pheasant, robin, pigeon, chicken, eagle, vulture, guil'lemot (gǐl'-e-mŏt), murre (mŭr), auk, ful'mar, pět'rel, sparrow, bluebird, woodpecker, owl, Colǔm'ba, pelican, Melanèr'pes, cormorant, meadow-lark, warbler, turkey, blue jay, Aythya, Cyanocitta, Uria, cow-bird, cuckoo, parrot, ptarmigan, whippoorwill, Antrǒs'tomus, gull, tern, fly-catcher, bittern, mocking-bird, shrike, bobolink, goose, humming-bird, oriole, puffin, tailor-bird, king-bird, nightingale, starling, skylark, passenger-pigeon, ouzel (ooz'-el), linnet, tanager, vireo, wood-warbler, Phälacrǒ'corax, Trŏch'ilus, Ornithöt'omus, Psaltr'p'p'arus.

\section{Ouss VI. Mammā'lia.}

Horse, ram, fur-seal, rabbit, cat, ox, tiger, lion, sheep, elephant, whale, bear, wolf, squirrel, lěm'ming, fox, dog, weasel, stoat, reindeer, otter, ant-eater, giraffe', skunk, porcupine, hedgehog, armadillo, Callorhï'nus, sea-lion, deer, buffalo, kangaroo, Măc'ropus, duck-bill, Mŏn'otrēme, monkey, gopher, elk, bison, praírie-dog, big-horn, hare, antelope, black-tail deer, hound, mole, hyena, mice, rodent, woodchuck, jack-rabbit, Macā'cus, Cërcoprtth'ecus, beaver, wood-rat, pocket-gopher, coyo'te, civet-cat, flying-fox, morn'goose, sea-cow, $\nabla^{u} l^{\prime} l^{\prime} p e s$, walrus, musk-ox, ape, rhīnð̌c'eros, hĭppopðt'amus, leopard, ass, le'mur, Tr'ch'échus, manatee, Le'épus, Odōba'mus, LE'mur. 



\section{GLOSSARY}

[Only those terms are defined in this glossary that are not explained in the text. In the case of the terms defined or explained in the text, reference is made to the number of the paragraph in which the explanation ocenrs. The pronunciation of the vernacular and scientific names of the animals mentioned in the text is given in the Classification.]

\section{Ăbomā'sum: 42 .}

Adaptation : 67,74 .

Albuminous : said of substances containing albumen.

Alimĕn'tary canal : 42.

Alluring coloration : 111.

Altrǐc'ial : 79.

Altruǐs'tio instinct: 129.

Amce'boid : having the changing form of an Amceba.

Anăd'romous: said of fishes that go from the sea up rivers to lay their eggs.

Anăt'omy : 39.

Animăl'cule : an animal of microscopic smallness.

Antĕn' næ: the "feelers," the most anterior pair of appendages of insects and insect-like animals; situated on the head, and the seat of organs of special sense.

Ăn'thropoid : man-like.

$\bar{A}^{\prime}$ nus : 42.

Appěn'dix vermifor'mis : 82.

Artificial selection : 72.

Assim'ilate : to receive food and transform it into a homogenous part of the body substance.

Atrll' : a ring-shaped coral island nearly or quite inclosing a lagoon.

Ăt'rophy : a stoppage of the growth or development of a part or organ. Auditory : referring to the sense of hearing.

Autrm'atism : the state of being automatic; involuntary action. 
Bassā'lian : 160.

Biðl'ogist : student of animals and plants.

Blăs'tōderm: 50.

Blăs'tula : 50.

Budding: the process of reproduction among animals in which a sman part of the body substance of an animal grows out from the surface, separates from the parent, and develops into a new individual.

Cæ'cum (sē-kum) : 42.

Carniv' orous : flesh-eating.

Căt'arrhǐne : nostril downward; said of the narrow-nosed Old-World monkeys.

Cell : 2.

Cél'lulose : a peculiar compound insoluble in all ordinary solvents, forming the fundamental material of the structure of plants, and also contained in the mantle of tunicates.

Chi'tin: 57.

Chlō'rophy̆ll : 13 .

Chró'matophore : a color-bearing granule or sac.

Chrō'mosome: 2.

Chry̆s'alis : 57.

Chȳle: 42 .

Cril'ia : 5.

Cleavage : 50.

Cólon : 42.

Comměn'salism: 90.

Crm'munal : 83.

Conjugā'tion : 5 .

Contractile vacuole: a vacuole that dilates and contracts regulariy, and is supposed to have an excretory function.

Cy̆st: 98 .

Cýtoplasm : 2.

\section{Degeneration : 95.}

Development: 46.

Differentiation : the setting apart of special organs for special work; progressive change from general to special; specialization.

Digestion : the process of dissolving and chemically changing food so that it can be assimilated by the blood and furnish nutriment to the body.

Dimor'phism : 24.

Divertǐc'ulum : a blind pouch arising from another larger pouch. 44. Duodê'num: 42. 
ت̆c'tōblast : 50.

ت̈c'tōderm: 20.

Egg-cell : 20.

Egois'tic instinot: 129.

Embry̌rı'ogy : 39.

Embry̆n'ic : 49.

Ën'dōblast : 50 .

Ën'dōderm : 20.

Envī'ronment : an organism's surroundings taken collectively.

Ex'cretory: referring to excretion, as excretory organs, the organs which get rid of waste matter in the animal body.

Fau'na (fawna): 157 .

Fertilized egg : 20.

Fìs'sion: 4.

Flagèl'la: 13.

Function: 37 .

Găn'glion (pl. ganglia) : a nerve-center composed of an aggregation of nerve-cells.

Găs'trula: 50.

Gĕm'mule: 20.

Generalization: 41.

Gérl'ogist: student of the structure and history of the earth.

Grëgä'rious: 87.

Growth: 46.

Habit: 139 .

Herbǐv'orous : plant-eating.

Herěd'ity ; 54 .

Hermăphrodit'ic: 35.

Hiberna'tion: passing the winter in a death-like sleep.

Hömogé'neous: of the same composition or structure throughout.

I'leum: 42 .

Inorganic: not being nor having been a living organism; not organic. Insectiv'orous : insect-eating.

Instinct: 128.

Intellect : 139.

Intercěl'lular: outside of and between the cells.

Jeju'num : 42. 
Lagoon': a pool or lake; the still water inclosed within an atoll.

Lar'va: 57.

Lĕpidðp'terous : referring to the Lepidoptera, or moths and butterflies,

Lit'toral : 160.

Iu'men: the cavity of a tubular organ. 44.

Medu'sa: 24.

Mĕg'alops : 59.

Měs'oderm: 20.

Mĕtăb'olism : the act or process by which dead food is built up into living matter, and living matter is broken down into simpler products within a cell or organism.

Mrtamor' phosis : 56.

Migra'tion: 70.

Mil'limeter: about one twenty-fifth of an inch; a term used in the metric system of measure.

Mím'icry : 112.

Mind: 140 .

Molt: 57.

Mrnð̌g'amous: said of animals in which a male mates with only a single female.

Multiplication: used in the text usually synonymously with reproduction.

MY̌rmecðph'ilous : said of insects which are found inhabiting the nests of ants.

Natural selection: 70 .

No'tochord: an elastic rod, or row of cells, formed in the early embryo of chordate animals (including all the vertebrates and some others), which lies below the dorsal nervous tube and above the ventral alimentary tube.

Nu'cleus (pl. nuclei): 2 .

Cssðph'agus: 42.

Olfactory : referring to the sense of smell.

Omā'sum: 42.

Organ: 37 .

Organic: referring to the matter of which animals and plants are composed.

Organism : a living being, plant or animal.

Orientātion: 95.

O'tolith: 121. 
Papil'la (pl. papillæ) : a small nipple-like process, as the papillæ of the skin or tongue.

Parasite : 93.

Parthěnogĕn'esis : 35.

Pèlăg'ic: inhabiting the surface of mid-ocean. 160.

Phar'ynx: 42.

Phy̆siðl'ogy : 39.

Plăt'yrrhine: broad-nosed; said of the New-World monkeys.

Plu'teus : 59.

Poly̆g'amous : said of animals in which a single male mates with sev* eral females: 35.

Prlymor' phism : 24.

Pǒl'yp: 21.

Post-embryonic: 49

Præcō'cial (prē-co'-shal): 79.

Prěd'atory : feeding on other animals.

Prō'polis: 84.

Protective resemblance: $10 \%$.

Prō'toplasm : 2.

Prōventrǐc'ulus : 42.

Pseu'dopod : 4.

Psȳ'chio : 140.

Pu'pa: 5\%.

Reason : 139.

Recognition mark: 77 , 115.

Rěc'tum: 42 .

Reflex action : $12 \%$.

Reproduction : 67 .

Respiration : 4.

Retic'ulum : 42.

Rĕt'ina : 123.

Ru'men : 42.

Ru'minant : 42 .

Salì'va : 42.

Sensation : 67 .

Sensorium : 126.

Sil ica : the mineral of which quartz, sand, flint, etc., are composed. Spawn, v.: to lay eggs.

Specialization: 41 .

Species: 151. 
Sperm cell : 20 .

Spir'acle: one of the breathing openings of an insoct situated on the side of the abdomen or thorax.

Spon'gin : 20.

Stimulus (pl. stimuli) : that which excites action in plant or animal tissue.

Strā'ta : layers, usually said of rocks.

Strídulātion : 122.

Sub-species : 151.

Š̆mbiō'sis: 90.

Tactile : referring to the sense of touch. 118.

Tadpole: 58.

Tern'tacle : a protruding flexible process or appendage, usually of the head of invertebrate animals, being used as an organ of touch, prehension, or motion.

Těrmitðph'ilous : said of insects inhabiting the nests of termites.

Văc'uole : a minute cavity containing air, water, or a chemical secretion of the protoplasm, found in an organ, tissue, or cell.

Vestrg'ial : 82.

Vir'cera : the organs in the great cavities of the body, commonly used for the organs in the abdominal cavity.

Yōlk (yōk) : 48.

Zoē'a : 59.

Zōogerg'raphy : 147 .

Zo'oid : one of the more or less independent members of a colonial or compound organism.

Zōol'ogist : a student of animals. 


\section{IN D E X}

Abomasum, 68.

Actinocephalus oligacanthus (ill.), 14.

Adaptations, 113 , 123 ; classsification of, 123 ; concerned with surroundings, 143 ; degree of structural change in', 146;" for defense of young, 137; for rivalry, 135 ; for self-defense, 128 ; for securing food, 125 ; origin of, 123.

Agassiz's cave-fish (illus.), 282.

Albula vulpes, metamorphosis of (illus.), 98.

Alimentary canal, 66 ; of cockroach (illus.), 73 ; of earthworm (illus.), 71 ; of flatworm (illus.), 70 ; of Holothurian (illus.), 70; of mussel (illus.), 72 ; of Obelia (illus.), 69 ; of ox (illus.), 67 ; of Planaria (illus.), 70; of seacucumber (illus.), 70.

Alligator (illus.), 290.

Alluring coloration, 216.

Alternation of generations, 42 . Altricial, 140.

. Amoeba, 5; multiplication of (ill.) 53. Amoeba polypodia (illus.), 8. Anatomy, 64.

Andrena, nest of (illus.), 160 . Andricus californicus, galls of (illus.), 143.
Angler, deep-sea (illus.), 124.

Animals, life of simplest, 1 ; manycelled, 2 ; one-celled, 2 ; slightly complex, 24 .

Anosia plexippus, metamorphosis of (illis.), 92 ; mimicked by $B a-$ 'silarchia archippus'(illus.), 219 Antenna of cray-fish (illus.), 233;; of leaf-exting beetle (illus.), 230 . Antennæ, specialized, of promethea moth (illus.); 231.

Antrostomus vociferus (illus.), 203. Ants (illus.), 155.

Anus, 68.

Appearance, terrifying, 212.

Arctic realm, 297.

Area, faunal, 296.

Artificial selection, 120.

Auditory organ of cray-fish (illus.), 233 ; of cricket (illus.), 234 ; of grasshopper (illus.), 234; of mollusk (illus.), 233; of mosquito (illus.), 235.

Auditory organs, 232.

Australian realm, 303.

Aythya (illus.), 137.

Barbadoes earth, 19.

Barnacle, adult and larva (illus.), 195 ; metamorphosis of (illus.), 101. 
Barrier, mountains a, to distribution, 293 ; sea a, to distribution, 288 ; temperature $a$, to distribution, 290.

Barriers affecting fresh-water animals, 294; effect of, 283 ; species debarred by, 274; to distribution, character of, 288.

Basilarehia archippus mimicking Anosia plexippus (illus.), 219.

Bassalian fauna, 305.

Beavers, nest of (illus.), 269 .

Beetle, larva of (illus.), 146.

Beetles, lady-bird (illus.), 214.

Bird, egg of (illus.), 79.

Bird-louse (illus.), 188.

Bird of paradise (illus.), 58.

Birds, nest-making habits of, 264.

Birth, 78.

Bittern, cestlings of (illus.), 246, 247.

Blastoderm, 82.

Blastula, 82.

Blue jay (illus.), 138.

Brain, 241.

Budding, 13.

Bumble-bee, 159, (illus.), 161.

Bush-tit, nest of California (illus.), 270.

Butterfly, egg of (illus.), 79; monarch, metamorphosis of (illus.), 92.

\section{Cæecum, 68.}

Calcolynthus porimigenius (illus.), 33.

Calf, taste buds of (illus.), 229 .

Callorhinus alascanus (illus.), 136.

Camponotus (illus.), 155.

Canadian skipper butterfly, distribution of (illus.), 273.
Canal, alimentary, 66.

Cankerworm-moth (illus.), 59.

Care of young of mammals, 268.

Carpenter-bee, nest of (illus.), 160.

Caterpillar parasitized (illus.), 189 , (illus.), 190.

Cave blind-fish (illus.), 282.

Ceanothus (illus.), 141.

Cell, animal, 2 ; egg, 21, 56 ; plant, 2; products, 3 ; wall, 3.

Cells, brood, of honey-bee (illus.), 152 ; nerve, 240 ; reproductive, 29,55 .

Cellulose, 24, 27.

Centiped (illus.), 130.

Cerura, larva of (illus.), 216.

Chalk, 18.

Chick, embryonic stages of (illus.),

87.

Chitin, 91.

Chlorophyll, 24.

Chologaster agassizi (illus.), 282.

Chologaster avetus (illus.), 282.

Chromatophore, 24.

Chromosome, 3.

Chrysalid of butterfly, showing protective resemblance (illus.), 206.

Chrysalis, 93.

Chyle, 68.

Cilia, 9.

Cleavage, 82.

Climate, influencing distribution, 291 ; instincts of, 248.

Clouded skipper butterfly, distribution of (illus.), 273.

Coccidium oviforme (illus.), 14.

Cockroach, alimentary canal of (iilus.), 73; egg case of (illus.), 140.

Cocoon of Cecropia moth (illus.), 141. 
Colon, 68.

Colonial jelly-fishes, 45 ; Protozoa, 24.

Colony, 31.

Color, 222.

Coloration, alluring, 216.

Colors, warning, 212.

Commensalism, 172, 173.

Communal life, 168; advantages of, 170.

Communities, animal, 149.

Conditions, primary, of animal life, 106.

Conjugating cells, 28.

Conjugation, 11, 27, 55 .

Contractile vacuole, 10.

Coral, brain, 45 ; island (illns.), 44 ; organ-pipe (illus.), 45 ; red, 45.

Corals, 37-43.

Corynolophus reinhardti (illus.), 124.

Cottony eushion scale (illus.), 142.

Courtship, instincts of, 248.

Crab, metamorphosis of (illus.), 97 ; with sea-anemone (illus.), 177 .

Cray-fish, auditory organ of (illus.), 233.

Cricket, auditory organ of (illus.), 234.

Cricket, mole (illus.), 146.

Crinoid (illus.), 305 .

Crop, 71.

Crowd of animals, 114.

Crustaceans, adults and larvæ (illus.), 195.

Cteniza californica, nest of (illus.), 261.

Cyanocitta cristata (illus.), 138.

Cycle, life, 78.

Cypselurus (illus.), 131.

Cytoplasm, 3.
Dead-leaf butterfly (illus.), 211.

Death, 103.

Deep-sea angler (illus.), 124.

Deer, horns of (illus.), 148.

Defense of the young, 137 .

Degeneration, causes of, 197,198 ; human, 200 ; through quiescence, 193.

Desiccation, 104.

Development, 78 ; continuity of, 83 ; divergence of, 84 ; embryonic, 80 ; first stages in (illus.), 81 ; laws of, 86 ; metamorphic, 90 ; of flounder (illus.), 100 ; of locust (illus.), 91 ; of vertebrates, (illus.), 87 ; post-embryonic, 80 ; significance of facts of, 89 .

Diapheromera femorata (illus.), 209.

Differentiation, 41 ; of structure, 64.

Dimorphism, 42 ; sex, 58.

Diodon hystrix (illus.), 134.

Dismal Swamp fish (illus.), 282.

Distribution, character of barriers, to, 288 ; geographical, 272 ; influenced by climate, 291; laws of, 274 ; modes of, 296 ; monntains a barrier to, 293 ; of Canadian Skipper butterfly (illus.), 273 ; of clouded Skipper butterfly (illus.), 273; of Erynnis ? anitoba (illus.), 273 ; sea a barrier to, 288 ; temperature a burrier to, 290 .

Diverticula, 74.

Division of labor, 22, 168.

Dog, pointer (illus.), 256.

Dragon-fly, eye of (illus.), 239.

Duck, frmily (illus.), 137.

Duoder am, 68.

Durati sn of life, 101. 
Earthworm, alimentary canal of (illus.), 71.

Ectoblast, 82.

Ectoderm, 33.

Egg case of Californian barn-door skate (illus.), 140 ; cockroach (illus.), 140.

Egg cell, 21, 56.

Egg, fertilized, 35; of bird (illus.), 79; of butterfly (illus.), 79; of fish (illus.), 79 ; of katydid (illus.), 79 ; of skate (illus.), 79 ; of toad (illus.), 79.

Electric ray, (illus.), 135.

Eimbryology, 64.

Embryonic development, 80; of the pond snail, 81 .

Emmydrichthys vulcanus (illus.), 132.

Endoblast, 82.

Endoderm, 33.

Environment, instincts of, 248.

Epizoanthus paguriphilus, with sea-anemone (illus.), 177.

Erynnis mnnitoba, distribution of (illus.), 273.

Eucope (illus.), 42.

Eudorina, 27.

Eudorina elegans (illus.), 28.

Exocoetus (illus.), 131.

Eye of dragon-fly (illus.), 239; of jelly-fish (illus.), 238.

Fauna, 296; bassalian, 305 ; littoral, 306 ; pelagic, 304.

Faunal areas of the sea, 304.

Feeding habit of Californian woodpecker (illus.), 128,129 ; of Melanerpes formicivorus bairdii (illus.), 128, 129; instincts of, 244.

Female, 57.
Fish, egg of (illus.), 79 ; embryonic stages of (illus.), 87 ; -louse (illus.), 188.

Fishes, man-of-war (illus.), 175; nest-making habits of, 264.

Fission, 9 ; binary, 54.

Flagella, 25.

Flagellata, 24.

Flatworm, alimentary canal of (illus.), 70.

Flounder, development of (illus.), 100; wide-eyed (illus.), 100.

Flying fishes (illus.), 131.

Food, adaptations for securing, 125; necessary to animal life, 106.

Form. primitive, 20.

Fossil, 18.

Fresh-water animals, barriers affecting, 294.

Function, 63.

Fur seal (illus.), 136.

Galapagos Islands, animals of (illus.), 278 ; locusts of (illus.), 280.

Gull, giant, of white oak (illus.), 143.

Galls, insect, on leaf (illus.), 144.

Gapes, worm which causes, 60

Gastrula, 82.

Gemmule, 35.

Generalization, 66.

Generation, spontaneous, 51.

Generations, alternation of, 51 .

Geographical distribution, 272.

Geometrical larva on branch(illus.), 209.

Gerrhonotus scincicauda (illus.), 204.

Giraffe (illus.), 126.

Gizzard, 71. 
Globigerina-оoze, 18.

Globigerinæ, 16.

Gonium, 25-30.

Gonium pectorale (illus.), 25.

Grasshopper, auditory organ of (illus.), 234.

Green-leaf insect (illus.), 210.

Gregarina, 13, 182.

Gregarina polymorpha (illus.), 14.

Gregarinidæ, 14.

Gregariousness, 163.

Growth, 78.

Gryllotalpa (illus.), 146.

Habit, 251.

Habitat, relation of species of, 283. Habits, domestic, 25\%.

Habits, nest-making, of birds, 264 ; of fishes, 264 ; of insects, 262 ; of invertebrates, 258 ; of spiders, 259 ; of vertebrates, 264.

Hearing, sense of, 232.

Heliosphara actinota (illus.), 19.

Heredity, 89.

Bermaphroditism, 60 .

Hermit-crab, with the sea-anemone (illus.), 176.

Hibernation, 108.

Hiving honey-bees (illus.), 154.

Tolothurian, alimentary canal of (illus.), 70.

llomes, $25 \%$.

IInney-bee (illus.), 150 ; adult and larva (illus.), 83; leg of (illus.), 151 : life history of, 149.

Honey-bees, hiving a swarm of (illus.), 154.

Host, relation of parasite to, 179 .

Human degeneration, 200.

Humming-bird, nest of rufus (illus.), 265, 266.

Hydra, 37.
Fydra vulgans (illus.), 38.

Hydrophilus (illus.), 146.

Hyla regilla (illus.), 145.

Icerya and Vedalia, 121.

Icerya purchasi (illus.), 142.

Ileum, 68.

Individual, 31.

Indo-African realm, 301.

Inorganic matter, 112.

Insect galls on leaf (illus.), 144.

Insects, metamorphosis of, 90 ; nestmaking habits of, 262 ; parasitic, 188.

Instinct, 242.

Instincts, altruistic, 243 ; classification of, 243 ; concerned with care of the young, 250 ; egoistic, 243 ; of climate, 248 ; of courtship, 248; of environment, 248; of feeding, 244: of play, 247; of reproduction, 249: of self-defense, 245 ; variability of, 251 .

Intellect, $\mathbf{2 5 4}$.

Intestine, 68.

Invertebrates, nest-making habits of, 258.

Irritability, 8, 240.

Island, coral (illus.), 44.

Itch-mite (illus.), 192.

Jack-rabbits, showing variation (illus.), 281.

Jay, Canada (illus.), 138.

Jejunum, 68.

Jelly-fish, eye of (illus.), 238.

Jelly-fishes, 37 ; colonial, 45.

Kallima (illus.), 211.

Kangaroo (illus.), 139.

Katydid, egg of (illus.), 79.

Lady-bird beetles (illus.), 214. 
Lady-fish, metamorphosis of (illus.), 98.

Larva, 92; of the mosquito, 93 ; of butterfly pupating (illus.), 94 ; of the honey-bee, 152.

Leaf-cutting ant mimicked by treehoppers (illus.), 220.

Lemur (illus.), 302.

Lemur varius (illus.), 302.

Lemurian realm, 302.

Lepas, adult and larva (illus.), 195 ; metamorphosis of (illus.), 101.

Lerema accius, distribution of (illus.), 273.

Lernœecera (illus.), 188.

Life cycle, 78.

Life, communal, 168; duration of, 101 ; primitive, 21 ; processes, 21 ; social, 149.

Light, influence of, on animals, 237.

Lipeurens densus (illus.), 188.

Littoral fauna, 306.

Lizard, alligator (illus.), 204.

Lizzia koellikeri, eye of (illus.), 238.

Locust, post-embryonic development of (illus.), 91.

Locusts of Galapagos Islands (illus.), 280.

Louse, sucking (illus.), 188.

Macropus rufus, 139.

Mad Tom (illus.), 132.

Male, $5 \%$.

Mammals, care of young of, 268 .

Manatee (illus.), 277.

Man-of-war, Portuguese (illus.), 175.

Mantis (illus.), 127.

Many-celled animal, 2.

Marine Protozoa, 15.
Marks, recognition, 22, 129, 223.

Medusi, 41.

Megalops, 97.

Melanerpes formicivorus bairdii, feeding habit of (illus.), 128, 129.

Membracida mimicking Sauba ant (illus.), 220.

Mesoderm, 33.

Metamorphosis, 90 ; of Albula vulpes (illus.), 98; of Anosia plexippus (illus.), 92; of barmacle (illus.), 101 ; of butterfly (illus.), 92 ; of crab (illus.), 97 ; of insects, 90 ; of lady-fish (illus.), 98; of Lepas (illus.), 101; of mosquito (illus.), 93 ; of sea-urchin (illus.), 96: of sword-fish (illus.), 99; of 1oad, 94, (illus.), 95; of Xiphias gladius (illus.), 99.

Metazoa, 32.

Metridium dianthus (illus.), 43.

Miero-organism, 16.

Migration of lemming, 118 ; of locust, 118.

Mimickry, 218.

Mind, 255.

Mining-bee, nest of (illus.), 160.

Molt, 91.

Monarch butterfly (illus.), 219 ; mimicked by Viceroy butterfly (illus.), 219.

Monogamy, 135.

Mosquito, auditor organ of (illus.), 235 ; head of (illus.), 127; metrmorphosis of (illus.), 93 ; young stages of (illus.), 147.

Moth, cankerworm (illus.), 59.

Mountains as barriers to distribution, 293.

Mouth parts of mosquito (illus.), 127. 
Mouse-fish in gulf-weed (illus), 208. Mt. Orizaba (illus.), 300 .

Multiplication, 50 ; of animals, 114 ; simplest method of, 53 ; slightly complex methods of, 54 . Murres, Pallas's (illus.). 165.

Mussel, alimentary canal of (illus.), 72.

Mutual aid, 163.

Narcine brasiliensis (illus.), 135.

Natural selection, 117.

Neotropical realm; 301.

Nerve cells, 240.

Nerve fibers, 240.

Nest-making habits of birds, 264 ; of fishes, 264; of insects, 262; of invertebrates, 258 ; of spiders, 259 ; of vertebrates, 264 .

Nest of Baltimore oriole (illus.), 267 ; of beavers (illus.), 269 ; of Californian bush-tit (illus.), 270; of Cieniza californica (illus.), 261; of pocket-gopher (illus.), 271 ; of rufus humming-bird (illus.), 265, 266; of tailor-bird (illus.), 268; of trap-door spider (illus.), 261; of turret-spider (illus.), 262.

Nokee (illus.), 182.

Nomeus gronovii (illus.), 175.

North Temperate realm, 299.

Nuclear membrane, 3.

Nucleus, 3.

Obelia, alimentary sạc of (illus.), 69.

Esophagus, 67.

Omasum, 67.

One-celled animals, 2.

Organ, 63; auditory, of cray-fish (illus.), 233; of cricket (illus.),
234; of grasshopper (illus.), 234 ; of mosquito (illus.), 235; of mollusk (illus.), 233.

Organic matter, 112.

Organs, auditory, 232 ; of smell, 229 ; of sound-making, 235 ; of taste, 228 ; of touch, 226 ; specialization of, 66 ; vestigial, 147. Oriole, Baltimore, nest of (illus.), 267.

Ornithotomous sutorius, nest of, 268.

Osprey Falls (illus.), 285.

Otolith, 232.

Ox, alimentary canal of (illus.) 67 . Oxygen, necessary to animal life, $10 \%$.

Pagurus (illus.), 176.

Pandorina, 26.

Pandorina $s p$. (illus.), 26.

Pandorina morum (illus.), 27.

Papilio, chrysalid of (illus.). 205.

Papilla, tactile, of skin of man (illus.), 227.

Papillæ, 67.

Paramcecium, 9.

Paramocium aurelia (illus.), 10.

Paramocium caudatum (illus.), 11.

Paramoecium plutorinum (illus.), 11.

Parasite of caterpillar (illus.), 190 ; relation to host, 179 .

Parasites, simple structure of, 181. Parasitism, 179 ; kinds of, 180.

Parthenogenesis, 60.

Patagonian realm, 302.

Pediculus (illus.), 188.

Pelagic fauna, 304.

Pelican, brown (illus.), 125.

Peneus, adult and larva (illus.), 195. 
Pharynx, 71.

Phlegethontius carolina, larva of (illus.), 215.

Phrynosoma blainvillei (illus.), 131.

Phyllium (illus.), 210.

Phyllopteryx (illus.), 212.

Physalia (illus.), 175.

Physiology, 64.

Physoptora (illus.), 47.

Pocket-gopher, nest of (illus.), 271.

Pointer dog (illus.), 256.

Polistes, parasitized by Stylops (illus.), 192.

Polygamy, 59.

Polymorphism, 42.

Polyps, 37.

Polystomella strigillata (illus.), 17. Porcupine-fish (illus.), 134.

Post-embryonic development. 80.

Pigeon horn-tail (illus.), 191.

Pipe-fish (illus.), 212.

Planaria, alimentary canal of (illus.), 70.

Plankton, 304.

Plants, difference between animals and, 111.

Platophrys lunatus (illus.), 100.

Play, instincts of, 247.

Pluteus, 96.

Præcocial, 140.

Prawn, adult and larva (illus.), 195.

Praying-horse (illus.), $12 \%$.

Pressure, a condition of animal life, 109.

Primitive form, 20.

Primitive life, 21.

Prionus, larva of (illus.), 146.

Processes, life, 21.

Promethea moth (illus.), 231.

Prophysema primordiale (illus.), 34.
Protective resemblance, 201.

Protoplasm, 3; chemical constitution of, 4 ; physical constitution of, 4 .

Protozoa, 1 ; colonial, 24 ; marine, 15.

Psaltriparus minimus, nest of (illus.), 270.

Pseudopod, 5.

Pterophryne histrio in Sargassum (illns.), 208.

Pupa, 93.

Puss moth, larva of (illus.), 216.

Quiescence, degeneration through, 193.

Rabbit, embryonic stages of (illus.), 87.

Radiolaria, 16.

Radiolaria-ooze, 19.

Raja binoculata (illus.), 140.

Realm, Aretic, 297; Australian, 303 ; Indo-A frican, 301 ; Lemurian, 302; Neotropical, 301; North Temperate, 299 ; of animal life, 297; Patagonian, 302; South American, 301.

Realms, subordinate, 303 .

Reason, 251.

Recognition marks, 22, 129, 223.

Rectum, 68.

Reflex action, 241.

Remora (illus.), 173.

Remora remora (illus.), 125.

Reproduction, 9 , 50; instincts of, 249.

Reproductive cells, 28, 55 .

Resemblance, aggressive, 202 ; general protective, 202; protective, 201 ; special protective, 207 ; variable protective, 204. 
Respiration, 7.

Resting spore, 28.

Reticulum, 67.

Rhizocrinus loxotensis (illus.), 305.

Rivalry, adaptations for, 135.

Rookeries, fur-seal (illus.), 169.

Rumen, 67.

Sacculina (illus.), 187.

Sacculina, adult and larva (illus.), 195.

Salamander, embryonic stages of (illus.), 87.

Saliva, 67.

Salmon leaping (illus.), 289.

Salmo viridens (illus.), 145.

Sarcoptes (illus.), 192.

Sauba, ant mimicked by Membracidae (illus.), 220.

Scale, red orange (illus.), 196.

Schilbeodes furiosus (illus.), 132.

Schistocer'ca (illus.), 280.

Scorpion (illus.), 127.

Scorpion-fish (illus.), 132.

Sea, a barrier to distribution, 288.

Sea, faunal areas of, 304.

Sea-anemone, 37; with algæ in body (illus.), 178.

Sea-cow (illus.), $27 \%$.

Sea-cucumber, alimentary canal of (illus.), 70.

Sea-squirt (illus.), 194.

Sea-urchin, metamorphosis of (illus.), 96.

Sea-urchins (illus.), 259.

Seal, fur (illus.), 136; pups killed by parasite (illus.), 186 ; rookeries (illus.), 169.

Selection, artificial,120; natural,117.

Self-defense, adaptations for, 128 ; instincts of, 245 .

Sensation, 8 ,
Senses, special, 224 ; of the simplest animals, 225.

Sensorium, 241.

Serphus (illus.), 141.

Sex, 57 ; object of, 57 ; dimorphism, 58.

Shark-clinging fish (illus.), 125.

Sheep, bighorn (illus.), 167; Rocky Mountain (illus.), 167.

Sight, sense of, 237.

Simplest animals, life of, 1.

Siphonophora, 46.

Skate, egg case of California barndoor (illus.), 140; egg of (illus.), 79.

Skin of man, tactile papilla of (illus.), 227.

Smell, sense of, 229.

Smelling organs, 229.

Smelling pits of leaf-eating beetle (illus.), 230.

Social life, 149.

Sound-making, 285 ; organs, 235.

South American realm, 301.

Specialization, 66 ; of organs, 66.

Special senses, 224.

Species, altered by adaptation to new conditions, 276; debarred by barriers, 274 ; debarred by inability to maintain their ground, 275 ; definition of, 279 ; relation of, to habitat, 283.

Sperm cell, 35, 56.

Sphinx moth, larva of (illus.), 215. Spicules, sponge, 33.

Spiders (illus.), 212 ; nest-making habits of, 259.

Sponges, 32.

Spongin, 36.

Spontaneous generation, 51.

Spore, 15, 52 ; resting, 28.

Sting-ray (illus.), 133 . 
Structure, 63; differentiation of, 64 . Struggle for existence, 116.

Stylops parasitizing Polistes (illus.), 192.

Sub-species, definition of, 282.

Surroundings, adaptations concerned with, 143.

Swallow-tail butterfly, chrysalid of (illus.), 205.

Sword-fish, metamorphosis of (illus.), 99.

Symbiosis, 172, 175.

Syngamus trachealis (illus.), 60.

Systematic zoölogy, 64 .

Tactile organs, 226.

Tactile papilla of skin of man (illus.), $22 \%$.

Tadpole, 94.

Tania solium (illus.), 183.

Tailor-bird, nest of (illus.), 268.

Tape-worm (illus.), 183.

Taste buds of ealf (illus.), 229.

Taste organs, 228.

Taste, sense of, 228.

Temperature a barrier to distribution. 290 ; a condition of animal life, 108.

Tentacle, 37.

Termite, 158, (illus.), 159.

Terrifying appearances, 212.

Thalessa lunator (illus.), 191.

Toad, egg of (illus.), 79; horned (illus.), 131 ; metamorphosis of, 94, (illus.), 95.

Torpedo (illus.), 135.

Tortoise, embryonic stages of (illus.), 87.

Touch, sense of, 226.

Trap-door spider nest (illus.). 201. Tree-hoppers mimicking leaf-cutting ant (illus.), 220.
Tree-toad (illus.), 145.

Tremex columba (illus.), 191.

Trichechus latirostris (illus.), 277.

Trichina spiralis (illus.), 184.

Tripoli, 19.

Trochilus rufus, nest of (illus.), $265,266$.

Trout, rainbow, head of (illus.), 145.

Two Ocean Pass (illus.), 287.

Tunicate (illus.), 194.

Turret-spider, nest of (illus.), 262.

Typhlichthys subterraneus (illus.), 282.

Uncinaria, killing fur-seal pups (illus.), 186.

Uria lomvia arra (illus.), 165.

Urolophus goodei (illus.), 133.

Vacuole, 10 ; contractile, 10.

Variety, definition of, 282.

Vedalia and Icerya, 121.

Vertebrates, early stages in development of (illus.), 87 ; nest-making habits of, 264 ; parasitic, 193.

Vespa (illus.), 162 ; nest of (illus.), 163.

Vestigial organs, 147.

Viceroy butterfly mimicking Monarch butterfly (illus.), 219.

Voice, 236.

Volvocinæ, 24.

Volvox, 28.

Volvox globator (illus.), 29.

Volvox minor (illus.), 29.

Vorticella, 12.

Vorticella microtoma (illus.), 12.

Walking-stick insect (illus.), 209.

Warning colors, 212.

Walrus, Atlantic (illus.), 298. 
Wasps, social, 161.

Yellow-jacket (illus.), 162.

Water - beetle (illus.), 146; bug, Yolk, 80 .

giant (illus.), 141.

Young, adaptations for defense of,

Whippoorwill (illus.), 203.

Woodpecker, Californian, feeding habit of (illus.), 128, 129.

Xiphias gladius, metamorphosis of (illus.), 99. 137 ; care of the, 250,257 ; number of, 61 .

\section{Zoea, 97.}

Zoögeography, 272.

Zoölogy, systematic, 64 .

(15)

THE END 



\section{TWENTIETH CENTURY TEXT-BOOKS.}

\section{TEXT-BOOKS OF ZOOLOGY.}

By David Starr Jordan, President of Leland Stanford Jr. University; Vernon Lyman Kellogg, Professor of Entomology; Harold Heath, Assistant Professor of Invertebrate Zoology.

\section{Evolution and Animal Life.}

This is a popular discussion of the facts, processes, laws, and theories relating to the life and evolution of animals. The reader of it will have a very clear idea of the all-important theory of evolution as it has been developed and as it is held to-day by scientists. 8vo. Cloth, with about 300 illustrations, $\$ 2.50$ net; postage 20 cents additional.

\section{Animal Studies.}

A compact but complete treatment of elementary zoology, especially prepared for institutions of learning that prefer to find in a single book an ecological as well as morphological survey of the animal world, I2mo. Cloth, $\$ 1.25$ net.

\section{Animal Life.}

An elementary account of animal ecology-that is, of the relations of animals to their surroundings. It treats of animals from the standpoint of the observer, and shows why the present conditions and habits of animal life are as we find them. I2mo. Cloth, $\$ 1.20$ net.

\section{Animal Forms.}

This book deals in an elementary way with animal morphology. It describes the structure and life processes of animals, from the lowest creations to the highest and most complex. I2mo. Cloth, $\$$ I. Io net.

\section{Animals.}

This consists of "Animal Life" and "Animal Forms" bound in one volume. I2mo. Cloth, \$I.80.

\section{Animal Structures.}

A laboratory guide in the teaching of elementary zoology. I2mo, Cloth, 50 cents net.

\section{A PPLETON AND COMPANY,}

NEW YORK. BOSTON. CHICAGO. LONDON.




\section{TWENTIETH CENTURY TEXT-BOOKS OF BOTANY.}

By JOHN M. COULTER, A.M., Ph.D.,

Head of Department of Botany, University of Chicago.

A Text-Book of Botany. I2mo. Illustrated. \$1.25. Plant Relations. A First Book of Botany. I2mo. Cloth, \$r. Io.

"Plant Relations" is the first part of the botanical section of Biology, and, as its itle indicates, treats what might be termed the human interests of plant life, the conditions under which plants grow, their means of adaptation to environments, how the protect theinselves from enemies of various kinds in their struggle for existence, their habits individually and in family groups, and their relations to other forms of life-all of which constitute the economic and sociological phases of plant study.

Plant Structures. A Second Book of Botany. I2mo. Cloth, $\$$ i.2o.

This volume treats of the structural and morphological features of plant life and plant growth. It is intended to follow "Plant Relations," but may precede this buok, and either ray be used independently for a half-year's work in botanical study.

Plant Studies. An Elementary Botany. I2mo. Cloth, $\$ 1.25$.

This book is designed for those schools in which there is not a sufficient allotment of time to permit the developmen' of plant Ecology and Morphology as outlined in "Plant Relations" and "Plant Structures," and yet which are desirous of imparting instruction from both points of view.

Plants. A Text-Book of Botany. 12mo. Cloth, \$1.80.

Many of the high schools as $w \neq 1$ as the smaller colleges and seminaries that devote one year to botanical work prifer a single volume covering the complete course of study. For their convenience, th erefore, "Plant Relations" and "Plant Structures " have been bound together in one book, under the title uf "Plants."

Analytical Keys to Flowering Plants. 12mo. Limp Cloth. Northern States. By Professor Cotrter. 25c.

Pacific Slope. By Prof. W. L. Jepson, University of California. $45 \mathrm{c}$.

Rocky Mountain Regions. By Prof. Aven Nelson, University of Wyoming. $45 \mathrm{C}$.

These Keys may be used with any text-book of botany, but they have references to the text of Professor Coulter's books.

A Laboratory Manual of Botany. By OTIS W. CaldWELL, Ph.D., State Normal School, Charleston, Ill. 5oc.

D. A P P L E T O N A N D C O M P A N Y,




\section{CHEMISTRY FROM A NEW STANDPOINT'}

\section{An Inductive Chemistry}

By Robert H. Bradbury, A.M., Ph.D., Head of the Department of Science, Southern High School, Philadelphia. I2mo, Cloth, \$1.25.

This is a complete, modern text, practical and teachable, for high-school students.

The subject is developed along lines adapted to the pupil's equipment. Both method and order of presentation are particularly sound. Constant appeal is made to the experience of the student's everyday life, and new material is introduced in logical order, according to the interest and natural comprehension of the student.

The text is eminently modern in spirit, as to subject matter. Recent developments of the first importance, absent in other texts, are simply but adequately treated here. Emphasis is likewise laid on the method of reasoning followed in attaining results as well as on the mere facts of the science.

The book is unusually teachable, in many ways. It introduces the history of the subject to the best advantage. It contains helpful classifications, in the form of tables, and lists of definitions. The illustrations, too, are unusually clear and relevant.

The Syllabus and Entrance Examination requirements have been thoroughly covered. The fact that these required topics are printed in bold-faced type in the index, will be of great assistance to teachers and students.

D. A P PLETON AND COMPANY NEW YORK 


\section{TWENTIETH CENTURY TEXT-BOOKS}

\section{A High School Course in Physics}

By Frederick R. Gorton, Ph.D., Associate Professor of Physics, Michigan State Normal College. Fully and Practically Illustrated. I2mo, Cloth, \$1.25 net.

The author has written a text-book in Physics which is above all things practical, from the point of view of both teacher and pupil. All scientific facts are clearly stated and referred, wherever such reference will be valuable, to the student's own experience and to the ordinary phenomena of his everyday observation. Without sacrificing the essentially scientific nature of the subject the author recognizes it as a science which has a very definite bearing upon everyday life.

The author believes that the class-room work should be accompanied by suitable laboratory experimentation by the pupils supplemented with demonstrative experiments by the instructor.

Stress is laid upon the beneficial results to which the study of Physics has led as its development has progressed. Especial attention has been given to the interesting historical development of the subject. Portraits and adequate biographical sketches of many scientists to whom the discovery of great principles is due have been inserted.

The problems throughout the book eliminate the usual exercises in pure reduction and substitute those of a more concrete and practical nature.

The apparatus described is as simple as experience has shown to be consistent with satisfactory results.

The illustrations are abundant and each is given a descriptive legend.

To aid the pupil in reviewing and the teacher in quizzing, there are summaries at the ends of the chapters.

No subject has been left out that is called for in the report of the College Entrance Requirement Board.

\section{A P PLETON A N C OM P A N Y NEW YORK \\ CHICAGO}







